PERFORMANCE TRENDS FOR AEROSPIKES \& SUPERSONIC NOZZLES WITH CENTER-BODIES

by

\author{
Bassel El-Dahr \\ Bachelor of Engineering, Ryerson University (2016)
}

A project presented to Ryerson University in partial fulfilment of the requirements for the degree of Master of Engineering in the program of Aerospace Engineering

Toronto, Ontario, Canada, 2019

(C) Bassel El-Dahr, 2019 
AUTHOR'S DECLARATION FOR ELECTRONIC SUBMISSION OF A PROJECT

I hereby declare that I am the sole author of this project. This is a true copy of the project, including any required final revisions.

I authorize Ryerson University to lend this project to other institutions or individuals for the purpose of scholarly research.

I further authorize Ryerson University to reproduce this project by photocopying or by other means, in total or in part, at the request of other institutions or individuals for the purpose of scholarly research.

I understand that my project may be made electronically available to the public. 


\title{
PERFORMANCE TRENDS FOR AEROSPIKES \& SUPERSONIC NOZZLES WITH CENTER-BODIES
}

\author{
Bassel El-Dahr \\ Master's of Engineering \\ Aerospace Engineering \\ Ryerson University, 2019
}

\begin{abstract}
The aim of this report is to examine performance trends for Aerospikes and Supersonic nozzles with center - bodies. The initial case that was tested is a convergent - divergent conical nozzle with a geometry and inlet flow conditions obtained from a NASA technical note. The technical note mentions that air was used as the working fluid for the nozzle. This case served as the base case for comparison with the performance of later nozzle designs. Nozzle flow for all the cases that were tested was simulated using ANSYS Fluent, for ambient conditions at 20km standard atmosphere. The convergent - divergent conical nozzle has the following calculated performance parameters using results from ANSYS Fluent: mass flow rate of $9.660 \mathrm{~kg} / \mathrm{s}$, axial Thrust of 10,583.5 N, and a specific impulse of 111.7s. All of the Supersonic nozzles with center - bodies have calculated specific impulse values lower than $111.7 \mathrm{~s}$ by $0.4-1.6 \mathrm{~s}$, for approximately the same calculated mass flow rates as the base case. Adding a center - body to the original conical nozzle, was simply detrimental to performance. With regards to the Aerospike nozzles, 18 of them were tested. Aerospike 18 has the highest calculated specific impulse, at $115.3 \mathrm{~s}$ for a calculated mass flow rate of $9.671 \mathrm{~kg} / \mathrm{s}$. Aerospike 13 came in second at $114.6 \mathrm{~s}$, for a calculated mass flow rate of $9.676 \mathrm{~kg} / \mathrm{s}$. Several of the Aerospike designs did not out-perform the base case in terms of specific impulse. For those Aerospikes, the convergent divergent section had a significantly lower thrust than the base case and the center - body was
\end{abstract}


not able to over-compensate for the lower thrust. This report also looks at trends in thrust contribution by the convergent - divergent sections and center - bodies of Aerospikes at different nozzle geometries. The working fluid for all the cases tested in ANSYS Fluent including the base case, is air at a ratio of specific heats equal to 1.4. 


\section{ACKNOWLEDGEMENT}

I would like to thank my project supervisor Dr. Jeffrey Yokota for his valuable input towards this project. Dr. Yokota was always there when I ran into problems or had any questions. His advice was always in the right place and he would always ask me the right questions, which definitely steered me in the appropriate direction. 


\section{TABLE OF CONTENTS}

ABSTRACT .iii

LIST OF FIGURES ix

LIST OF TABLES xix

NOMENCLATURE . $\mathrm{xx}$

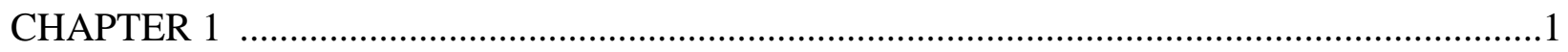

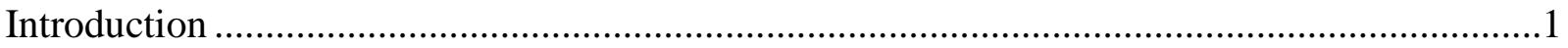

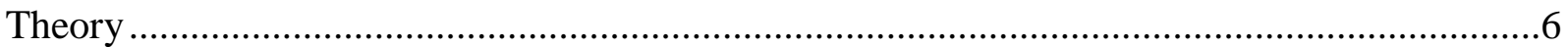

Derivation of the Thrust Equation for a CD Nozzle ............................................................6

Derivation of the Thrust Equation for a CD Nozzle \& CB and an Aerospike ........................8

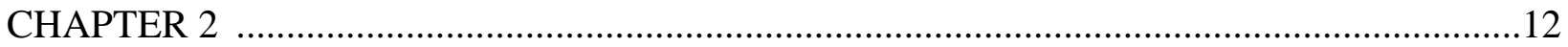

Convergence of CFD Results and Comparison with Published Data ....................................12

Simulation of Supersonic Nozzle Flow with Ambient Conditions at $20 \mathrm{~km}$ Standard

Atmosphere

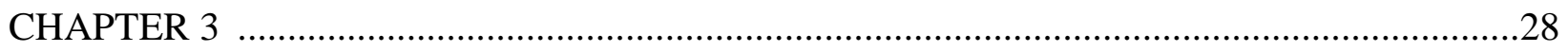

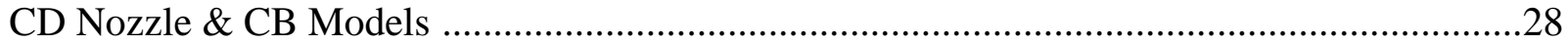

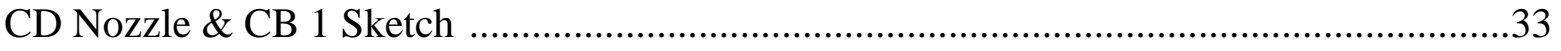

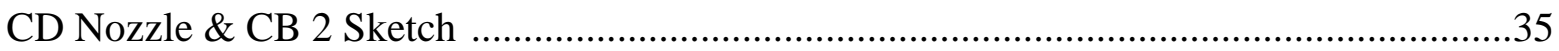

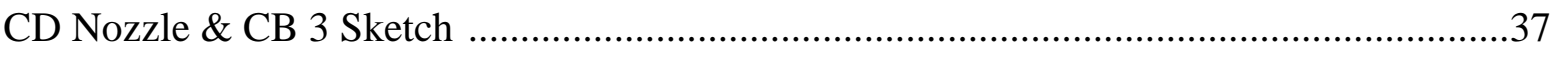

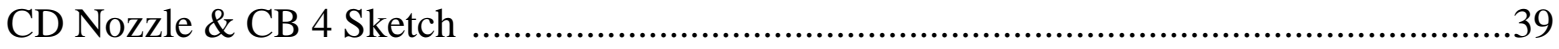

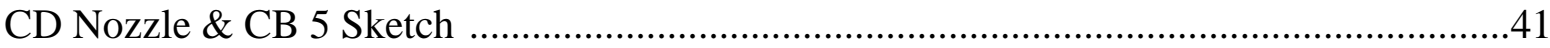

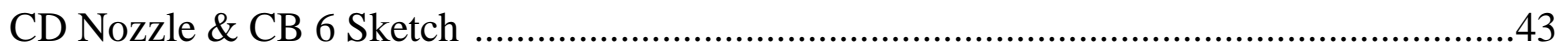

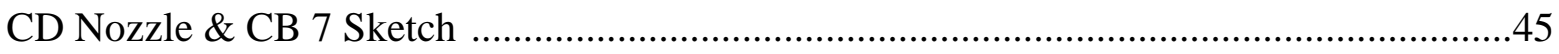

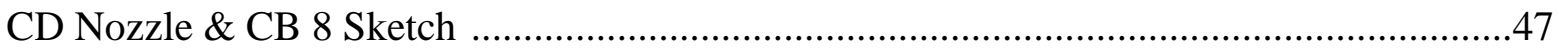

Design of Aerospike 1 ....................................................................................................

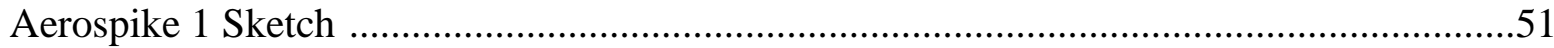

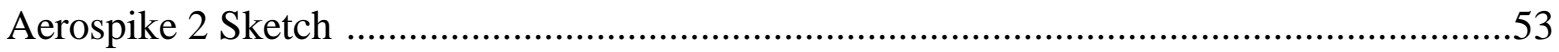

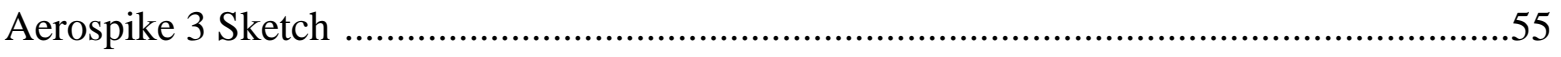

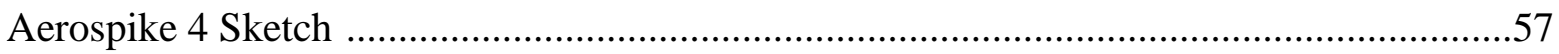




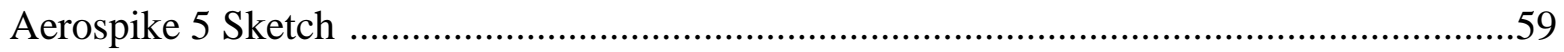

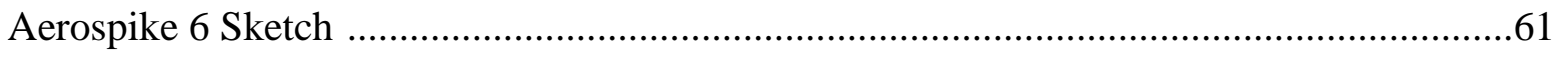

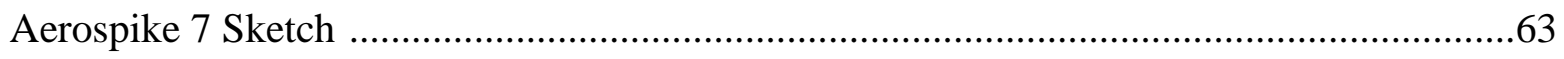

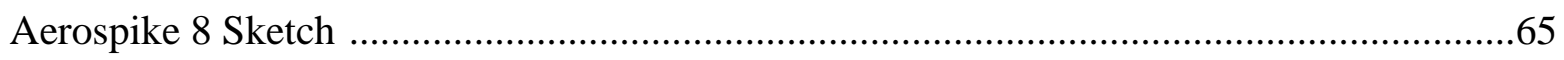

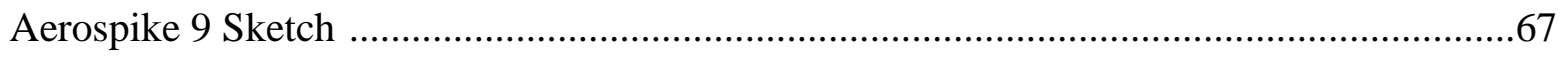

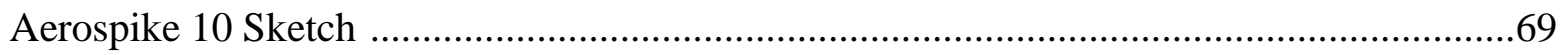

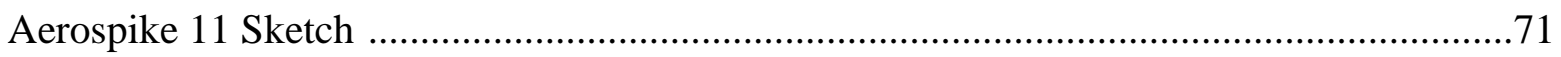

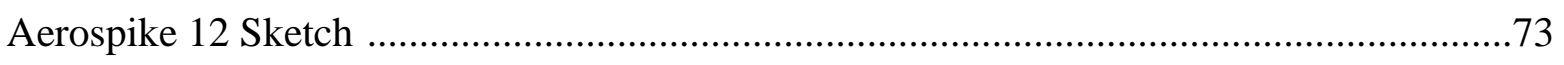

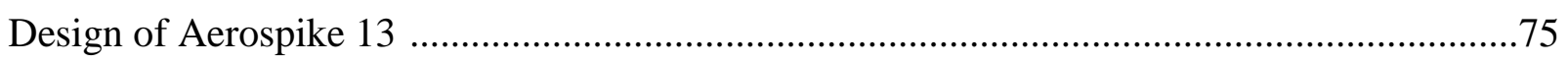

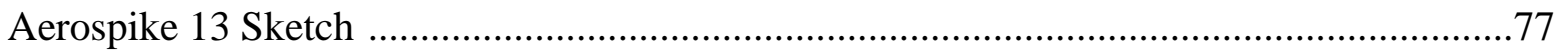

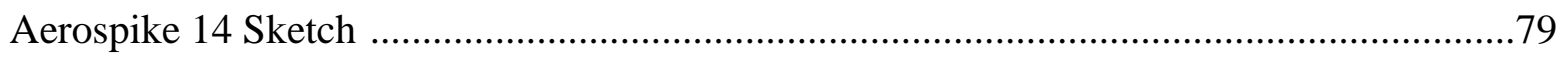

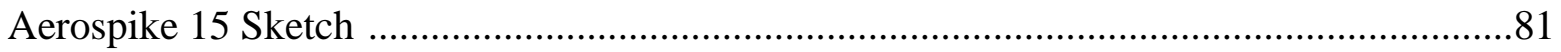

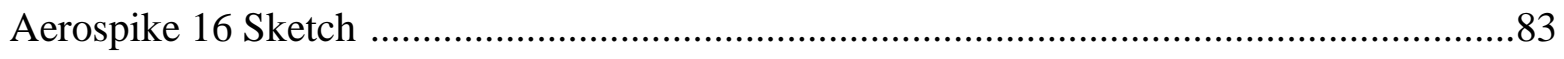

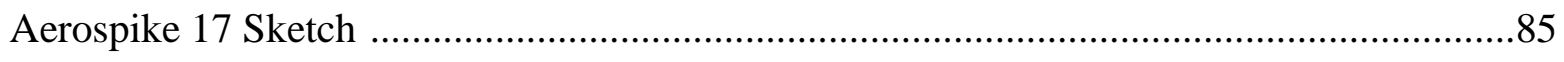

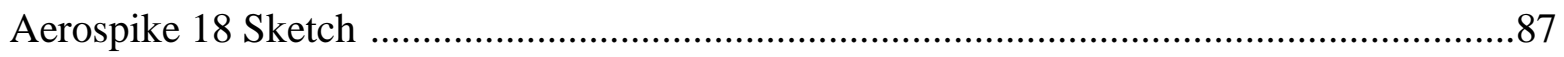

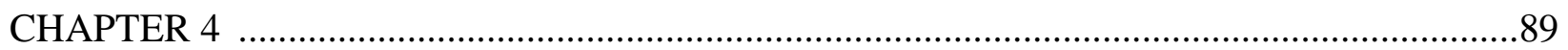

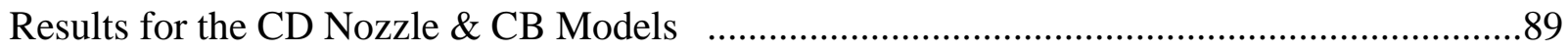

CD Nozzle \& CB 1 Flow Contours .....................................................................................93

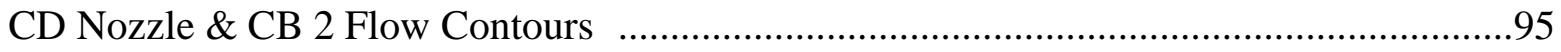

CD Nozzle \& CB 3 Flow Contours ………………......................................................97

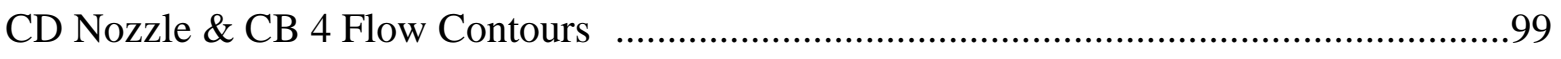

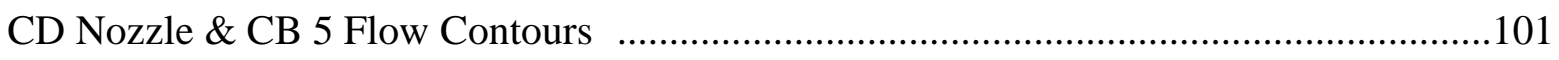

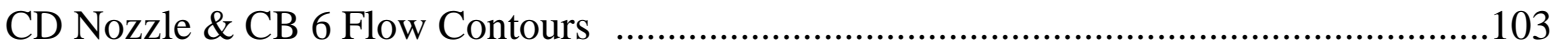

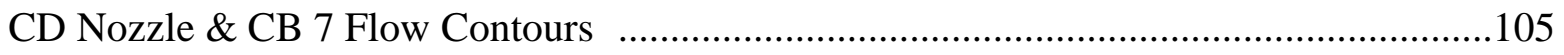

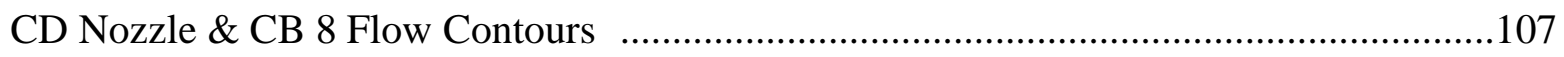

Results for the Aerospike Models ……………………...................................................109

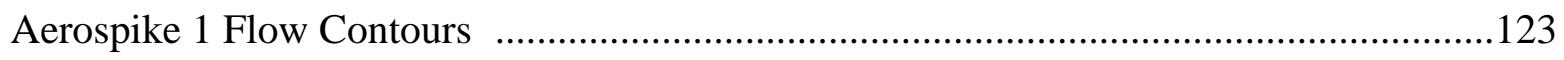

Aerospike 9 Flow Contours ……………………...............................................126

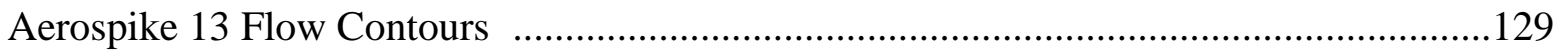

Aerospike 18 Flow Contours ………………………................................................132

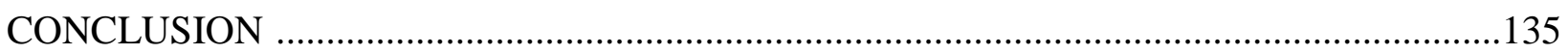




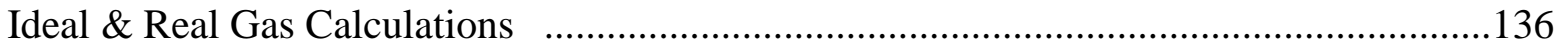

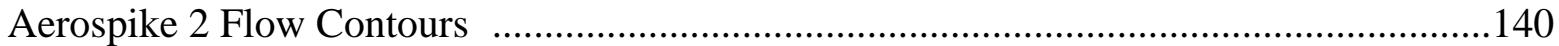

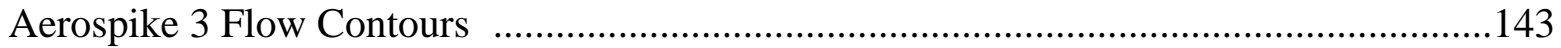

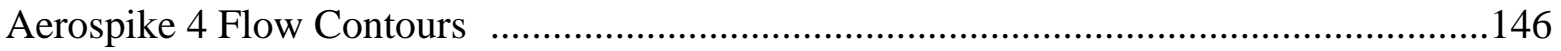

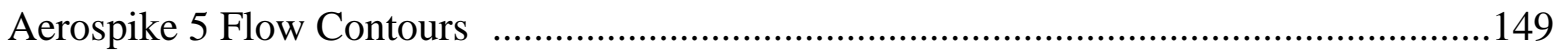

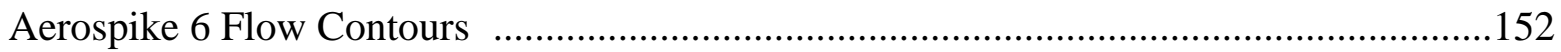

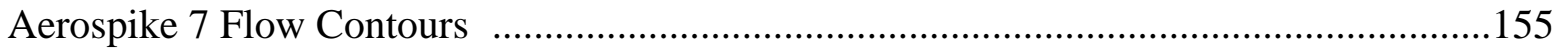

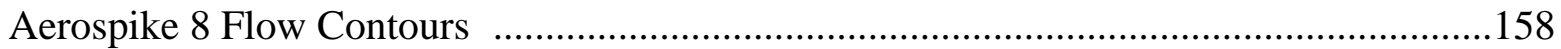

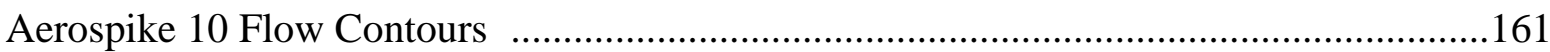

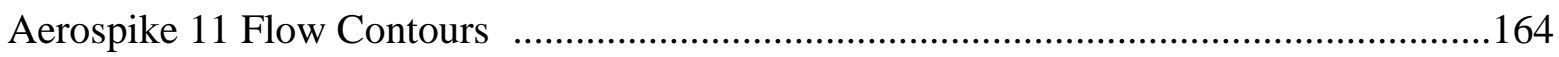

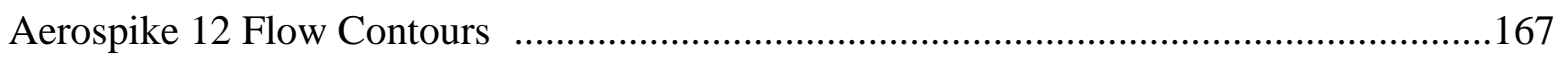

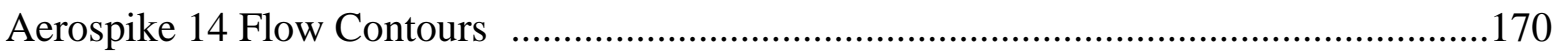

Aerospike 15 Flow Contours ……………………….............................................173

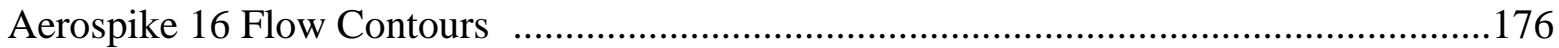

Aerospike 17 Flow Contours .....................................................................................179

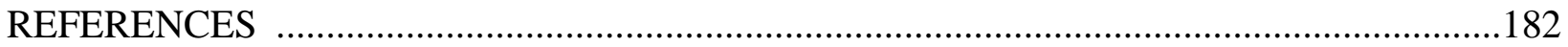




\section{LIST OF FIGURES}

Figure 1: Drawings outlining the general differences in design between between a bell nozzle

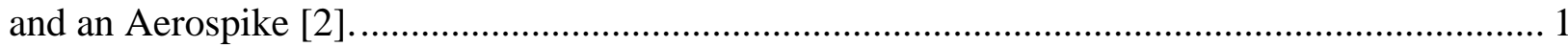

Figure 2: An artist's conception of the X-33 Venture Star, possibly in orbital flight around Earth [3]

Figure 3: Over-expanded (left), ideal (center), and under-expanded flows (right) for a convergent - divergent bell nozzle, from sea-level to high-altitude [5]......................................................... 3

Figure 4: A sketch showing the main features of an Aerospike nozzle and its flow characteristics

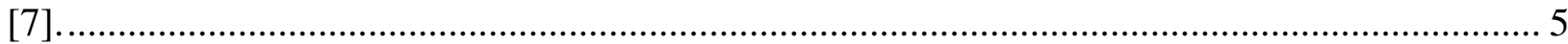

Figure 5: A sketch of the control volume used in the derivation of the thrust equation for a nozzle [4]

Figure 6: A sketch of the control volume for a rocket nozzle. …….............................................. 7

Figure 7: A sketch of the control volume used in the derivation of the Thrust equation for a CD nozzle and Center - Body model.......................................................................................... 8

Figure 8: A sketch of the control volume used in the derivation of the Thrust equation for an

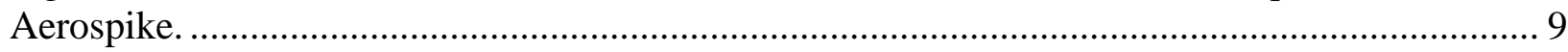

Figure 9: A sketch of the control volume for rocket nozzle with a Center - Body...................... 10

Figure 10: A sketch of the conical nozzle used for data convergence in CFD, obtained from the technical note, NASA TN D-467 [8]; all dimensions are in inches.

Figure 11: A meshed model for the conical nozzle in Figure 10 up to an axial distance of 28.88in or $\mathrm{A} / \mathrm{A}_{\text {cr }}$ of 9.2, re-created in ANSYS for data convergence in CFD.

Figure 12: Integral of nozzle pressure ratio with respect to area ratio for three different conical nozzles at varying divergence angles [8].

Figure 13: Plots of integral of nozzle pressure ratio with respect to area ratio for the experimental result [8] and results from CFD.

Figure 14: A sketch showing the dimensions used in defining the boundary limits of the ambient volume, through which supersonic nozzle flow will expand.

Figure 15: A CAD design of the CD Nozzle with the ambient volume based on dimensions from Figure 14, with names of boundaries.

Figure 16: The same model from Figure 15, with the view zoomed in on the nozzle, including names of boundaries. 
Figure 17: A screenshot of the mesh generated for the model in Figure 15.

Figure 18: Contour of turbulent viscosity ratio distribution for the model in Figure 15, with nozzle flow expansion into ambient air at $20 \mathrm{~km}$ standard atmosphere. 22

Figure 19: Line contours of Mach number for the model in Figure 15, with nozzle flow expansion into ambient air at $20 \mathrm{~km}$ standard atmosphere.

Figure 20: Contour of Mach number for the model in Figure 15, with nozzle flow expansion into ambient air at $20 \mathrm{~km}$ standard atmosphere. 24

Figure 21: Contour of Mach number for the model in Figure 15, with nozzle flow expansion into ambient air at $20 \mathrm{~km}$ standard atmosphere. 25

Figure 22: A screenshot of the mesh for Aerospike 11......................................................... 26

Figure 23: A screenshot of the mesh for Aerospike 11 with the names of boundaries. .............. 27

Figure 24: A CATIA sketch of the CD Nozzle; all dimensions are in millimeters.................... 28

Figure 25: A screenshot of the CD Nozzle re-created in CATIA by revolving the sketch from Figure 24 about its axis of symmetry.

Figure 26: A CATIA sketch used in the geometry definition of CD Nozzle \& CB models $1-4$; all dimensions are in millimeters.

Figure 27: A CATIA sketch used in the geometry definition of CD Nozzle \& CB models 5 - 8;

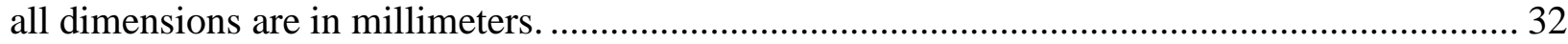

Figure 28: A CATIA sketch of CD Nozzle \& CB 1; all dimensions are in millimeters. ............ 33

Figure 29: CD Nozzle \& CB 1 created in CATIA by revolving the sketch from Figure 28 about

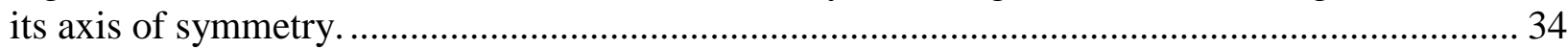

Figure 30: A CATIA sketch of CD Nozzle \& CB 2; all dimensions are in millimeters. ............ 35

Figure 31: CD Nozzle \& CB 2 created in CATIA by revolving the sketch from Figure 30 about

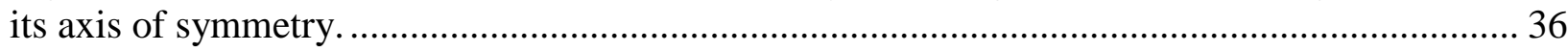

Figure 32: A CATIA sketch of CD Nozzle \& CB 3; all dimensions are in millimeters. ............ 37

Figure 33: CD Nozzle \& CB 3 created in CATIA by revolving the sketch from Figure 32 about

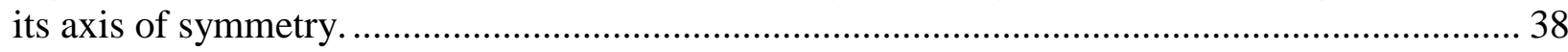

Figure 34: A CATIA sketch of CD Nozzle \& CB 4; all dimensions are in millimeters. ............ 39 
Figure 35: CD Nozzle \& CB 4 created in CATIA by revolving the sketch from Figure 34 about its axis of symmetry.

Figure 36: A CATIA sketch of CD Nozzle \& CB 5; all dimensions are in millimeters.

Figure 37: CD Nozzle \& CB 5 created in CATIA by revolving the sketch from Figure 36 about its axis of symmetry. 42

Figure 38: A CATIA sketch of CD Nozzle \& CB 6; all dimensions are in millimeters. 43

Figure 39: CD Nozzle \& CB 6 created in CATIA by revolving the sketch from Figure 38 about its axis of symmetry. 44

Figure 40: A CATIA sketch of CD Nozzle \& CB 7; all dimensions are in millimeters. 45

Figure 41: CD Nozzle \& CB 7 created in CATIA by revolving the sketch from Figure 40 about its axis of symmetry. 46

Figure 42: A CATIA sketch of CD Nozzle \& CB 8; all dimensions are in millimeters. 47

Figure 43: CD Nozzle \& CB 8 created in CATIA by revolving the sketch from Figure 42 about its axis of symmetry. 48

Figure 44: A CATIA sketch of Aerospike 1; all dimensions are in millimeters. 51

Figure 45: An isometric view of Aerospike 1 created in CATIA, by revolving the sketch from Figure 44 about its axis of symmetry. 52

Figure 46: A CATIA sketch of Aerospike 2; all dimensions are in millimeters. 53

Figure 47: An isometric view of Aerospike 2 created in CATIA, by revolving the sketch from Figure 46 about its axis of symmetry 54

Figure 48: A CATIA sketch of Aerospike 3; all dimensions are in millimeters. 55

Figure 49: An isometric view of Aerospike 3 created in CATIA, by revolving the sketch from Figure 48 about its axis of symmetry. 56

Figure 50: A CATIA sketch of Aerospike 4; all dimensions are in millimeters. 57

Figure 51: An isometric view of Aerospike 4 created in CATIA, by revolving the sketch from Figure 50 about its axis of symmetry. 58

Figure 52: A CATIA sketch of Aerospike 5; all dimensions are in millimeters. 59

Figure 53: An isometric view of Aerospike 5 created in CATIA, by revolving the sketch from Figure 52 about its axis of symmetry. 
Figure 54: A CATIA sketch of Aerospike 6; all dimensions are in millimeters.

Figure 55: An isometric view of Aerospike 6 created in CATIA, by revolving the sketch from Figure 54 about its axis of symmetry. 62

Figure 56: A CATIA sketch of Aerospike 7; all dimensions are in millimeters. 63

Figure 57: An isometric view of Aerospike 7 created in CATIA, by revolving the sketch from Figure 56 about its axis of symmetry. 64

Figure 58: A CATIA sketch of Aerospike 8; all dimensions are in millimeters. 65

Figure 59: An isometric view of Aerospike 8 created in CATIA, by revolving the sketch from Figure 58 about its axis of symmetry. 66

Figure 60: A CATIA sketch of Aerospike 9; all dimensions are in millimeters. 67

Figure 61: An isometric view of Aerospike 9 created in CATIA, by revolving the sketch from Figure 60 about its axis of symmetry. 68

Figure 62: A CATIA sketch of Aerospike 10; all dimensions are in millimeters. 69

Figure 63: An isometric view of Aerospike 10 created in CATIA, by revolving the sketch from Figure 62 about its axis of symmetry. 70

Figure 64: A CATIA sketch of Aerospike 11; all dimensions are in millimeters. 71

Figure 65: An isometric view of Aerospike 11 created in CATIA, by revolving the sketch from Figure 64 about its axis of symmetry..... 72

Figure 66: A CATIA sketch of Aerospike 12; all dimensions are in millimeters. 73

Figure 67: An isometric view of Aerospike 12 created in CATIA, by revolving the sketch from Figure 66 about its axis of symmetry. 74

Figure 68: A CATIA sketch of Aerospike 13; all dimensions are in millimeters. 77

Figure 69: An isometric view of Aerospike 13 created in CATIA, by revolving the sketch from Figure 68 about its axis of symmetry.... 78

Figure 70: A CATIA sketch of Aerospike 14; all dimensions are in millimeters. 79

Figure 71: An isometric view of Aerospike 14 created in CATIA, by revolving the sketch from Figure 70 about its axis of symmetry. 80

Figure 72: A CATIA sketch of Aerospike 15; all dimensions are in millimeters. 81 
Figure 73: An isometric view of Aerospike 15 created in CATIA, by revolving the sketch from Figure 72 about its axis of symmetry.

Figure 74: A CATIA sketch of Aerospike 16; all dimensions are in millimeters. 83

Figure 75: An isometric view of Aerospike 16 created in CATIA, by revolving the sketch from Figure 74 about its axis of symmetry.

Figure 76: A CATIA sketch of Aerospike 17; all dimensions are in millimeters. 85

Figure 77: An isometric view of Aerospike 17 created in CATIA, by revolving the sketch from Figure 76 about its axis of symmetry.

Figure 78: A CATIA sketch of Aerospike 18; all dimensions are in millimeters. 87

Figure 79: An isometric view of Aerospike 18 created in CATIA, by revolving the sketch from Figure 78 about its axis of symmetry. 88

Figure 80: CD Nozzle \& CB 1 with CB exposed surface area shown in red.

Figure 81: CD Nozzle \& CB 4 with CB exposed surface area equal to base area, shown in red. 91

Figure 82: A plot of the ratio of center body thrust to total thrust versus the ratio of center body surface area to base area.

Figure 83: Contour of Mach number for CD Nozzle \& CB 1, with nozzle flow expansion into ambient air at $20 \mathrm{~km}$ standard atmosphere.

Figure 84: Contour of Mach number for CD Nozzle \& CB 1, with nozzle flow expansion into ambient air at $20 \mathrm{~km}$ standard atmosphere.

Figure 85: Contour of Mach number for CD Nozzle \& CB 2, with nozzle flow expansion into ambient air at $20 \mathrm{~km}$ standard atmosphere.

Figure 86: Contour of Mach number for CD Nozzle \& CB 2, with nozzle flow expansion into ambient air at $20 \mathrm{~km}$ standard atmosphere.

Figure 87: Contour of Mach number for CD Nozzle \& CB 3, with nozzle flow expansion into ambient air at $20 \mathrm{~km}$ standard atmosphere.

Figure 88: Contour of Mach number for CD Nozzle \& CB 3, with nozzle flow expansion into ambient air at $20 \mathrm{~km}$ standard atmosphere.

Figure 89: Contour of Mach number for CD Nozzle \& CB 4, with nozzle flow expansion into ambient air at $20 \mathrm{~km}$ standard atmosphere. 
Figure 90: Contour of Mach number for CD Nozzle \& CB 4, with nozzle flow expansion into ambient air at $20 \mathrm{~km}$ standard atmosphere.

Figure 91: Contour of Mach number for CD Nozzle \& CB 5, with nozzle flow expansion into ambient air at $20 \mathrm{~km}$ standard atmosphere.

Figure 92: Contour of Mach number for CD Nozzle \& CB 5, with nozzle flow expansion into ambient air at $20 \mathrm{~km}$ standard atmosphere.

Figure 93: Contour of Mach number for CD Nozzle \& CB 6, with nozzle flow expansion into ambient air at $20 \mathrm{~km}$ standard atmosphere.

Figure 94: Contour of Mach number for CD Nozzle \& CB 6, with nozzle flow expansion into ambient air at $20 \mathrm{~km}$ standard atmosphere. 104

Figure 95: Contour of Mach number for CD Nozzle \& CB 7, with nozzle flow expansion into ambient air at $20 \mathrm{~km}$ standard atmosphere.

Figure 96: Contour of Mach number for CD Nozzle \& CB 7, with nozzle flow expansion into ambient air at $20 \mathrm{~km}$ standard atmosphere.

Figure 97: Contour of Mach number for CD Nozzle \& CB 8, with nozzle flow expansion into ambient air at $20 \mathrm{~km}$ standard atmosphere.

Figure 98: Contour of Mach number for CD Nozzle \& CB 8, with nozzle flow expansion into ambient air at $20 \mathrm{~km}$ standard atmosphere.

Figure 99: Plots of static pressure distribution over the center - body sloped section versus axial distance, for Aerospikes 10 and 11.

Figure 100: Plots of static pressure distribution over the center - body blunt end versus radial distance, for Aerospikes 10 and 11.

Figure 101: A plot of the ratio of center body thrust to total thrust versus the ratio of center body surface area to base area. 116

Figure 102: Thrust of CD section versus exit - to - throat area ratio at $20 \mathrm{~km}$ standard atmosphere. For each case $P o=344,738.0 \mathrm{~Pa}$.

Figure 103: Thrust of CD section versus exit - to - throat area ratio at $20 \mathrm{~km}$ standard atmosphere. For each case $P o=660,132.4 \mathrm{~Pa}$.

Figure 104: Exit axial velocity versus radial position for Aerospikes 13 and 17..................... 119

Figure 105: Exit magnitude of velocity versus radial position for Aerospikes 13 and 17......... 120

Figure 106: Exit axial velocity versus radial position for Aerospikes 14 and 16. 121 
Figure 107: Exit magnitude of velocity versus radial position for Aerospikes 14 and 16.

Figure 108: Contour of Mach number for Aerospike 1, with nozzle flow expansion into ambient air at $20 \mathrm{~km}$ standard atmosphere.

Figure 109: Contour of Mach number for Aerospike 1, with nozzle flow expansion into ambient air at $20 \mathrm{~km}$ standard atmosphere.

Figure 110: Line contours of Mach number for Aerospike 1, with nozzle flow expansion into ambient air at $20 \mathrm{~km}$ standard atmosphere.

Figure 111: Contour of Mach number for Aerospike 9, with nozzle flow expansion into ambient air at $20 \mathrm{~km}$ standard atmosphere.

Figure 112: Contour of Mach number for Aerospike 9, with nozzle flow expansion into ambient air at $20 \mathrm{~km}$ standard atmosphere.

Figure 113: Line contours of Mach number for Aerospike 9, with nozzle flow expansion into ambient air at $20 \mathrm{~km}$ standard atmosphere.

Figure 114: Contour of Mach number for Aerospike 13, with nozzle flow expansion into ambient air at $20 \mathrm{~km}$ standard atmosphere. 129

Figure 115: Contour of Mach number for Aerospike 13, with nozzle flow expansion into ambient air at $20 \mathrm{~km}$ standard atmosphere. 130

Figure 116: Line contours of Mach number for Aerospike 13, with nozzle flow expansion into ambient air at $20 \mathrm{~km}$ standard atmosphere.

Figure 117: Contour of Mach number for Aerospike 18, with nozzle flow expansion into ambient air at $20 \mathrm{~km}$ standard atmosphere. 132

Figure 118: Contour of Mach number for Aerospike 18, with nozzle flow expansion into ambient air at $20 \mathrm{~km}$ standard atmosphere. 133

Figure 119: Line contours of Mach number for Aerospike 18, with nozzle flow expansion into ambient air at $20 \mathrm{~km}$ standard atmosphere.

Figure 120: Contour of Mach number for Aerospike 2, with nozzle flow expansion into ambient air at $20 \mathrm{~km}$ standard atmosphere.

Figure 121: Contour of Mach number for Aerospike 2, with nozzle flow expansion into ambient air at $20 \mathrm{~km}$ standard atmosphere.

Figure 122: Line contours of Mach number for Aerospike 2, with nozzle flow expansion into ambient air at $20 \mathrm{~km}$ standard atmosphere. 
Figure 123: Contour of Mach number for Aerospike 3, with nozzle flow expansion into ambient air at $20 \mathrm{~km}$ standard atmosphere.

Figure 124: Contour of Mach number for Aerospike 3, with nozzle flow expansion into ambient air at $20 \mathrm{~km}$ standard atmosphere. 144

Figure 125: Line contours of Mach number for Aerospike 3, with nozzle flow expansion into ambient air at $20 \mathrm{~km}$ standard atmosphere.

Figure 126: Contour of Mach number for Aerospike 4, with nozzle flow expansion into ambient air at $20 \mathrm{~km}$ standard atmosphere.

Figure 127: Contour of Mach number for Aerospike 4, with nozzle flow expansion into ambient air at $20 \mathrm{~km}$ standard atmosphere. 147

Figure 128: Line contours of Mach number for Aerospike 4, with nozzle flow expansion into ambient air at $20 \mathrm{~km}$ standard atmosphere. 148

Figure 129: Contour of Mach number for Aerospike 5, with nozzle flow expansion into ambient air at $20 \mathrm{~km}$ standard atmosphere.

Figure 130: Contour of Mach number for Aerospike 5, with nozzle flow expansion into ambient air at $20 \mathrm{~km}$ standard atmosphere.

Figure 131: Line contours of Mach number for Aerospike 5, with nozzle flow expansion into ambient air at $20 \mathrm{~km}$ standard atmosphere.

Figure 132: Contour of Mach number for Aerospike 6, with nozzle flow expansion into ambient air at $20 \mathrm{~km}$ standard atmosphere.

Figure 133: Contour of Mach number for Aerospike 6, with nozzle flow expansion into ambient air at $20 \mathrm{~km}$ standard atmosphere. 153

Figure 134: Line contours of Mach number for Aerospike 6, with nozzle flow expansion into ambient air at $20 \mathrm{~km}$ standard atmosphere.

Figure 135: Contour of Mach number for Aerospike 7, with nozzle flow expansion into ambient air at $20 \mathrm{~km}$ standard atmosphere.

Figure 136: Contour of Mach number for Aerospike 7, with nozzle flow expansion into ambient air at $20 \mathrm{~km}$ standard atmosphere.

Figure 137: Line contours of Mach number for Aerospike 7, with nozzle flow expansion into ambient air at $20 \mathrm{~km}$ standard atmosphere.

Figure 138: Contour of Mach number for Aerospike 8, with nozzle flow expansion into ambient air at $20 \mathrm{~km}$ standard atmosphere. 
Figure 139: Contour of Mach number for Aerospike 8, with nozzle flow expansion into ambient air at $20 \mathrm{~km}$ standard atmosphere.

Figure 140: Line contours of Mach number for Aerospike 8, with nozzle flow expansion into ambient air at $20 \mathrm{~km}$ standard atmosphere.

Figure 141: Contour of Mach number for Aerospike 10, with nozzle flow expansion into ambient air at $20 \mathrm{~km}$ standard atmosphere. 161

Figure 142: Contour of Mach number for Aerospike 10, with nozzle flow expansion into ambient air at $20 \mathrm{~km}$ standard atmosphere. 162

Figure 143: Line contours of Mach number for Aerospike 10, with nozzle flow expansion into ambient air at $20 \mathrm{~km}$ standard atmosphere. 163

Figure 144: Contour of Mach number for Aerospike 11, with nozzle flow expansion into ambient air at $20 \mathrm{~km}$ standard atmosphere. 164

Figure 145: Contour of Mach number for Aerospike 11, with nozzle flow expansion into ambient air at $20 \mathrm{~km}$ standard atmosphere. 165

Figure 146: Line contours of Mach number for Aerospike 11, with nozzle flow expansion into ambient air at $20 \mathrm{~km}$ standard atmosphere. 166

Figure 147: Contour of Mach number for Aerospike 12, with nozzle flow expansion into ambient air at $20 \mathrm{~km}$ standard atmosphere. 167

Figure 148: Contour of Mach number for Aerospike 12, with nozzle flow expansion into ambient air at $20 \mathrm{~km}$ standard atmosphere. 168

Figure 149: Line contours of Mach number for Aerospike 12, with nozzle flow expansion into ambient air at $20 \mathrm{~km}$ standard atmosphere. 169

Figure 150: Contour of Mach number for Aerospike 14, with nozzle flow expansion into ambient air at $20 \mathrm{~km}$ standard atmosphere. 170

Figure 151: Contour of Mach number for Aerospike 14, with nozzle flow expansion into ambient air at $20 \mathrm{~km}$ standard atmosphere. 171

Figure 152: Line contours of Mach number for Aerospike 14, with nozzle flow expansion into ambient air at $20 \mathrm{~km}$ standard atmosphere. 172

Figure 153: Contour of Mach number for Aerospike 15, with nozzle flow expansion into ambient air at $20 \mathrm{~km}$ standard atmosphere. 173

Figure 154: Contour of Mach number for Aerospike 15, with nozzle flow expansion into ambient air at $20 \mathrm{~km}$ standard atmosphere. 174 
Figure 155: Line contours of Mach number for Aerospike 15, with nozzle flow expansion into ambient air at $20 \mathrm{~km}$ standard atmosphere.

Figure 156: Contour of Mach number for Aerospike 16, with nozzle flow expansion into ambient air at $20 \mathrm{~km}$ standard atmosphere. 176

Figure 157: Contour of Mach number for Aerospike 16, with nozzle flow expansion into ambient air at $20 \mathrm{~km}$ standard atmosphere.

Figure 158: Line contours of Mach number for Aerospike 16, with nozzle flow expansion into ambient air at $20 \mathrm{~km}$ standard atmosphere.

Figure 159: Contour of Mach number for Aerospike 17, with nozzle flow expansion into ambient air at $20 \mathrm{~km}$ standard atmosphere. 179

Figure 160: Contour of Mach number for Aerospike 17, with nozzle flow expansion into ambient air at $20 \mathrm{~km}$ standard atmosphere. 180

Figure 161: Line contours of Mach number for Aerospike 17, with nozzle flow expansion into ambient air at $20 \mathrm{~km}$ standard atmosphere. 


\section{LIST OF TABLES}

Table 1: A listing of the names of boundary conditions and their corresponding definitions in CFD and input parameters.

Table 2: A listing of the names of boundary conditions and their corresponding definitions in CFD and input parameters.

Table 3: The original CD Nozzle and CD Nozzle \& CB models $1-8$, with their corresponding predicted flow parameters and the results for the same parameters obtained using CFD. 89

Table 4: Summarized performance results for the original CD Nozzle and CD Nozzle \& CB models $1-8$ at $20 \mathrm{~km}$ standard atmosphere.

Table 5: Summarized performance results for the CD Nozzle case and Aerospikes $1-18$ at $20 \mathrm{~km}$ standard atmosphere.

Table 6: Aerospikes 1 - 12 with their corresponding predicted flow parameters and the results for the same parameters obtained using CFD. For each case, $P o=344,738.0 \mathrm{~Pa}$.

Table 7: Aerospikes 13, 16, 17, and 18 with their corresponding predicted flow parameters and the results for the same parameters obtained using CFD. For the CD Nozzle base case, $P o=$ 344,738.0Pa. For Aerospikes 13, 16, 17, and 18, $P o=660,132.4 \mathrm{~Pa}$.

Table 8: CD Nozzle base case and Aerospikes 1 - 12 with their corresponding calculated mass flow rates and CD Thrust (at 20km standard atmosphere) using CFD results. For each case, $P o=$ 344,738.0Pa......

Table 9: Aerospikes 13 - 18 with their corresponding calculated mass flow rates and CD Thrust (at $20 \mathrm{~km}$ standard atmosphere) using CFD results. For the CD Nozzle base case, $P o=$ 344,738.0Pa. For each case in Aerospikes $13-18, P o=660,132.4 \mathrm{~Pa}$. 115 
NOMENCLATURE

$\begin{array}{ll}A & \text { Area } \\ A_{e} & \text { Exit area } \\ A_{i} & \text { Inlet area } \\ A^{*}, A_{c r} & \text { Throat area } \\ a & \text { Speed of sound } \\ C B & \text { Center - Body } \\ C D & \text { Convergent - Divergent } \\ C A D & \text { Computer Assisted Design } \\ C F D & \text { Computational Fluid Dynamics } \\ I_{s p} & \text { Specific Impulse } \\ M & \text { Mach number } \\ \dot{m} & \text { Mass flow rate } \\ M_{e} & \text { Exit Mach number } \\ M_{i} & \text { Inlet Mach number } \\ P_{a m b}, P_{\infty} & \text { Ambient static pressure } \\ P_{c} & \text { Chamber pressure for a rocket engine } \\ P_{c r} & \text { equivalent to total pressure } \\ P_{e} & \text { Critical static pressure at the triple point in a } \\ P_{i} & \text { phase diagram } \\ P_{o} & \text { Exit static pressure } \\ T & \text { Inlet static pressure } \\ T_{a m b} & \text { Total pressure } \\ T_{c r} & \text { Thrust } \\ T_{e} & \text { Ambient static temperature } \\ T_{i} & \text { Critical static temperature at the triple point in } \\ u_{e} & \text { a phase diagram } \\ V & \text { Exit static temperature } \\ V_{m} & \text { Inlet static temperature } \\ \gamma & \text { Exit axial velocity } \\ & \text { Magnitude of velocity } \\ & \text { Molar Volume } \\ & \text { Ratio of specific heats; Gamma } \\ \end{array}$




\section{CHAPTER 1}

Introduction

The design concept behind an Aerospike nozzle is to overcome the limitations of a conventional Convergent - Divergent (CD) bell nozzle [1]. A conventional CD bell nozzle rocket engine and an Aerospike rocket engine, are shown in Figure 1. A CD nozzle is generally limited by a fixed range of operating altitude. An individual CD nozzle is designed to operate either from sea-level and within higher density atmosphere or within lower density atmosphere up to the vacuum of space [1]. Aerospike nozzles are generally designed to operate from sealevel to the vacuum of space, delivering larger specific impulse values, at sea-level and in vacuum, than conventional bell nozzles. Aerospikes have been proposed as a propulsion method for single-stage-to-orbit (SSTO) vehicles, including the X-33 Venture Star [1] shown in Figure 2.

Normal Bell-Nozzle

Rocket Engine

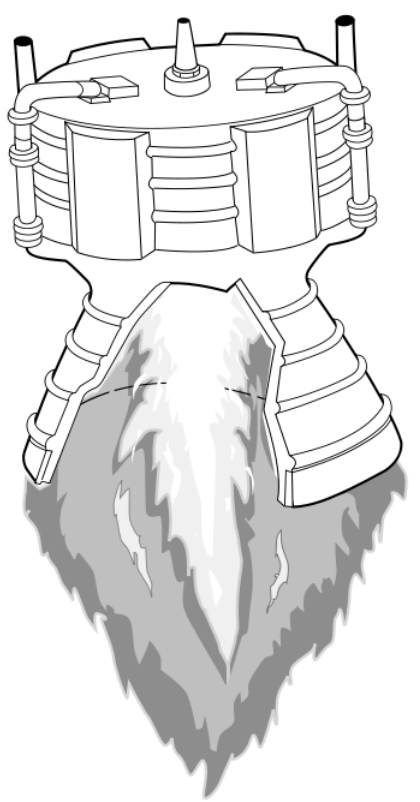

Dryden Flight Research Center February 1998

Normal Bell-Nozzle Rocket Engine and X-33 Linear Aerospike Rocket Engine
Linear Aerospike

Rocket Engine

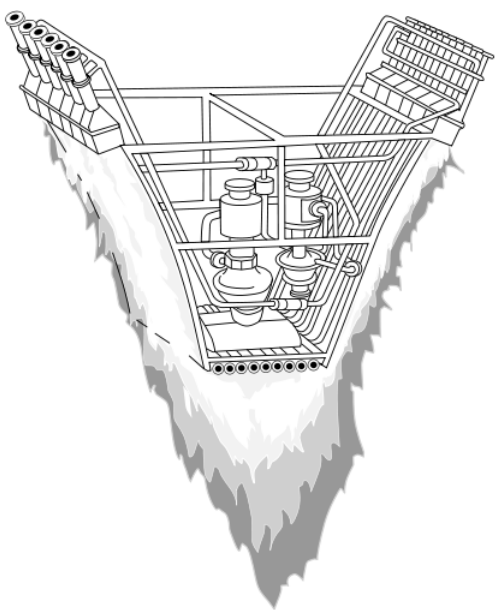

Figure 1: Drawings outlining the general differences in design between between a bell nozzle and an Aerospike [2]. 


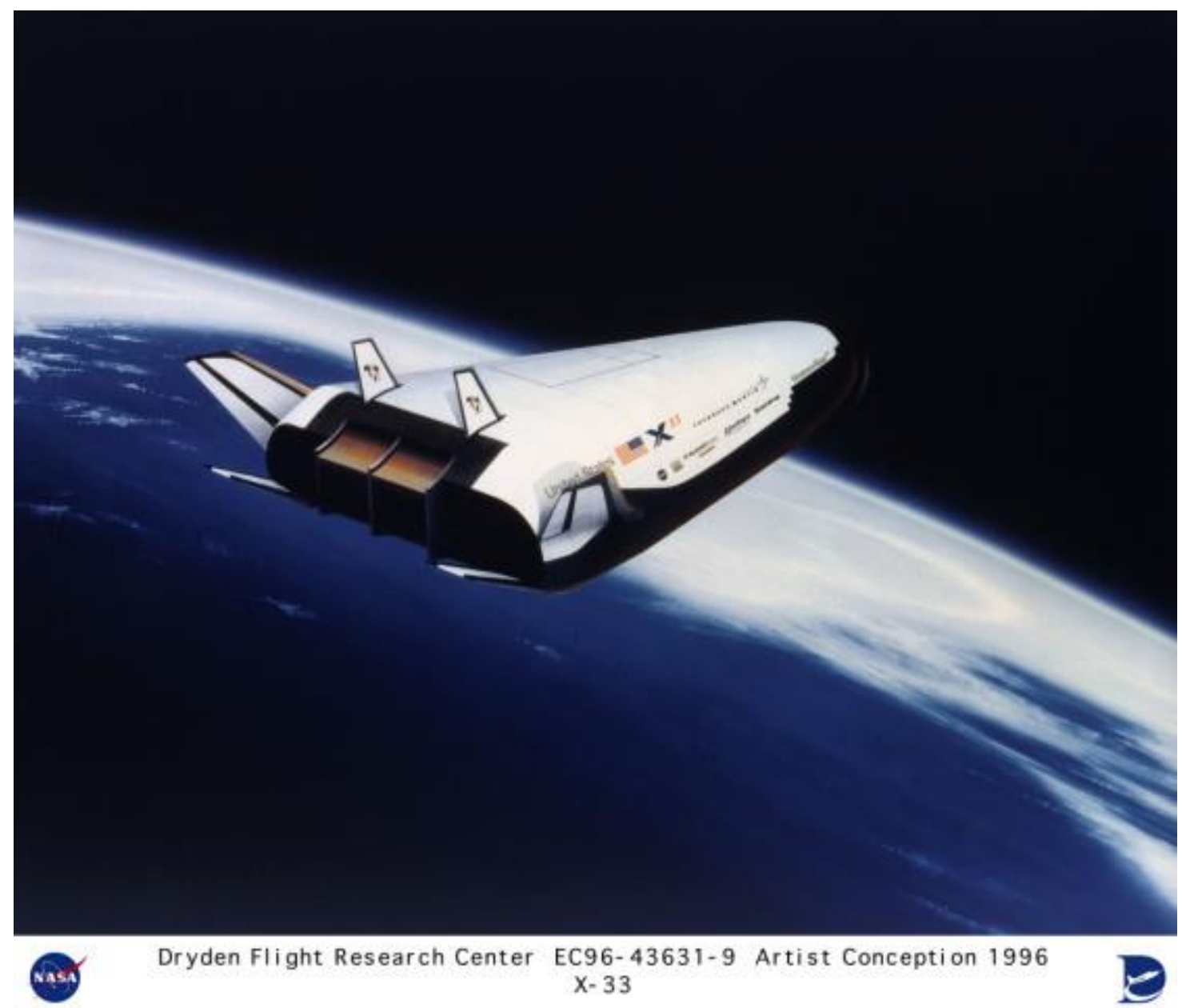

Figure 2: An artist's conception of the X-33 Venture Star, possibly in orbital flight around Earth [3].

In order to describe the advantage of an aerospike nozzle, the disadvantage associated with a conventional CD nozzle must be understood. For a CD nozzle operating in real-life conditions, the supersonic flow exiting from the nozzle will encounter at least one of the following [4]:

1) Over-expanded flow; the supersonic flow will form a series of oblique shocks, as the flow adjusts to the ambient back pressure; this is for the case were the static pressure at the nozzle exit $\left(P_{e}\right)$ is lower than that of the static ambient back pressure $\left(P_{a m b}\right)$ (shock waves will occur downstream until the static pressure of the nozzle flow is equal to the ambient static pressure); for cases were $P_{a m b}$ is large enough, an adverse pressure gradient will occur inside the nozzle wall and the flow in the nozzle will undergo separation forming a combination of normal and oblique shock waves [4]. This type of flow is represented by the drawing on the left in Figure 3, under the title: Sea Level $\left(P_{a} \gg P_{\text {Design }}\right)$

2) Ideal almost fully axial expansion of flow; $P_{e}$ at the nozzle exit is equal to $P_{a m b}$ [4]. Supersonic nozzles operating at varying altitudes will rarely encounter ideal expansion. This type of flow is represented by the drawing on the center in Figure 3, under the title: Design Altitude $\left(P_{a}=P_{\text {Design }}\right)$ 
3) Under-expanded flow; the supersonic flow will form expansion waves at the edge of the nozzle exit, as the flow adjusts to the ambient back pressure; this is for the case were $P_{e}$ is larger than $P_{a m b}$ [4]. This type of flow is represented by the drawing on the right in Figure 3, under the title: High Altitude $\left(P_{a} \ll P_{\text {Design }}\right)$

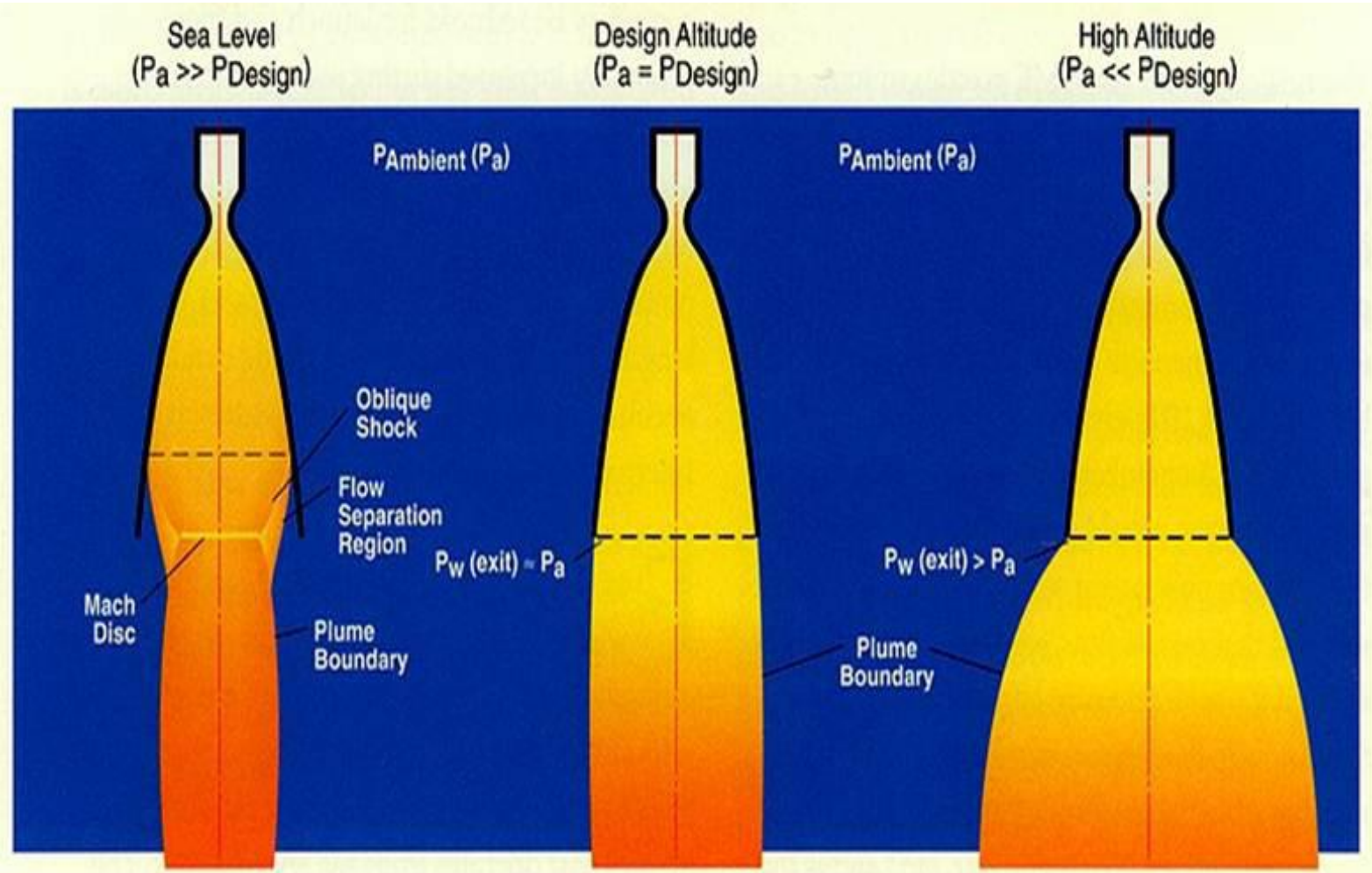

Figure 3: Over-expanded (left), ideal (center), and under-expanded flows (right) for a convergent-divergent bell nozzle, from sea-level to high-altitude [5]. 
For a rocket engine CD nozzle, the thrust generated can calculated by:

$$
T=\dot{m} u_{\text {exit }}+\left(P_{\text {exit }}-P_{\text {amb }}\right) A_{\text {exit }}
$$

$T:$ thrust

$\dot{m}$ : mass flow rate through the nozzle

$u_{\text {exit }}$ : axial velocity at the nozzle exit

$P_{\text {exit }}:$ static pressure at the nozzle exit

$P_{a m b}:$ static ambient back pressure

$A_{\text {exit }}$ : exit area of the nozzle

Based on Equation (1) for thrust, an under-expanded flow is expected to produce a higher thrust, since the term $\left(P_{\text {exit }}-P_{a m b}\right) A_{\text {exit }}$ will be positive, given that $u_{\text {exit }}$ dose not change. For an over-expanded flow, the term $\left(P_{\text {exit }}-P_{\text {amb }}\right) A_{\text {exit }}$ will be negative, decreasing the total thrust, and for an ideal expansion, the term $\left(P_{\text {exit }}-P_{a m b}\right) A_{\text {exit }}$ is zero, adding no contribution to the total thrust. Rocket nozzles will produce minimum specific impulse at sea-level and maximum specific impulse at vacuum [6]. It can be assumed that for a CD nozzle operating in real-life, it would be desirable to achieve as much of an under-expanded flow as possible, or to maximize the term $\left(P_{\text {exit }}-P_{a m b}\right) A_{\text {exit }}$, given that $u_{\text {exit }}$ does not change. As altitude increases, $P_{\text {exit }}$ remains constant, while $P_{a m b}$ decreases and $A_{\text {exit }}$ does not change. The increasing difference between $P_{\text {exit }}$ and $P_{a m b}$, such that $P_{\text {exit }}>P_{a m b}$, implies that the static pressure distribution acting along the inside of a nozzle wall may result in the destruction of the nozzle itself, if the ambient static pressure acting along the outside of the nozzle wall is not sufficient enough to counter the effect of the interior static pressure distribution that is pushing outwards.

An over-expanded flow with nozzle flow separation, results in an average exit axial velocity $u_{\text {exit }}$, that is lower than what would be expected if the flow were to remain attached throughout the interior of the nozzle. A reduced average $u_{\text {exit }}$, implies that thrust is reduced, while $\dot{m}$ does not change. The thrust is also reduced by the term $\left(P_{\text {exit }}-P_{\text {amb }}\right) A_{\text {exit }}$, since $P_{\text {exit }}<P_{a m b}$ in this case. For an over-expanded flow with no nozzle flow separation, the average $u_{\text {exit }}$ is larger than that for the separated flow case, but the term $\left(P_{\text {exit }}-P_{\text {amb }}\right) A_{\text {exit }}$ would still have a negative contribution on the overall thrust.

A CD Nozzle that is designed to operate within lower density atmosphere and up to the vacuum of space, will have a higher exit to throat area ratio than a nozzle designed for higher density atmosphere [1]. The higher exit - to - throat area ratio results in a higher exit Mach number and a lower static pressure at the nozzle exit. The lower static pressure is intended to reduce the magnitude of the $\left(P_{\text {exit }}-P_{\text {amb }}\right) A_{\text {exit }}$ term, such that $P_{\text {exit }}>P_{a m b}$, preventing the nozzle from possibly being destroyed by its own internal static pressure in the under-expanded case, and to allow for a larger expansion in the axial direction. If that same CD Nozzle is put in operation at sea-level and higher density atmosphere, where $P_{\text {exit }}<P_{a m b}$, it will very likely encounter nozzle flow separation for a very significant region within the higher density atmosphere, making it unfeasible as a nozzle design. A CD nozzle designed to operate from sea- 
level and within higher density atmosphere, will have a lower exit - to - throat area ratio, to reduce the magnitude of the $\left(P_{\text {exit }}-P_{a m b}\right) A_{\text {exit }}$ term, such that $P_{\text {exit }}<P_{a m b}$. For both cases, the intended exit static pressure is mainly controlled by exit - to - throat area ratio [4]. Nozzle contouring (rate of change in cross-sectional area of the nozzle, axially between the throat and exit) and adjusting the axial distance between the throat and exit, also play a role in controlling intended exit static pressure [4].

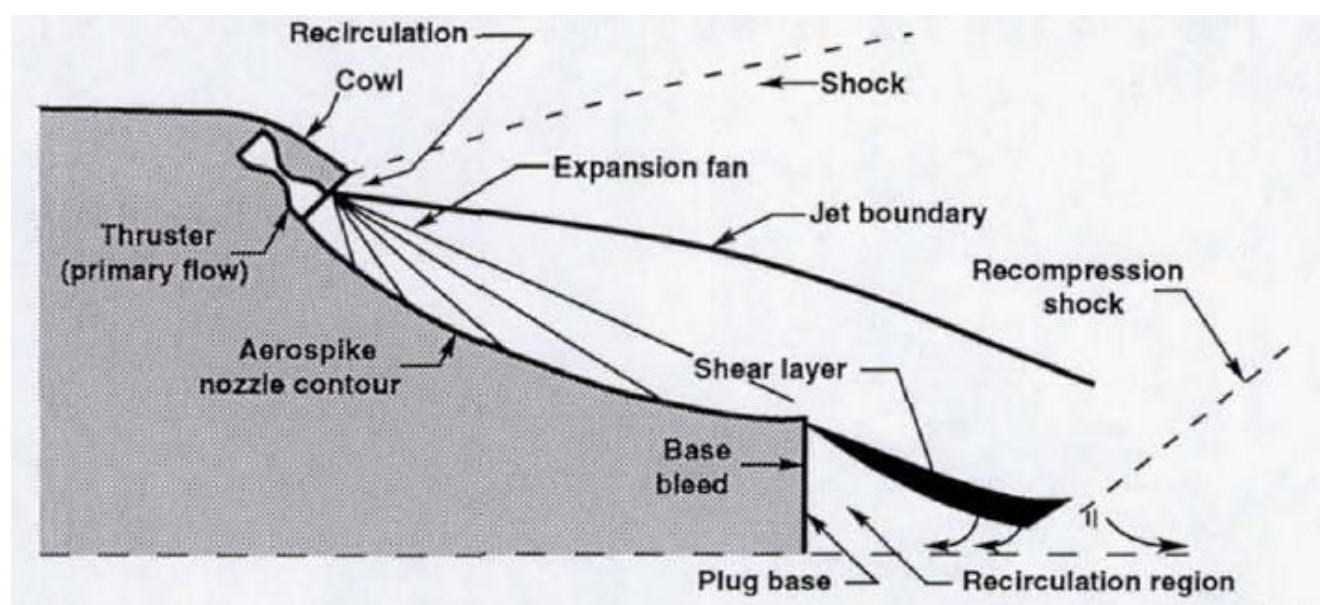

Figure 4: A sketch showing the main features of an Aerospike nozzle and its flow characteristics [7].

The aim behind an aerospike engine is to minimize the detrimental effects of overexpanded and under-expanded flows by providing a form of altitude adaptation [7]. The supersonic flow exiting from the convergent - divergent part of an aerospike engine (specified as Thruster in Figure 4) is allowed to expand against a center - body wall or Aerospike nozzle contour as shown in Figure 4 [7]. The supersonic flow above the center body wall will form a jet boundary as it interacts with the ambient air. The combination of the center-body wall and jet boundary, along with the supersonic flow that occurs in between, is in itself a divergent nozzle, or a continuation to the divergent section for the Thruster. A decreasing static ambient pressure (higher altitude) will result in the jet boundary moving away from the center - body, and vice versa. In both cases, the jet boundary adjusts to maximize axial expansion. The movement of the jet boundary relative to the nozzle contour is similar to a having a CD nozzle with a variable geometry to its divergent section, such that the divergent section will adjust based on altitude.

An essential parameter in assessing a rocket engine's performance is Specific Impulse $\left(I_{s p}\right)$. The formula for $I_{s p}$ is given by Equation (2):

$g_{o}:$ acceleration due to gravity at sea-level

$$
I_{s p}=\frac{T}{\dot{m} g_{o}}
$$

Equation (2) is used in the performance summary of every case that was tested for this report. Specific impulse can be thought of as the Thrust $(T)$, that is a force, divided by the weight flow rate of propellant $\left(\dot{m} g_{o}\right)$. The higher an $I_{s p}$ is for a rocket engine, the more thrust it can generate for a given mass flow rate of propellant. 
Theory

Derivation of the Thrust Equation for a CD Nozzle

The following sets of equations are used in the derivation of the thrust equations for a $C D$ nozzle. Thrust is produced in the axial direction and $x$ and $y$ represent the axial and radial directions, respectively.

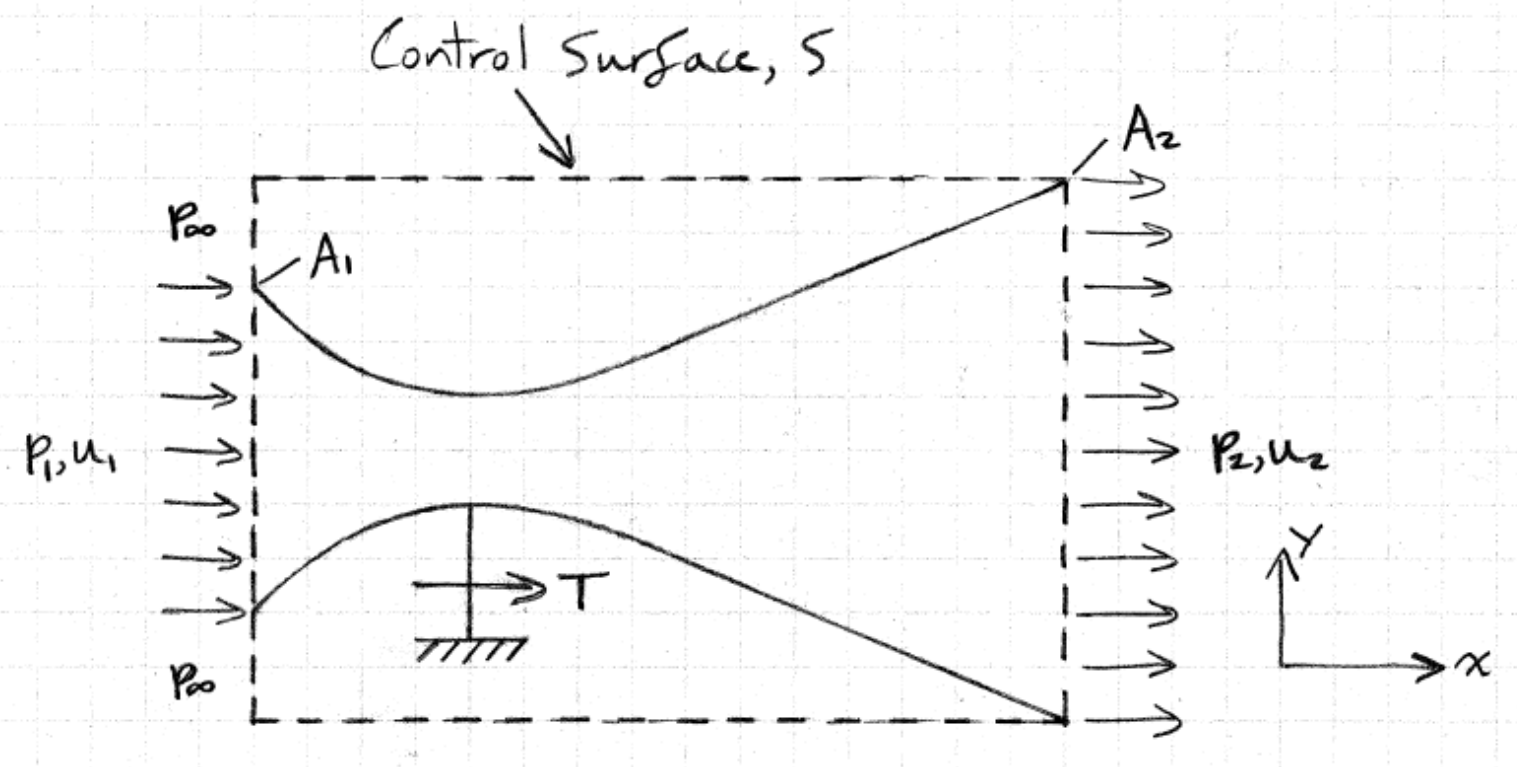

Figure 5: A sketch of the control volume used in the derivation of the thrust equation for a nozzle [4].

For a steady-state flow, with a negligible effect of body forces and viscous forces, the net flow of momentum into the control volume is equal to the net effect of pressure forces and external point forces acting on the control volume [4]:

$$
\begin{aligned}
& \begin{array}{l}
\sum F_{x}=0 ; \\
\text { net flow of momentum into the control volume } \\
=\text { net affect of pressure forces acting on the control volume }
\end{array} \\
& \qquad F_{x}=0 ; \oiint_{S}(\rho \vec{V} \cdot \overrightarrow{d S}) u=-\oiint_{S}(p d S)_{x} \\
& \qquad \begin{array}{l}
\rho_{2} u_{2}^{2} A_{2}-\rho_{1} u_{1}^{2} A_{1}=T+p_{1} A_{1}+p_{\infty}\left(A_{2}-A_{1}\right)-p_{2} A_{2} \\
T=\rho_{2} u_{2}^{2} A_{2}-\rho_{1} u_{1}^{2} A_{1}-p_{1} A_{1}-p_{\infty}\left(A_{2}-A_{1}\right)+p_{2} A_{2} \\
\dot{m}_{1}=\rho_{1} u_{1} A_{1}
\end{array}
\end{aligned}
$$




$$
\dot{m}_{2}=\rho_{2} u_{2} A_{2}
$$

For steady-state operation:

$$
\begin{gathered}
\dot{m}_{1}=\dot{m}_{2}=\dot{m} \\
T=\dot{m} u_{2}-\dot{m} u_{1}-p_{1} A_{1}-p_{\infty}\left(A_{2}-A_{1}\right)+p_{2} A_{2} \\
=\dot{m} u_{2}-\dot{m} u_{1}-p_{1} A_{1}-p_{\infty} A_{2}+p_{\infty} A_{1}+p_{2} A_{2} \\
=\dot{m} u_{2}-\dot{m} u_{1}+\left(p_{2}-p_{\infty}\right) A_{2}+\left(p_{\infty}-p_{1}\right) A_{1}
\end{gathered}
$$

For a rocket engine (non-airbreathing engine) mounted to a structure:

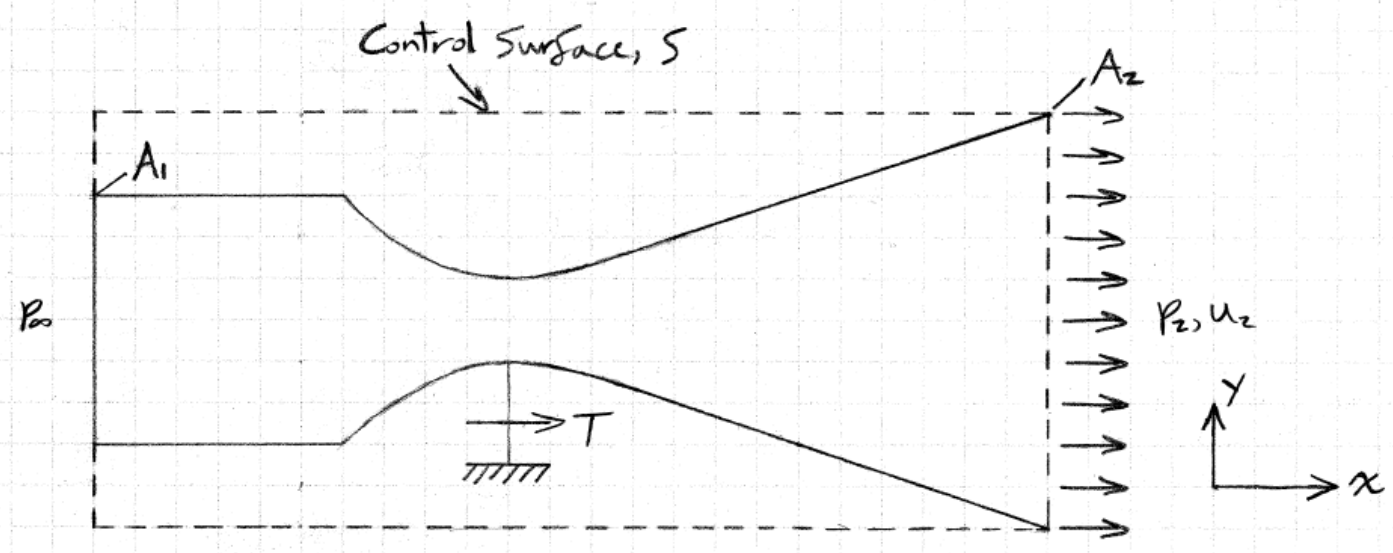

Figure 6: A sketch of the control volume for a rocket nozzle.

$$
\begin{gathered}
u_{1}=0 \\
p_{1}=p_{\infty} \\
T=\dot{m} u_{2}-\dot{m}(0)+\left(p_{2}-p_{\infty}\right) A_{2}+\left(p_{\infty}-p_{\infty}\right) A_{1}
\end{gathered}
$$

The thrust equation is therefore given by:

$$
T=\dot{m} u_{2}+\left(p_{2}-p_{\infty}\right) A_{2}
$$

Equation (3) has the same form as that of (1):

$$
T=\dot{m} u_{\text {exit }}+\left(p_{\text {exit }}-p_{\text {amb }}\right) A_{\text {exit }}
$$


Derivation of the Thrust Equation for a CD Nozzle \& CB and an Aerospike

The following sets of equations are used in the derivation of the thrust equations for a $C D$ Nozzle \& CB and an Aerospike. Thrust is produced in the axial direction and $x$ and $y$ represent the axial and radial directions, respectively.
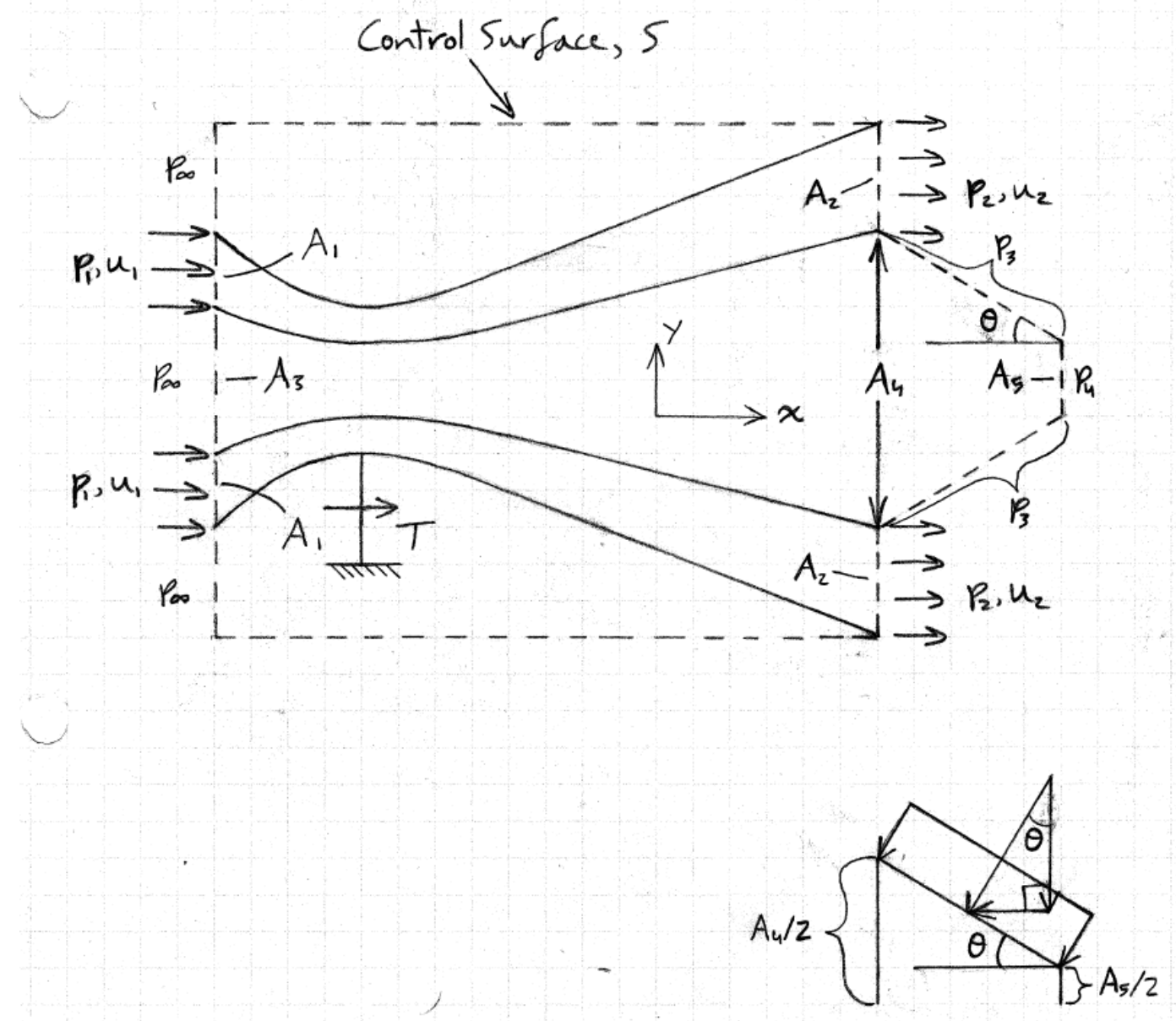

Figure 7: A sketch of the control volume used in the derivation of the Thrust equation for a CD nozzle and Center-Body model. 


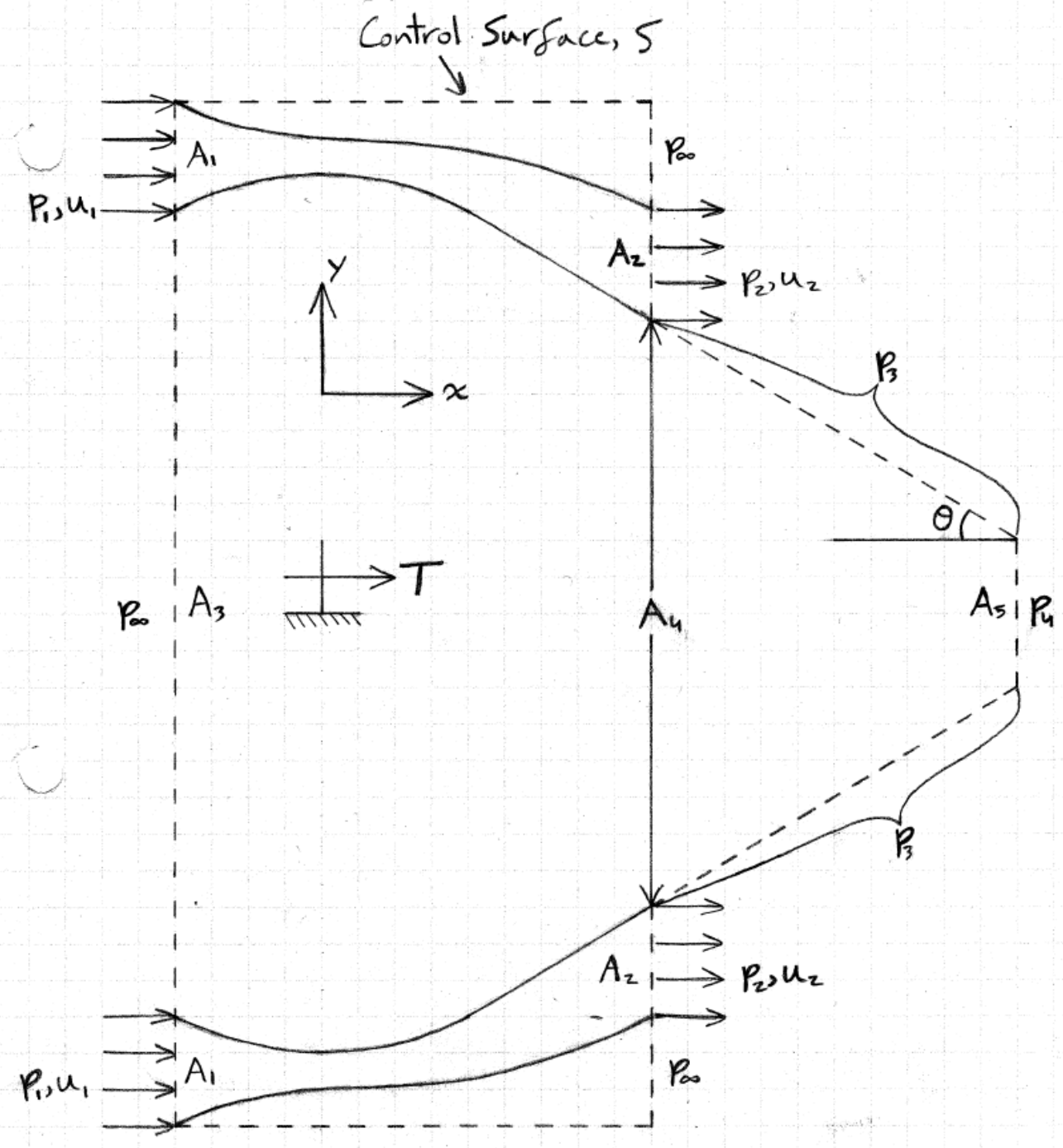

Figure 8: A sketch of the control volume used in the derivation of the Thrust equation for an Aerospike.

$$
\sum F_{x}=0 ; \oiint_{S}(\rho \vec{V} \cdot \overrightarrow{d S}) u=-\oiint_{S}(p d S)_{x} \quad[4]
$$

$2 \rho_{2} u_{2}^{2} A_{2}-2 \rho_{1} u_{1}^{2} A_{1}$

$$
\begin{aligned}
& =T+2 p_{1} A_{1}+p_{\infty} A_{3}+p_{\infty}\left(2 A_{2}+A_{4}-2 A_{1}-A_{3}\right)-2 p_{2} A_{2}-2 \int_{\frac{A_{4}}{2}}^{\frac{A_{5}}{2}}\left(p_{3}\right)_{x} d A \\
& -p_{4} A_{5}
\end{aligned}
$$

$$
\begin{aligned}
& \dot{m}_{1}=2 \rho_{1} u_{1} A_{1} \\
& \dot{m}_{2}=2 \rho_{2} u_{2} A_{2}
\end{aligned}
$$


For steady-state operation:

$$
\begin{gathered}
\dot{m}_{1}=\dot{m}_{2}=\dot{m} \\
\dot{m} u_{2}-\dot{m} u_{1}= \\
\quad-p_{4} A_{5} \\
T=\dot{m} u_{2}-\dot{m} u_{1}-2 p_{1} A_{1}-p_{\infty} A_{3}-p_{\infty}\left(2 A_{2}+A_{4}-2 A_{1}-A_{3}\right)+2 p_{2} A_{2}+2 \int_{\frac{A_{4}}{2}}^{\frac{A_{5}}{2}}\left(p_{3}\right)_{x} d A \\
+p_{4} A_{5}
\end{gathered}
$$

For both the CD Nozzle \& CB and Aerospike cases, the sloped exterior of the center - body is inclined clockwise from the negative $\mathrm{x}$-axis by an angle of $\theta$. This implies:

$$
\int_{\frac{A_{4}}{2}}^{\frac{A_{5}}{2}}\left(p_{3}\right)_{x} d A=\left(\int_{\frac{A_{4}}{2}}^{\frac{A_{5}}{2}} p_{3} d A\right) \sin \theta
$$

For a rocket engine (non-airbreathing engine) mounted to a structure:

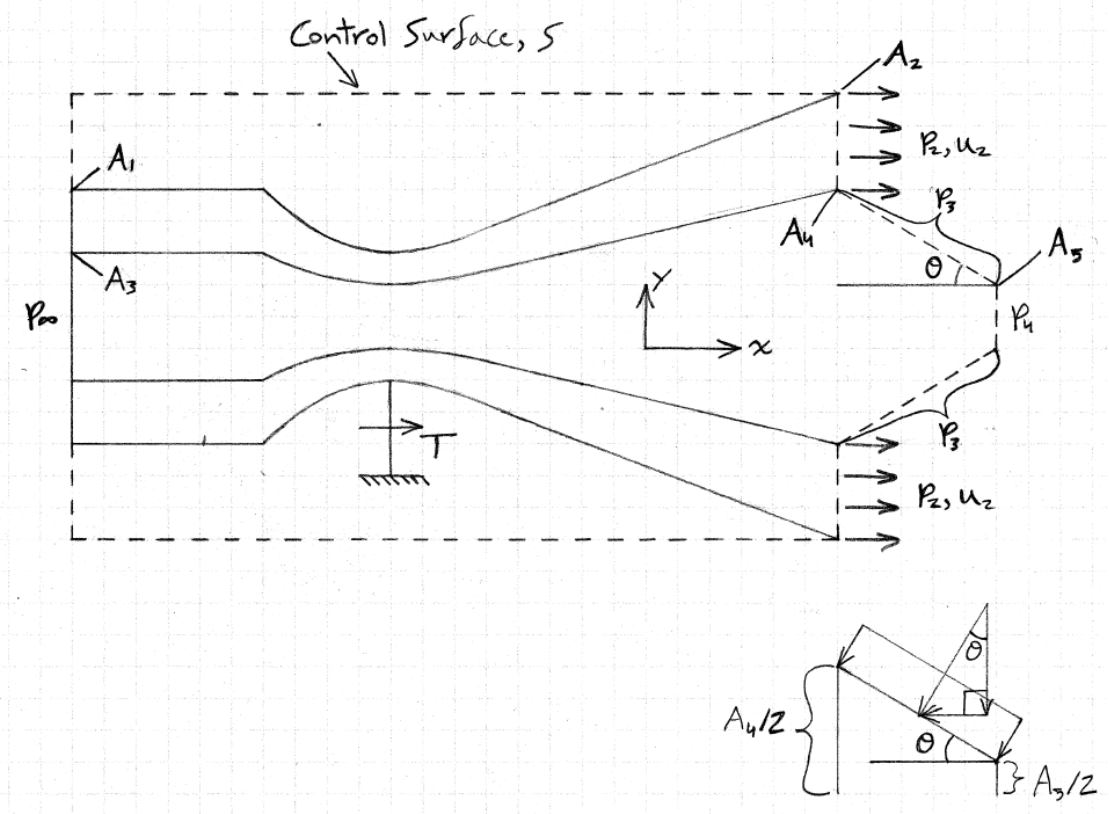

Figure 9: A sketch of the control volume for rocket nozzle with a Center-Body. 


$$
\begin{gathered}
u_{1}=0 \\
p_{1}=p_{\infty} \\
T=\dot{m} u_{2}-\dot{m}(0)-2 p_{\infty} A_{1}-p_{\infty} A_{3}-p_{\infty}\left(2 A_{2}+A_{4}-2 A_{1}-A_{3}\right)+2 p_{2} A_{2} \\
+2\left(\int_{\frac{A_{4}}{2}}^{\frac{A_{5}}{2}} p_{3} d A\right) \sin \theta+p_{4} A_{5} \\
=\dot{m} u_{2}-2 p_{\infty} A_{1}-p_{\infty} A_{3}-2 p_{\infty} A_{2}-p_{\infty} A_{4}+2 p_{\infty} A_{1}+p_{\infty} A_{3}+2 p_{2} A_{2}+2\left(\int_{\frac{A_{4}}{2}}^{\frac{A_{5}}{2}} p_{3} d A\right) \sin \theta \\
\left.+p_{4} A_{5}\right) \sin \theta+p_{4} A_{5} \\
=\dot{m} u_{2}-2 p_{\infty} A_{2}-p_{\infty} A_{4}+2 p_{2} A_{2}+2\left(\int_{\frac{A_{4}}{2}}^{\frac{A_{5}}{2}} p_{3} d A\right)
\end{gathered}
$$

The thrust equation is therefore given by:

$$
T=\dot{m} u_{2}+2\left(p_{2}-p_{\infty}\right) A_{2}-p_{\infty} A_{4}+2\left(\int_{\frac{A_{4}}{2}}^{\frac{A_{5}}{2}} p_{3} d A\right) \sin \theta+p_{4} A_{5}
$$




\section{CHAPTER 2}

Convergence of CFD Results \& Comparison with Published Data

A conical CD nozzle design was selected from a technical note by NASA; NASA TN D 467. The nozzle was re-modeled using CAD software and used for solution convergence in CFD. According to the technical note, the nozzle was tested using air at inlet total pressures of approximately 145,90 , and $50 \mathrm{psi}(999,739.8,620,528.1,344,738.0 \mathrm{~Pa}$ respectively) [8]. The static inlet temperature was maintained at $1,200^{\circ} \mathrm{F}(922.0 \mathrm{~K})$ using direct-fired heaters [8]. Originally the inlet air was considered as almost dry air, or dried to around 1 grain/lb $(0.142857$ $\mathrm{g} / \mathrm{kg}$ ) [8]. However, the burning of JP fuel in the direct-fired heaters added moisture to the inlet air along with other gas impurities [8]. The moisture content of the air resulted in condensation shocks as the air cooled and expanded in the divergent section of the nozzle [8].

The nozzle selected from NASA TN D - 467 is shown in Figure 10, was modeled in CFD, up to an exit - to - critical (throat) area ratio of 9.2, shown in Figure 11.

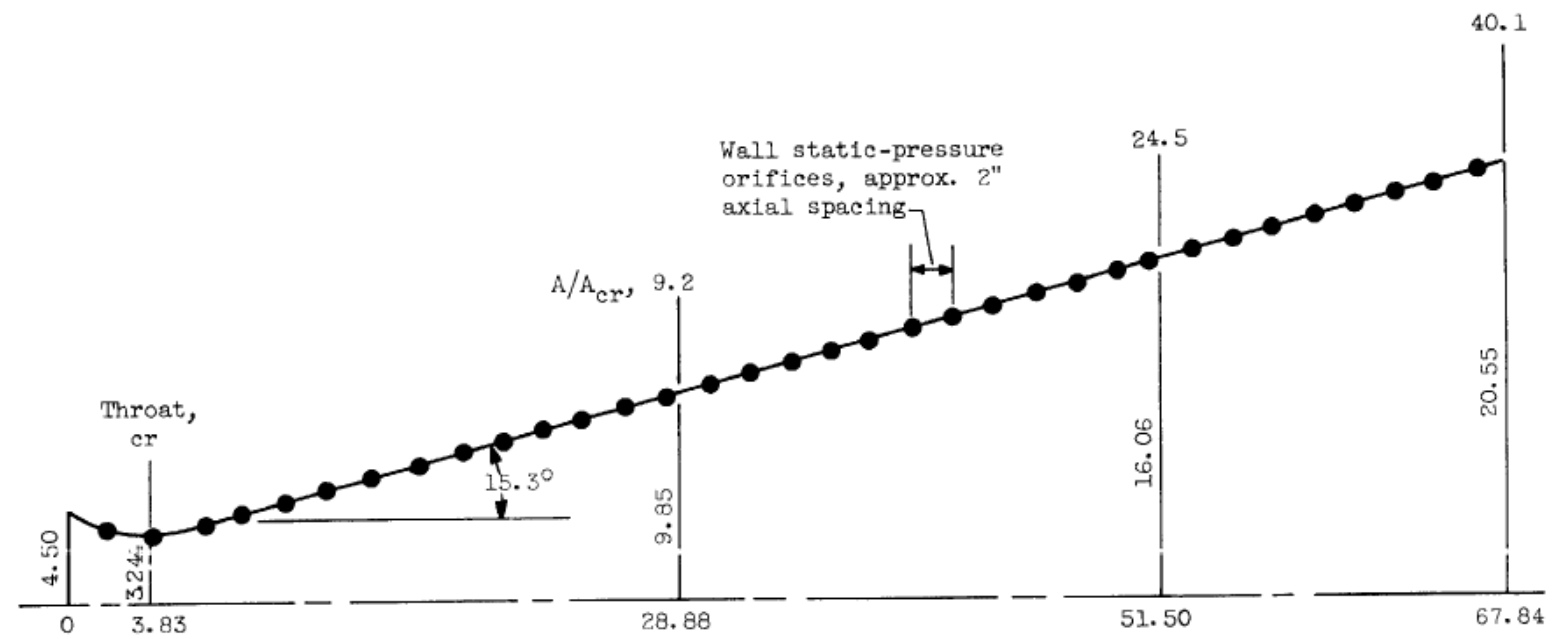

Figure 10: A sketch of the conical nozzle used for data convergence in CFD, obtained from the technical note, NASA TN D-467 [8]; all dimensions are in inches. 


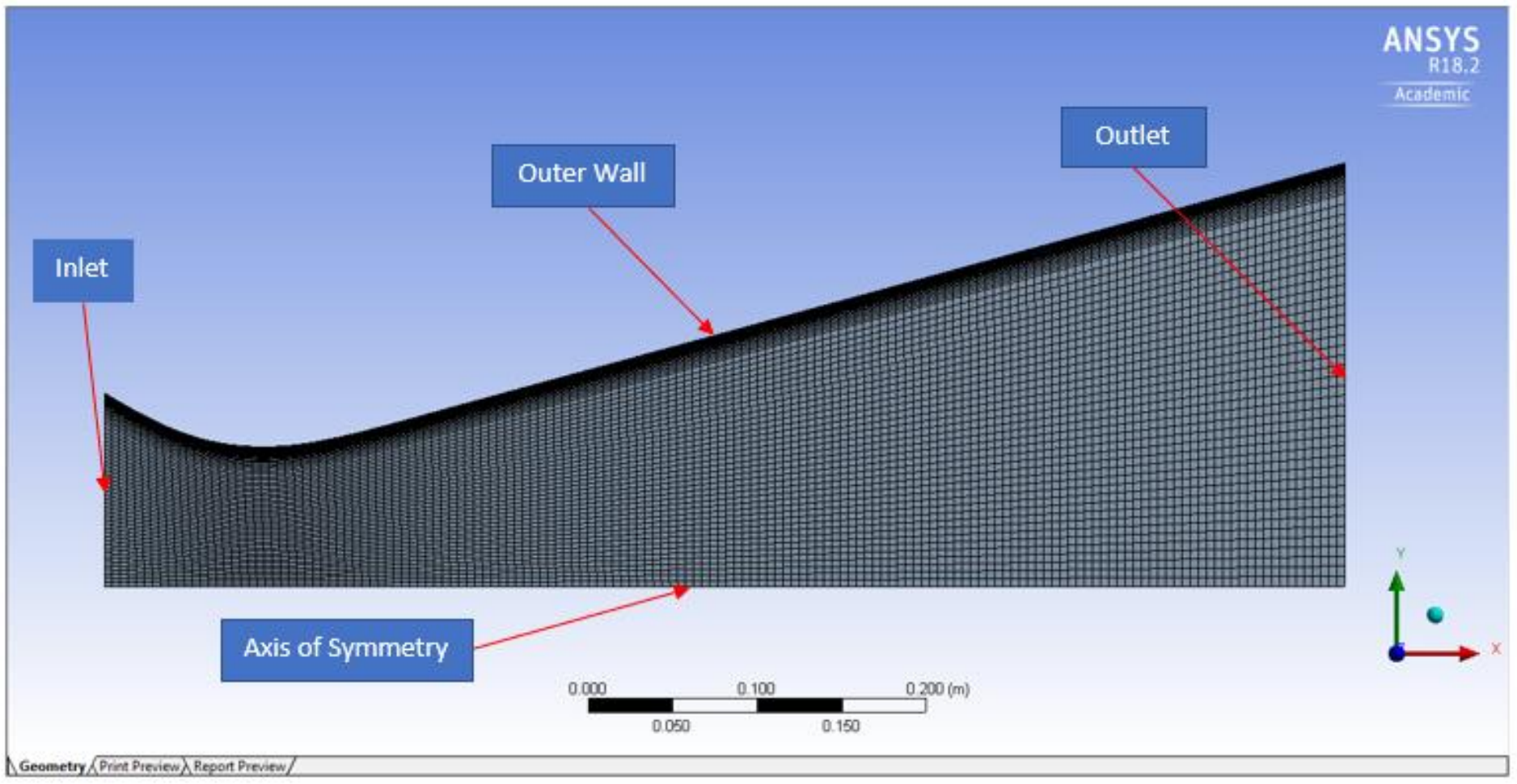

Figure 11: A meshed model for the conical nozzle in Figure 10 up to an axial distance of 28.88in or A/A cr of 9.2, re-created in ANSYS for data convergence in CFD.

Table 1: A listing of the names of boundary conditions and their corresponding definitions in CFD and input parameters.

\begin{tabular}{|l|l|l|}
\hline Boundary & Boundary Definition in CFD & Input Parameters \\
\hline Inlet & Pressure Inlet & $P_{o}, P_{i}$, and $T_{o}$ \\
\hline Outer Wall & Wall & $\begin{array}{l}\text { No-slip and adiabatic } \\
\text { conditions }\end{array}$ \\
\hline Outlet & Pressure Outlet & $P_{e}$, and $T_{o}$ \\
\hline Axis of Symmetry & Axis & \\
\hline
\end{tabular}


Before running a CFD solution to model the nozzle flow, the parameters $P_{i}, T_{o}$, and $P_{e}$ had to be determined based on the 1D isentropic calorically perfect gas equations [5], given that $P_{o}$ and $T_{i}$ are known. Valid predictions of $P_{i}, T_{o}$, and $P_{e}$ are required for specifying boundary conditions in CFD. Predictions of inlet and exit Mach numbers $\left(M_{i}\right.$ and $M_{e}$, respectively) were determined using Equations (5) and (6), for isentropic flow, given that Mach 1 occurs at the nozzle throat, and $\gamma=1.4$ [5]:

$$
\begin{gathered}
\left(\frac{A_{i}}{A^{*}}\right)^{2}=\frac{1}{M_{i}^{2}}\left[\frac{2}{\gamma+1}\left(1+\frac{\gamma-1}{2} M_{i}^{2}\right)\right]^{(\gamma+1) /(\gamma-1)} \\
\left(\frac{A_{e}}{A^{*}}\right)^{2}=\frac{1}{M_{e}^{2}}\left[\frac{2}{\gamma+1}\left(1+\frac{\gamma-1}{2} M_{e}^{2}\right)\right]^{(\gamma+1) /(\gamma-1)} \\
\frac{P_{o}}{P_{i}}=\left(1+\frac{\gamma-1}{2} M_{i}^{2}\right)^{\gamma /(\gamma-1)} \\
P_{i}=\frac{\left(1+\frac{\gamma-1}{2} M_{i}^{2}\right)^{\gamma /(\gamma-1)}}{(8)} \\
\frac{P_{o}}{P_{e}}=\left(1+\frac{\gamma-1}{2} M_{i}^{2}\right)^{\gamma /(\gamma-1)} \\
P_{e}=\frac{P_{o} A^{*}}{\sqrt{T_{o}}}=\frac{T_{i}\left(1+\frac{\gamma-1}{2} M_{i}^{2}\right)}{\left(1+\frac{\gamma-1}{2} M_{e}^{2}\right)^{\gamma /(\gamma-1)}} \\
\frac{T_{o}}{T_{i}}=1+\frac{\gamma-1}{2} M_{i}^{2}(10) \\
(\gamma+1) /(\gamma-1)
\end{gathered}
$$




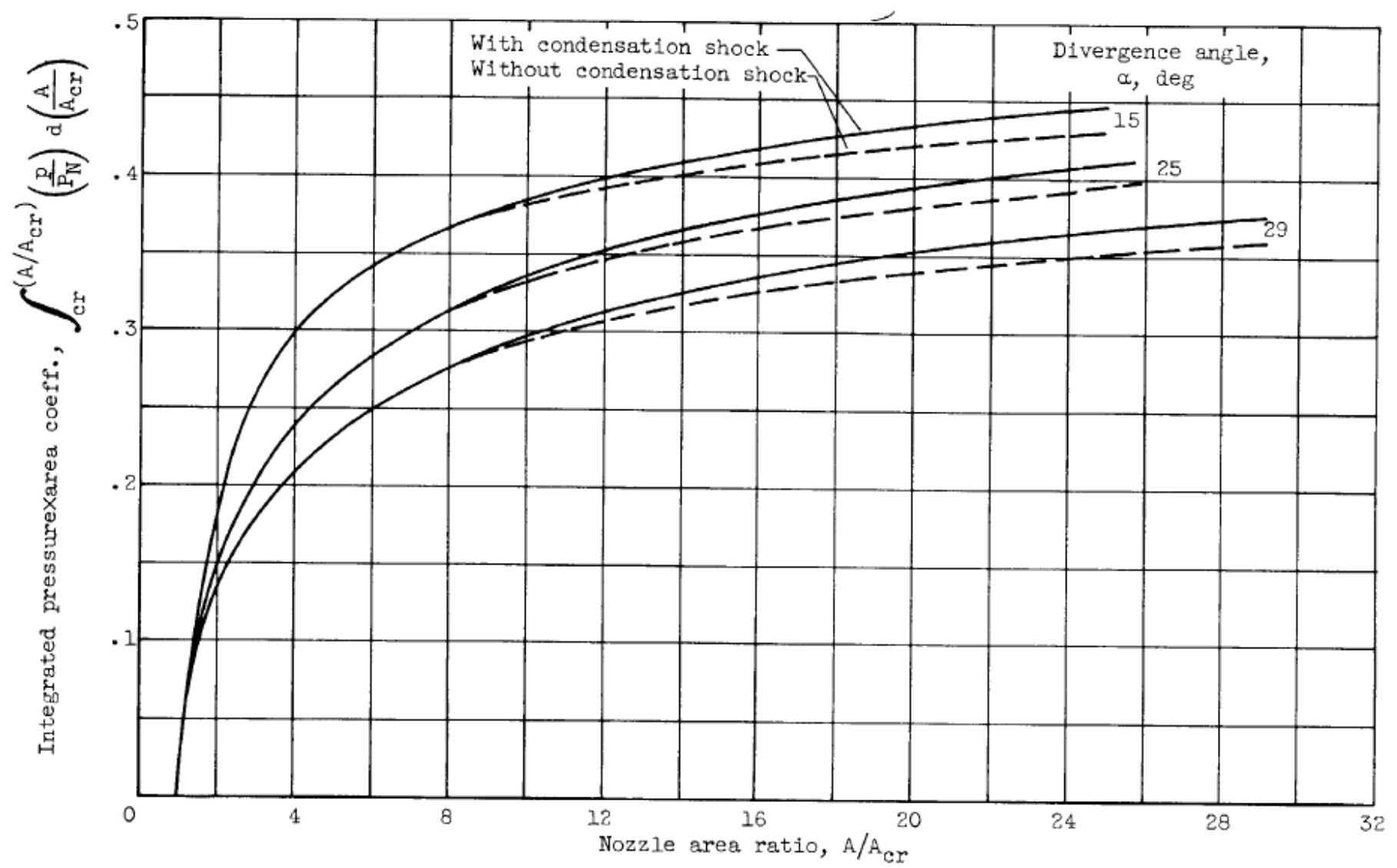

Figure 12: Integral of nozzle pressure ratio with respect to area ratio for three different conical nozzles at varying divergence angles [8]. 
INTEGRAL OF PRESSURE RATIO WITH RESPECT TO AREA COFFICIENT

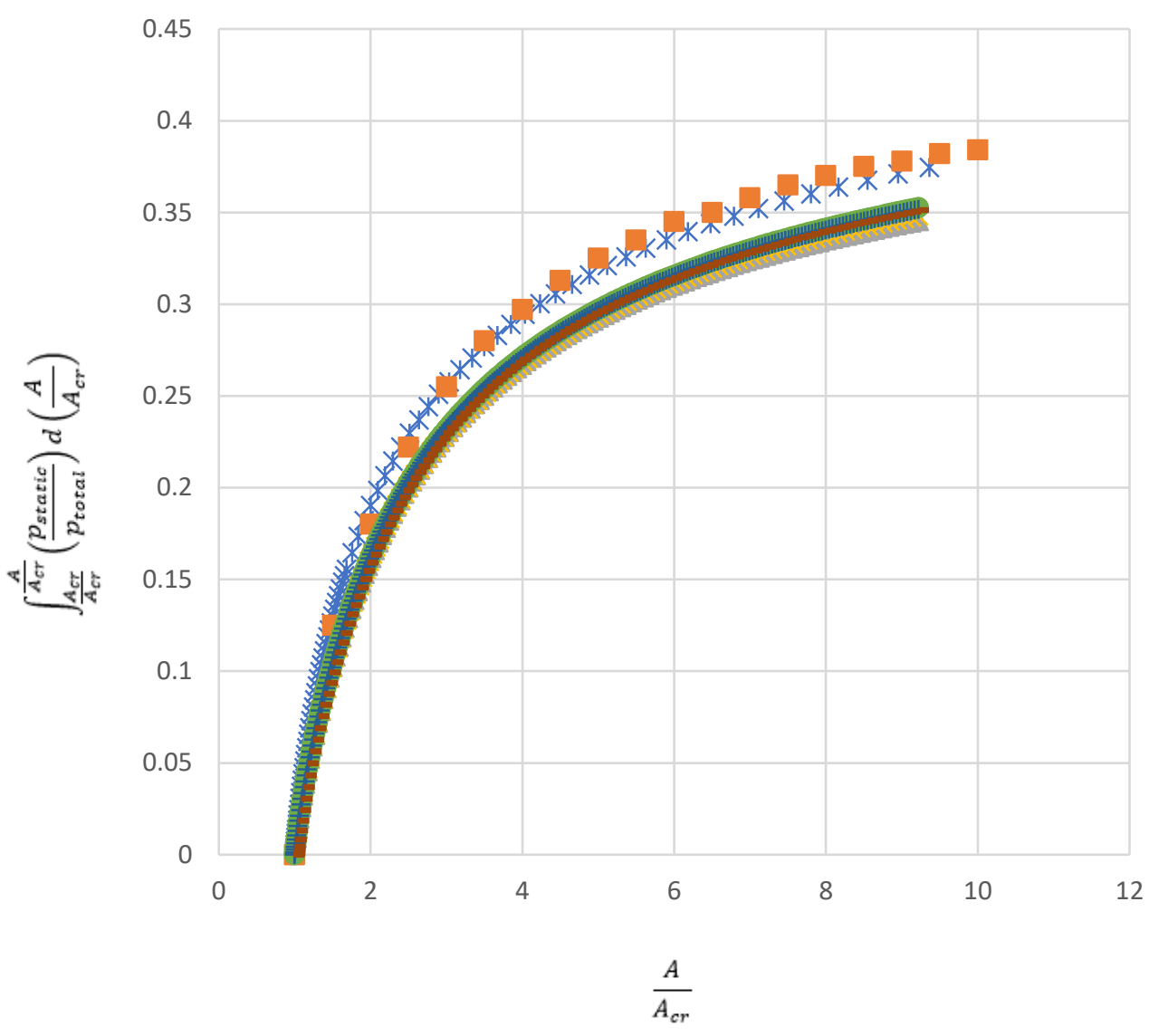

50psi Inlet Total Pressure; Realizable k-epsilon Model \& Enhanced Wall Treatment; $\mathrm{y}+=$ $11.5 ; 2.5 \mathrm{~mm} \times 5.0 \mathrm{~mm}$

$\triangle 50 p s i$ Inlet Total Pressure; Inviscid Flow 7600 Elements; Global Element Size $=5.0 \mathrm{~mm}$

$\times 50$ psi Inlet Total Pressure; Laminar Flow 10863 Elements; Global Element Size $=5.0 \mathrm{~mm}$

* 1D Equations' Result

Experimental Result

50psi Inlet Total Pressure; Realizable k-epsilon Model \& Enhanced Wall Treatment; $y+=1$; $1.0 \mathrm{~mm} \times 2.5 \mathrm{~mm}$

+50 psi Inlet Total Pressure; SST komega Model; $\mathrm{y}+=1 ; 1.0 \mathrm{~mm} x$ $2.5 \mathrm{~mm}$

- 90psi Inlet Total Pressure; Realizable k-epsilon Model \& Enhanced Wall Treatment; $\mathrm{y}+=$ $11.5 ; 2.5 \mathrm{~mm} \times 5.0 \mathrm{~mm}$

Figure 13: Plots of integral of nozzle pressure ratio with respect to area ratio for the experimental result [8] and results from CFD. 
In Figure (13), the plot for the Experimental result was created by using points extrapolated from the plot of the $15^{\circ}$ divergence angle conical nozzle, from Figure (12). For the convergence plots shown in Figure (13), discrepancies between the Experimental, 1D Equations', and CFD results are due to the following:

- The 1D Equations assume that gas properties change in only one direction, which in this case is along the axis of symmetry of the nozzle and that flow is isentropic [5]

- Both plots for the 1D Equations and CFD solutions assume a calorically perfect gas, such the ratio of specific heats $(\gamma)$ is constant at a value of 1.4 , while the plot for the Experimental result is one for a real gas, in which $\gamma$ will fluctuate from 1.4 based on temperature variation in the nozzle

- For the Experimental result, the air being used contained significant gas impurities when it entered the nozzle inlet, due to the direct-fired heaters [8], meaning the air varied chemically from pure dry air, in which $\gamma$ will vary even further from 1.4. 


\section{Simulation of Supersonic Nozzle Flow with Ambient Conditions at 20km Standard Atmosphere}

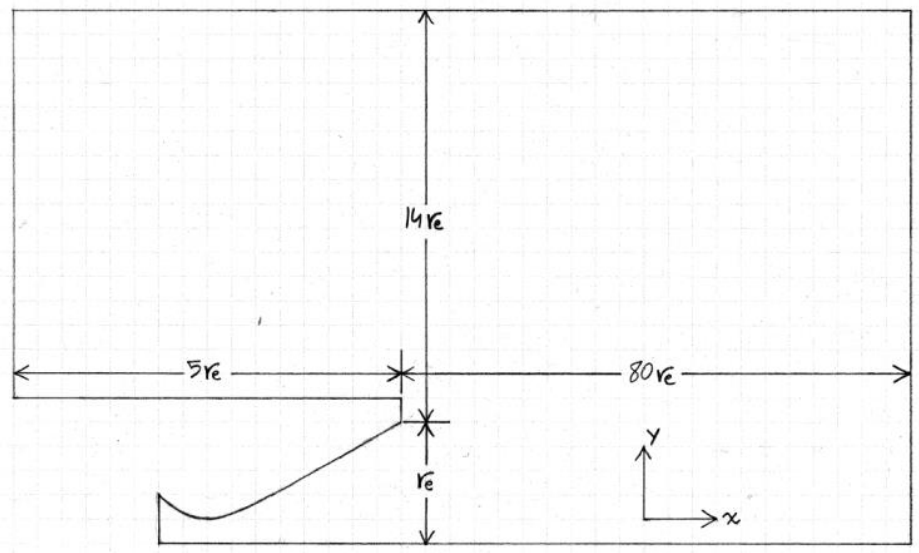

Figure 14: A sketch showing the dimensions used in defining the boundary limits of the ambient volume, through which supersonic nozzle flow will expand.

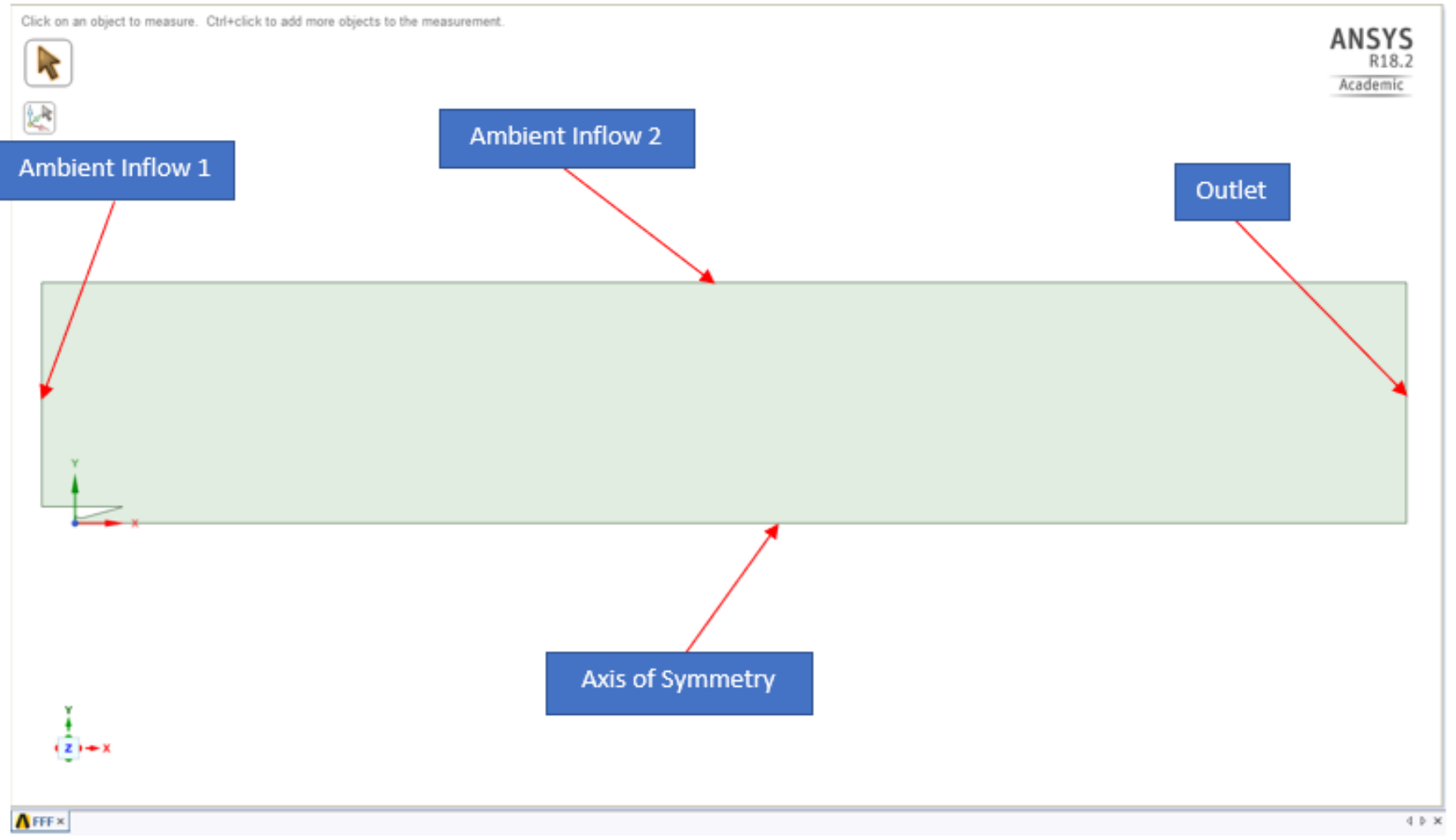

Figure 15: A CAD design of the CD Nozzle with the ambient volume based on dimensions from Figure 14, with names of boundaries. 


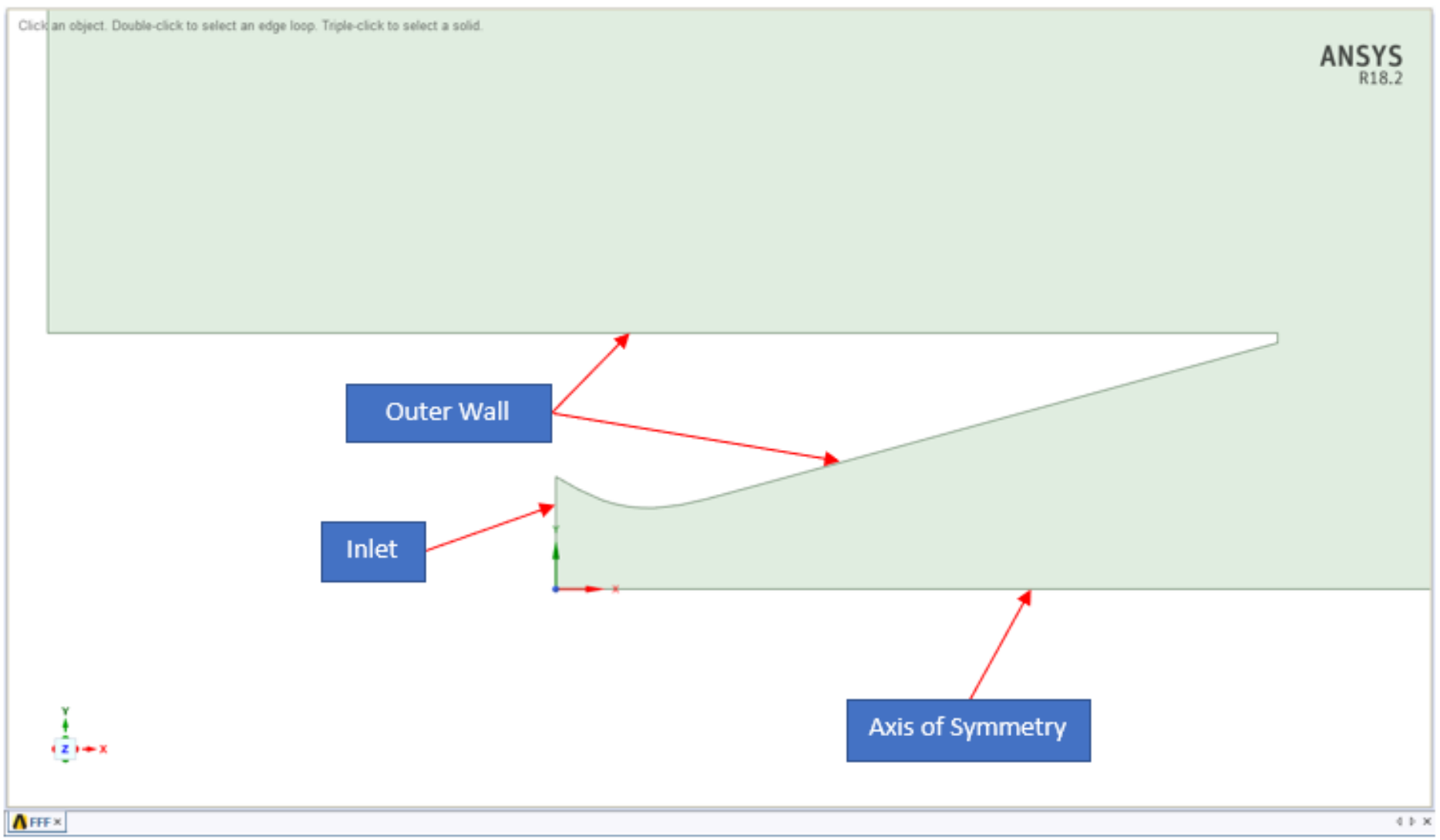

Figure 16: The same model from Figure 15, with the view zoomed in on the nozzle, including names of boundaries. 
Table 2: A listing of the names of boundary conditions and their corresponding definitions in CFD and input parameters.

\begin{tabular}{|l|l|l|}
\hline Boundary & Boundary Definition in CFD & $\begin{array}{l}\text { Input Parameters } \\
\text { Gauge total pressure }=P_{o}, \\
\text { Gauge static pressure }=P_{i}, \text { and } \\
\text { Total temperature }=T_{o}\end{array}$ \\
\hline Outer Wall & Pressure Inlet & $\begin{array}{l}\text { No-slip and adiabatic } \\
\text { conditions }\end{array}$ \\
\hline Ambient Inflow 1 & Pressure Inlet & $\begin{array}{l}\text { Gauge total pressure }=P_{a m b}, \\
\text { Gauge static pressure }=P_{a m b}, \\
\text { Total temperature }=T_{a m b}\end{array}$ \\
\hline Ambient Inflow 2 & Pressure Inlet & $\begin{array}{l}\text { Gauge total pressure }=P_{a m b}, \\
\text { Gauge static pressure }=P_{a m b}, \\
\text { Total temperature }=T_{a m b}\end{array}$ \\
\hline Outlet & Pressure Outlet & $\begin{array}{l}\text { Gauge static pressure }=P_{a m b} \\
\text { and Total temperature }=T_{o}\left(T_{o}\right. \\
\text { calculated at the nozzle inlet is } \\
\text { used as the total temperature } \\
\text { specification at the outlet } \\
\text { boundary, since in CFD, the } \\
\text { flow considered as adiabatic) }\end{array}$ \\
\hline Axis of Symmetry & Axis \\
\hline
\end{tabular}




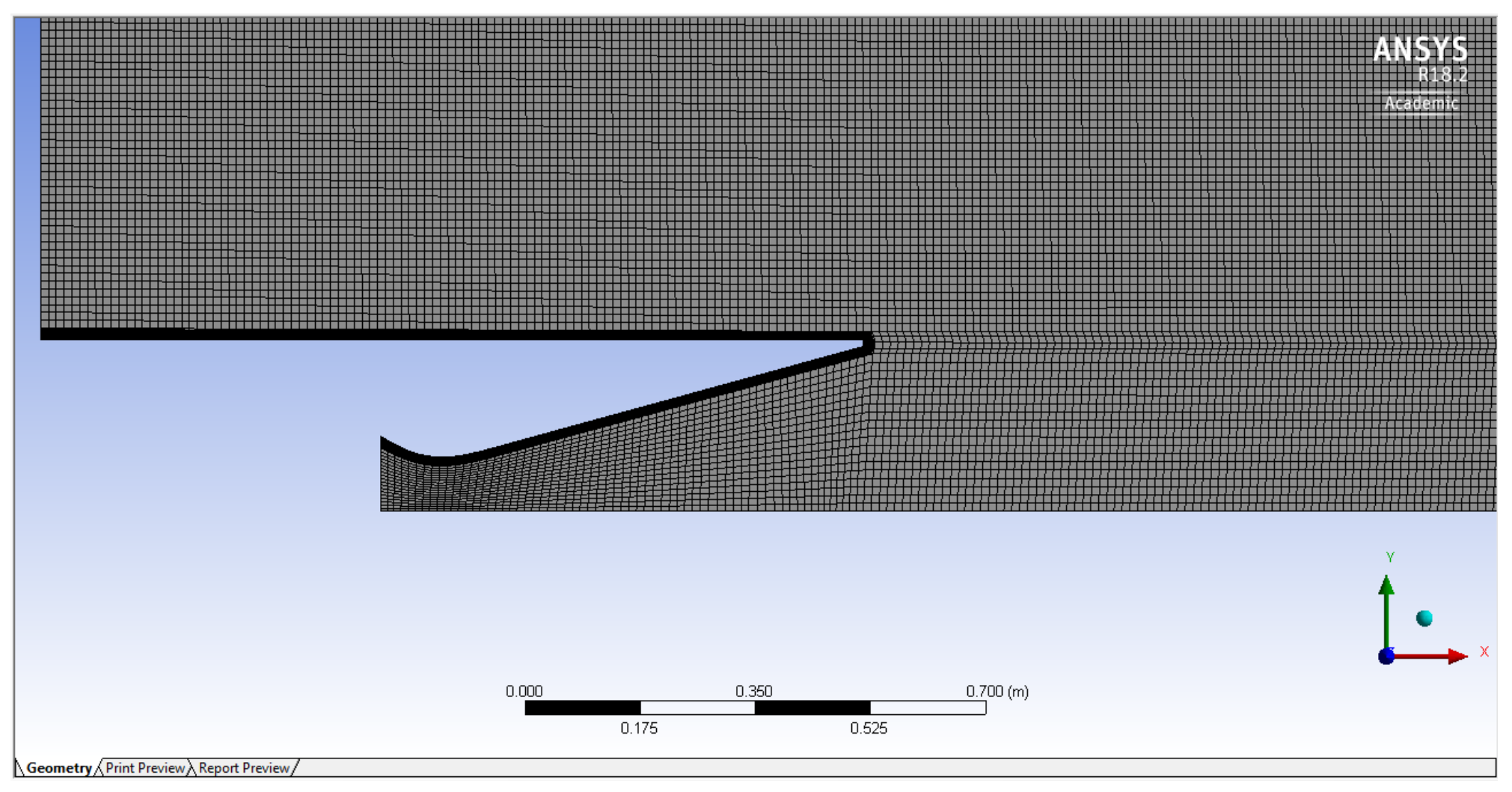

Figure 17: A screenshot of the mesh generated for the model in Figure 15. 


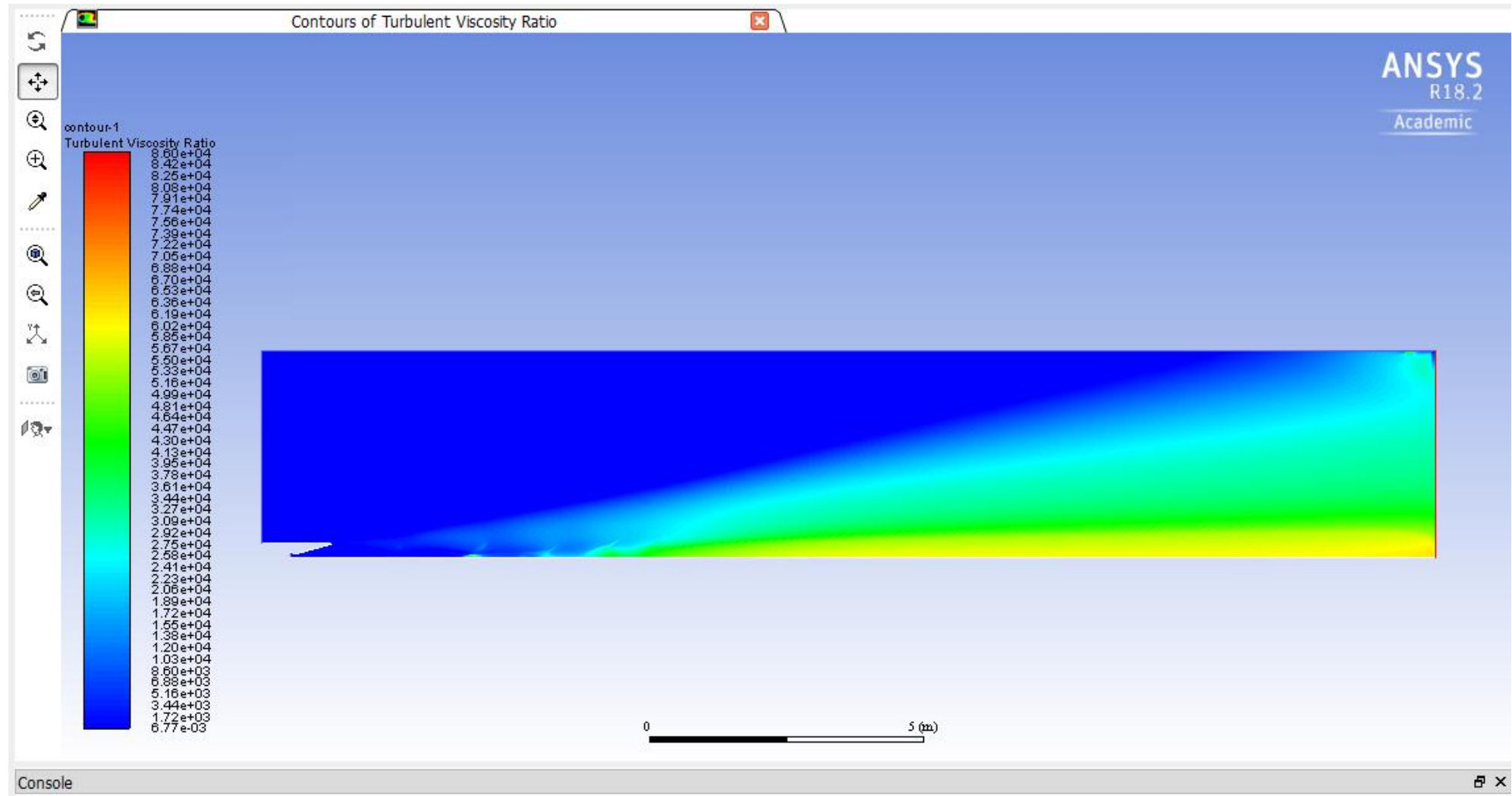

Figure 18: Contour of turbulent viscosity ratio distribution for the model in Figure 15, with nozzle flow expansion into ambient air at $20 \mathrm{~km}$ standard atmosphere. 


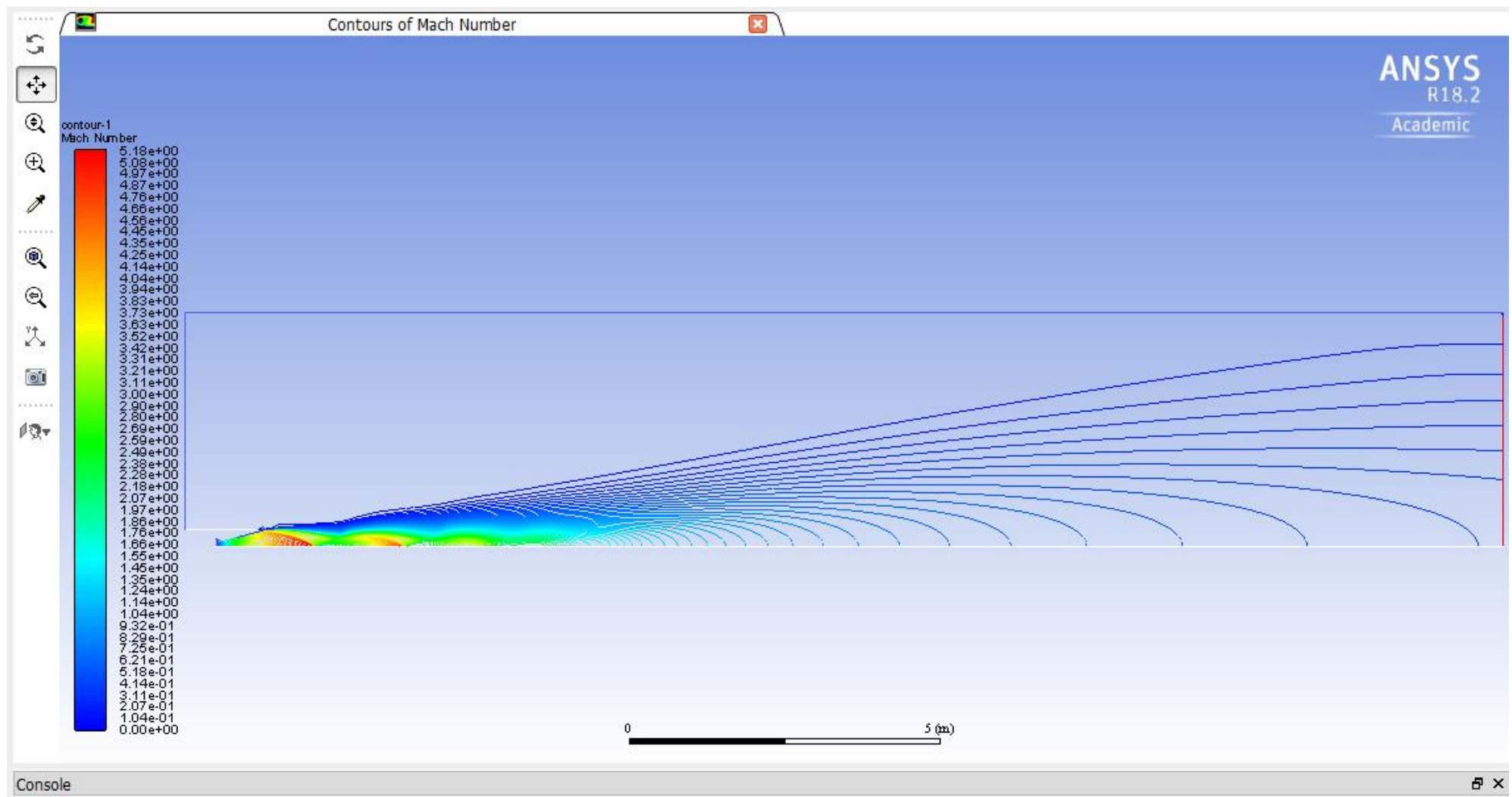

Figure 19: Line contours of Mach number for the model in Figure 15, with nozzle flow expansion into ambient air at $20 \mathrm{~km}$ standard atmosphere. 


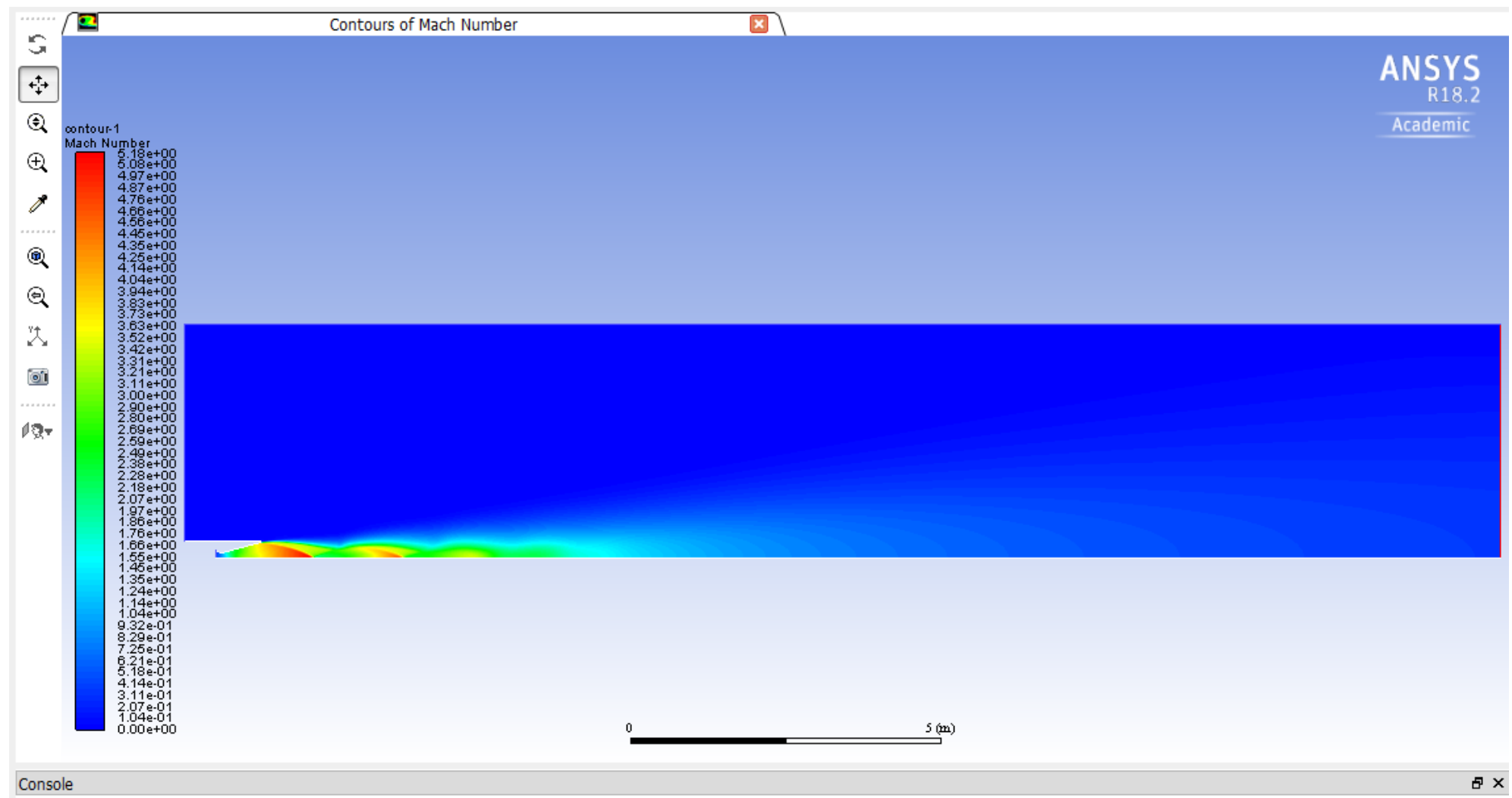

Figure 20: Contour of Mach number for the model in Figure 15, with nozzle flow expansion into ambient air at 20km standard atmosphere. 


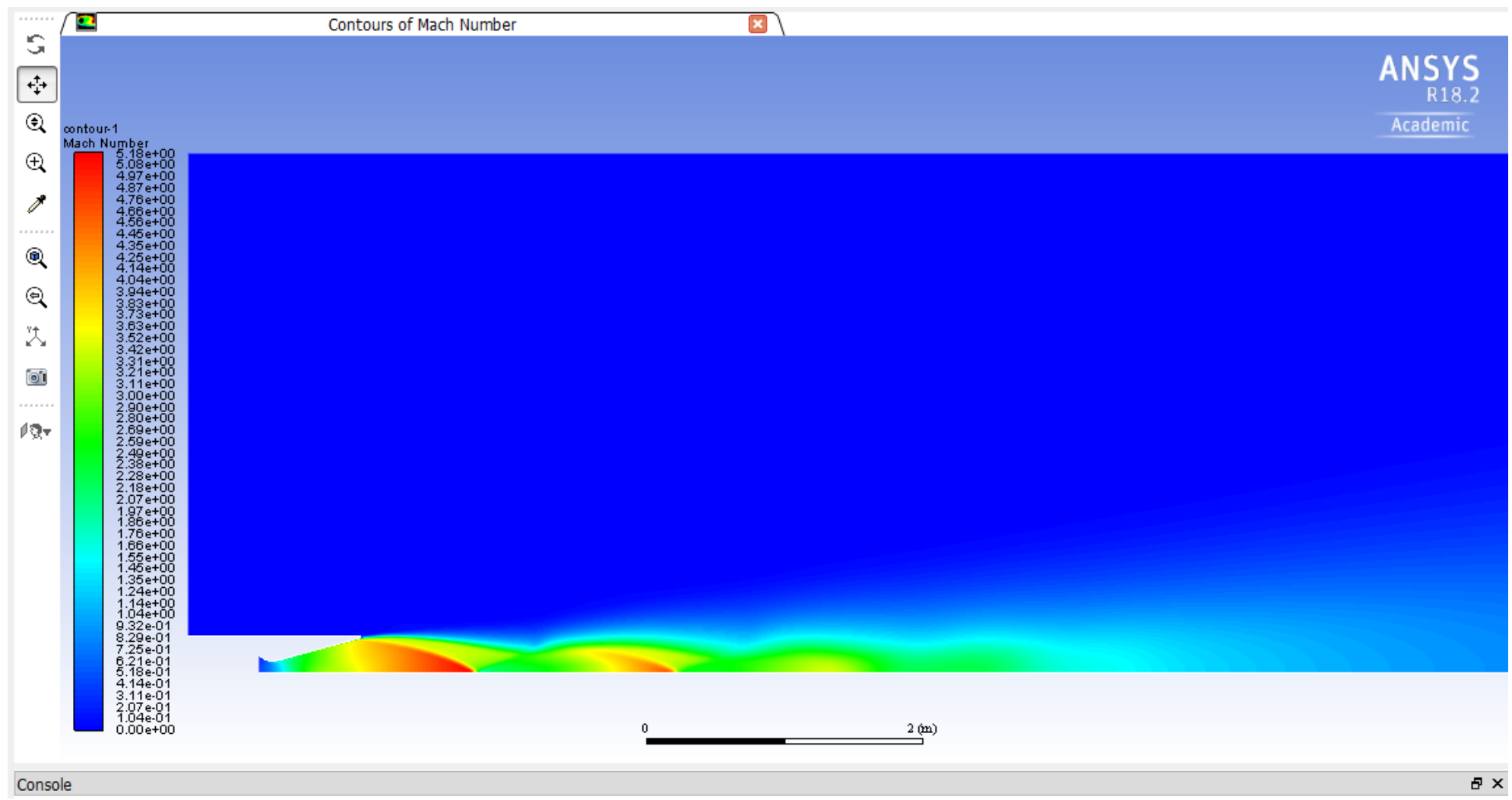

Figure 21: Contour of Mach number for the model in Figure 15, with nozzle flow expansion into ambient air at 20km standard atmosphere. 


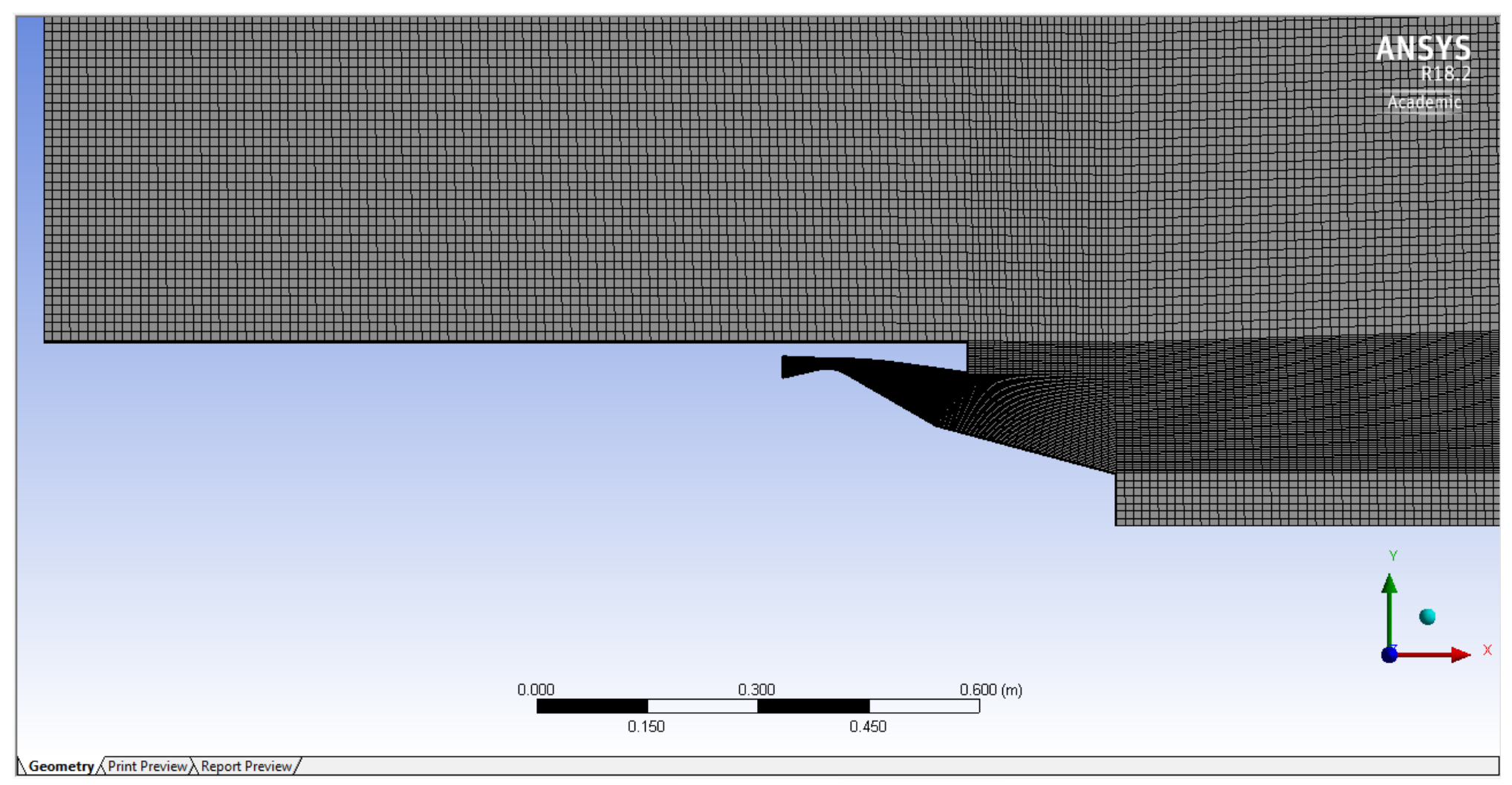

Figure 22: A screenshot of the mesh for Aerospike 11. 


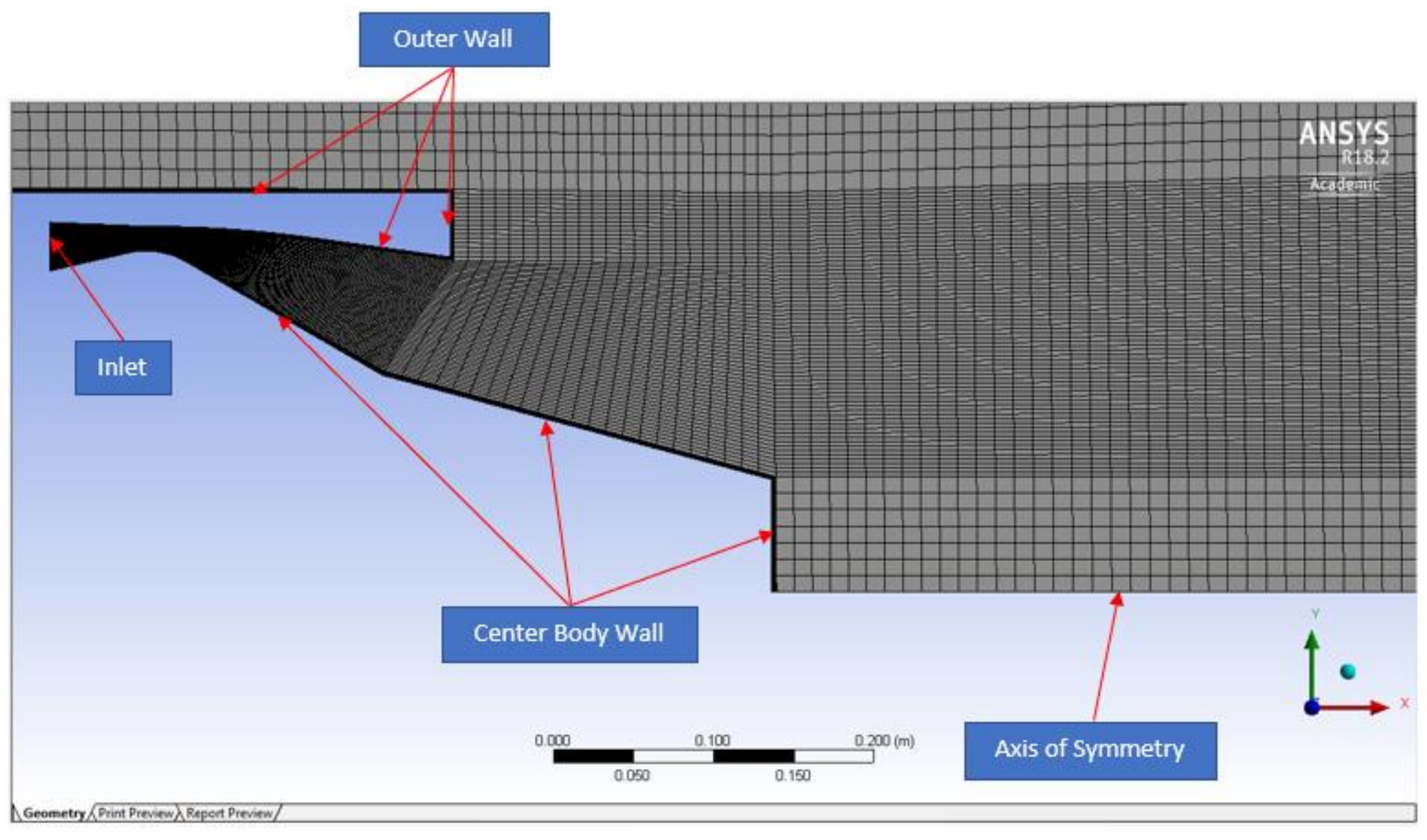

Figure 23: A screenshot of the mesh for Aerospike 11 with the names of boundaries. 


\section{CHAPTER 3}

CD Nozzle \& CB Models

The CD Nozzle and CD Nozzle \& CB design iterations all operate under the same mass flow rate. Having all test cases utilize the same mass flow rate, allows to better ascertain which design is more ideal. The CD Nozzle \& CB cases were also designed to have the same exit-tothroat axial area ratio as that for the CD Nozzle, implying the same prediction for exit Mach number. The contour of the $\mathrm{CB}$ was designed such that the throat area is not shifted axially from the CD Nozzle case and the contour of the outer body wall is kept the same as that of the CD Nozzle.

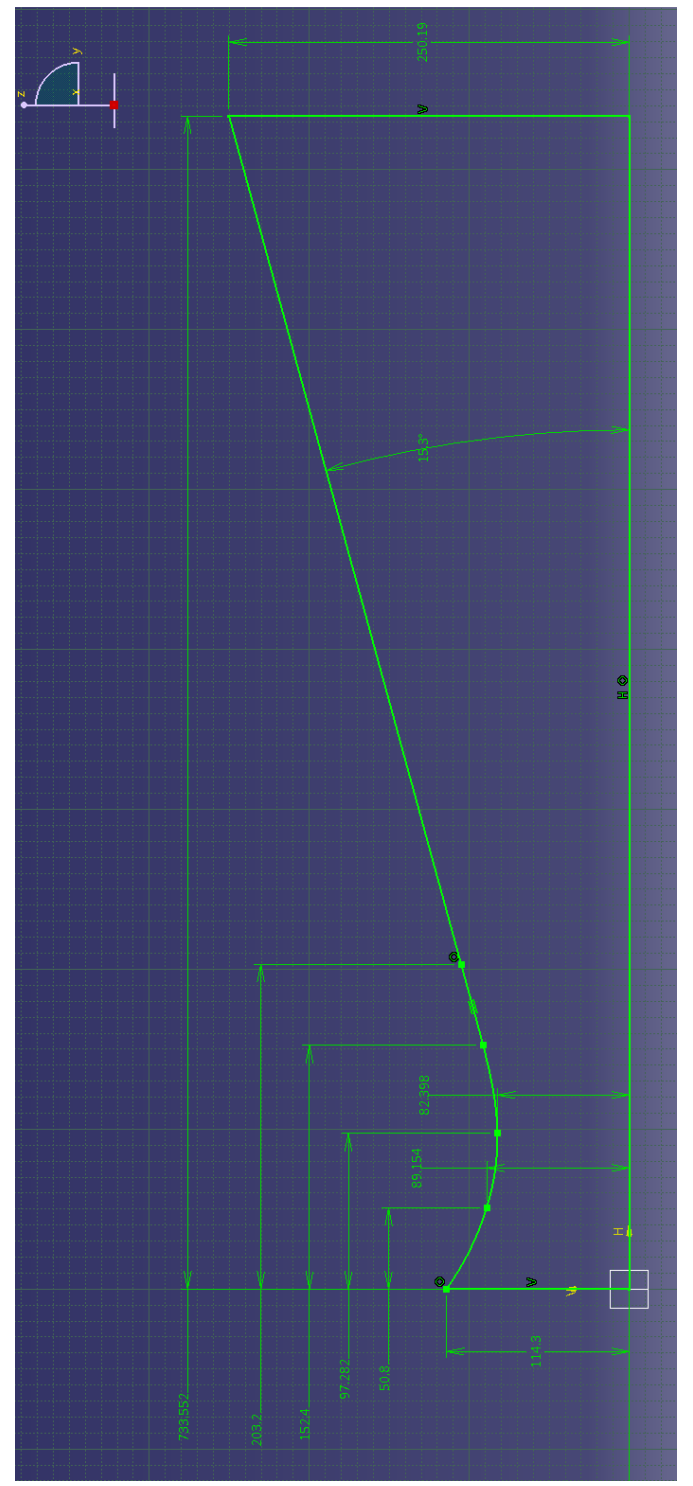

Figure 24: A CATIA sketch of the CD Nozzle; all dimensions are in millimeters. 


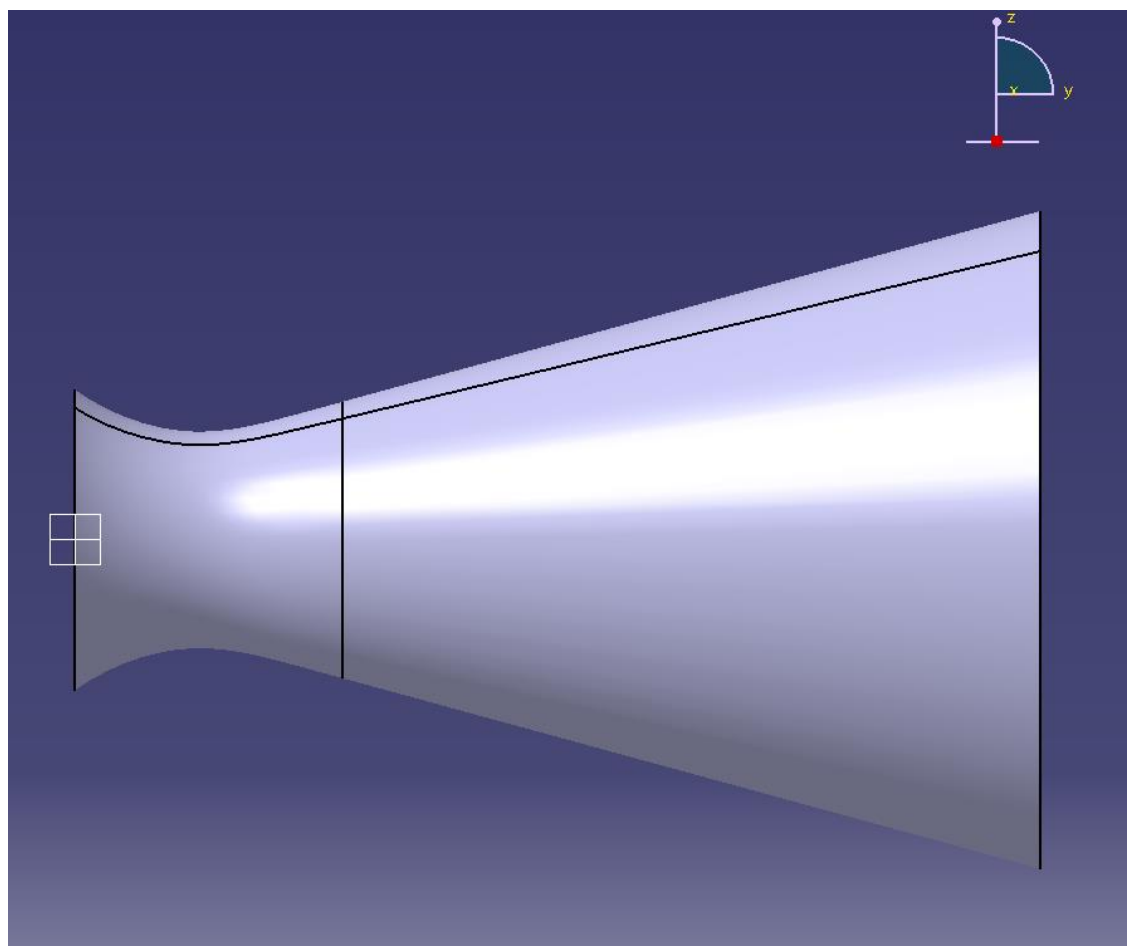

Figure 25: A screenshot of the CD Nozzle re-created in CATIA by revolving the sketch from Figure 24 about its axis of symmetry.

For the CD Nozzle base case:

$$
\begin{gathered}
P_{o}=344,738.0 P a \\
T_{i}=922.0389 K \\
\text { For } M=0.3196 \text { and } \gamma=1.4 \rightarrow \frac{A}{A^{*}}=1.923967157 \\
\Rightarrow M_{i} \approx 0.3196 \\
T_{o}=T_{i}\left(1+\frac{\gamma-1}{2} M_{i}^{2}\right) \\
=(922.0389 K)\left[1+\frac{1.4-1}{2}(0.3196)^{2}\right] \\
=940.875 K \\
\dot{m}=\frac{P_{o} A^{*}}{\sqrt{T_{o}}} \sqrt{\frac{\gamma}{R}\left(\frac{2}{\gamma+1}\right)^{(\gamma+1) /(\gamma-1)}} \\
=\frac{(344,738.0 P a)(\pi)(0.082398 m)^{2}}{\sqrt{940.875 K}} \sqrt{\frac{1.4}{287 J / k g \cdot K}\left(\frac{2}{1.4+1}\right)^{(1.4+1) /(1.4-1)}} \\
=9.68915 \mathrm{~kg} / \mathrm{s}
\end{gathered}
$$




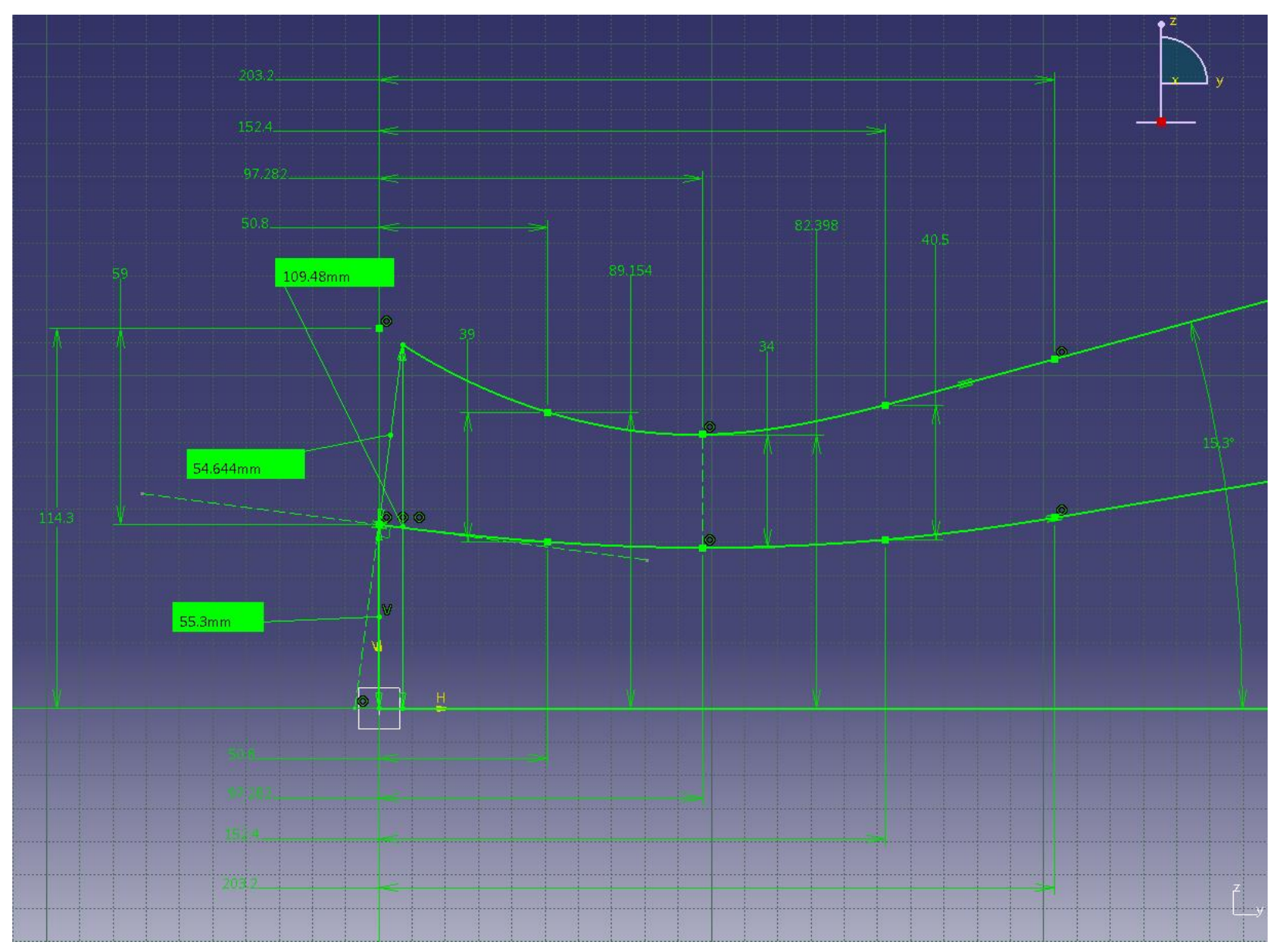

Figure 26: A CATIA sketch used in the geometry definition of CD Nozzle \& CB models 1-4; all dimensions are in millimeters.

The following are initial calculations regarding CD Nozzle \& CB models 1 - 4:

$$
\begin{gathered}
A_{i}=\frac{2 \pi\left(r_{1}+r_{2}\right)}{2} l_{1} \\
=\pi\left(r_{1}+r_{2}\right) l_{1} \\
=\pi(0.10948 m+0.0553 m)(0.054644 m) \\
=0.028287648 m^{2}
\end{gathered}
$$

The calculated inlet area, was determined based on drawing the line that is tangential to the center body at the inlet, and then by drawing another line that is perpendicular to the tangential line. $r_{1}$ is the first axial distance of the inlet area at the center body and $r_{2}$ is the second axial distance at the nozzle wall. $l_{1}$ is the distance between $r_{1}$ and $r_{2}$. The length of the line defined by $l_{1}$ can be revolved around the axis of symmetry to represent the inlet area. The inlet area was approximated as such, in order to minimize the error in the prediction of inlet Mach number based on the 1D Equations. By considering the inlet area as $A_{i}=\pi\left[(0.1143 m)^{2}-\right.$ 
$\left.(0.0553 m)^{2}\right]$, implies the flow will undergo more of a 2D expansion, and thus making the prediction of inlet Mach number and static pressure based on the 1D equations, less accurate.

$$
\begin{gathered}
A^{*}=\pi\left[(0.082398 m)^{2}-(0.048398 m)^{2}\right] \\
=0.013970863 m^{2} \\
\frac{A_{i}}{A^{*}}=2.0248
\end{gathered}
$$

Based on Equation (5), for $M=0.3017, \frac{A}{A^{*}}=2.0248$

$$
\Rightarrow M_{i} \approx 0.3017
$$

$T_{o}=T_{i}\left(1+\frac{\gamma-1}{2} M_{i}^{2}\right), T_{i}$ is kept constant from the CD Nozzle case for simplicity

$$
\begin{gathered}
=(922.0389 K)\left[1+\frac{1.4-1}{2}(0.3017)^{2}\right] \\
=938.824 K
\end{gathered}
$$

$$
\begin{aligned}
& \dot{m}=\frac{P_{o} A^{*}}{\sqrt{T_{o}}} \sqrt{\frac{\gamma}{R}\left(\frac{2}{\gamma+1}\right)^{(\gamma+1) /(\gamma-1)}} \\
& P_{o}=\frac{\dot{m}}{\frac{A^{*}}{\sqrt{T_{o}}} \sqrt{\frac{\gamma}{R}\left(\frac{2}{\gamma+1}\right)^{(\gamma+1) /(\gamma-1)}}} \\
& A^{*}=\pi\left[(0.082398 m)^{2}-(0.048398 m)^{2}\right] \\
& =0.013970863 m^{2} \\
& P_{o}=\frac{9.68915 \mathrm{~kg} / \mathrm{s}}{\frac{0.013970863 \mathrm{~m}^{2}}{\sqrt{938.824 K}} \sqrt{\frac{1.4}{287 \mathrm{~J} / \mathrm{kg} \cdot K}\left(\frac{2}{1.4+1}\right)^{(1.4+1) /(1.4-1)}}} \\
& =525,745.2 P a \\
& P_{i}=\frac{P_{o}}{\left(1+\frac{\gamma-1}{2} M_{i}^{2}\right)^{\gamma /(\gamma-1)}} \\
& =\frac{525745.2 P a}{\left[1+\frac{1.4-1}{2}(0.3017)^{2}\right]^{1.4 /(1.4-1)}} \\
& =493,574.4 P a
\end{aligned}
$$




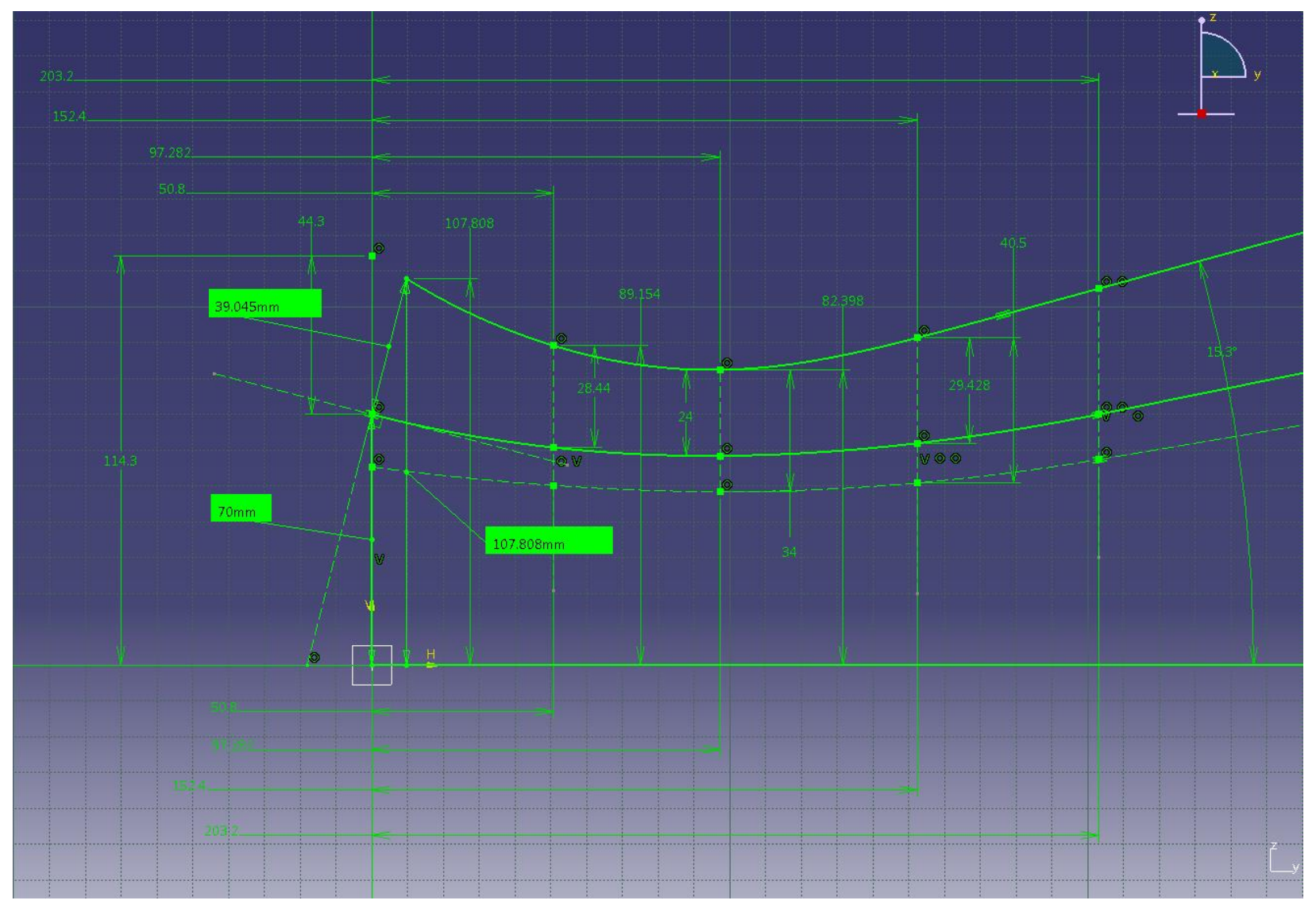

Figure 27: A CATIA sketch used in the geometry definition of CD Nozzle \& CB models 5-8; all dimensions are in millimeters.

The same initial calculations performed for CD Nozzle \& CB models 1 to 4, were also applied to CD Nozzle \& CB models 5 to 8. For the CD Nozzle \& CB models 5 to 8, the CB size was increased axially from models 1 to 4 . The calculated results at the inlet are the following:

$$
\begin{gathered}
A_{i}=0.021810548 \mathrm{~m}^{2} \\
A^{*}=0.010615768 \mathrm{~m}^{2} \\
M_{i} \approx 0.2968 \\
T_{o}=938.283 \mathrm{~K} \\
P_{o}=691,706.7 \mathrm{~Pa} \\
P_{i}=650,691.6 \mathrm{~Pa}
\end{gathered}
$$

In all cases of the CD Nozzle \& CB models, the gas properties can still be predicted with enough validity using the ideal gas law, as is proven in the Appendix. 
CD Nozzle \& CB 1 Sketch

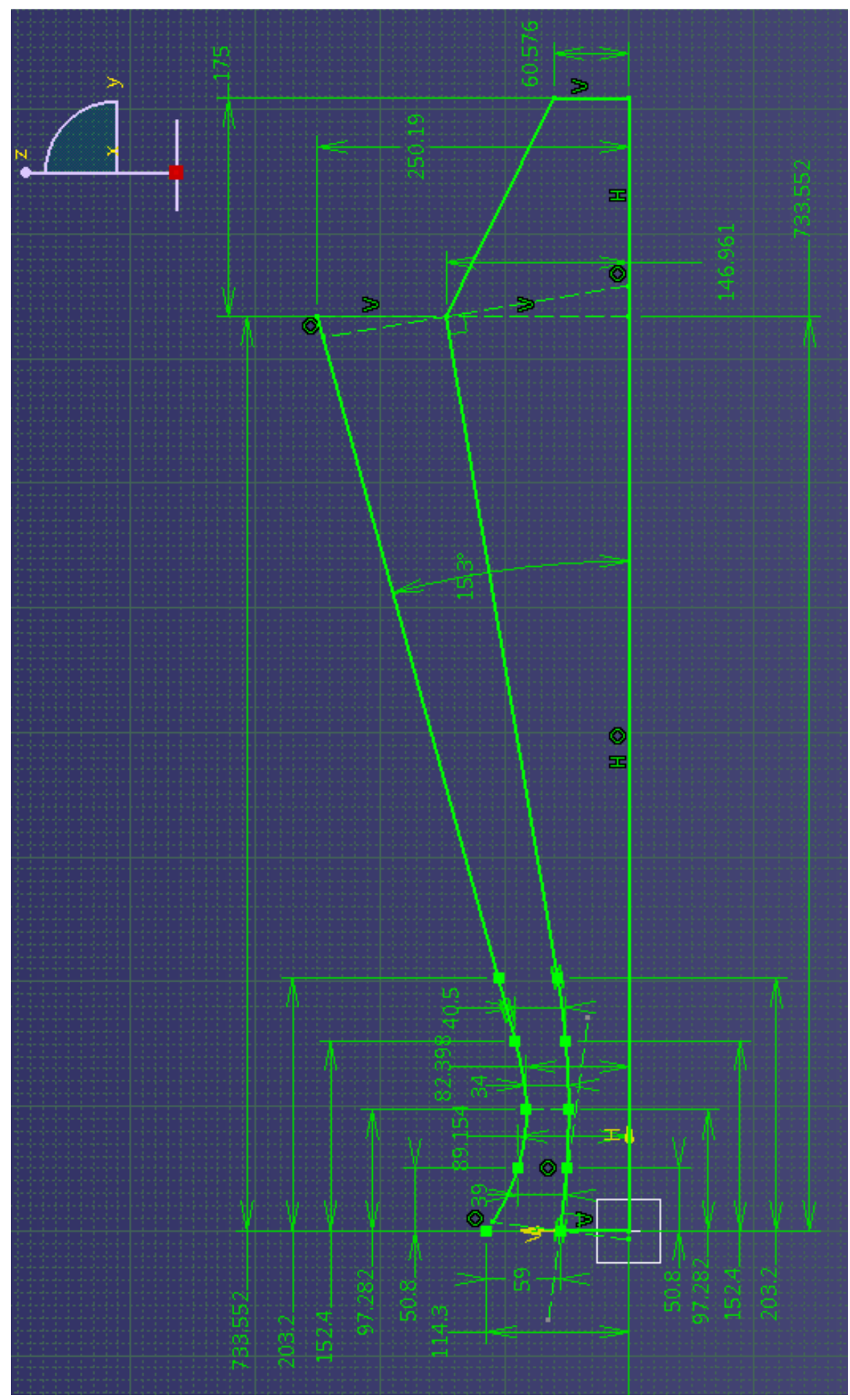

Figure 28: A CATIA sketch of CD Nozzle \& $C B$ 1; all dimensions are in millimeters. 


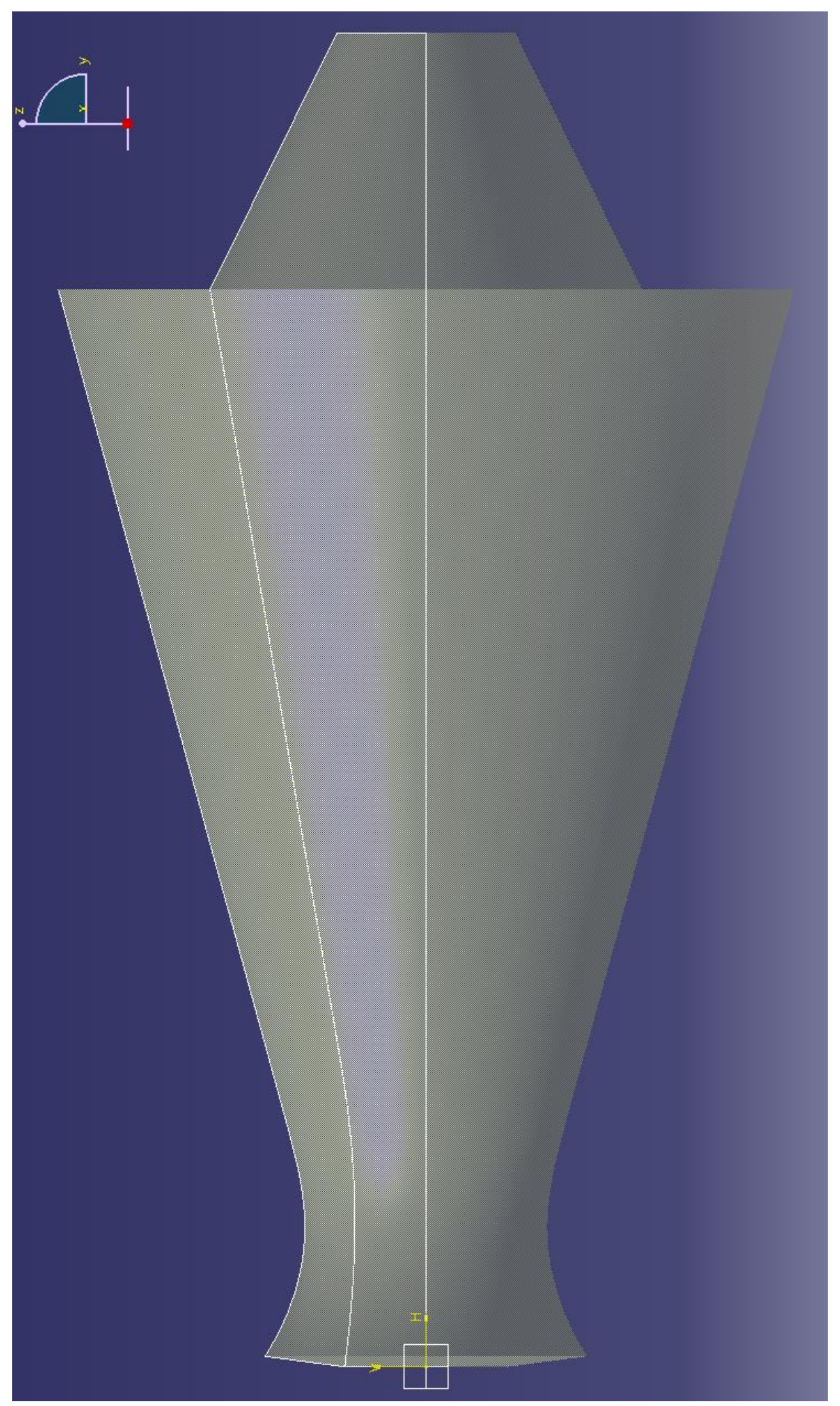

Figure 29: CD Nozzle \& CB 1 created in CATIA by revolving the sketch from Figure 28 about its axis of symmetry. 
CD Nozzle \& CB 2 Sketch

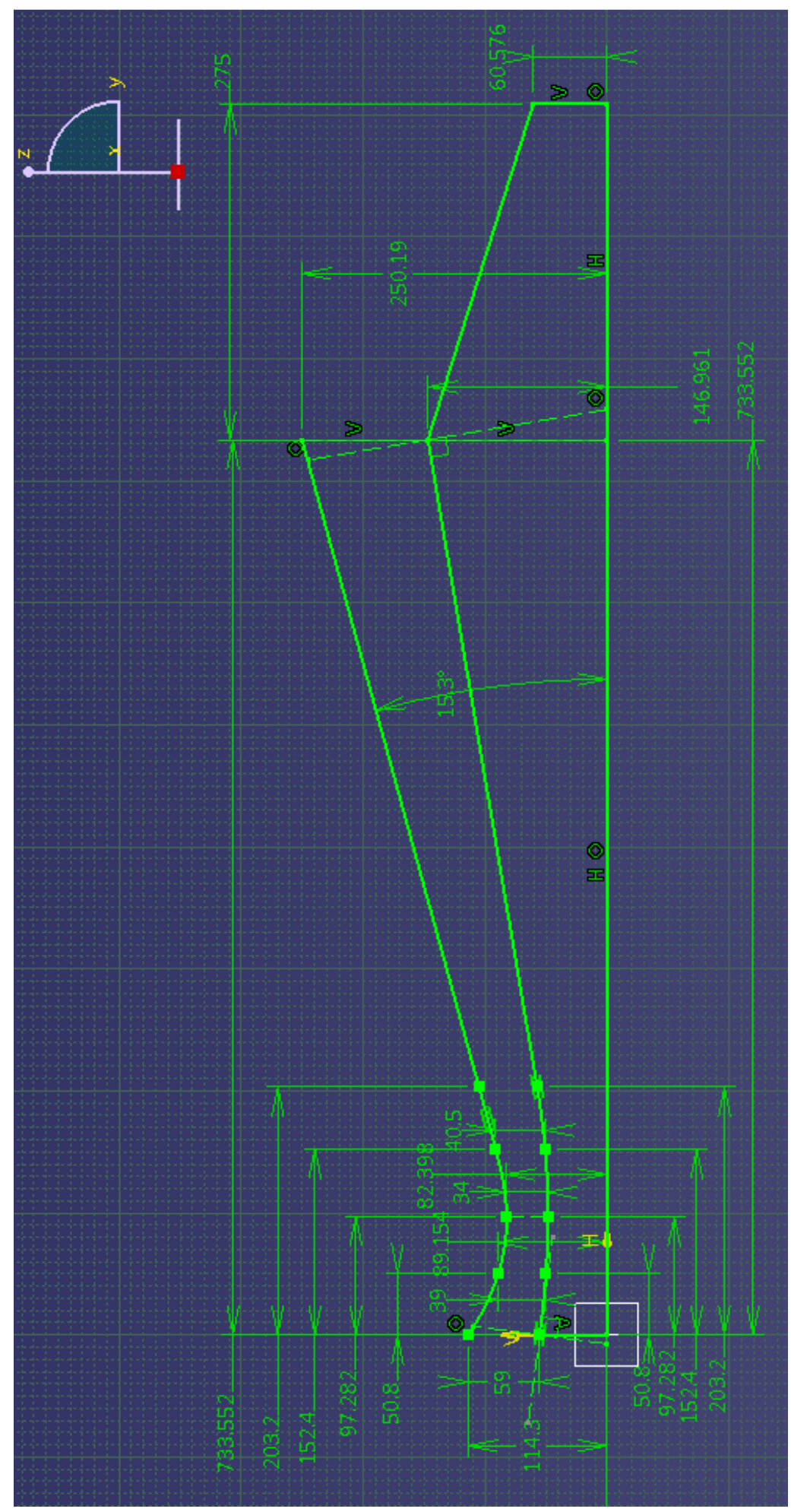

Figure 30: A CATIA sketch of CD Nozzle \& CB 2; all dimensions are in millimeters. 


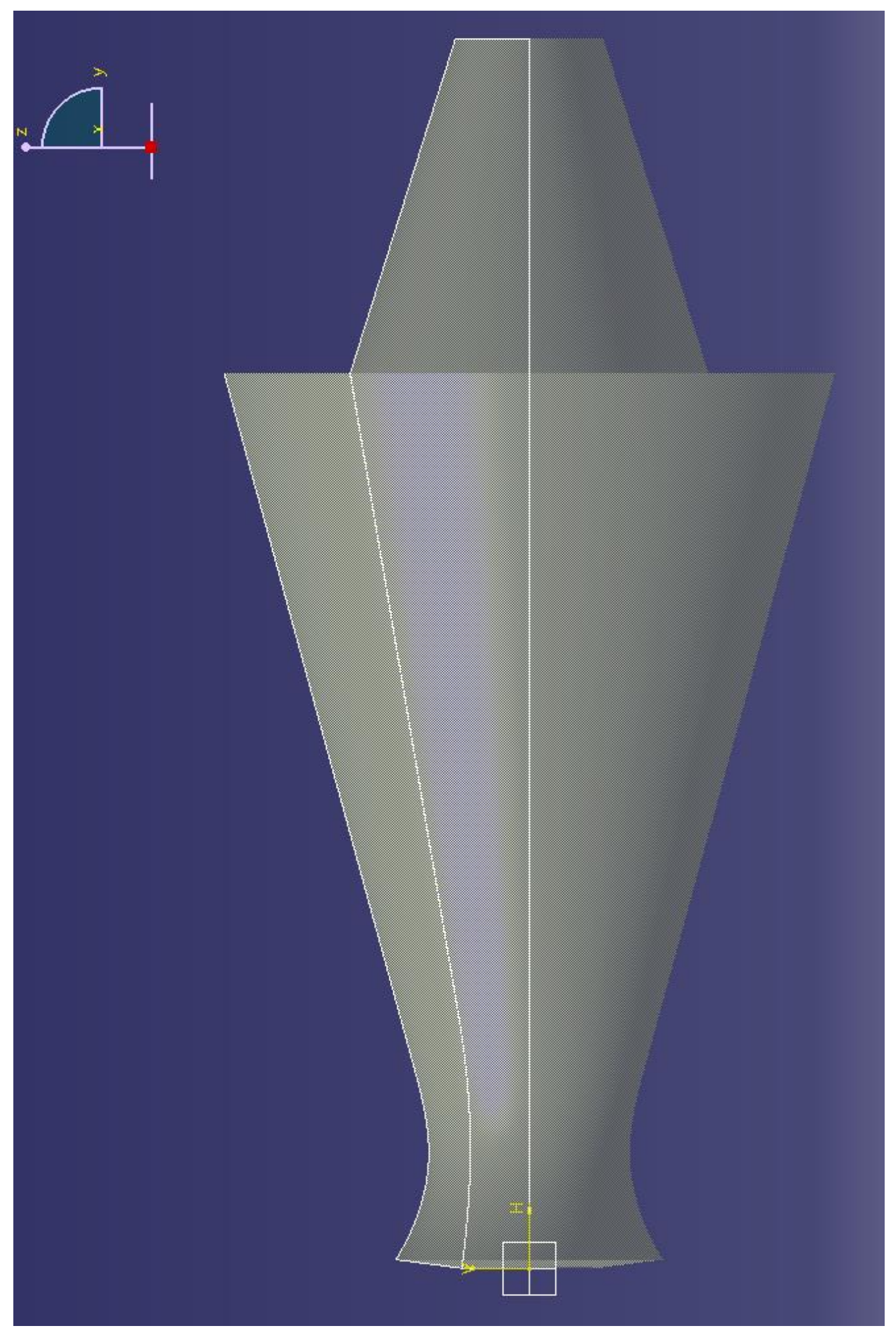

Figure 31: CD Nozzle \& CB 2 created in CATIA by revolving the sketch from Figure 30 about its axis of symmetry. 
CD Nozzle \& CB 3 Sketch

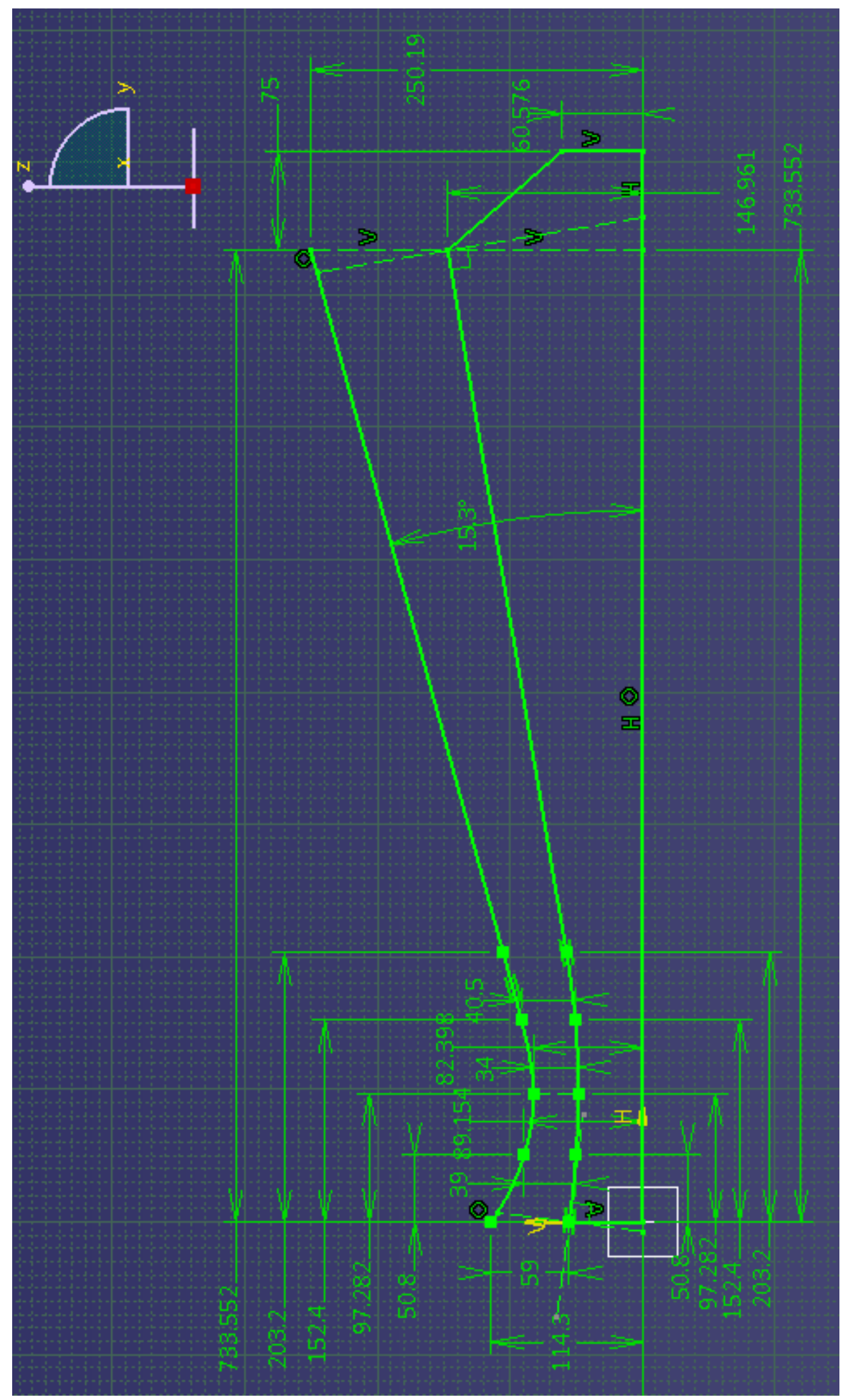

Figure 32: A CATIA sketch of $C D$ Nozzle \& $C B$ 3; all dimensions are in millimeters. 


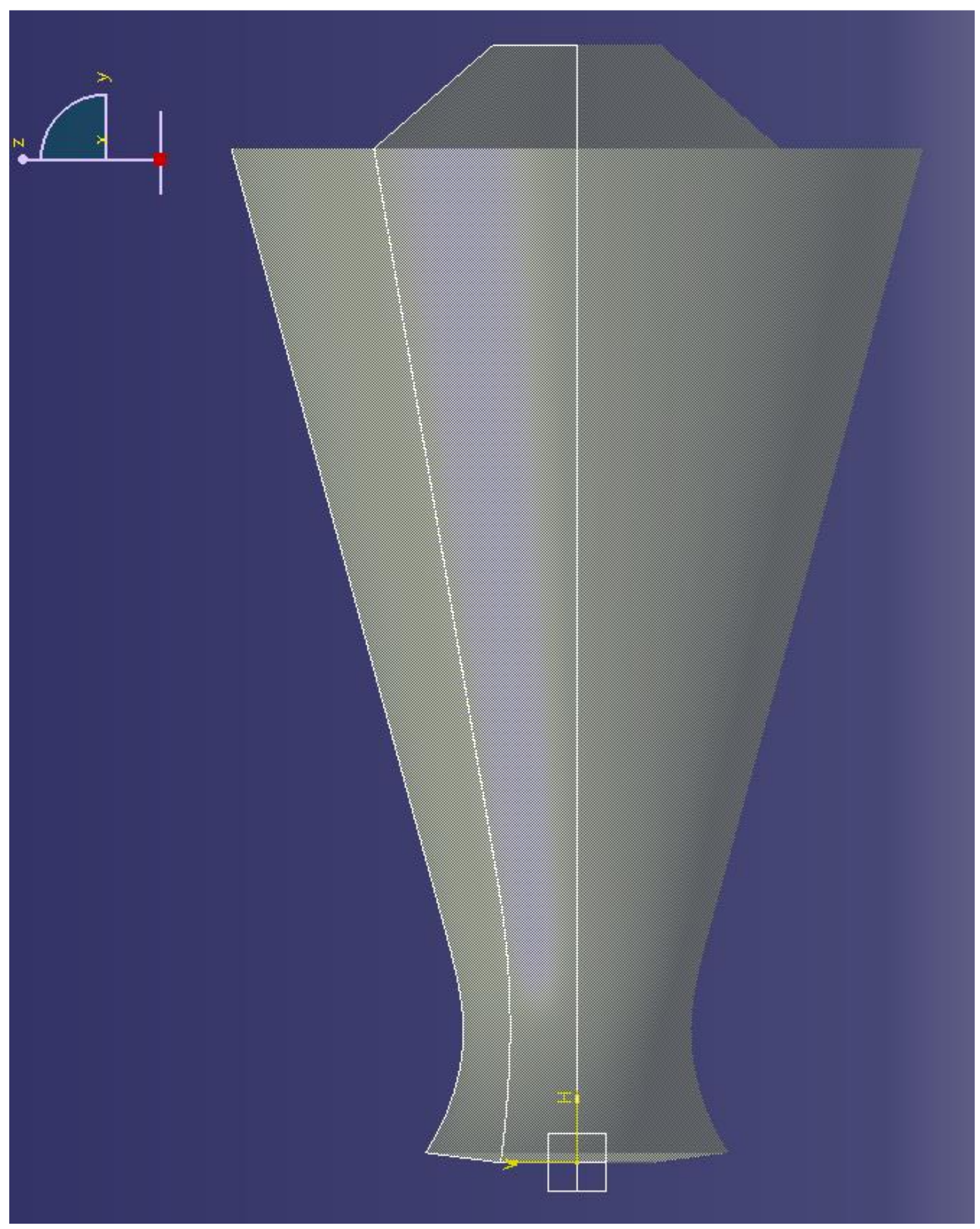

Figure 33: CD Nozzle \& CB 3 created in CATIA by revolving the sketch from Figure 32 about its axis of symmetry. 
CD Nozzle \& CB 4 Sketch

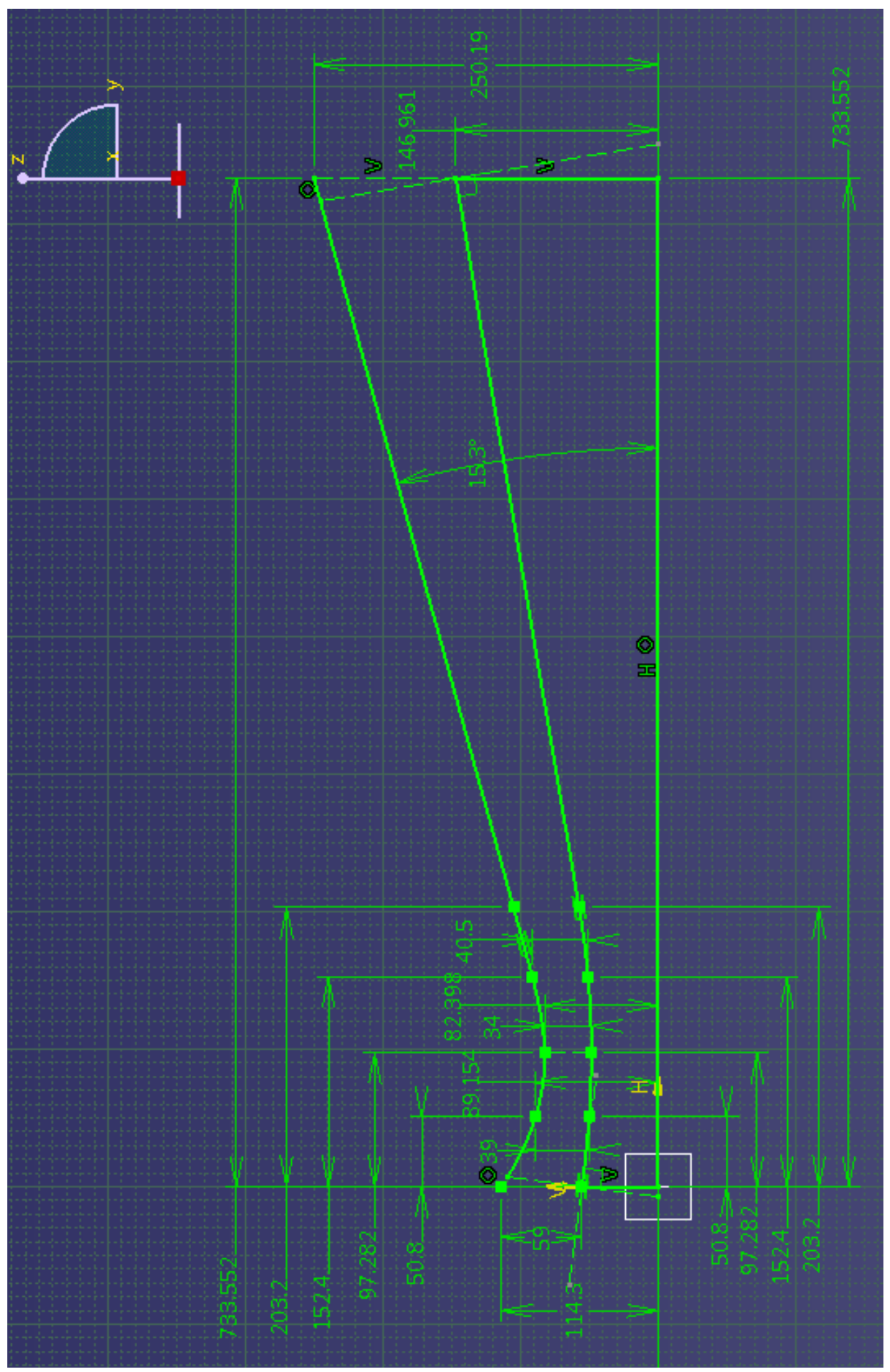

Figure 34: A CATIA sketch of CD Nozzle \& CB 4; all dimensions are in millimeters. 


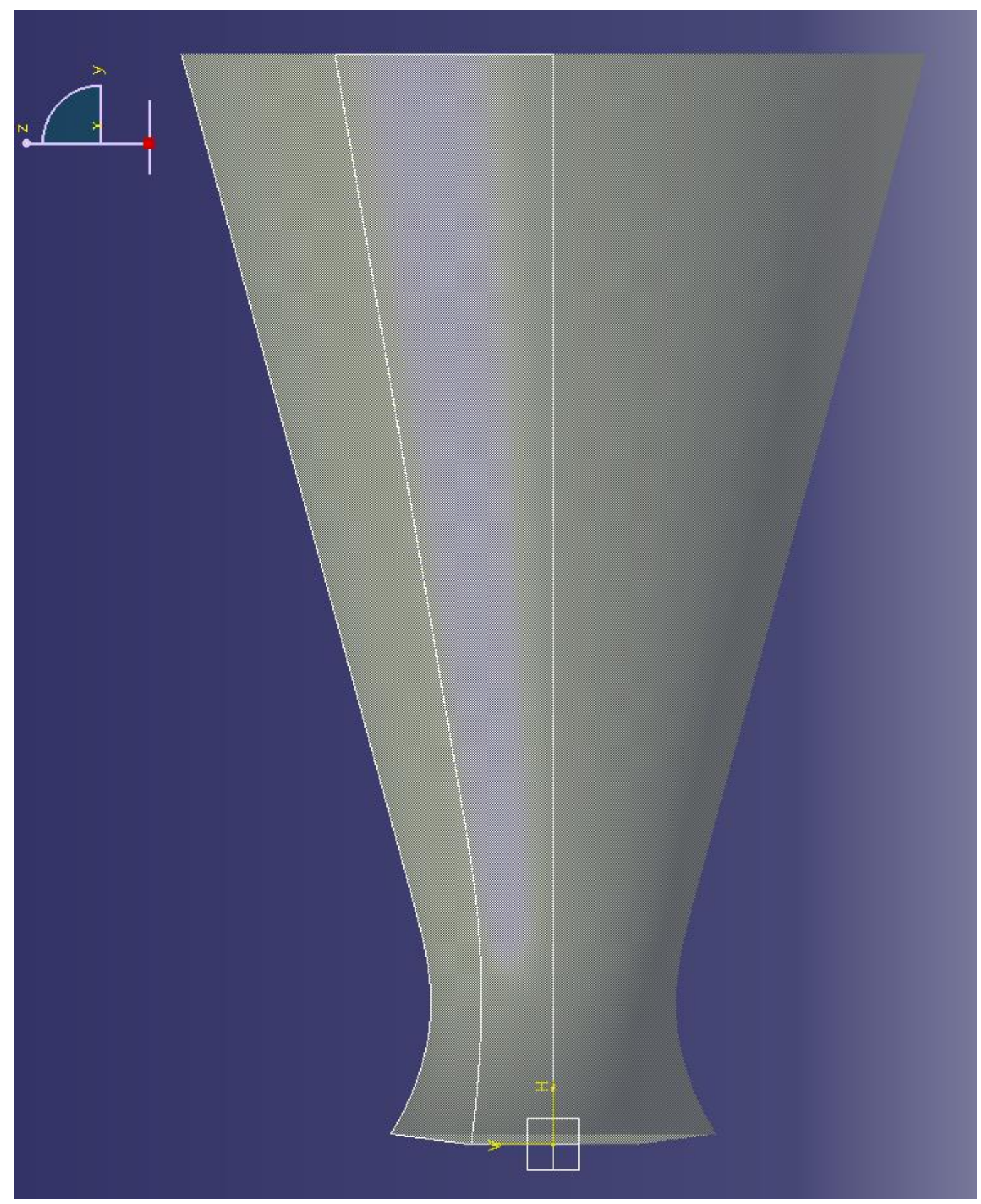

Figure 35: CD Nozzle \& CB 4 created in CATIA by revolving the sketch from Figure 34 about its axis of symmetry. 
CD Nozzle \& CB 5 Sketch

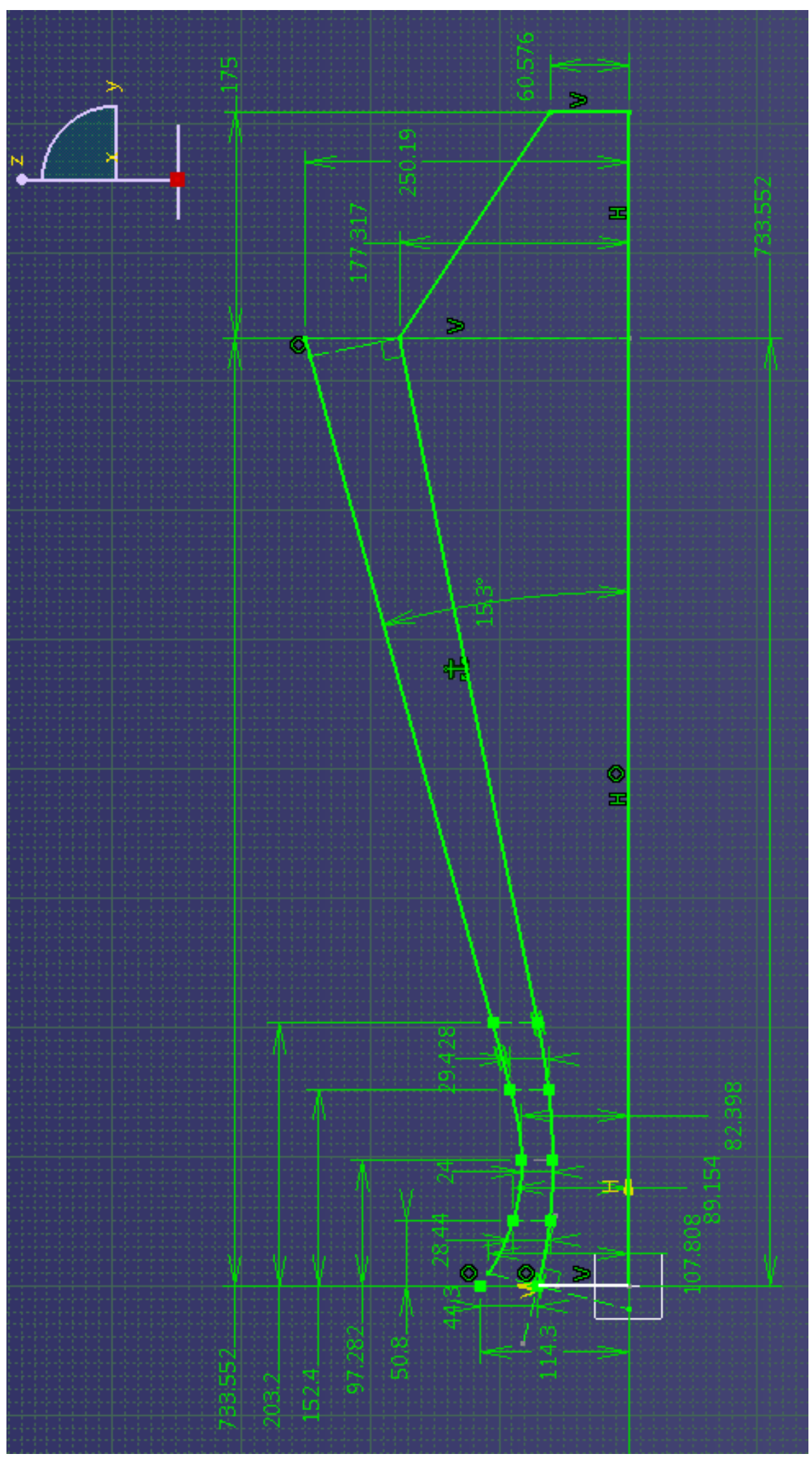

Figure 36: A CATIA sketch of CD Nozzle \& CB 5; all dimensions are in millimeters. 


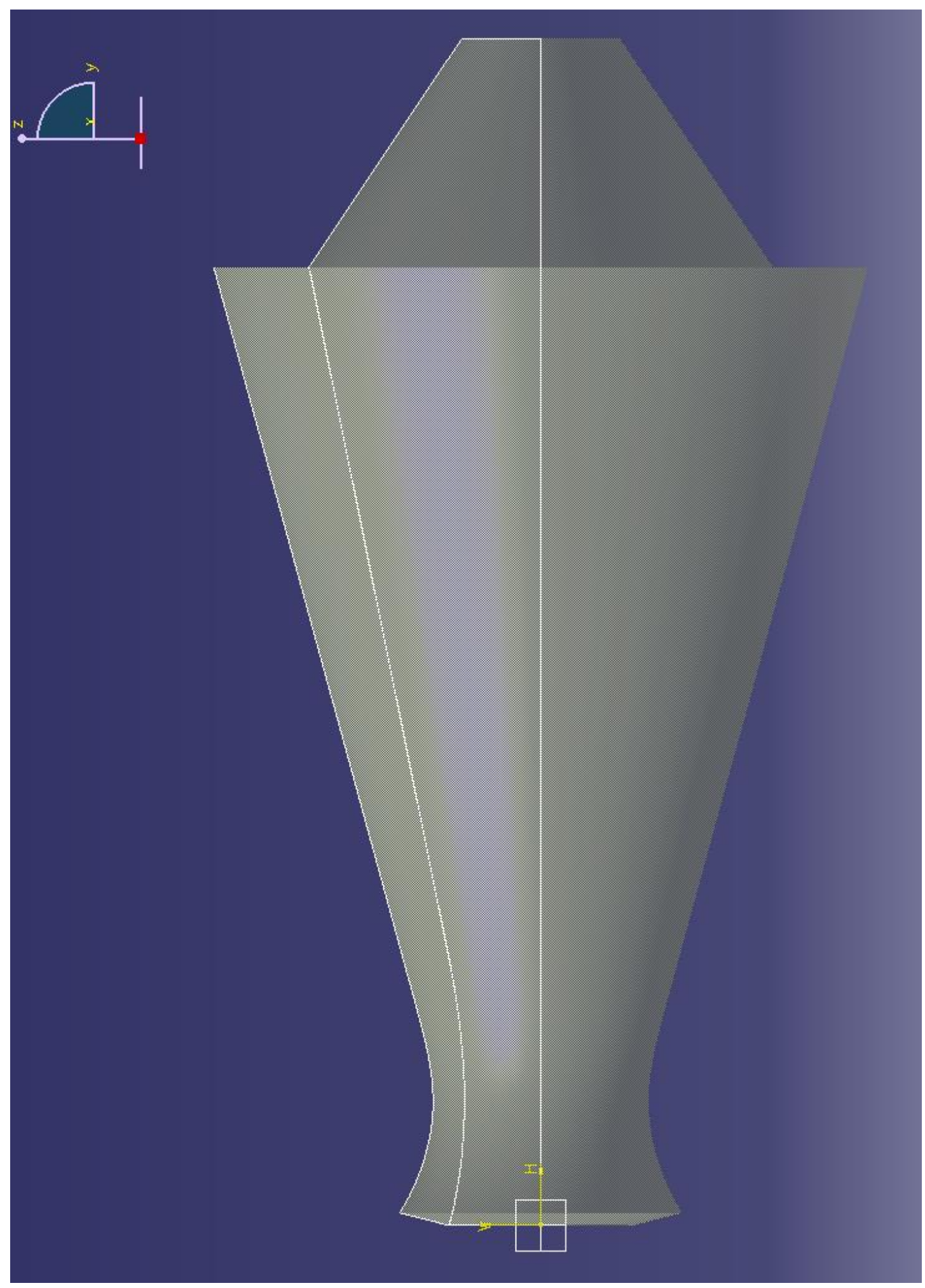

Figure 37: CD Nozzle \& CB 5 created in CATIA by revolving the sketch from Figure 36 about its axis of symmetry. 
CD Nozzle \& CB 6 Sketch

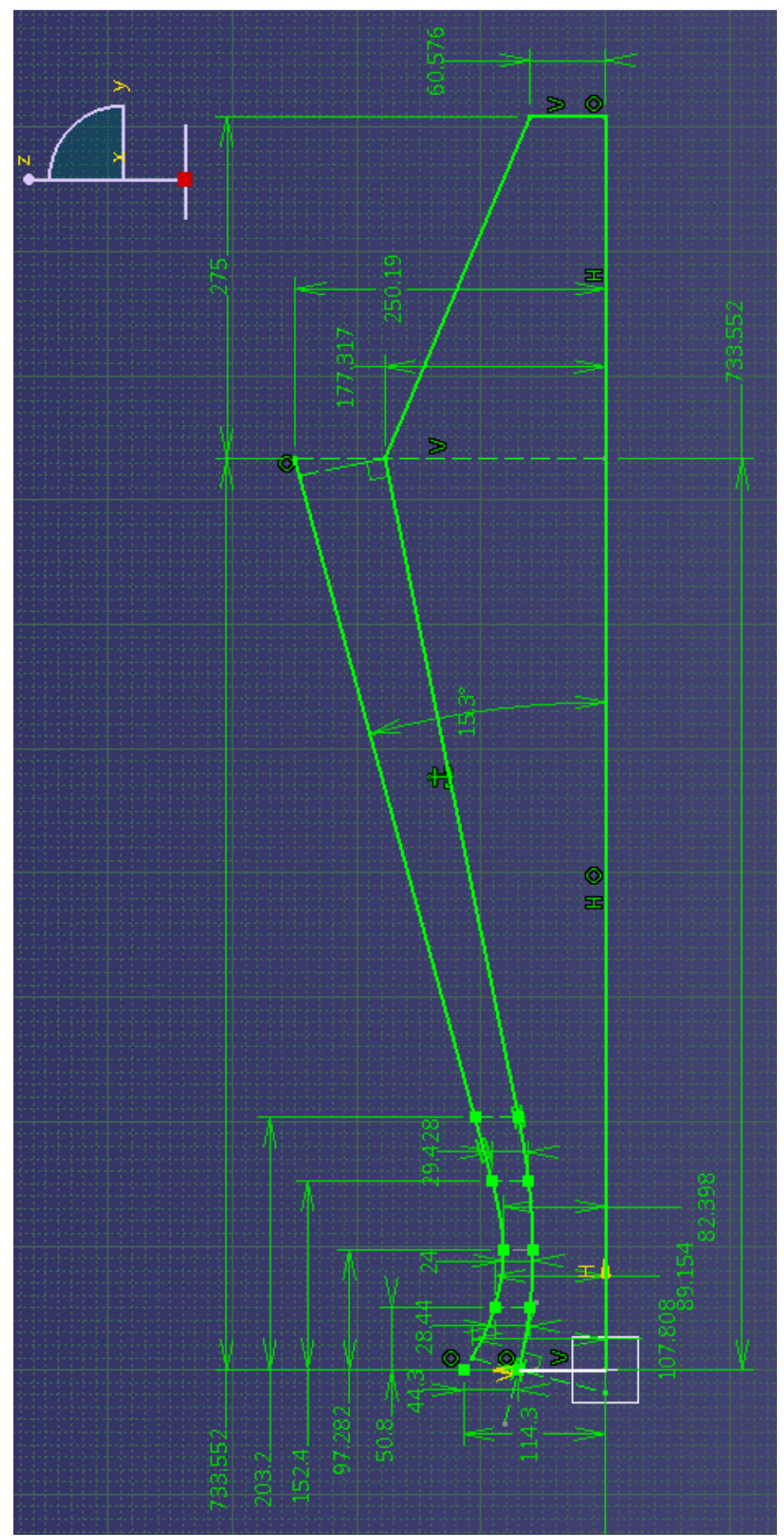

Figure 38: A CATIA sketch of CD Nozzle \& CB 6; all dimensions are in millimeters. 


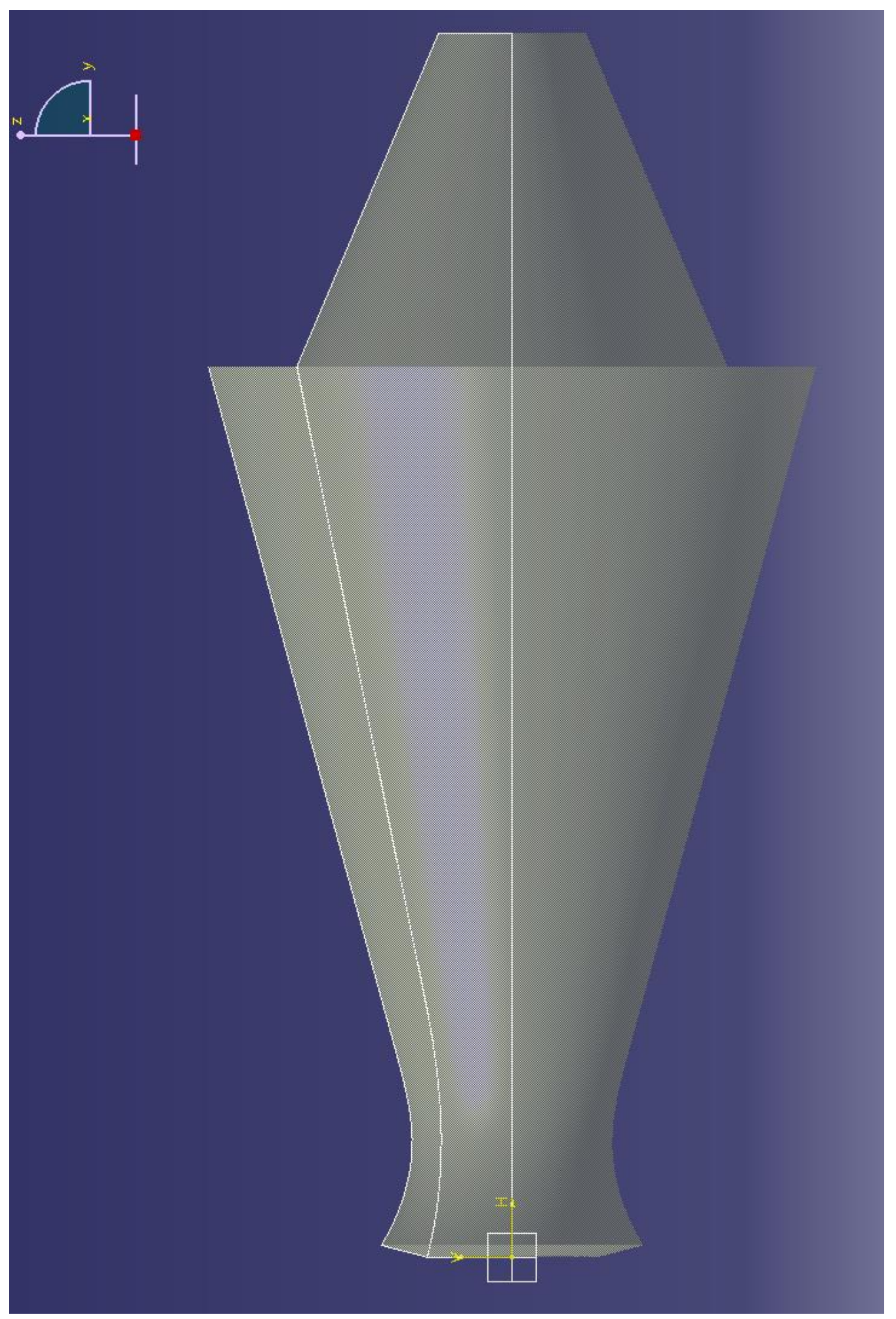

Figure 39: CD Nozzle \& CB 6 created in CATIA by revolving the sketch from Figure 38 about its axis of symmetry. 
CD Nozzle \& CB 7 Sketch

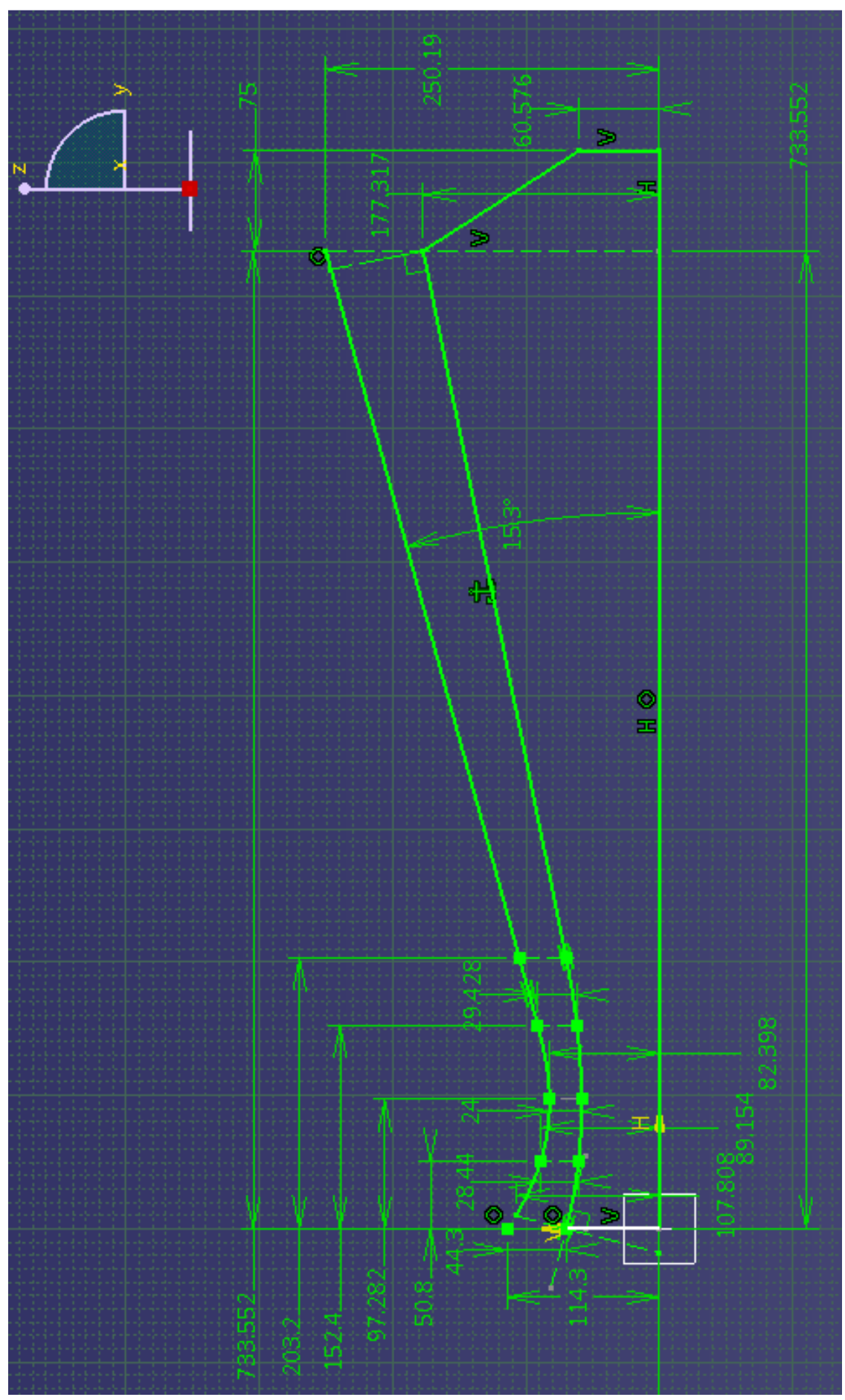

Figure 40: A CATIA sketch of CD Nozzle \& $C B$ 7; all dimensions are in millimeters. 


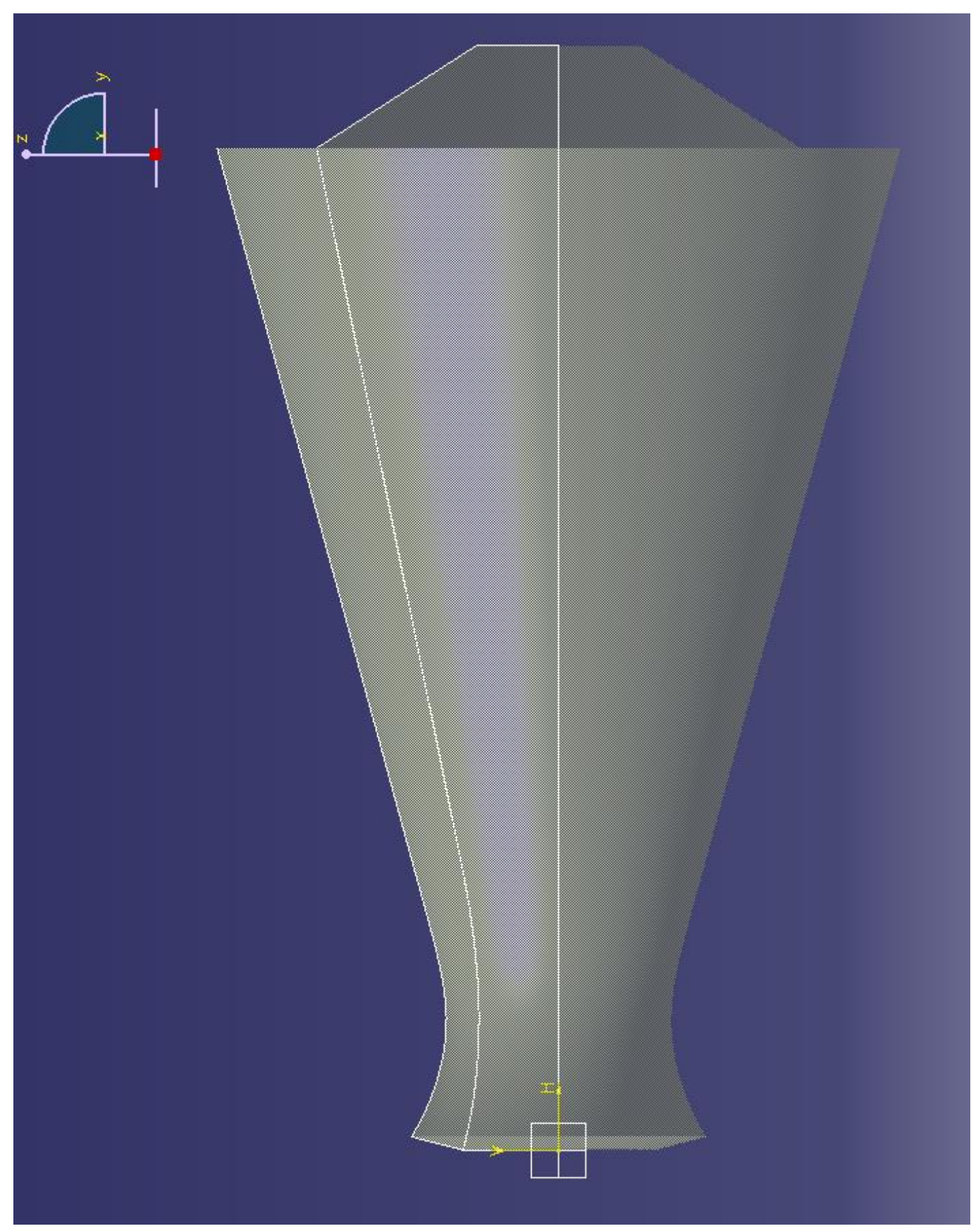

Figure 41: CD Nozzle \& CB 7 created in CATIA by revolving the sketch from Figure 40 about its axis of symmetry. 
CD Nozzle \& CB 8 Sketch

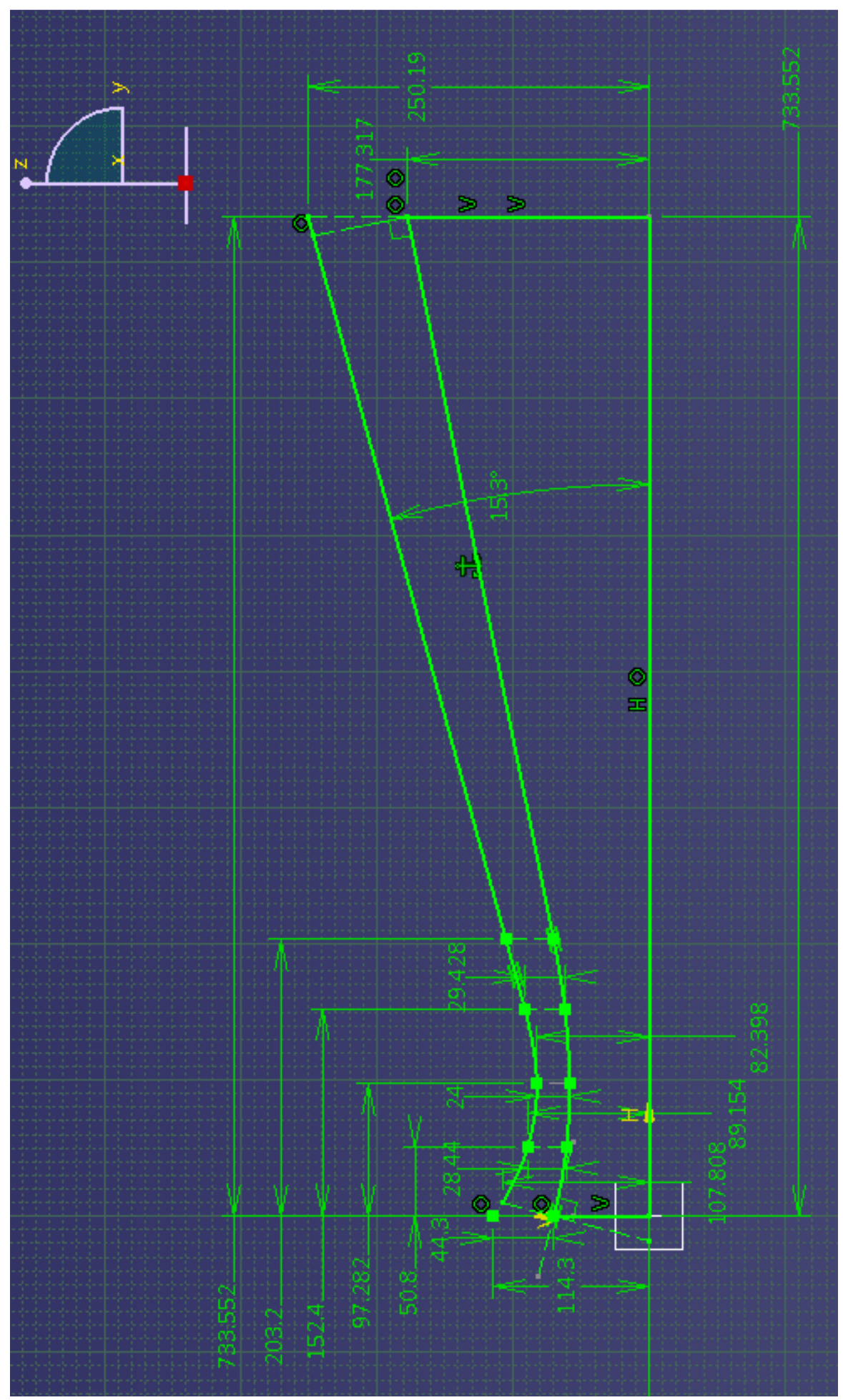

Figure 42: A CATIA sketch of CD Nozzle \& $C B$ 8; all dimensions are in millimeters. 


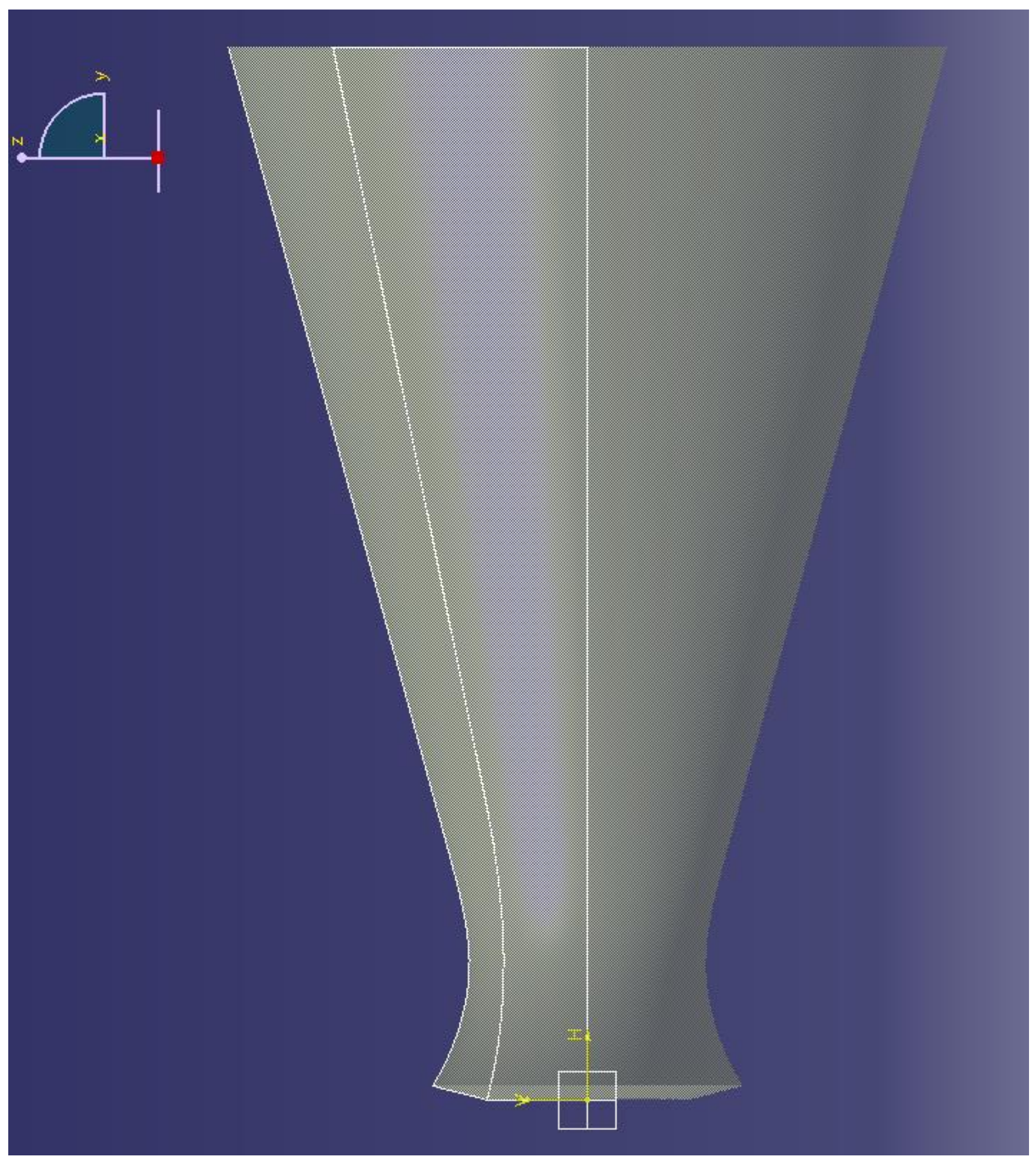

Figure 43: CD Nozzle \& CB 8 created in CATIA by revolving the sketch from Figure 42 about its axis of symmetry. 
Design of Aerospike 1

The sketch for Aerospike 1 is shown in Figure 44. Aerospike 1 was designed to operate under the same calculated mass flow rate of $9.689 \mathrm{~kg} / \mathrm{s}$ (calculated using Equation (13)) as the CD Nozzle case, making the comparison of performance between an Aerospike and a conventional nozzle easier. Aerospike 1, has the same flow total pressure $\left(P_{o}\right)$, static inlet temperature $\left(T_{i}\right)$, and throat area $\left(A_{c r}\right.$ or $\left.A^{*}\right)$ as that of the CD Nozzle case. The inlet - to - throat area ratio is also the same, meaning that the predictions for inlet Mach number $M_{i}$ and total temperature $\left(T_{o}\right)$ do not change. Given the initial design conditions, both Aerospike 1 and the CD Nozzle theoretically operate under the same mass flow rate, based on Equation (13). By using the same total pressure, it becomes even easier to ascertain which design is better.

For the CD Nozzle:

$$
\begin{aligned}
A_{i}=\pi r_{i}^{2} & =\pi(4.50 i n)^{2}=\pi(0.1143 m)^{2} \\
& =0.041043305 m^{2}
\end{aligned}
$$

For Aerospike 1:

$$
\begin{gathered}
A_{i}=\pi\left(r_{1}^{2}-r_{2}^{2}\right) \\
r_{1}^{2}-r_{2}^{2}=\frac{A_{i}}{\pi} \\
r_{1}^{2}=\frac{A_{i}}{\pi}+r_{2}^{2} \\
r_{2}=0.200 m
\end{gathered}
$$

The value for $r_{2}$ was selected randomly as an even number that is much larger than zero, but less than $0.25019 \mathrm{~m}$, which is the maximum radial length of the CD Nozzle.

$$
\begin{gathered}
r_{1}=\sqrt{\frac{A_{i}}{\pi}+r_{2}^{2}} \\
=\sqrt{\frac{0.041043305 m^{2}}{\pi}+(0.200 m)^{2}} \\
=0.230357309 m
\end{gathered}
$$


For the CD Nozzle:

$$
\begin{aligned}
A^{*}=\pi r^{* 2}= & \pi(3.244 i n)^{2}=\pi(0.0823976 m)^{2} \\
& =0.021329417 m^{2}
\end{aligned}
$$

For Aerospike 1:

$$
\begin{gathered}
A^{*}=\pi\left(r_{3}^{2}-r_{4}^{2}\right) \\
r_{3}^{2}-r_{4}^{2}=\frac{A^{*}}{\pi} \\
r_{3}^{2}=\frac{A^{*}}{\pi}+r_{4}^{2} \\
r_{4}=0.2125 m
\end{gathered}
$$

The value for $r_{4}$ was also randomly selected as with the value of $r_{2}$.

$$
\begin{gathered}
r_{3}=\sqrt{\frac{A^{*}}{\pi}+r_{4}^{2}} \\
=\sqrt{\frac{0.021329417 m^{2}}{\pi}+(0.2125 m)^{2}} \\
=0.227915805 m
\end{gathered}
$$

The sketch that the defines the entire geometry of Aerospike 1 is shown in Figure 44. Aerospikes $2-12$ are all design iterations from Aerospike 1 with varying exit areas, axial locations of exit areas, and center body geometries. 
Aerospike 1 Sketch

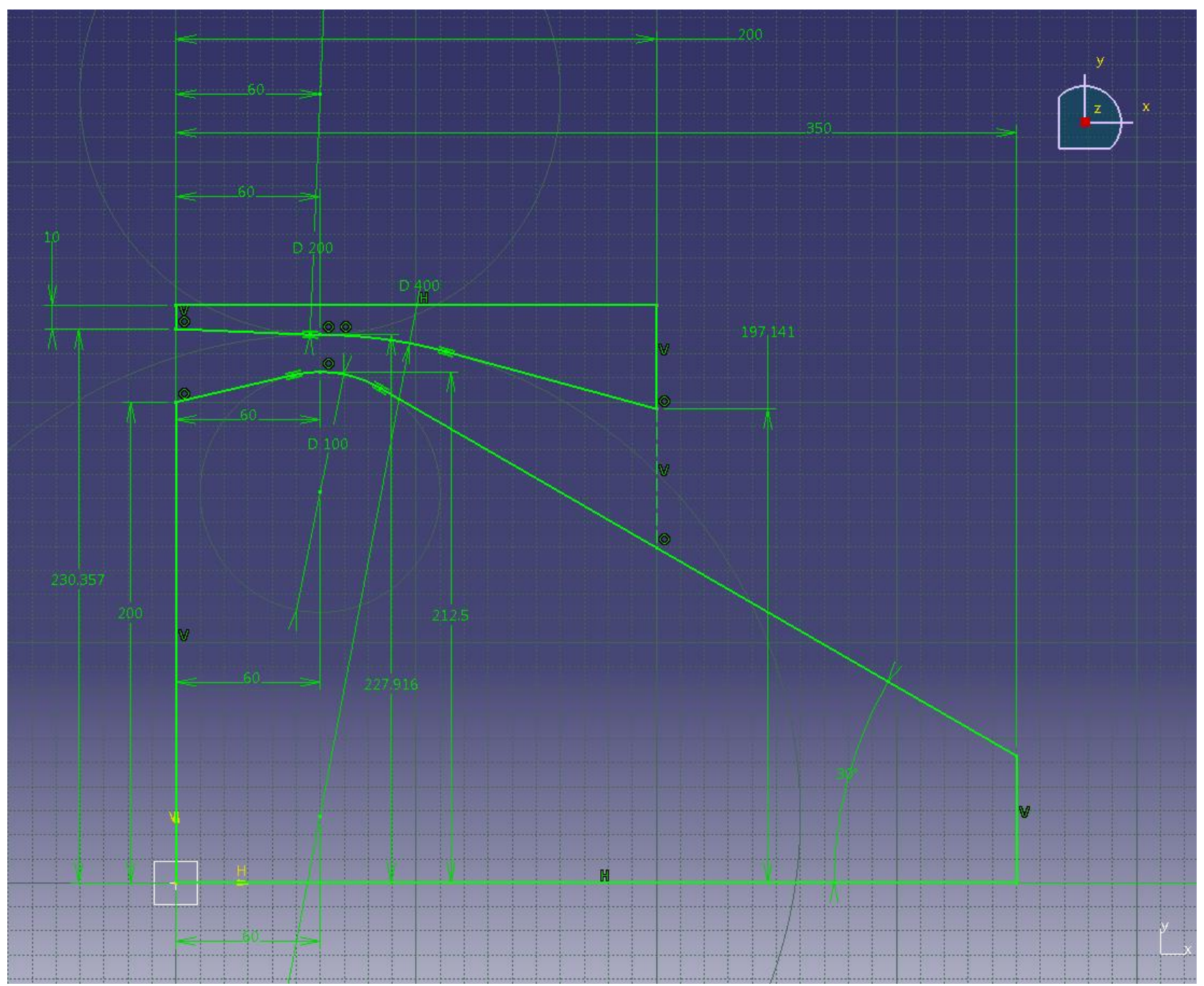

Figure 44: A CATIA sketch of Aerospike 1; all dimensions are in millimeters. 


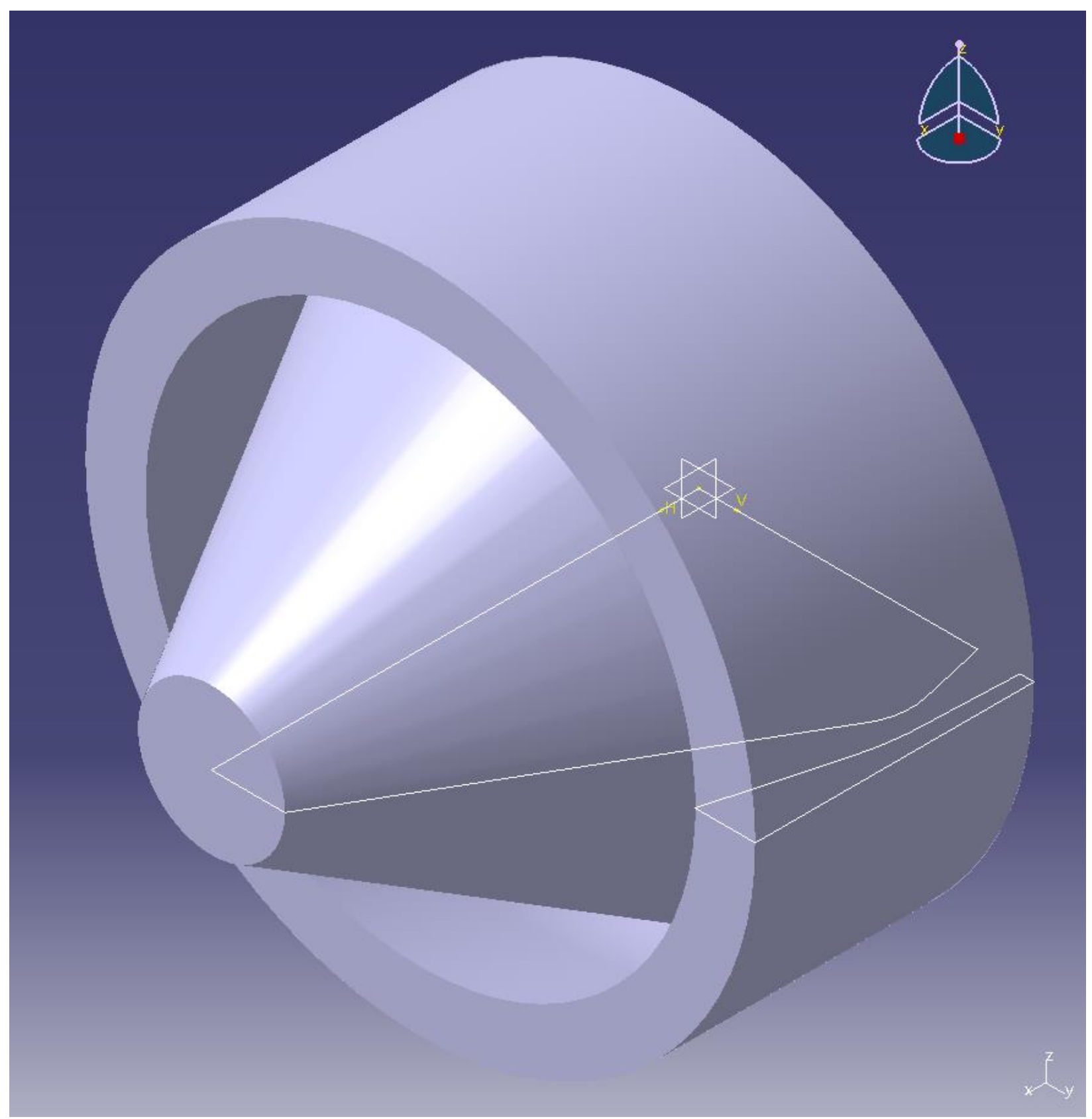

Figure 45: An isometric view of Aerospike 1 created in CATIA, by revolving the sketch from Figure 44 about its axis of symmetry. 
Aerospike 2 Sketch

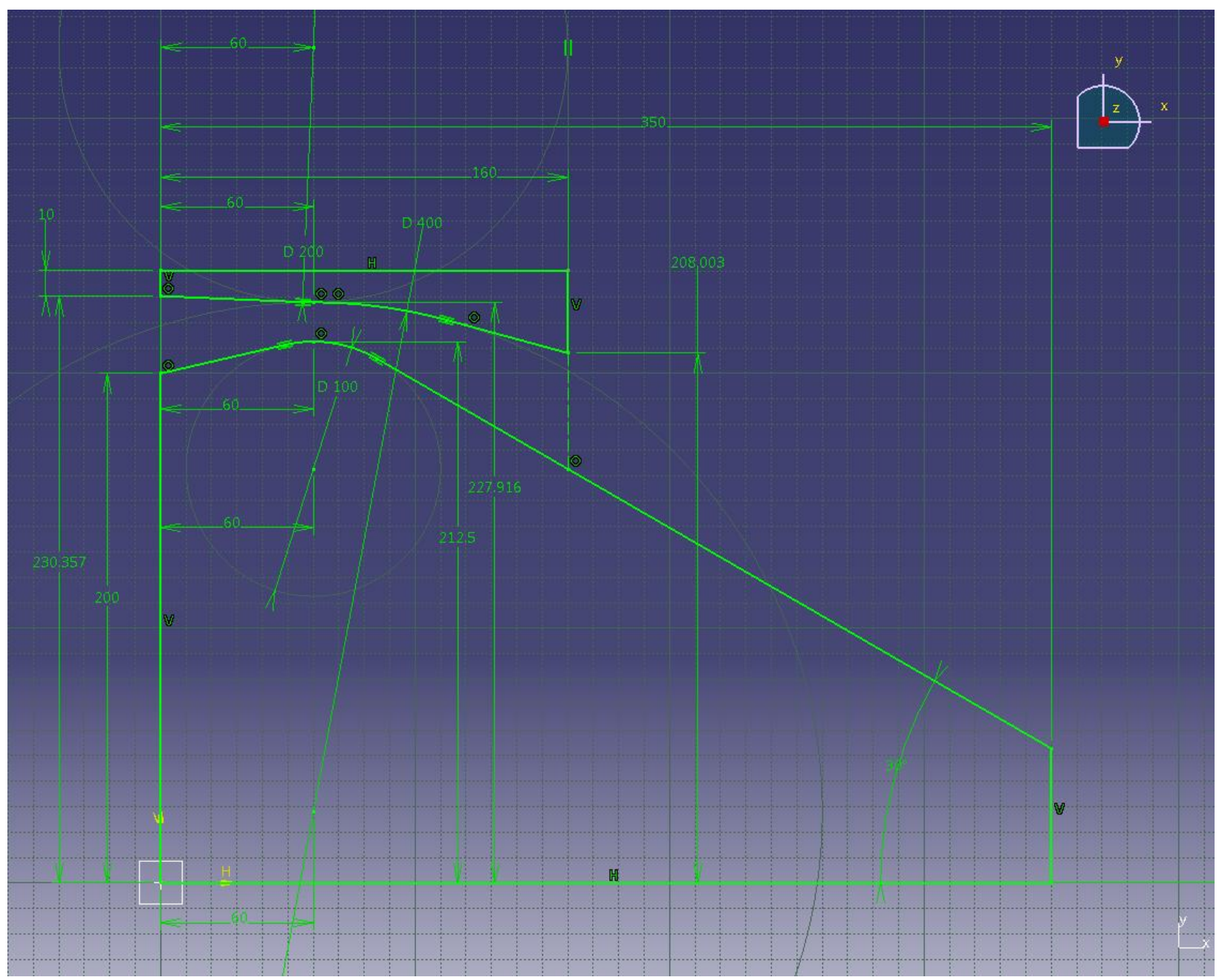

Figure 46: A CATIA sketch of Aerospike 2; all dimensions are in millimeters. 


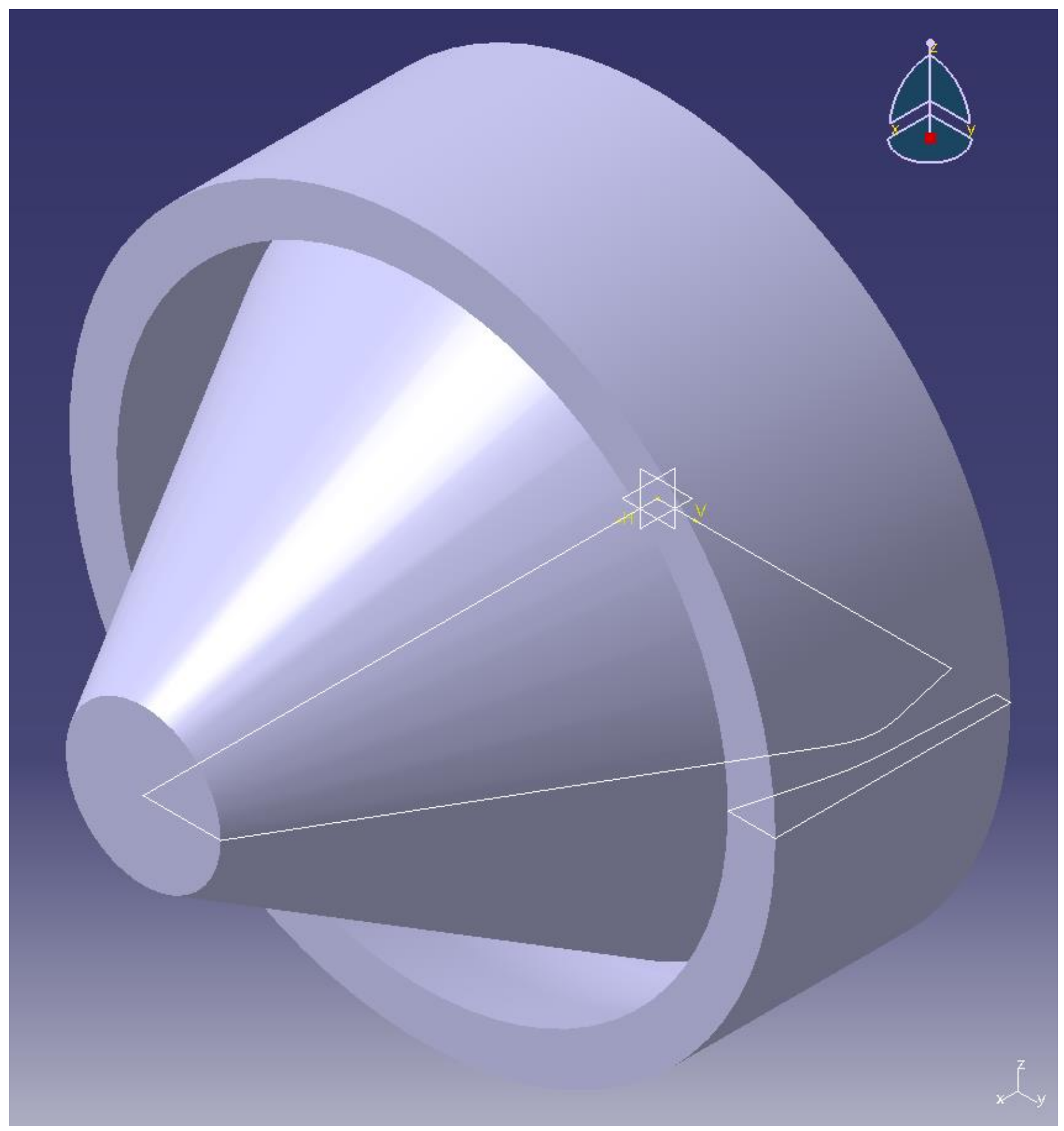

Figure 47: An isometric view of Aerospike 2 created in CATIA, by revolving the sketch from Figure 46 about its axis of symmetry. 
Aerospike 3 Sketch

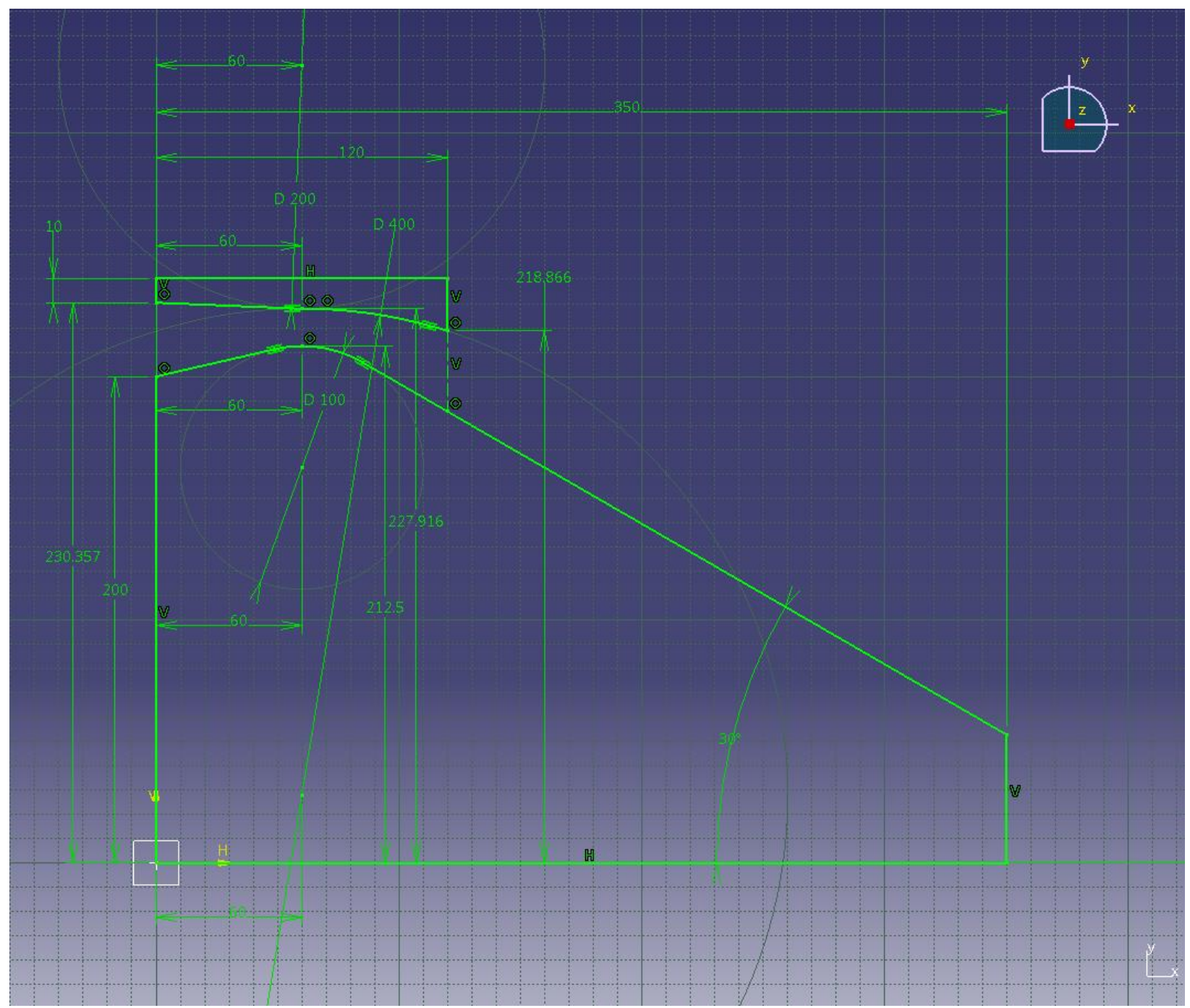

Figure 48: A CATIA sketch of Aerospike 3; all dimensions are in millimeters. 


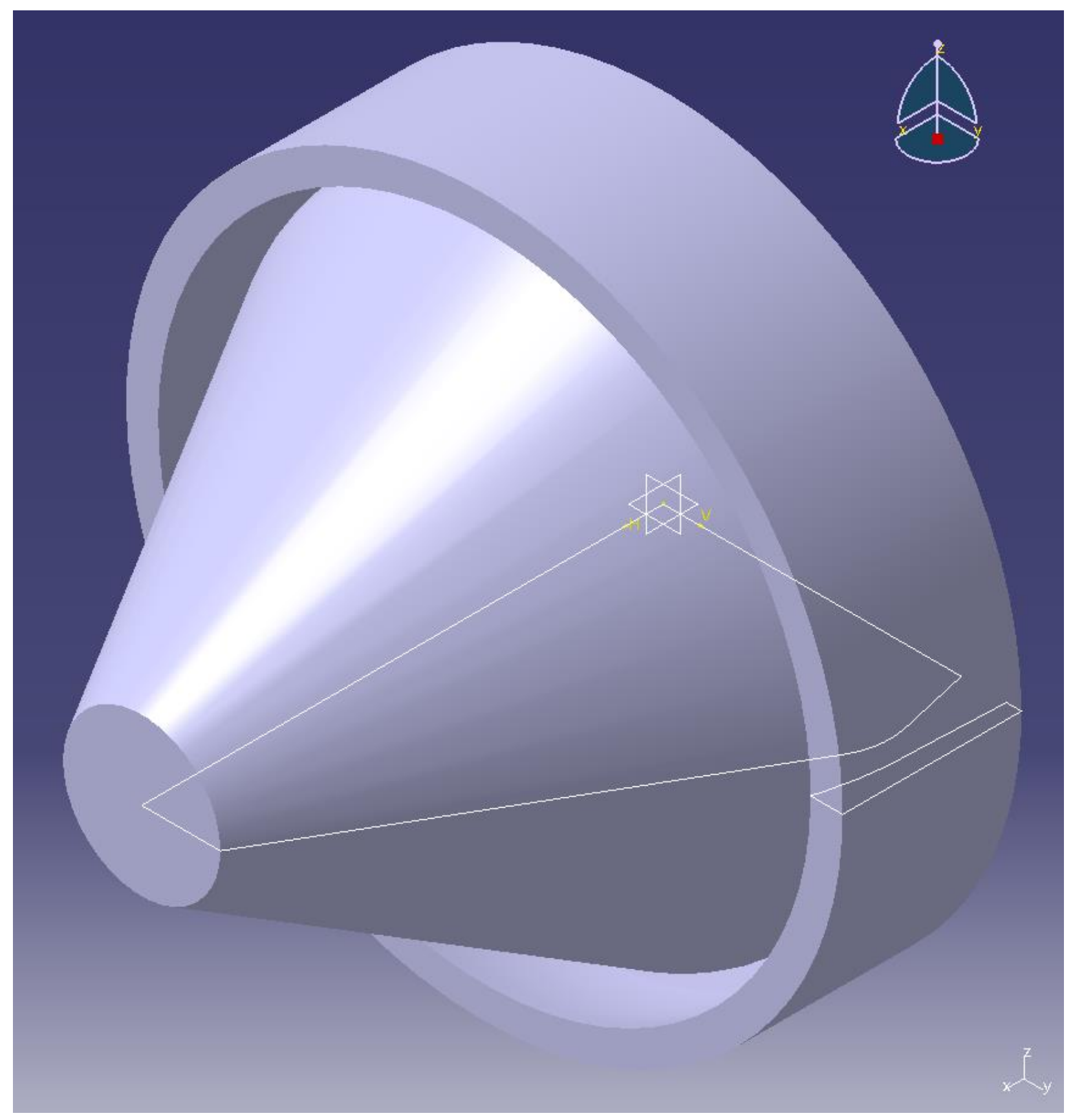

Figure 49: An isometric view of Aerospike 3 created in CATIA, by revolving the sketch from Figure 48 about its axis of symmetry. 
Aerospike 4 Sketch

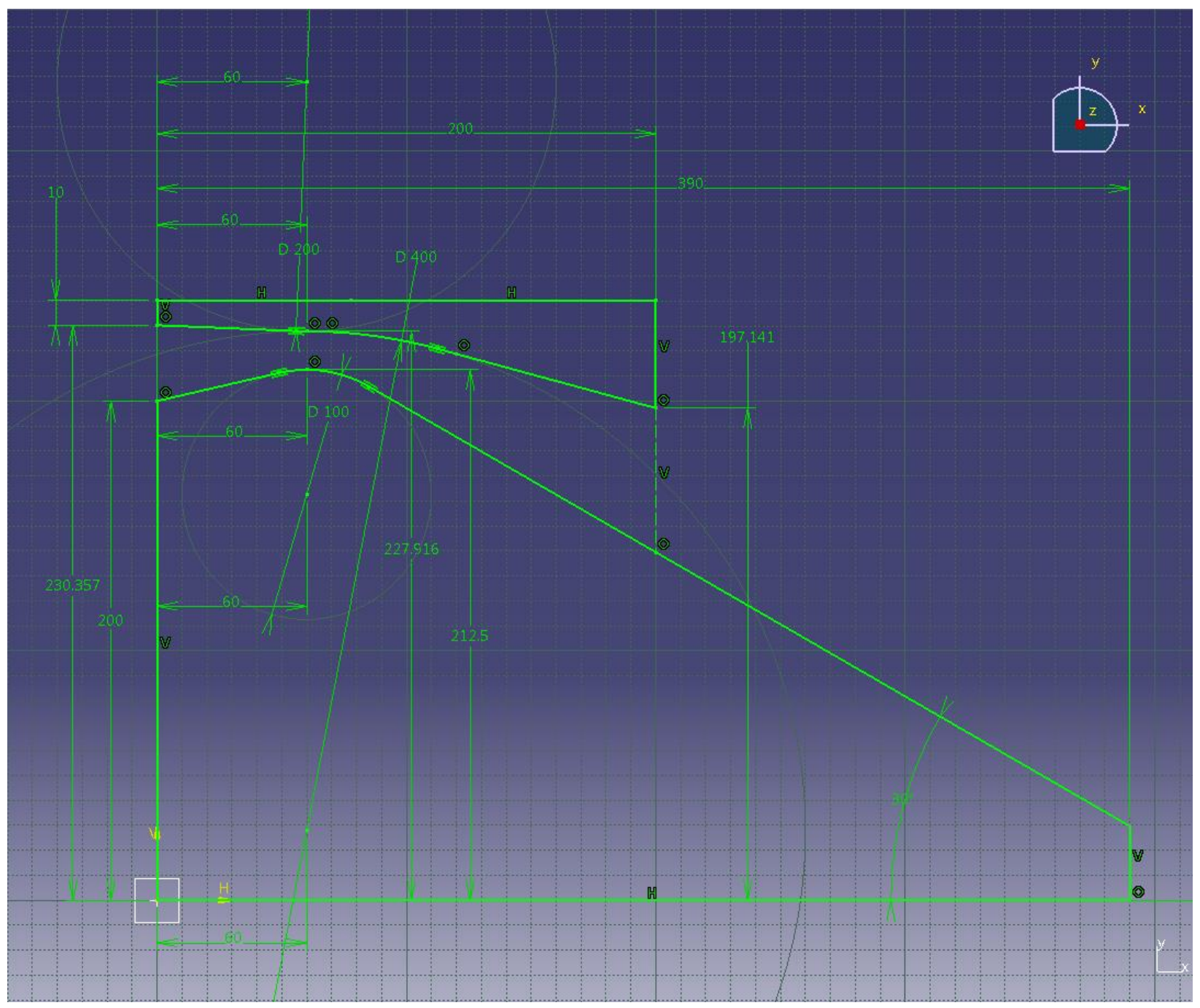

Figure 50: A CATIA sketch of Aerospike 4; all dimensions are in millimeters. 


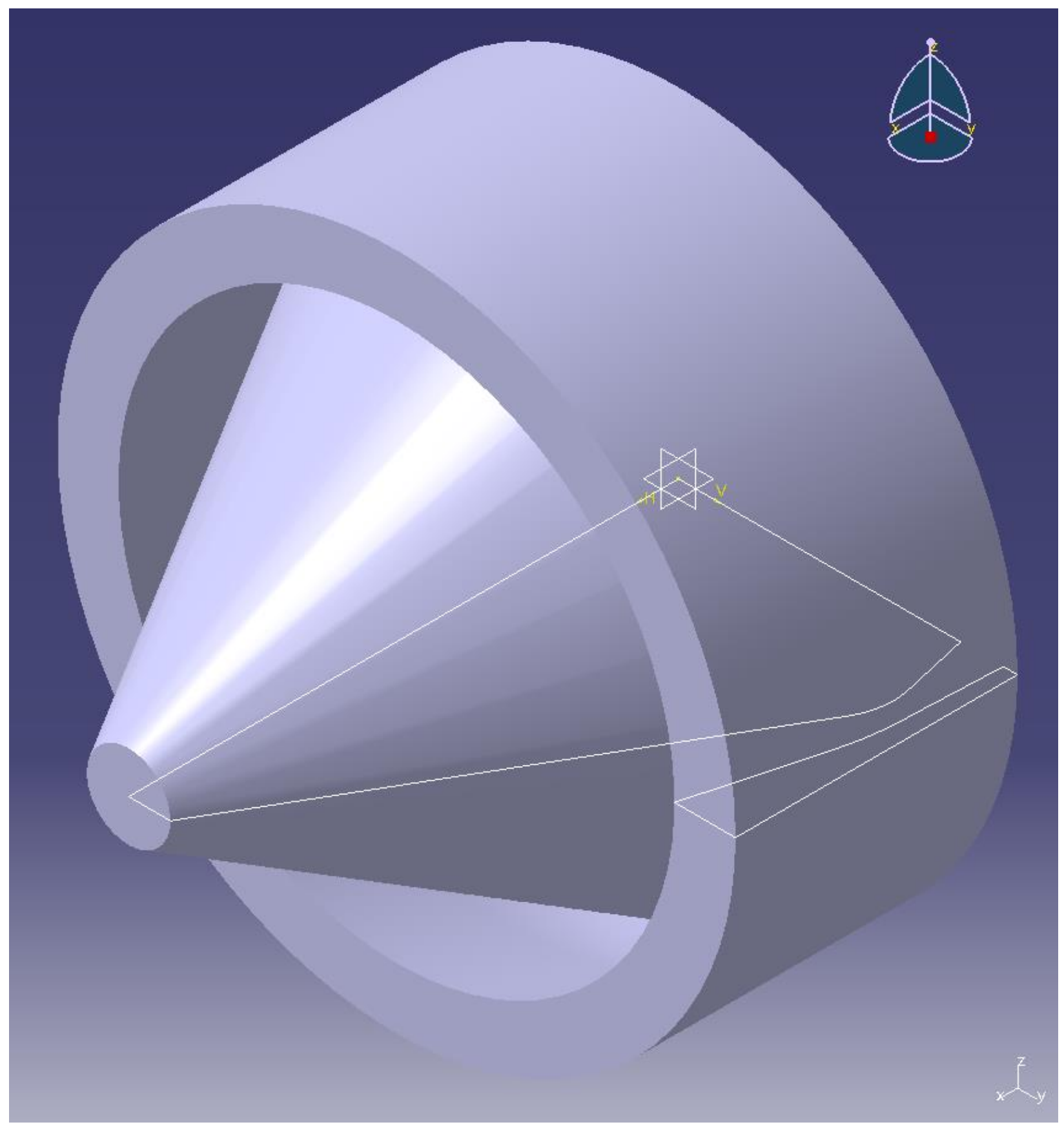

Figure 51: An isometric view of Aerospike 4 created in CATIA, by revolving the sketch from Figure 50 about its axis of symmetry. 
Aerospike 5 Sketch

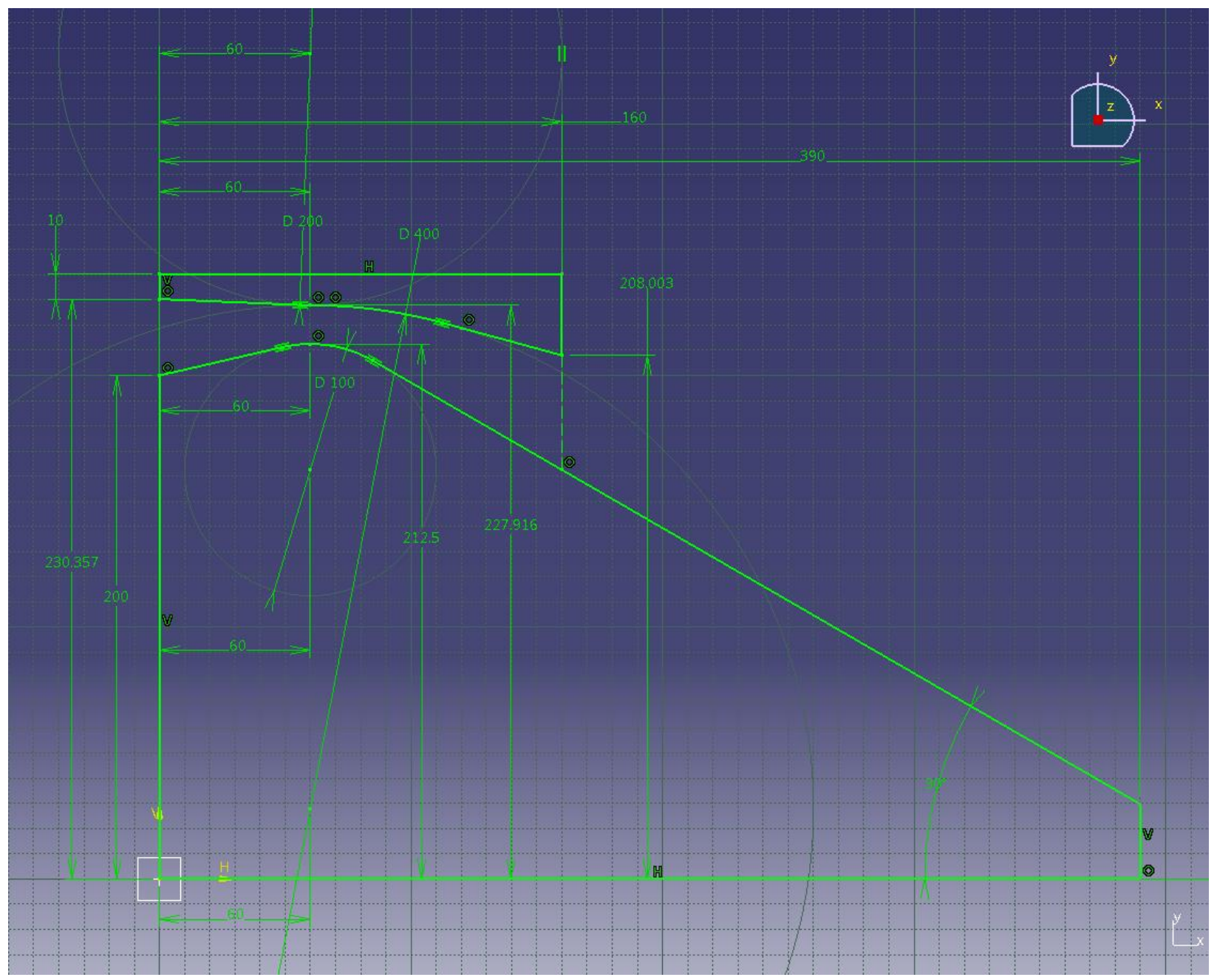

Figure 52: A CATIA sketch of Aerospike 5; all dimensions are in millimeters. 


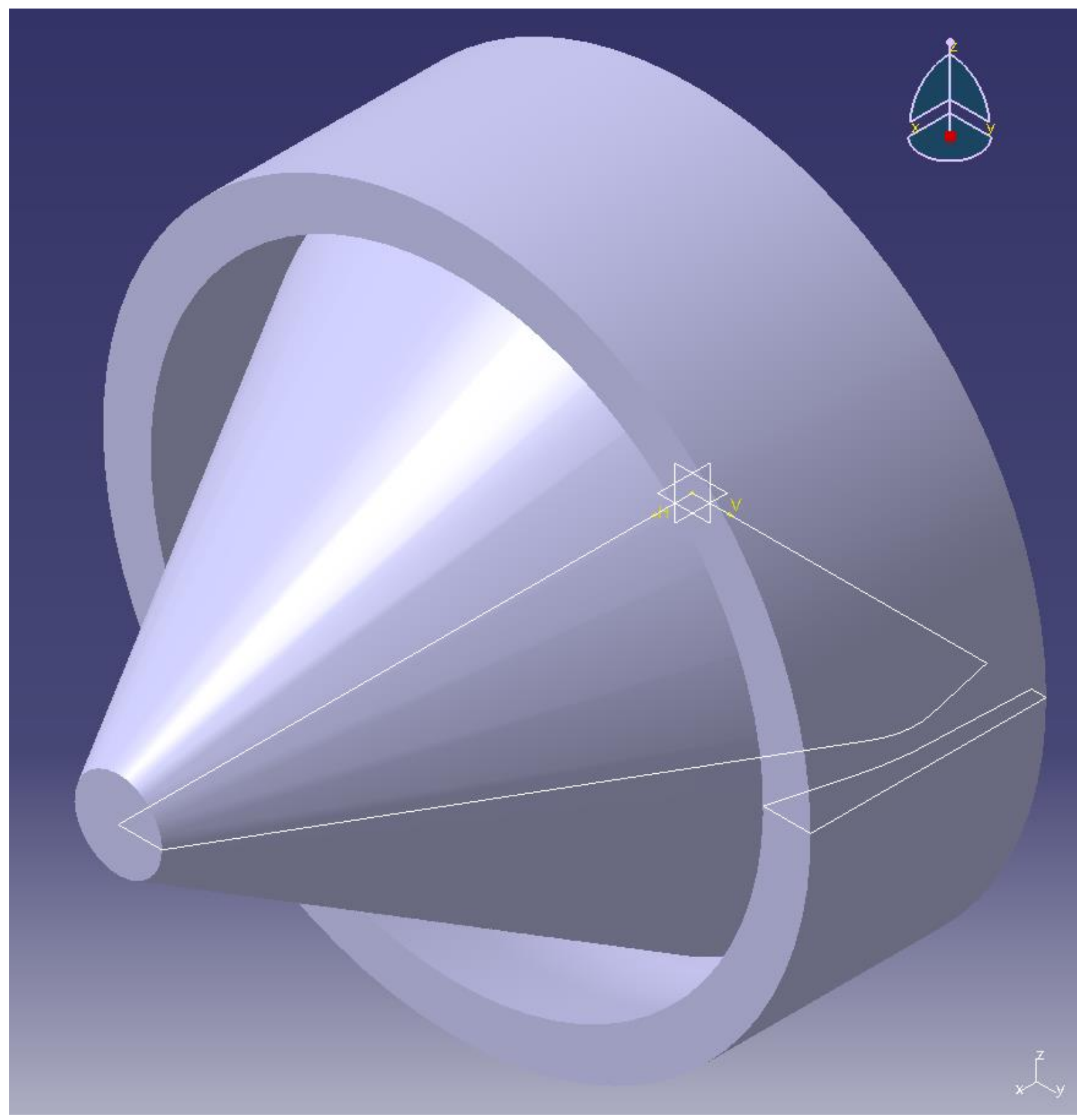

Figure 53: An isometric view of Aerospike 5 created in CATIA, by revolving the sketch from Figure 52 about its axis of symmetry. 
Aerospike 6 Sketch

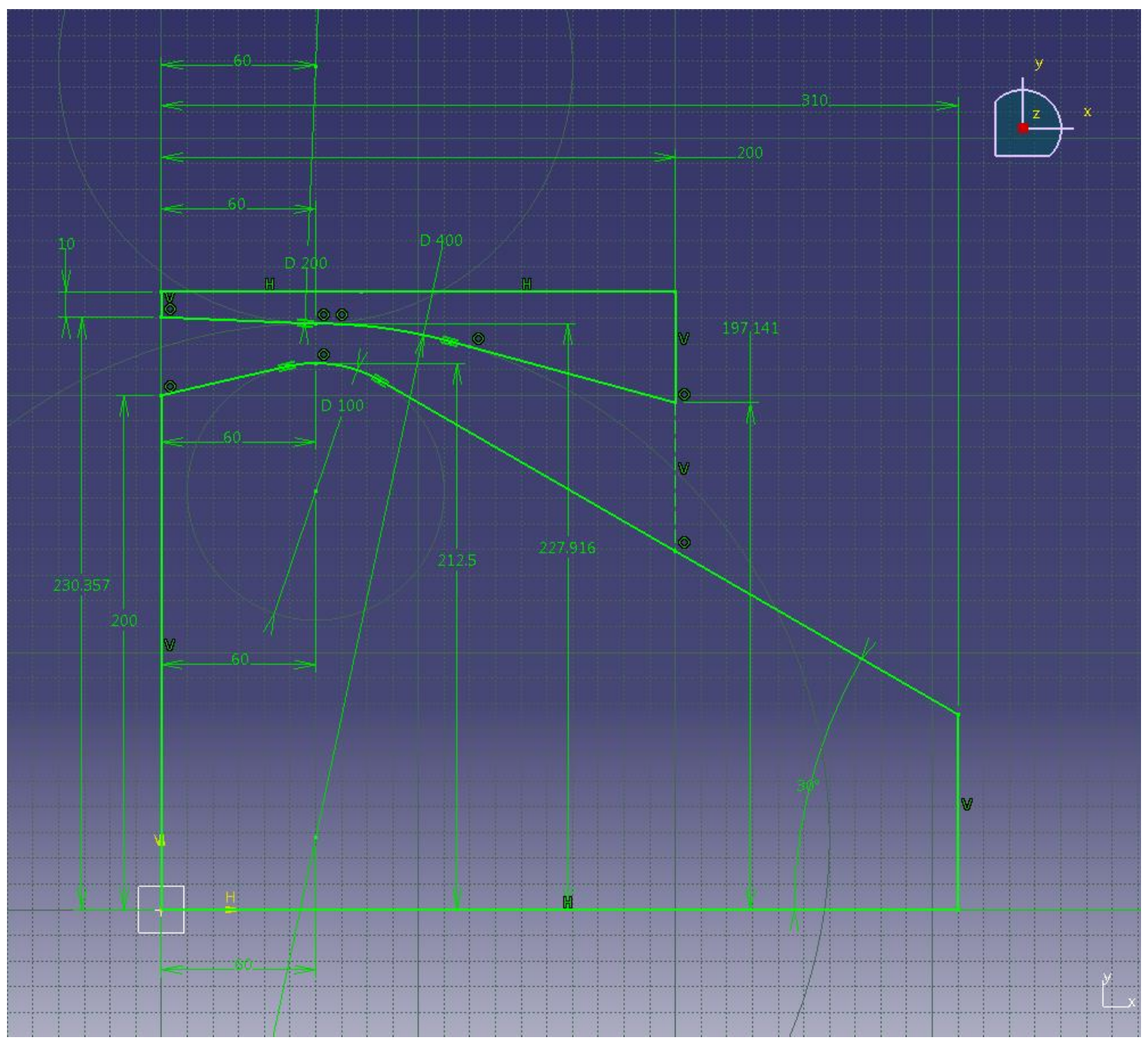

Figure 54: A CATIA sketch of Aerospike 6; all dimensions are in millimeters. 


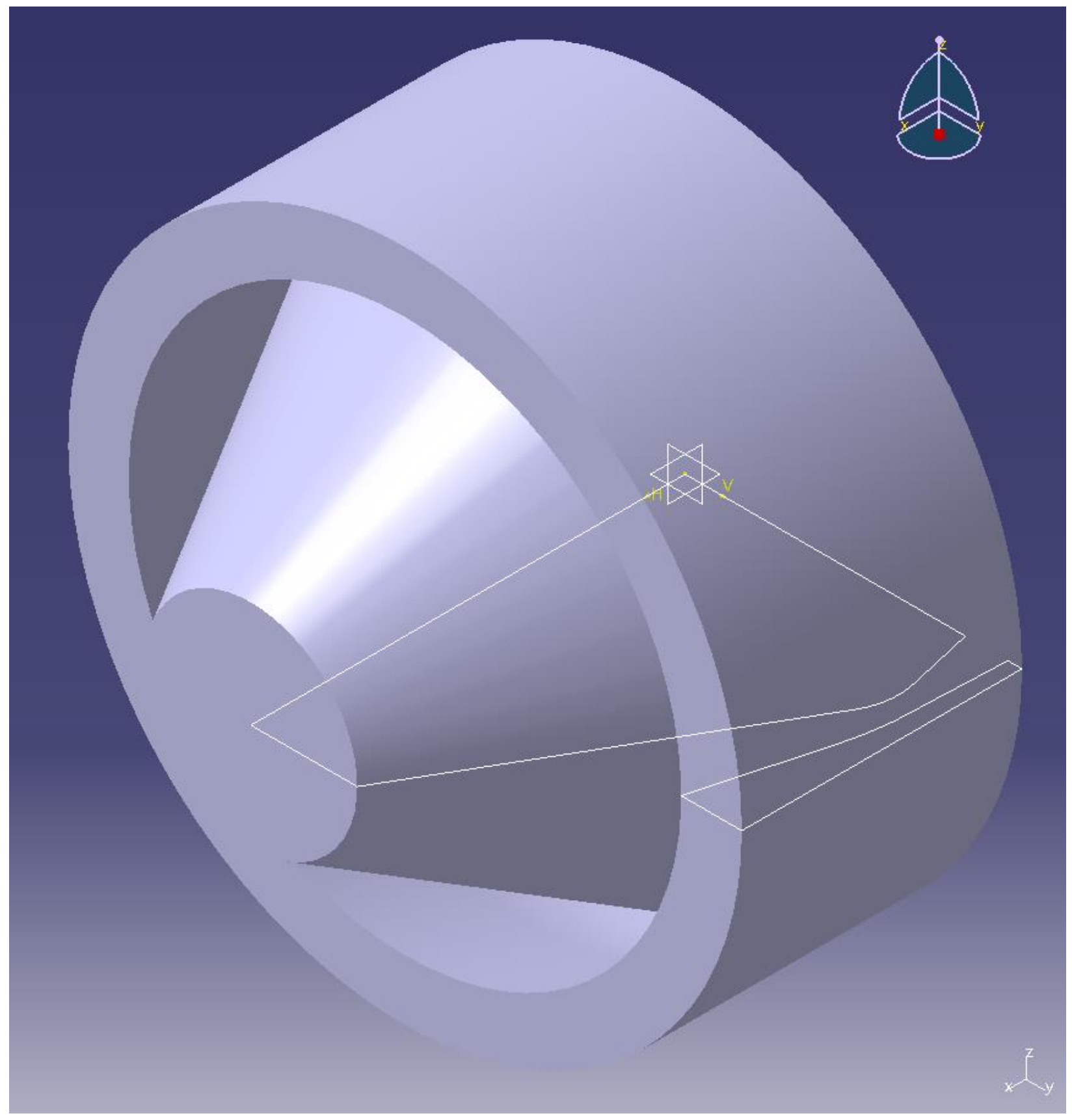

Figure 55: An isometric view of Aerospike 6 created in CATIA, by revolving the sketch from Figure 54 about its axis of symmetry. 
Aerospike 7 Sketch

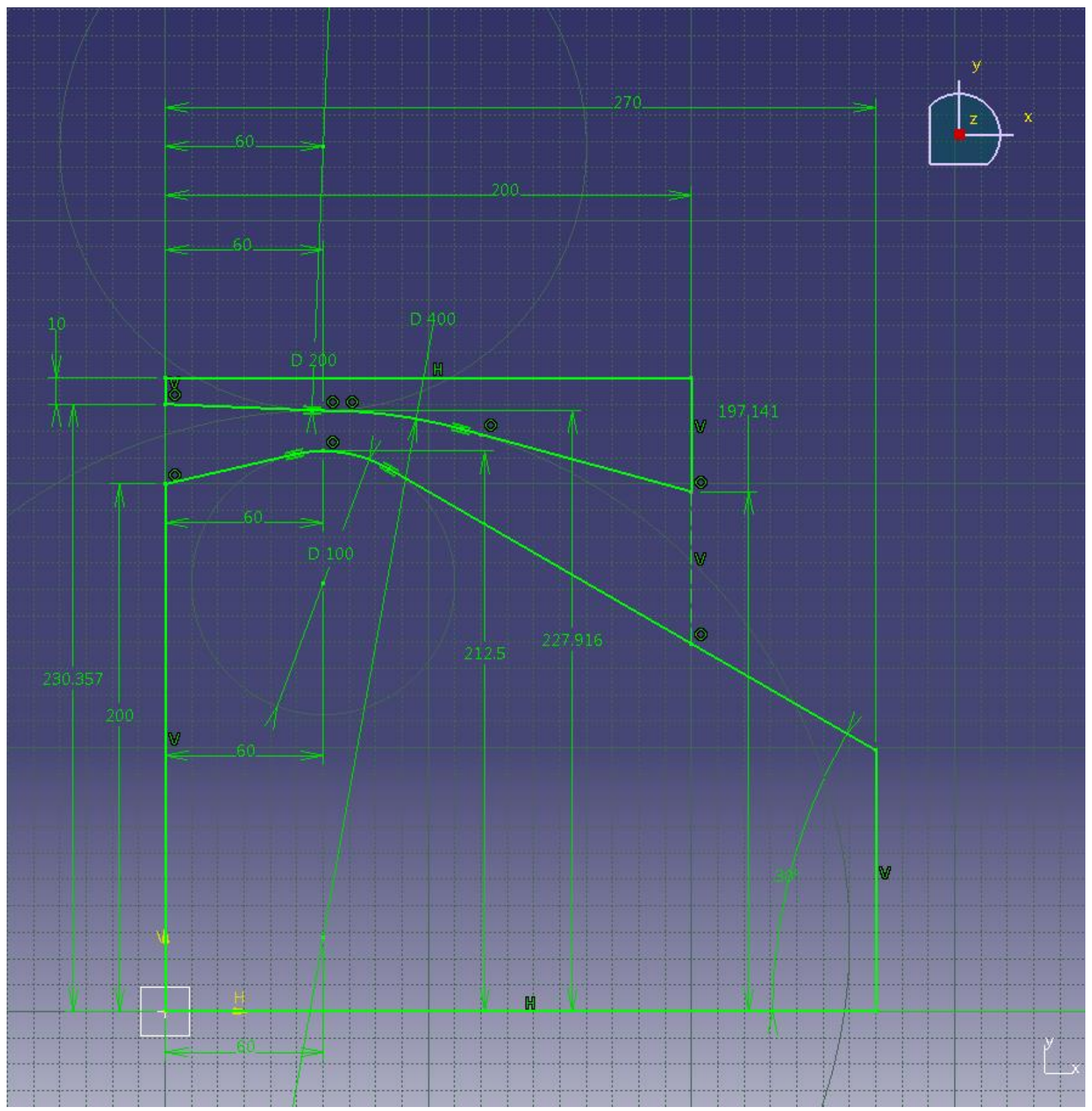

Figure 56: A CATIA sketch of Aerospike 7; all dimensions are in millimeters. 


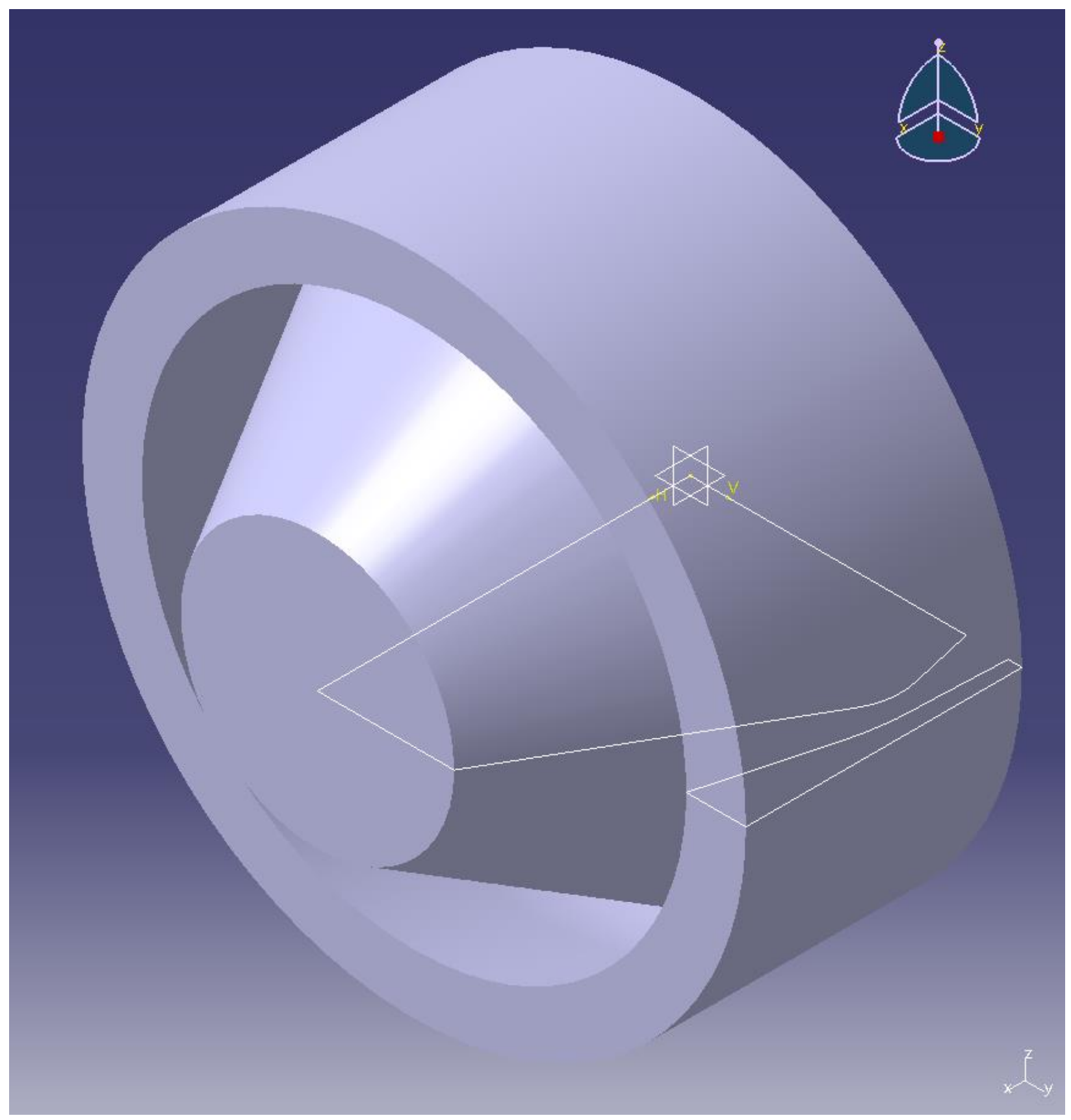

Figure 57: An isometric view of Aerospike 7 created in CATIA, by revolving the sketch from Figure 56 about its axis of symmetry. 
Aerospike 8 Sketch

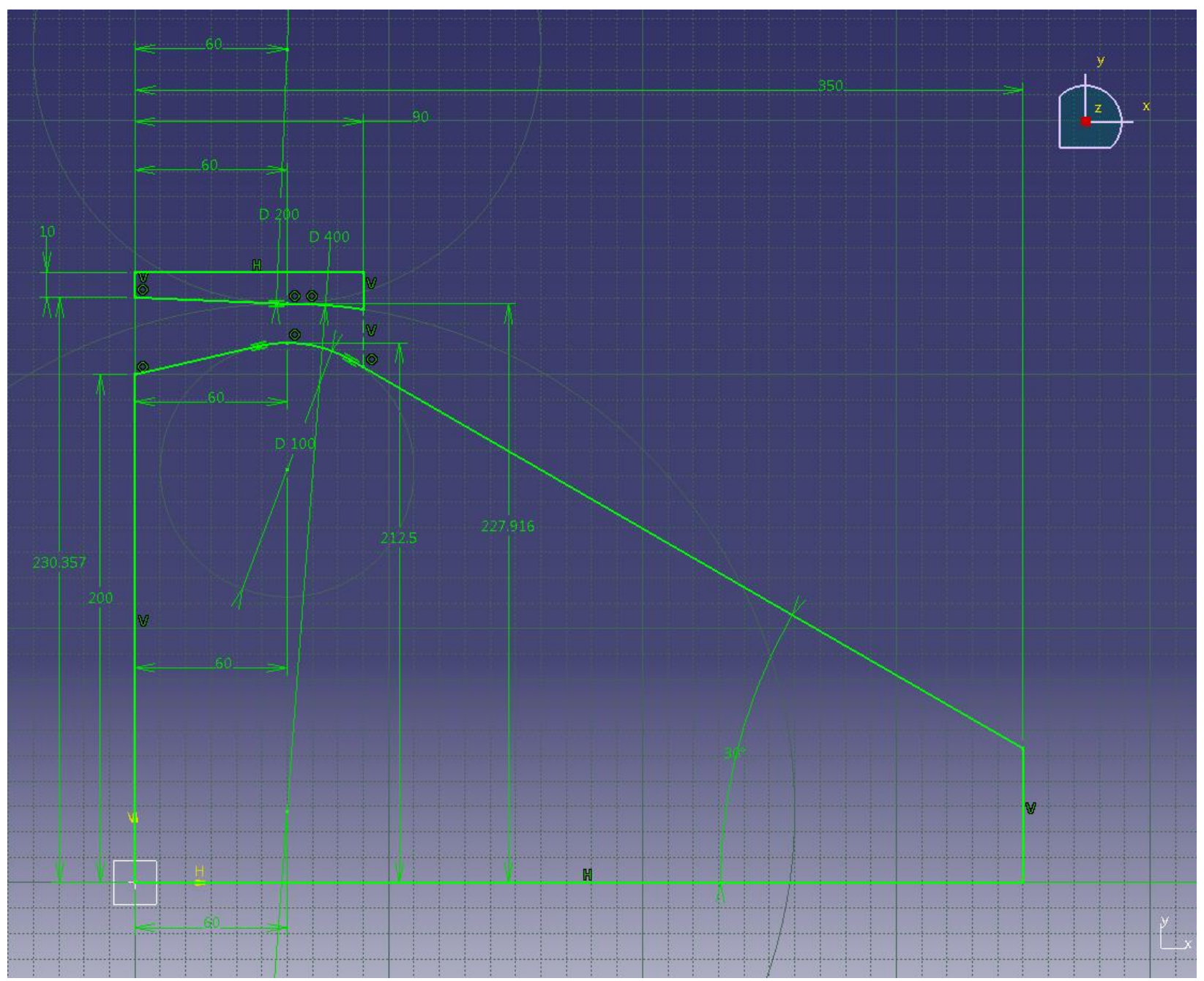

Figure 58: A CATIA sketch of Aerospike 8; all dimensions are in millimeters. 


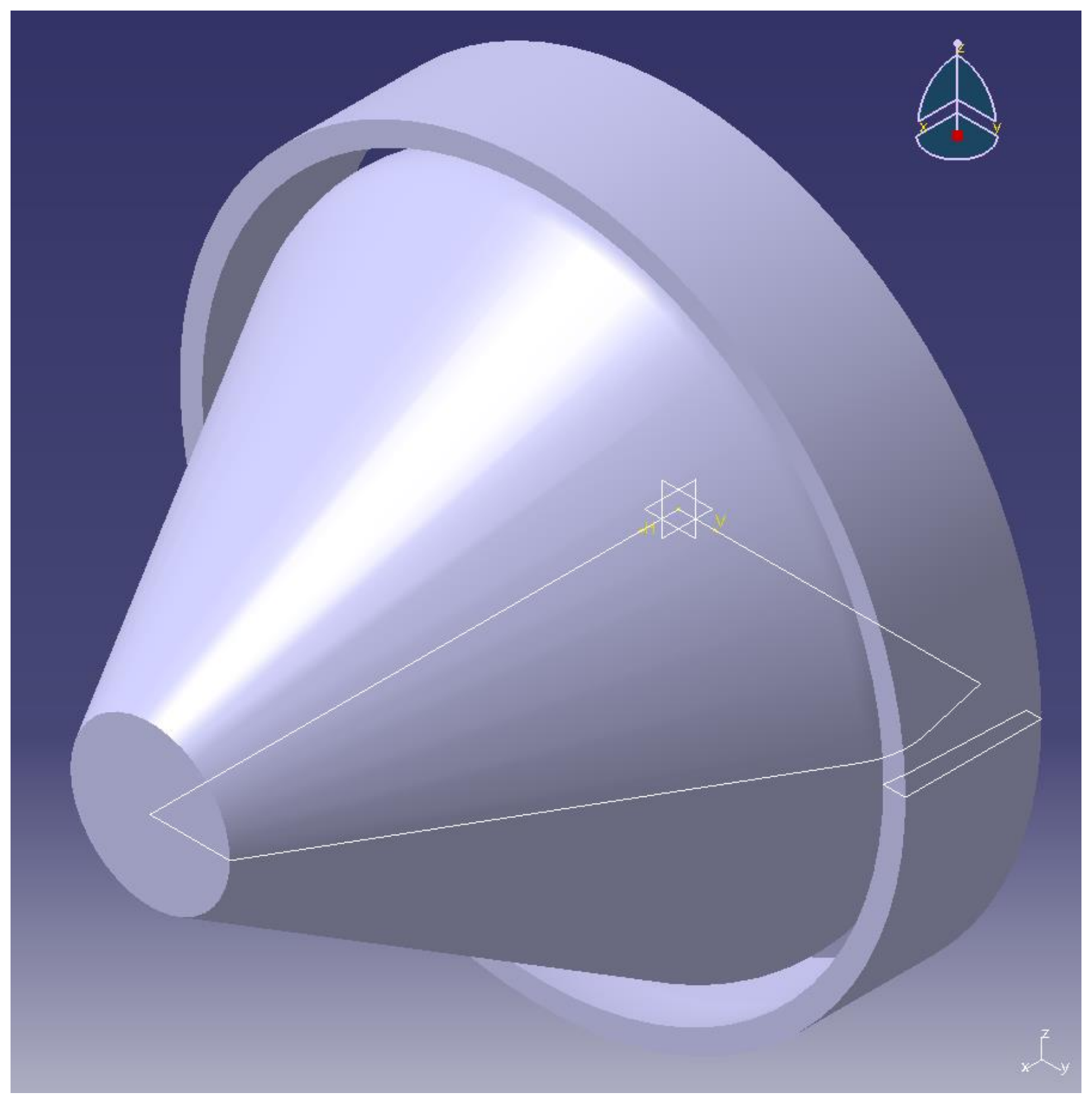

Figure 59: An isometric view of Aerospike 8 created in CATIA, by revolving the sketch from Figure 58 about its axis of symmetry. 
Aerospike 9 Sketch

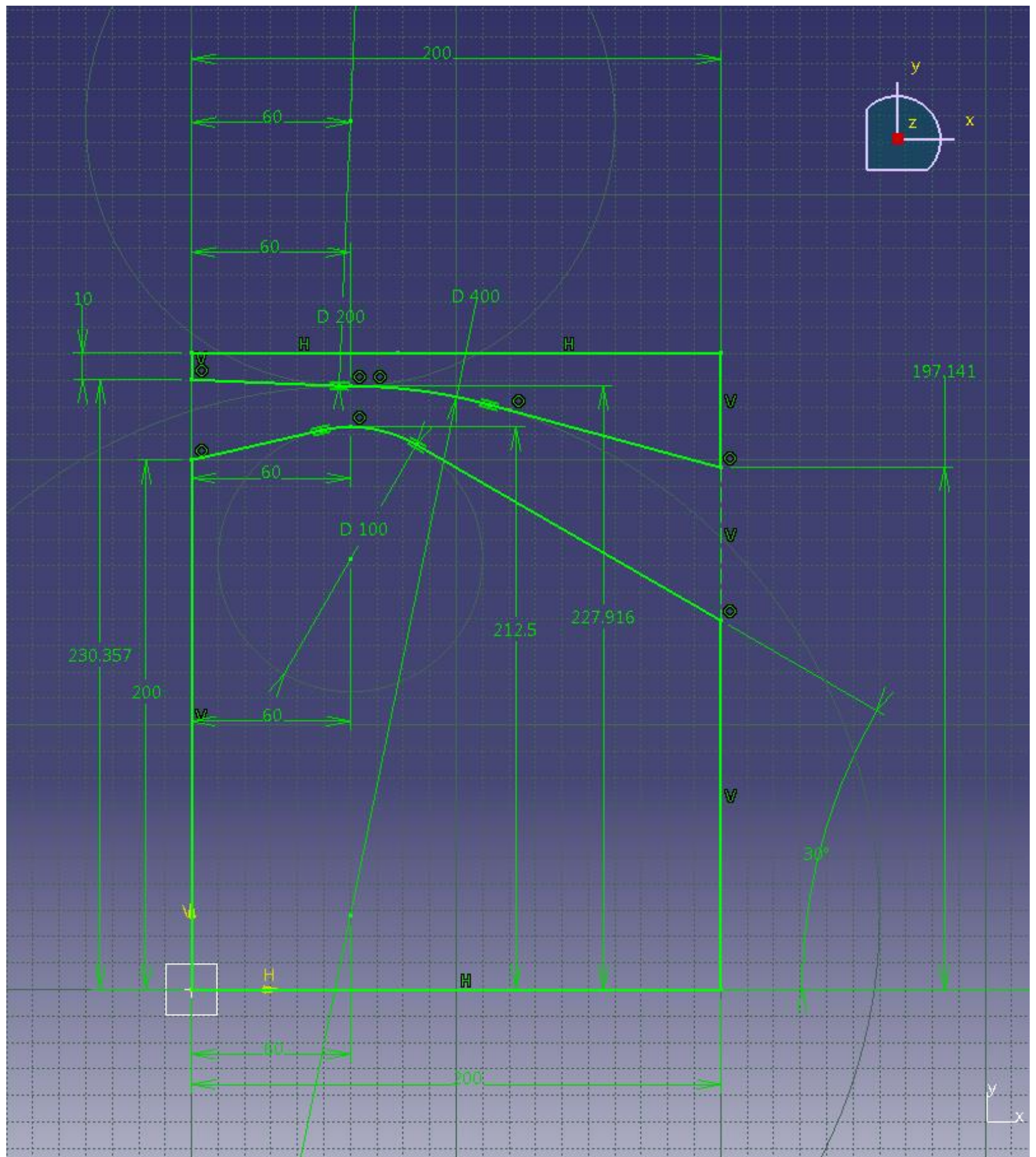

Figure 60: A CATIA sketch of Aerospike 9; all dimensions are in millimeters. 


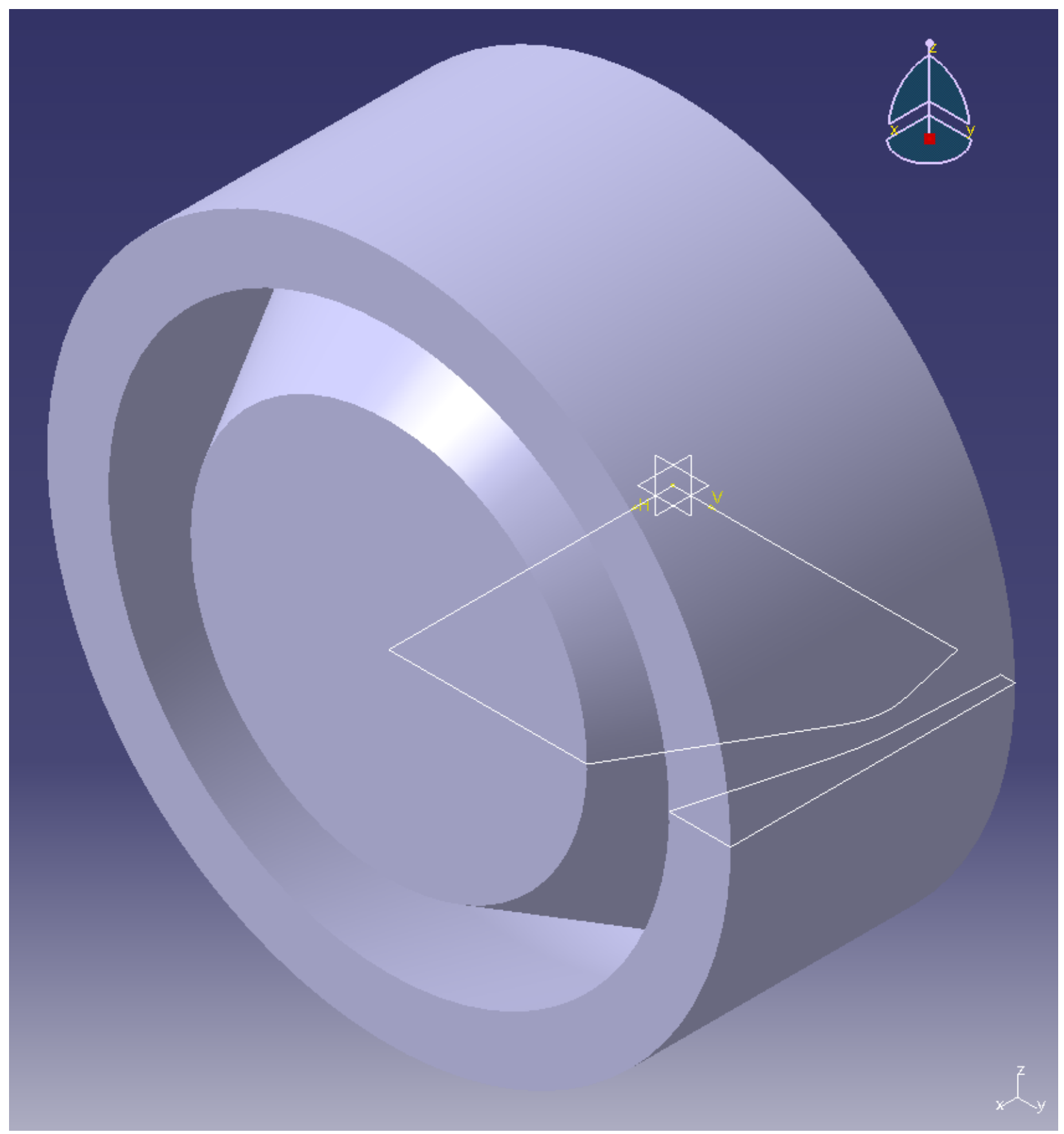

Figure 61: An isometric view of Aerospike 9 created in CATIA, by revolving the sketch from Figure 60 about its axis of symmetry. 
Aerospike 10 Sketch

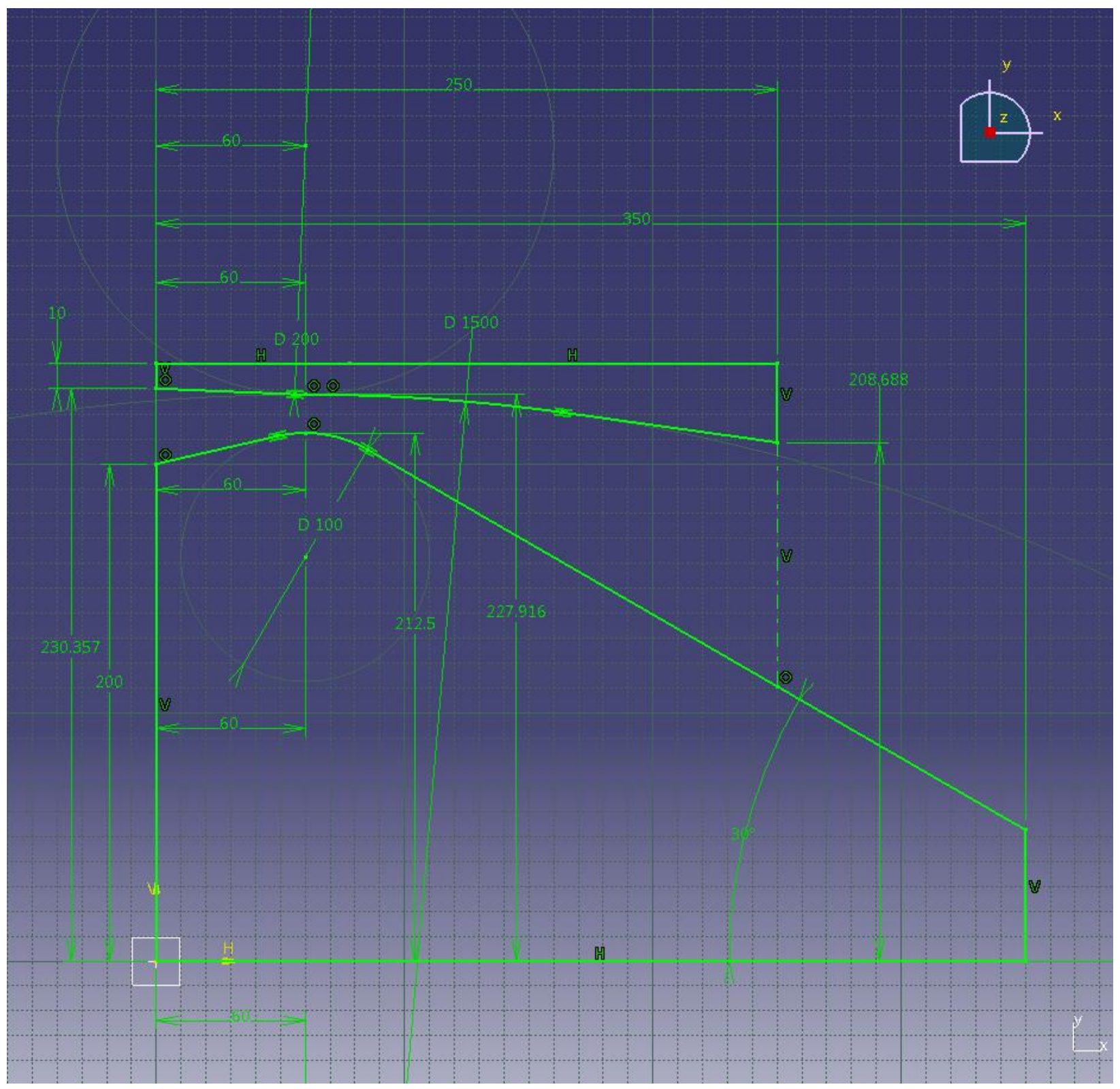

Figure 62: A CATIA sketch of Aerospike 10; all dimensions are in millimeters. 


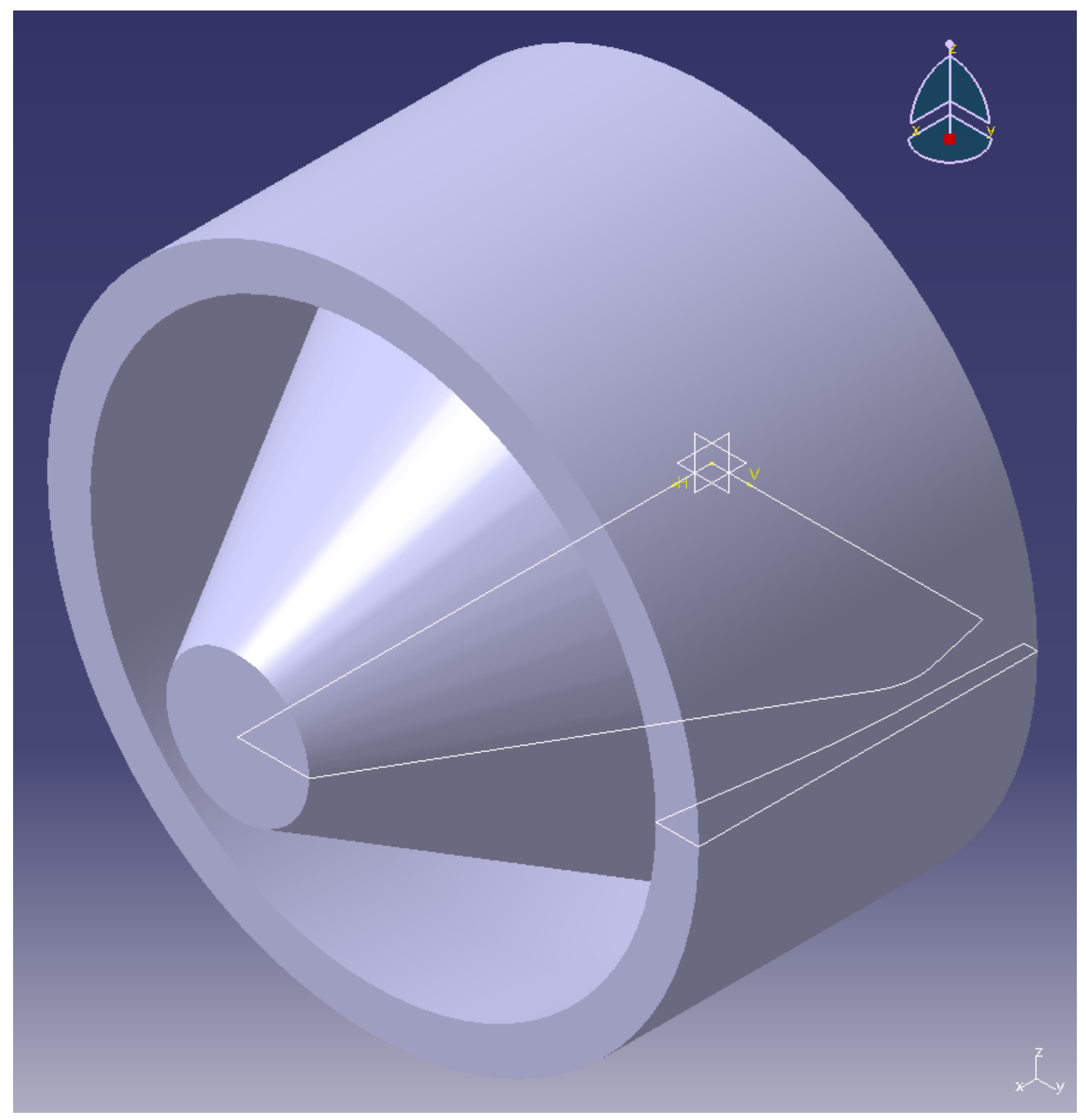

Figure 63: An isometric view of Aerospike 10 created in CATIA, by revolving the sketch from Figure 62 about its axis of symmetry. 
Aerospike 11 Sketch

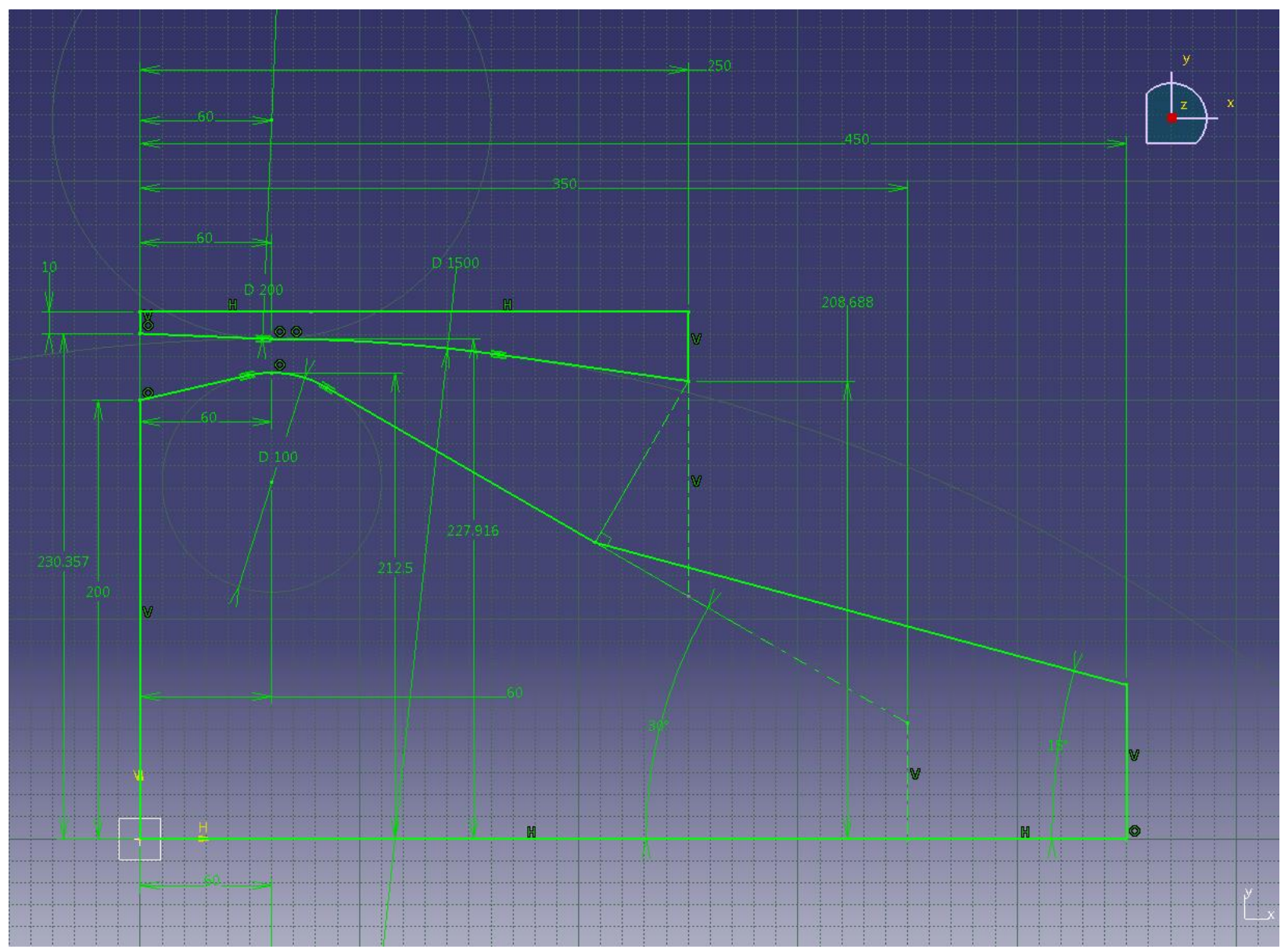

Figure 64: A CATIA sketch of Aerospike 11; all dimensions are in millimeters. 


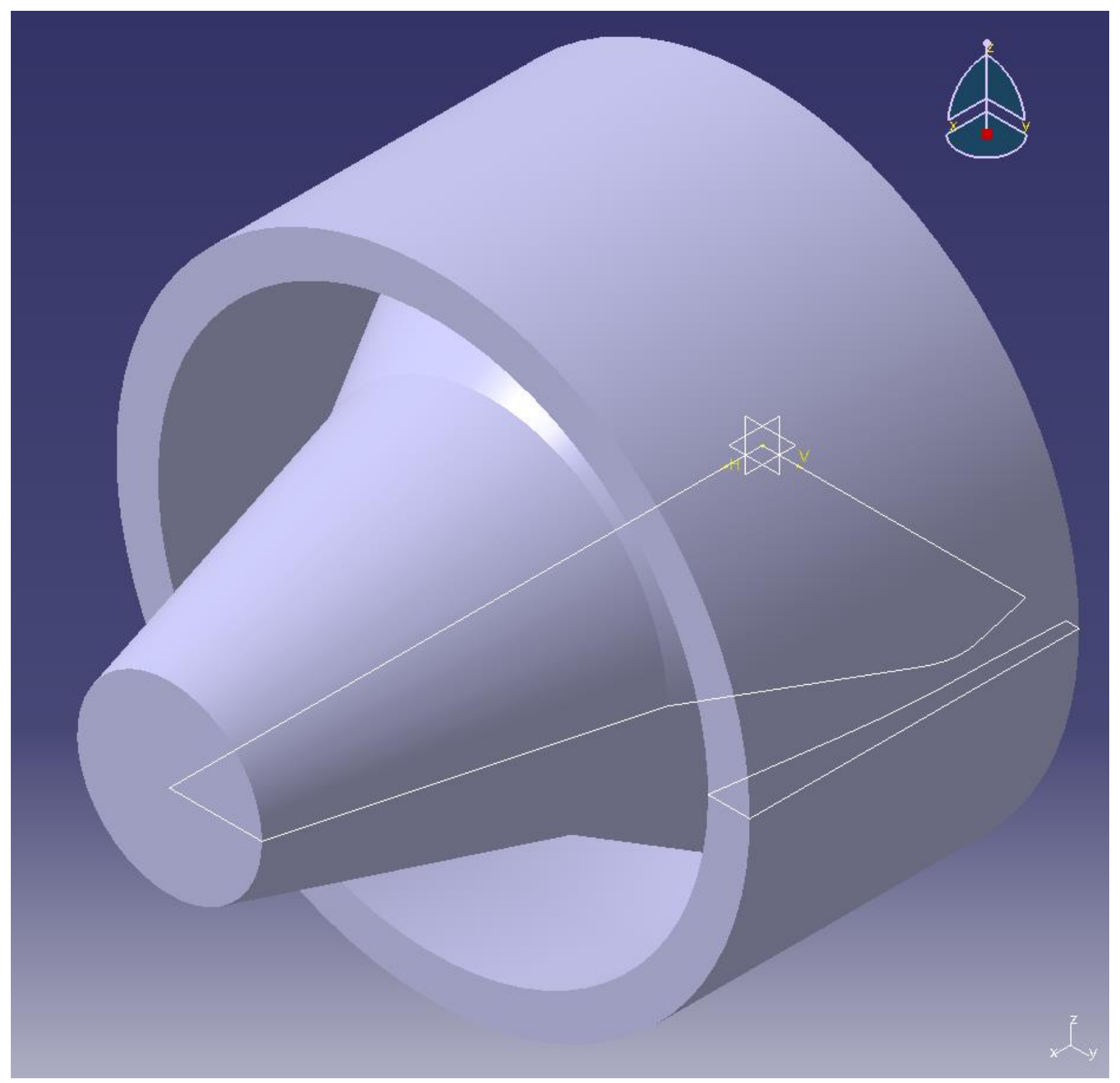

Figure 65: An isometric view of Aerospike 11 created in CATIA, by revolving the sketch from Figure 64 about its axis of symmetry. 
Aerospike 12 Sketch

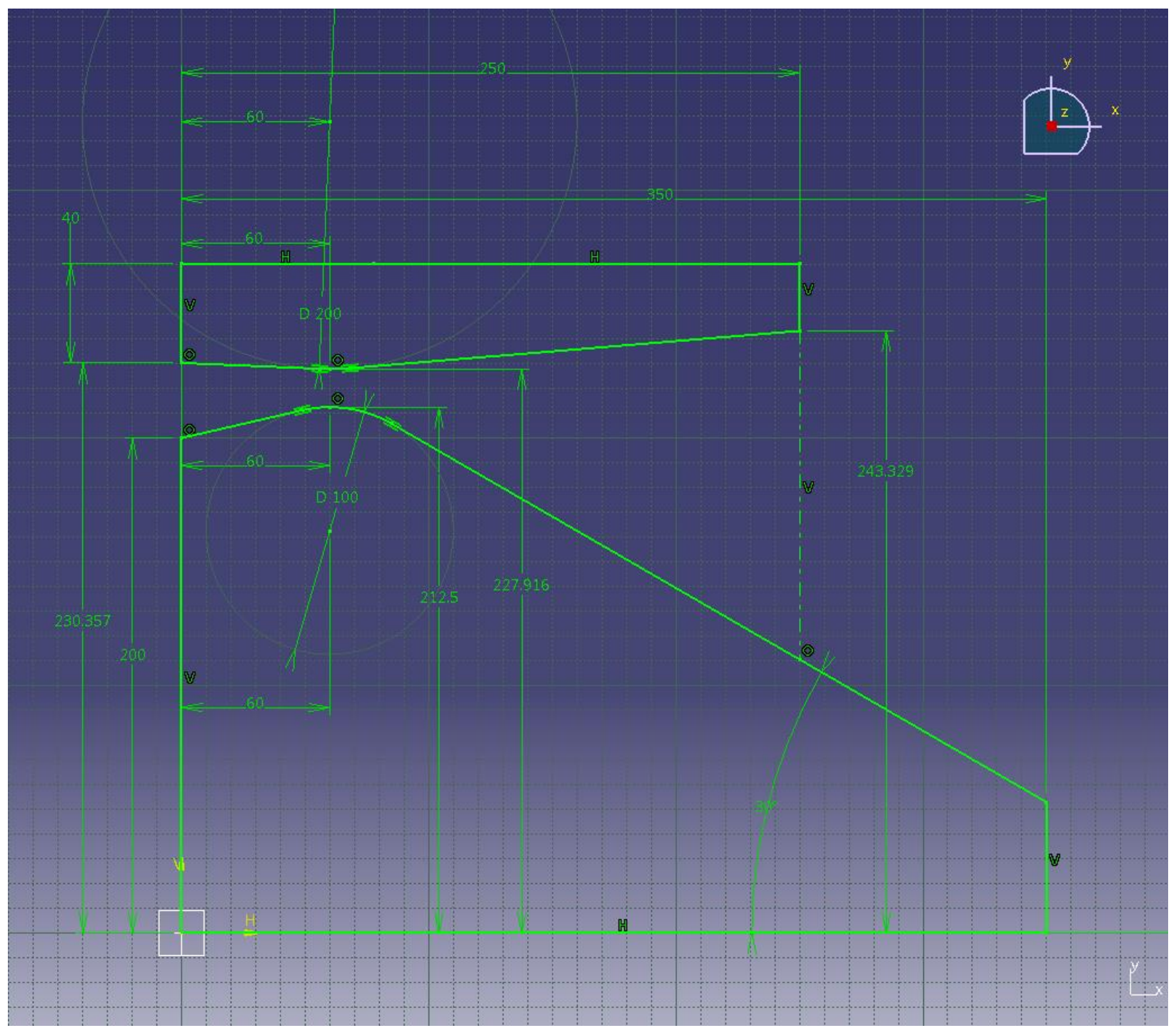

Figure 66: A CATIA sketch of Aerospike 12; all dimensions are in millimeters. 


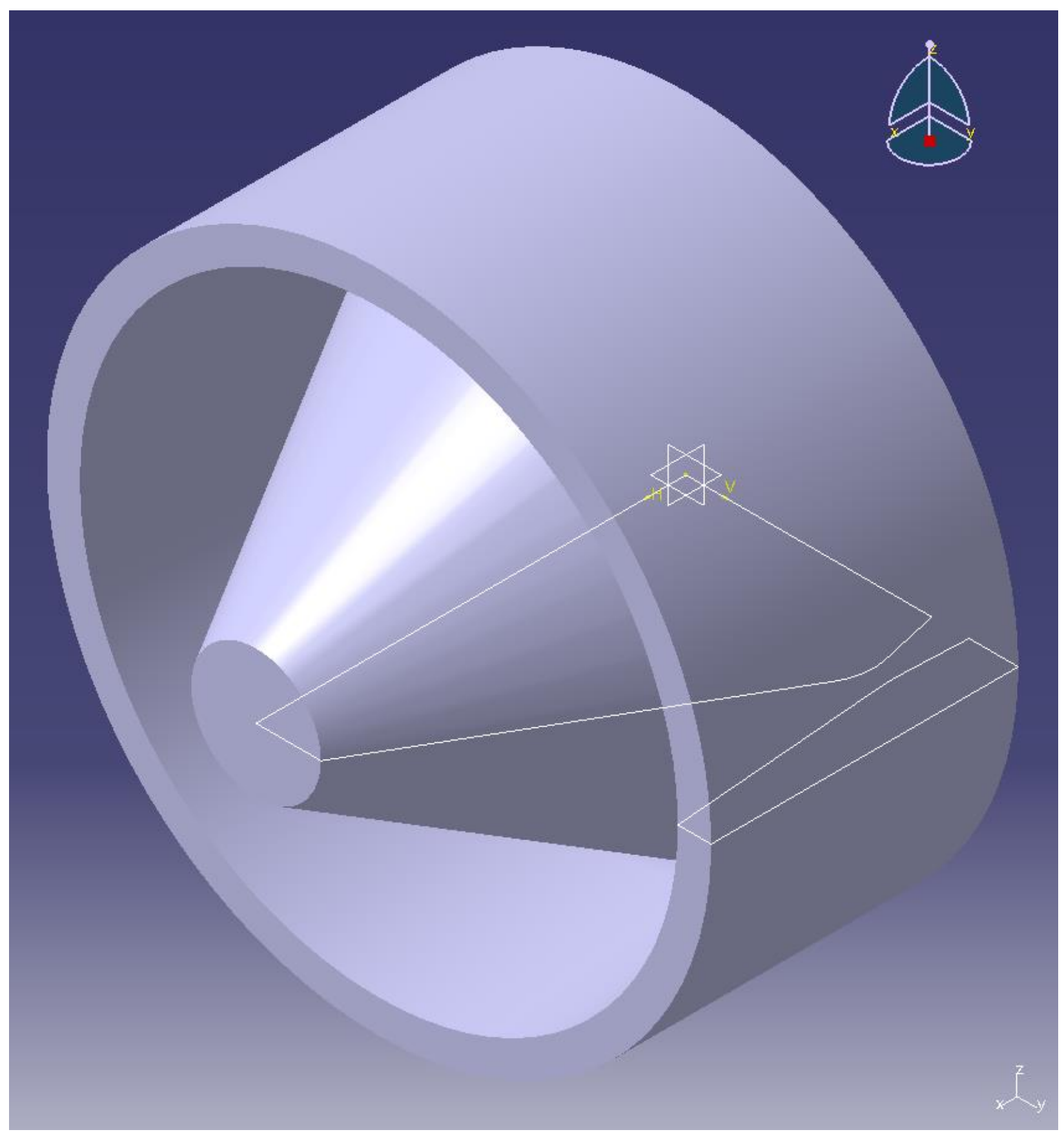

Figure 67: An isometric view of Aerospike 12 created in CATIA, by revolving the sketch from Figure 66 about its axis of symmetry. 


\section{Design of Aerospike 13}

The sketch for Aerospike 13 is shown in Figure 68. Aerospike 13 was designed to operate under a higher total pressure $\left(P_{o}\right)$ than Aerospike 1. In order to achieve a higher $P_{o}$ while maintaining the same mass flow rate, Aerospike 13 had to be designed with a smaller throat area than Aerospike 1. The dimensions for $r_{1}$ and $r_{3}$ were retained from Aerospike 1 as well as the inlet - to - throat area ratio. Using the same inlet - to - throat area ratio implies that the predictions for inlet Mach number and total temperature do not change.

$$
\begin{aligned}
& r_{1}=0.230357309 m \text { from Aerospike } 1 \\
& r_{3}=0.227915805 m \text { from Aerospike } 1 \\
& r_{4}=0.220 m \text { raised from } 0.200 m \text { for Aerospike } 1 \\
& \frac{A_{i}}{A^{*}}=\left(\frac{r_{i}}{r^{*}}\right)^{2}=\left(\frac{4.50 \mathrm{in}}{3.244 \mathrm{in}}\right)^{2}=1.924258158 \text { from the CD Nozzle case } \\
& M_{i} \approx 0.3196 \\
& \frac{A_{i}}{A^{*}}=\frac{\pi\left(r_{1}^{2}-r_{2}^{2}\right)}{\pi\left(r_{3}^{2}-r_{4}^{2}\right)} \\
& =\frac{r_{1}^{2}-r_{2}^{2}}{r_{3}^{2}-r_{4}^{2}} \\
& r_{1}^{2}-r_{2}^{2}=\frac{A_{i}}{A^{*}}\left(r_{3}^{2}-r_{4}^{2}\right) \\
& r_{2}^{2}=r_{1}^{2}-\frac{A_{i}}{A^{*}}\left(r_{3}^{2}-r_{4}^{2}\right) \\
& r_{2}=\sqrt{r_{1}^{2}-\frac{A_{i}}{A^{*}}\left(r_{3}^{2}-r_{4}^{2}\right)} \\
& =\sqrt{(0.230357309 m)^{2}-(1.924258158)\left[(0.227915805 m)^{2}-(0.220 m)^{2}\right]} \\
& =0.215039096 \mathrm{~m} \\
& \dot{m}=\frac{P_{o} A^{*}}{\sqrt{T_{o}}} \sqrt{\frac{\gamma}{R}\left(\frac{2}{\gamma+1}\right)^{(\gamma+1) /(\gamma-1)}} \\
& P_{o}=\frac{\dot{m}}{\frac{A^{*}}{\sqrt{T_{o}}} \sqrt{\frac{\gamma}{R}\left(\frac{2}{\gamma+1}\right)^{(\gamma+1) /(\gamma-1)}}}
\end{aligned}
$$




$$
\begin{gathered}
=\frac{9.689151311 \mathrm{~kg} / \mathrm{s}}{\left(\frac{0.011138875 \mathrm{~m}^{2}}{\sqrt{940.875 K}}\right) \sqrt{\frac{1.4}{287 \mathrm{~J} / \mathrm{kg} \cdot \mathrm{K}}\left(\frac{2}{1.4+1}\right)^{(1.4+1) /(1.4-1)}}} \\
=660,132.388 \mathrm{~Pa}
\end{gathered}
$$

The sketch that the defines the entire geometry of Aerospike 13 is shown in Figure 68. Aerospikes $14-18$ are all design iterations from Aerospike 13 with varying exit areas, axial locations of exit areas, and center body geometries. 
Aerospike 13 Sketch

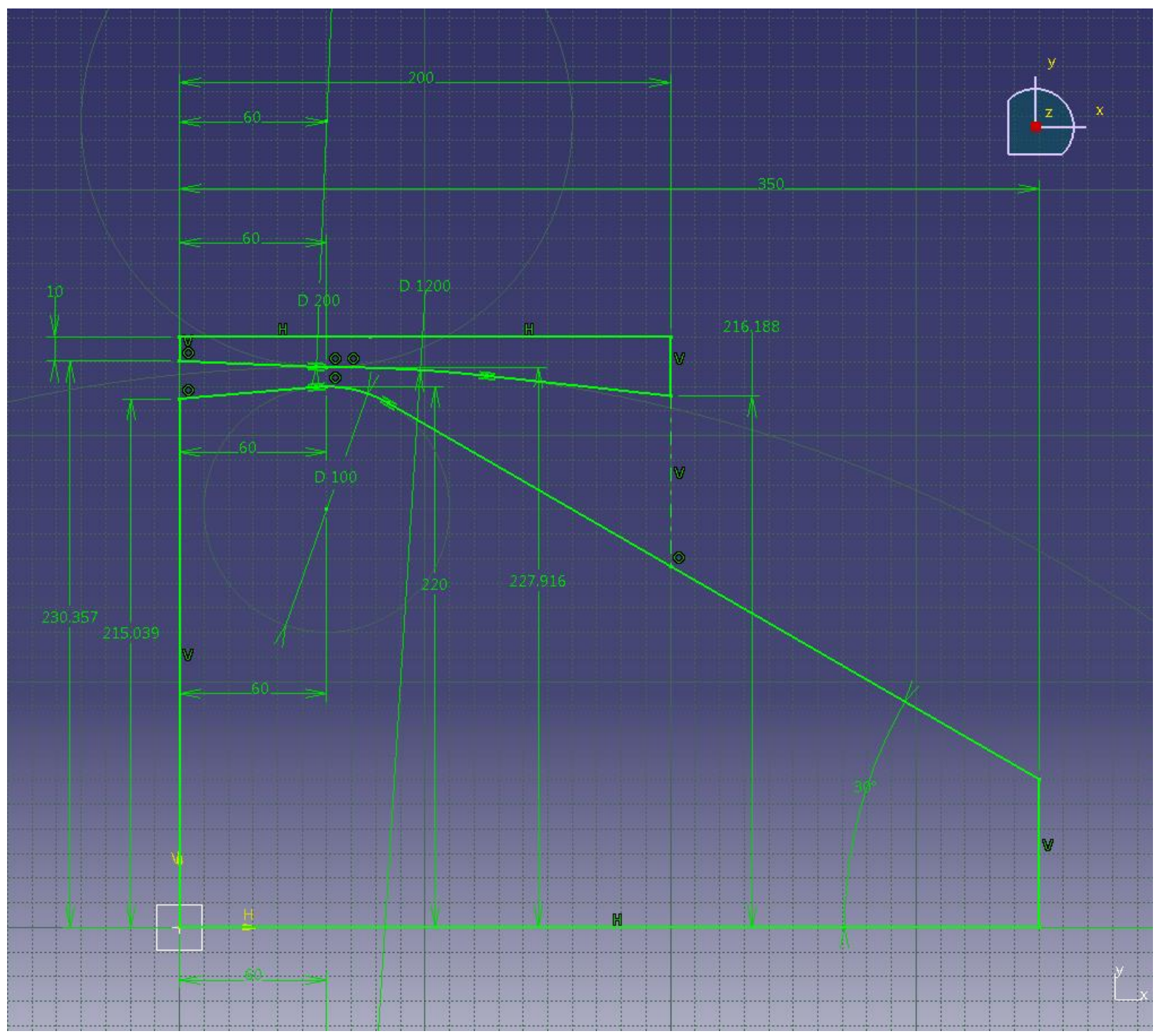

Figure 68: A CATIA sketch of Aerospike 13; all dimensions are in millimeters. 


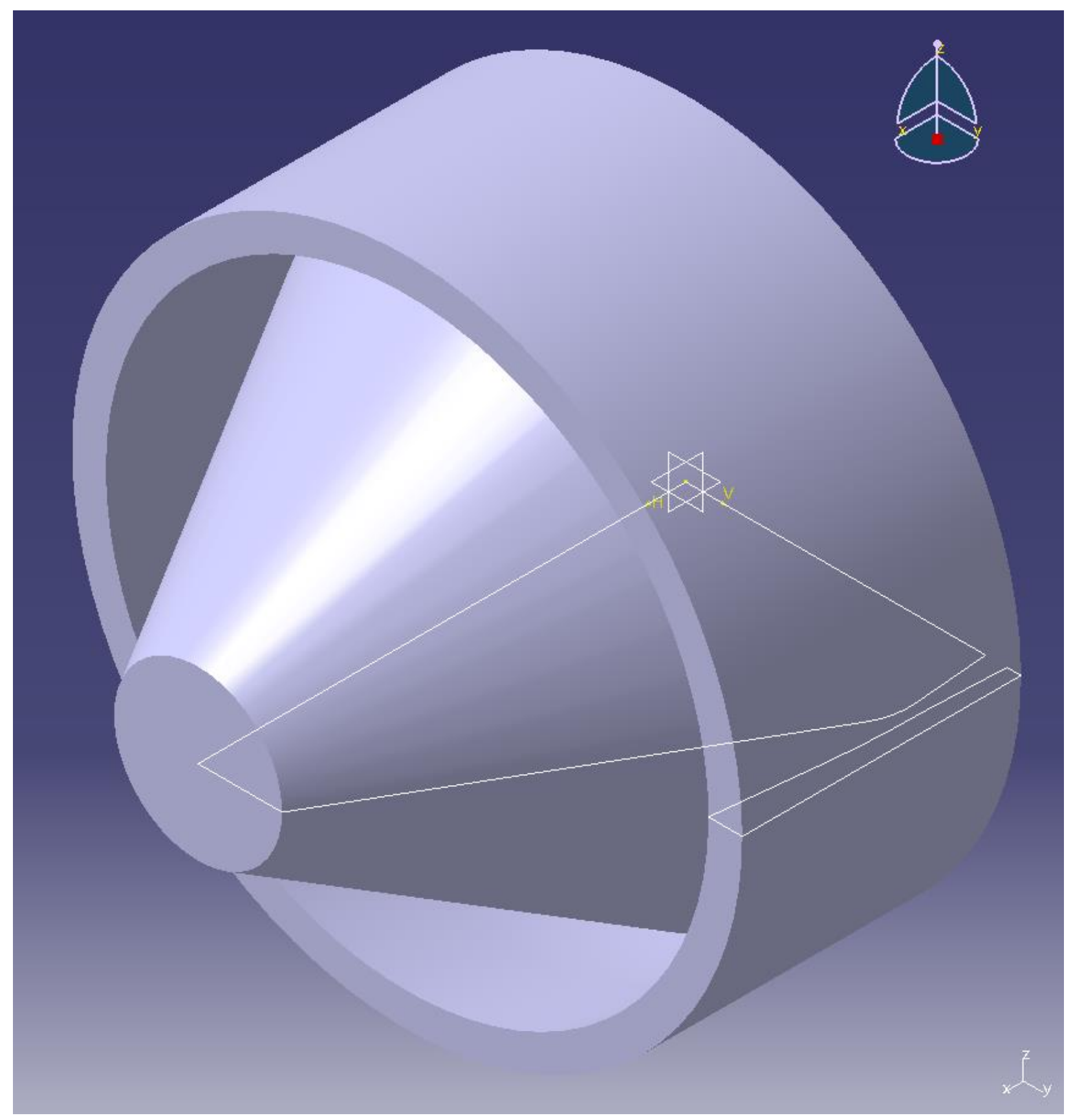

Figure 69: An isometric view of Aerospike 13 created in CATIA, by revolving the sketch from Figure 68 about its axis of symmetry. 
Aerospike 14 Sketch

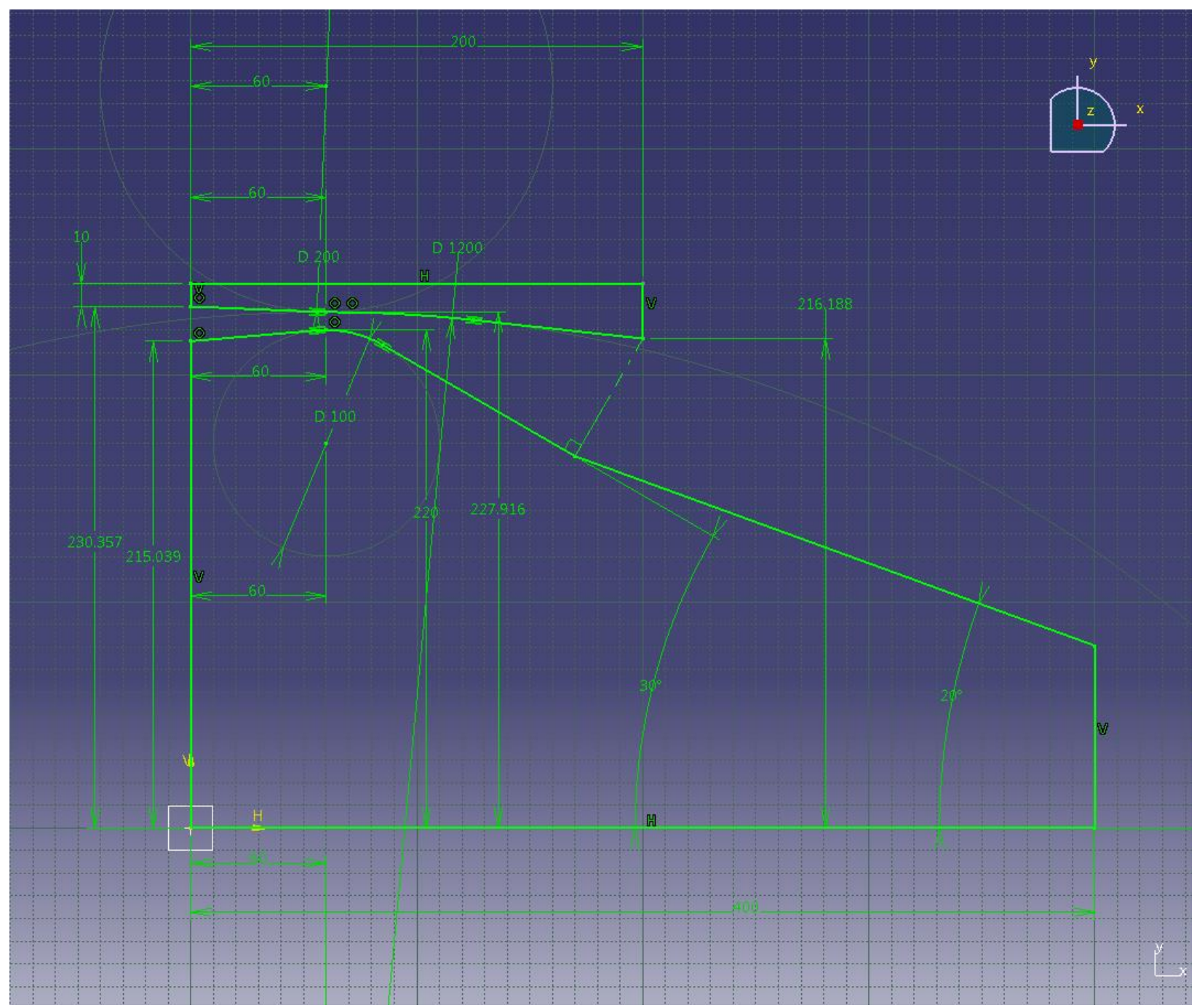

Figure 70: A CATIA sketch of Aerospike 14; all dimensions are in millimeters. 


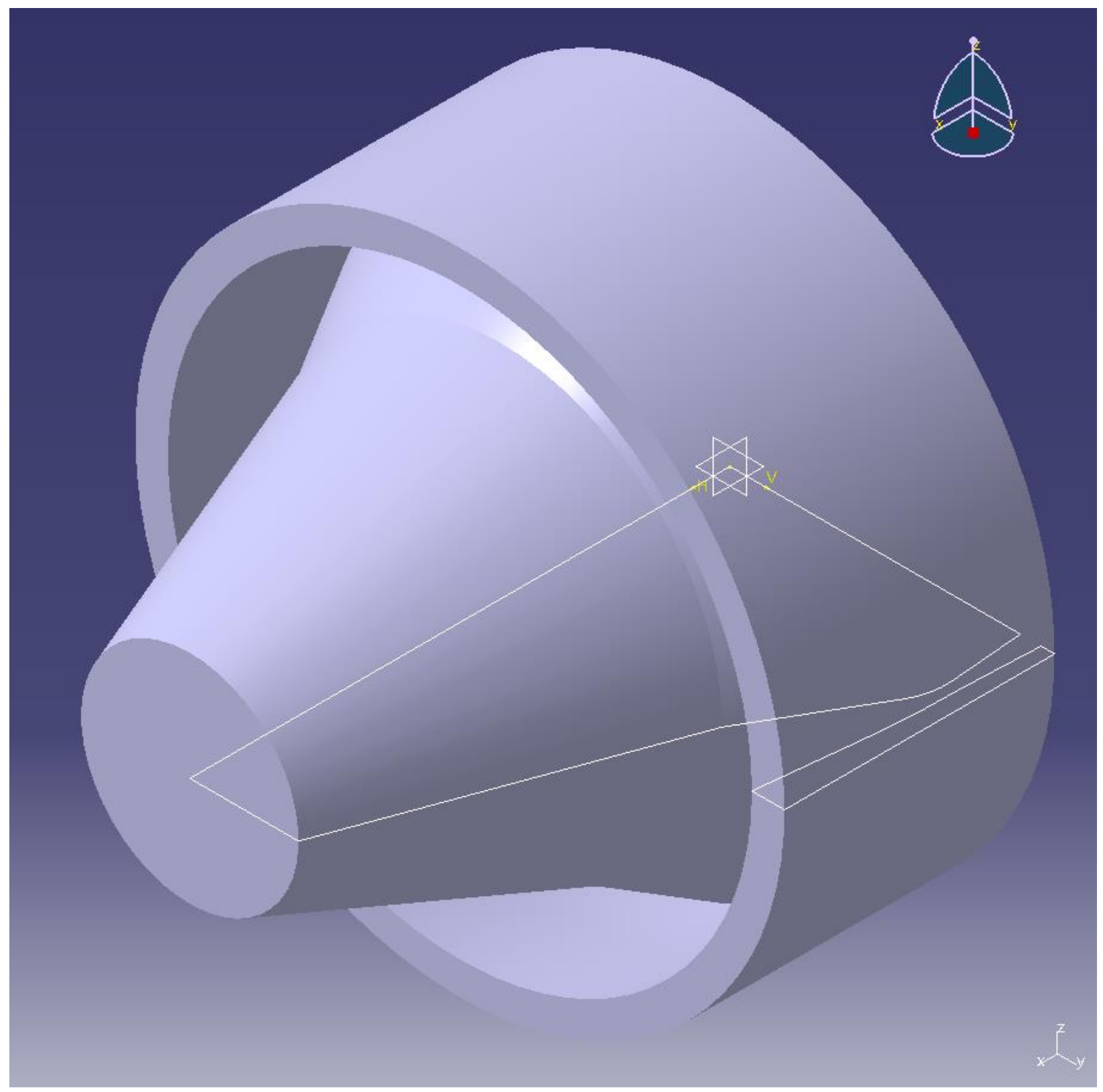

Figure 71: An isometric view of Aerospike 14 created in CATIA, by revolving the sketch from Figure 70 about its axis of symmetry. 
Aerospike 15 Sketch

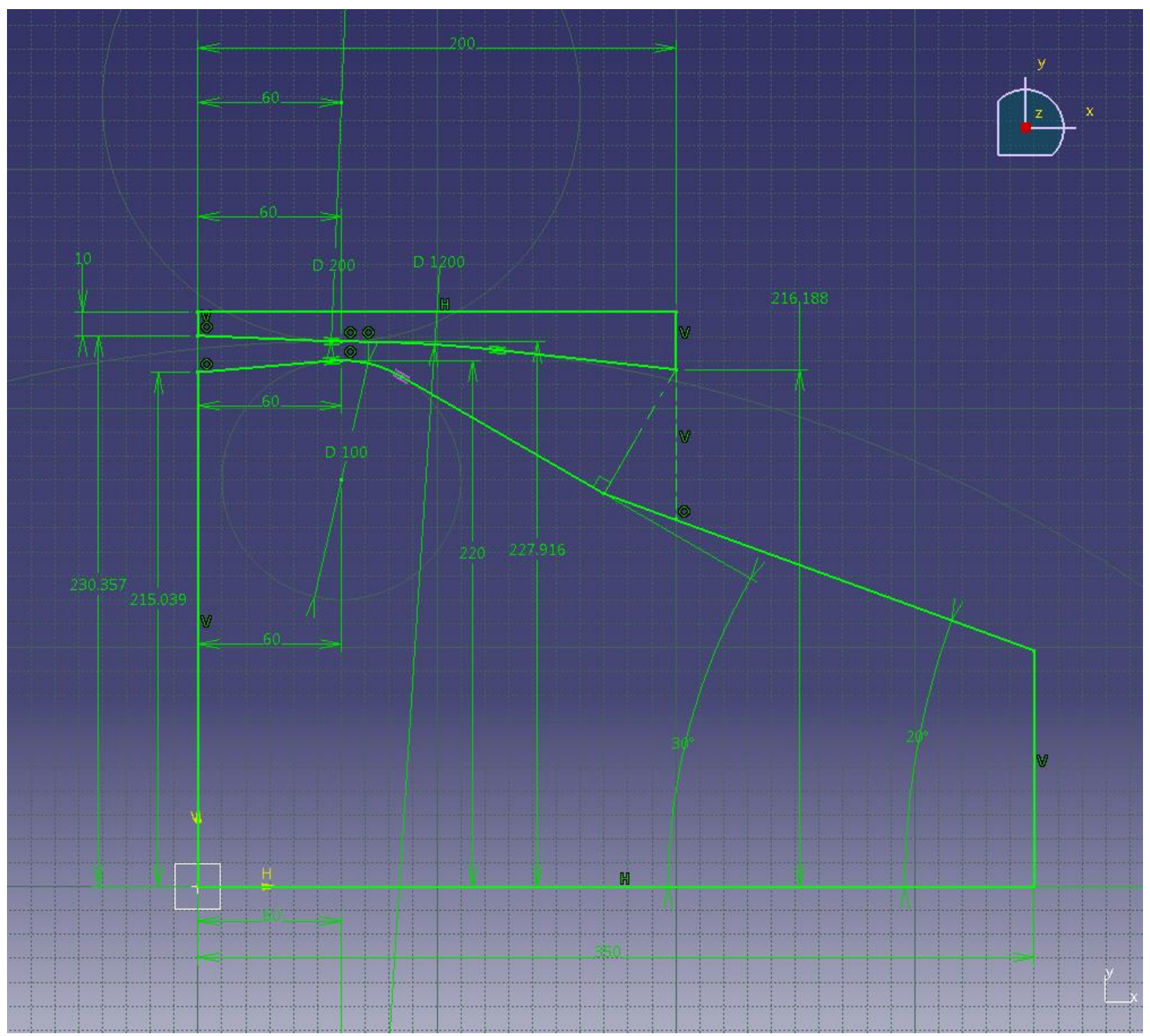

Figure 72: A CATIA sketch of Aerospike 15; all dimensions are in millimeters. 


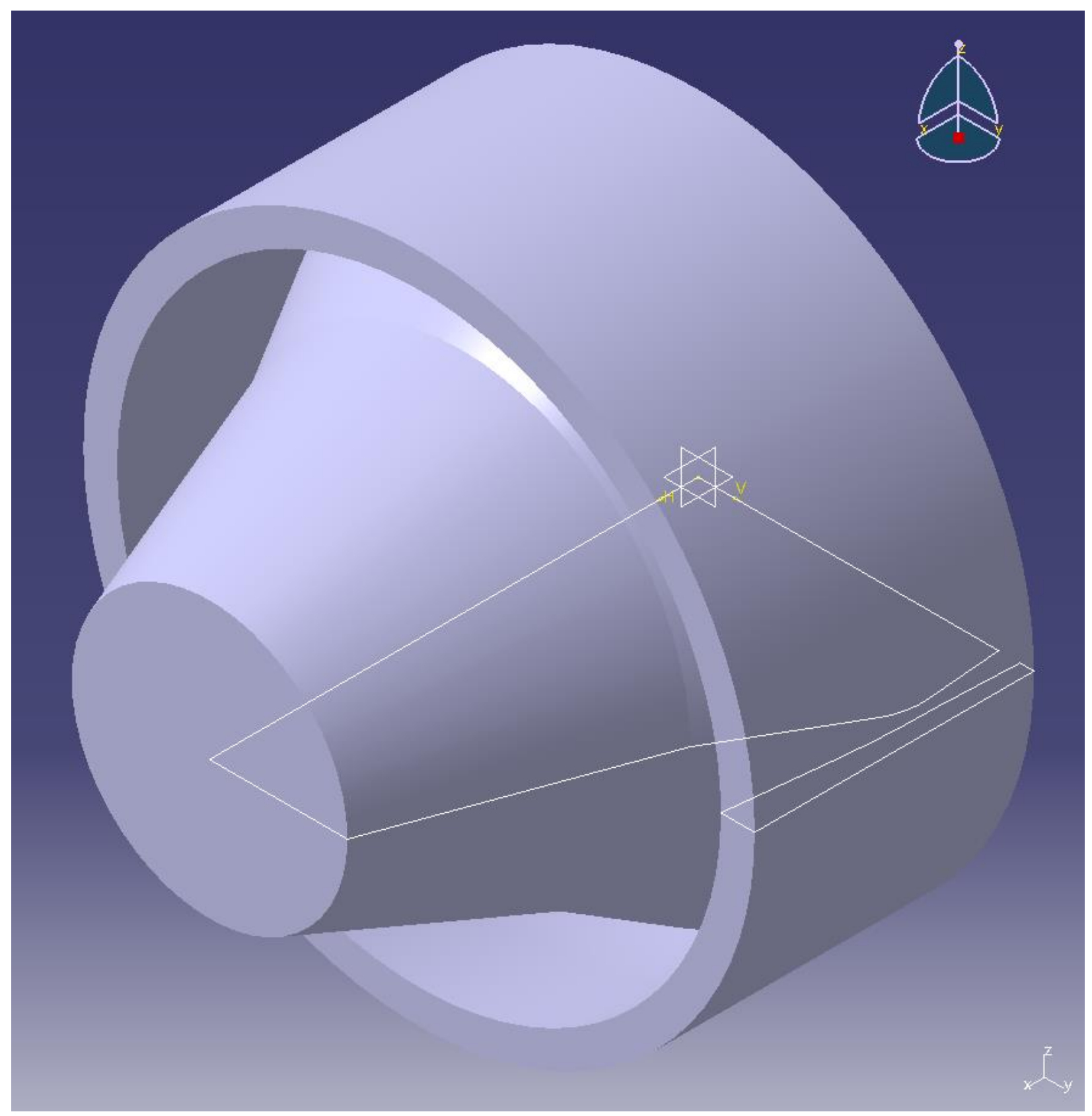

Figure 73: An isometric view of Aerospike 15 created in CATIA, by revolving the sketch from Figure 72 about its axis of symmetry. 
Aerospike 16 Sketch

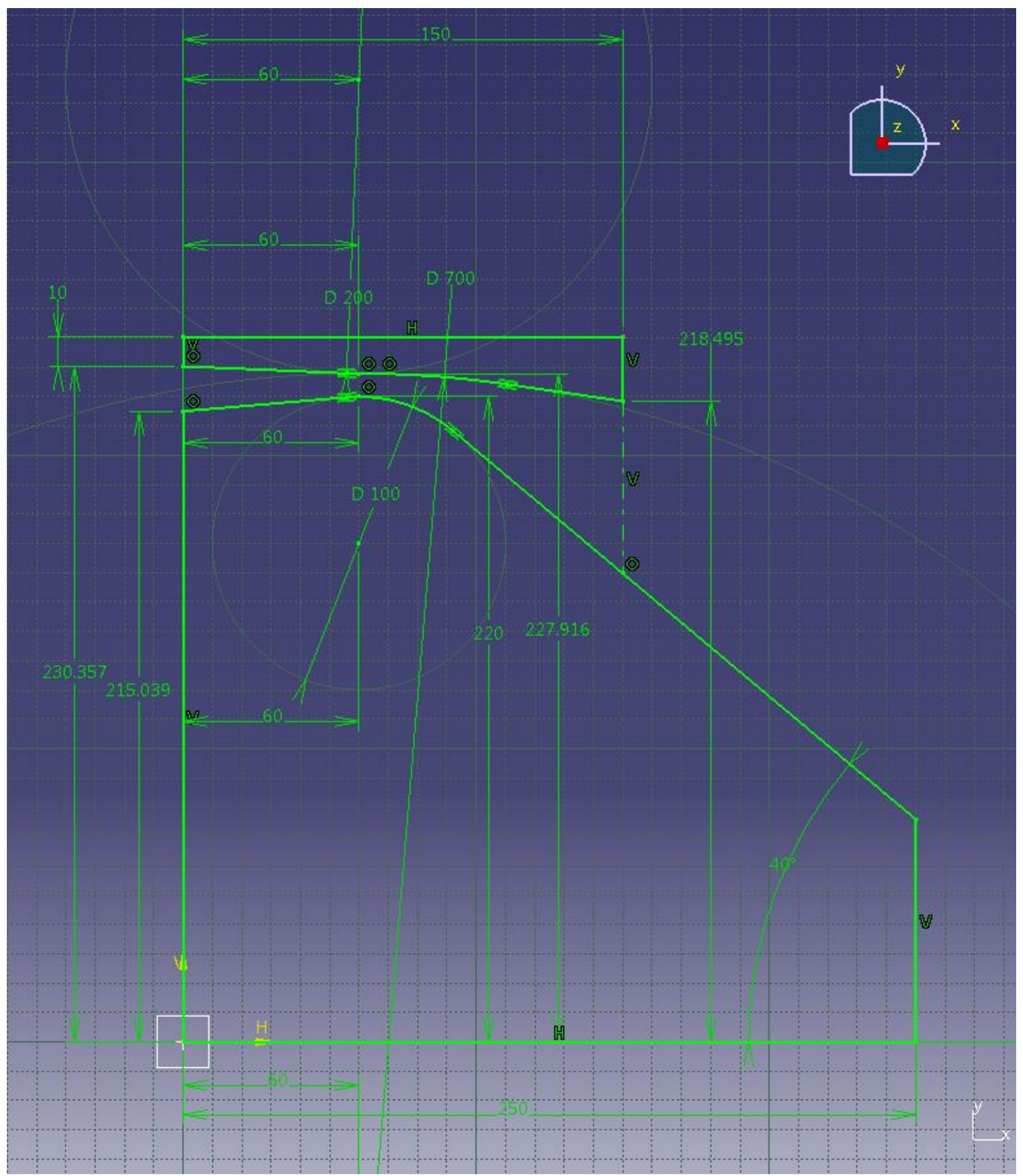

Figure 74: A CATIA sketch of Aerospike 16; all dimensions are in millimeters. 


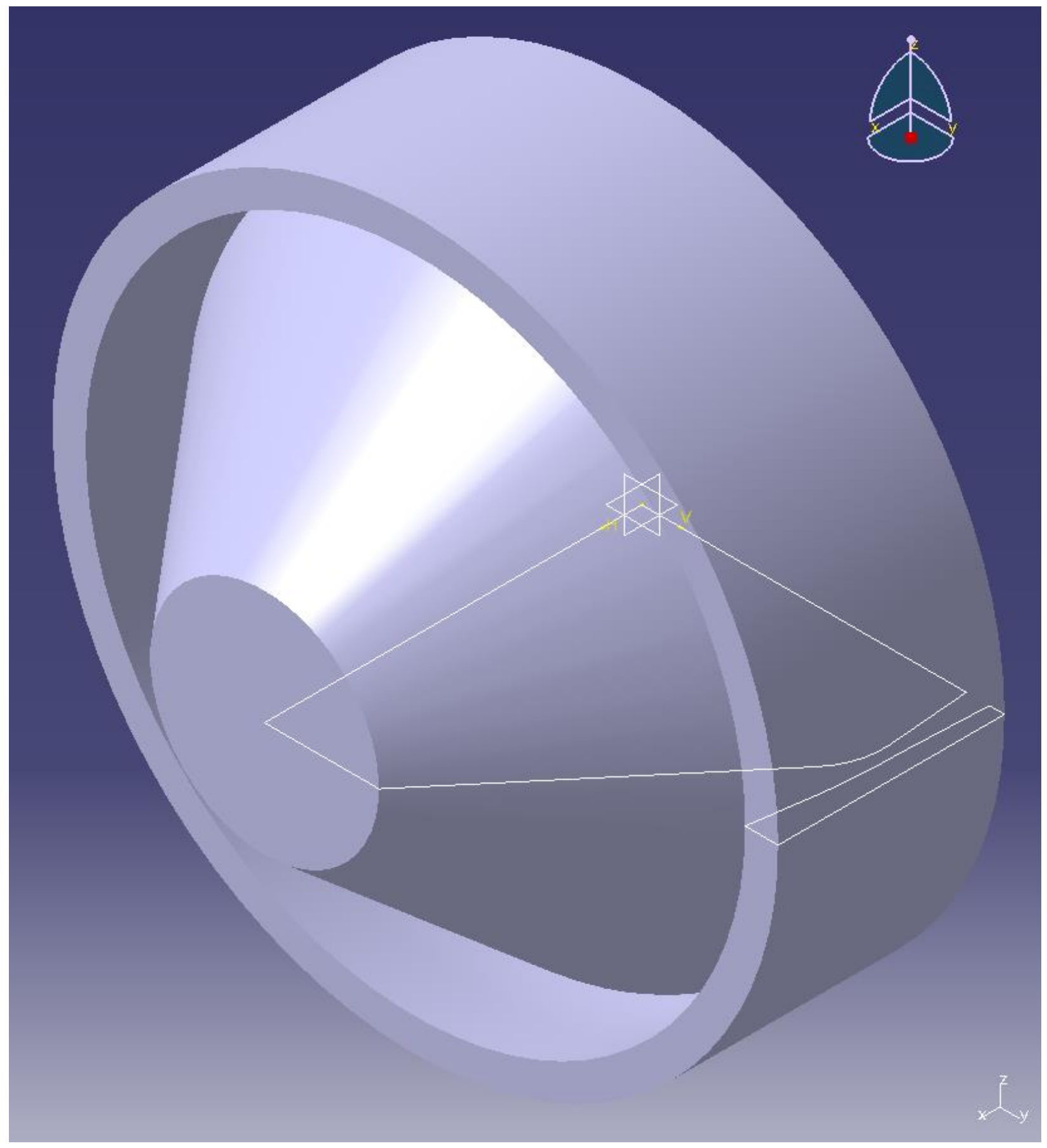

Figure 75: An isometric view of Aerospike 16 created in CATIA, by revolving the sketch from Figure 74 about its axis of symmetry. 
Aerospike 17 Sketch

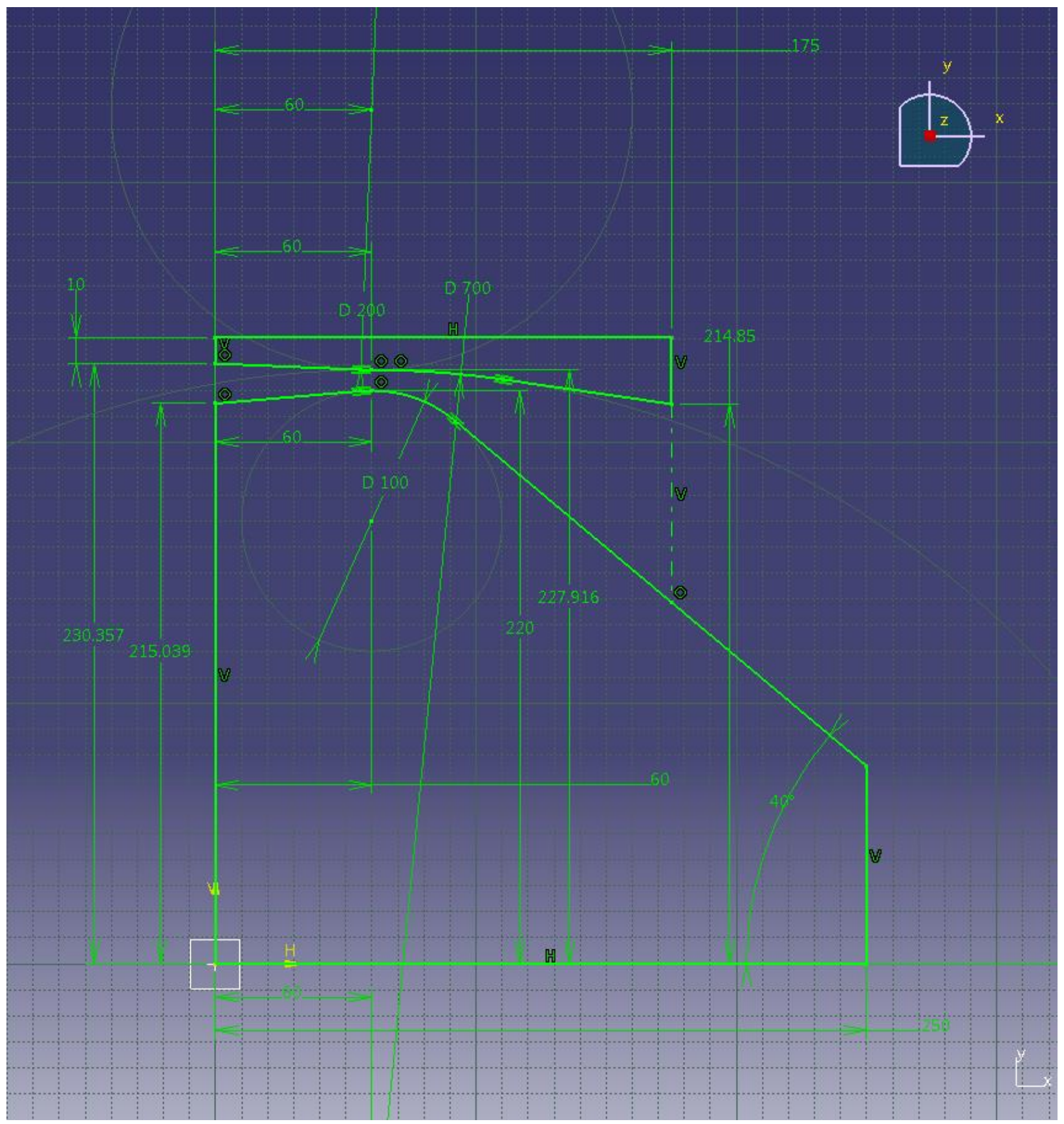

Figure 76: A CATIA sketch of Aerospike 17; all dimensions are in millimeters. 


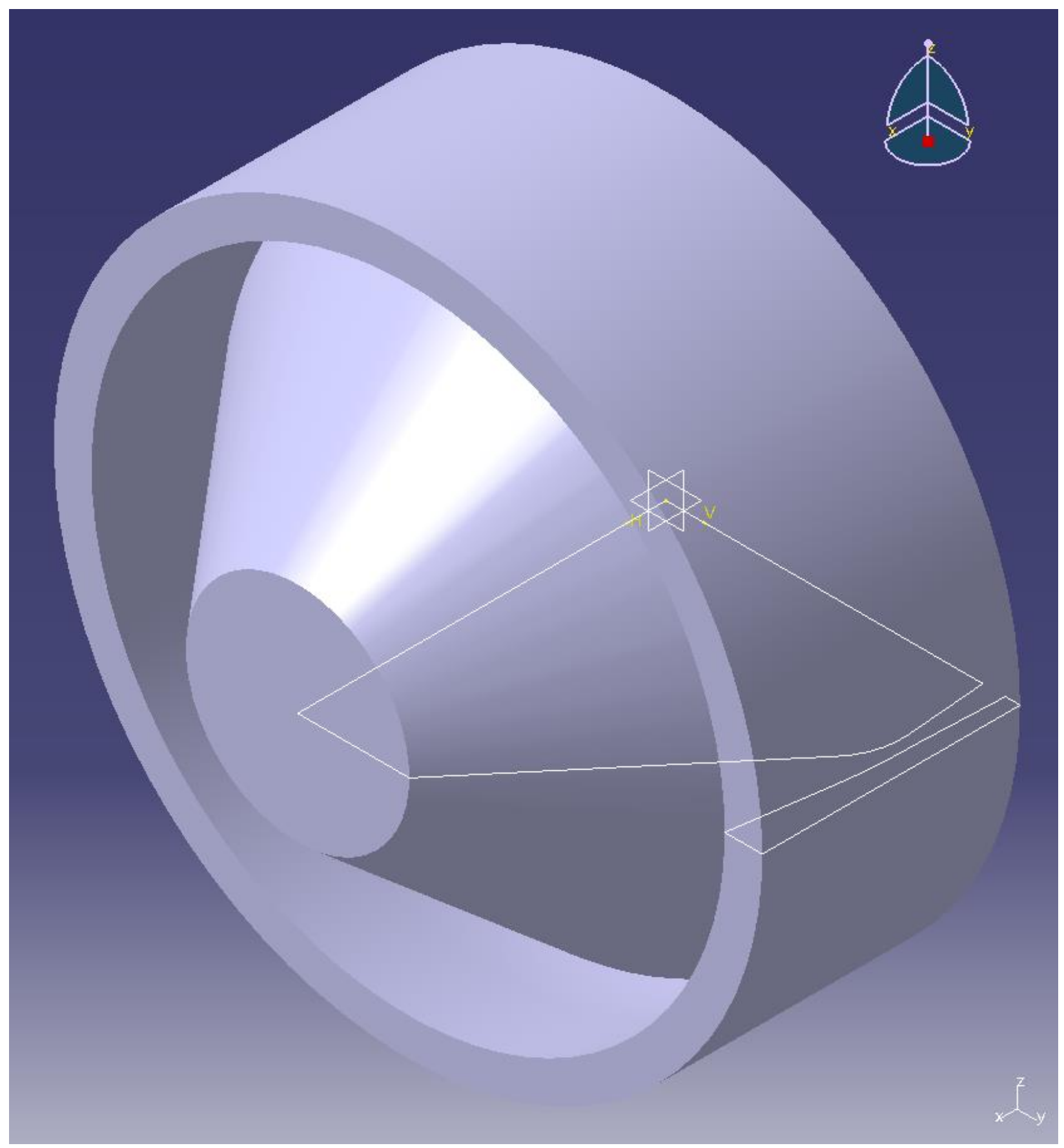

Figure 77: An isometric view of Aerospike 17 created in CATIA, by revolving the sketch from Figure 76 about its axis of symmetry. 
Aerospike 18 Sketch

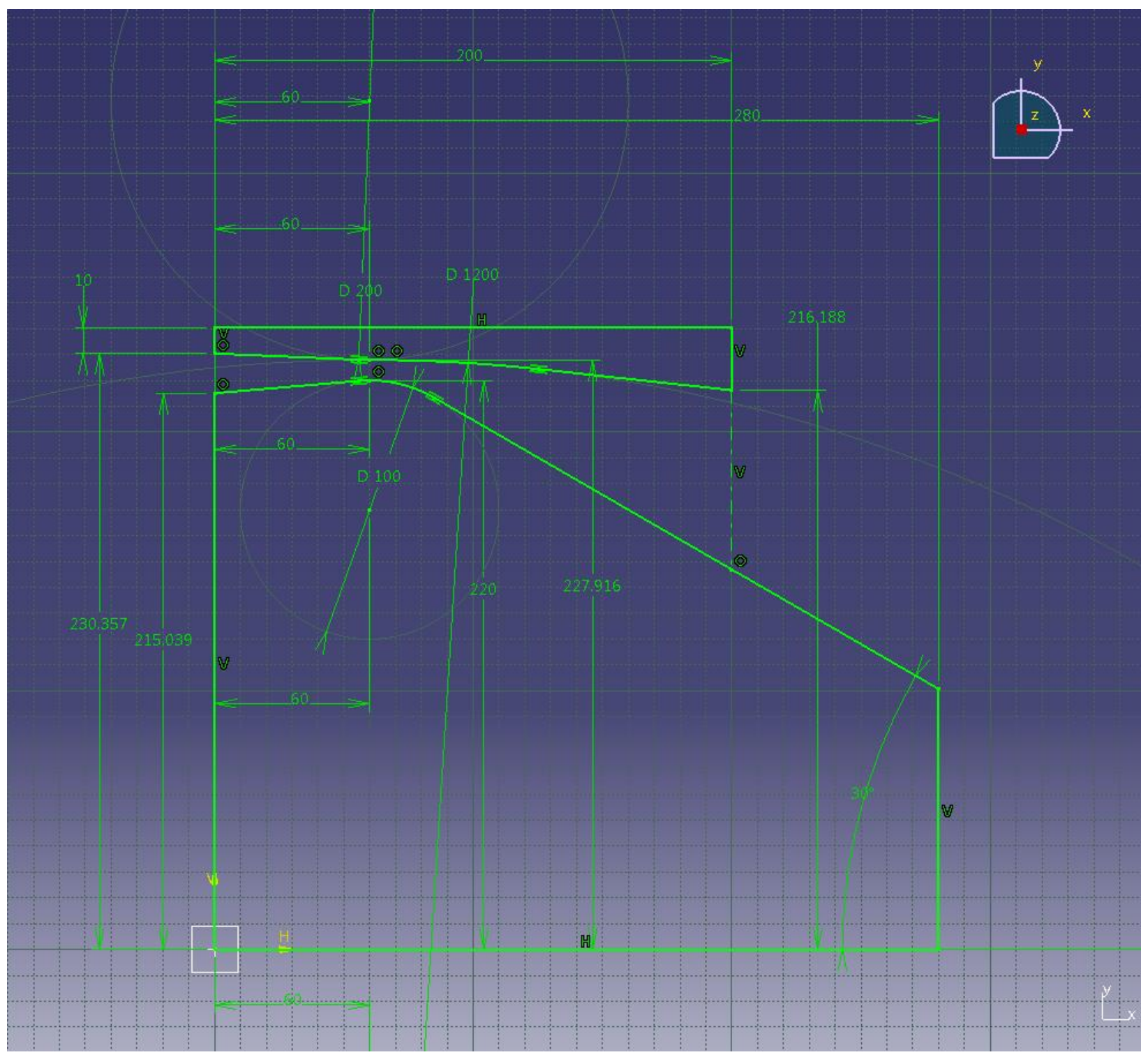

Figure 78: A CATIA sketch of Aerospike 18; all dimensions are in millimeters. 


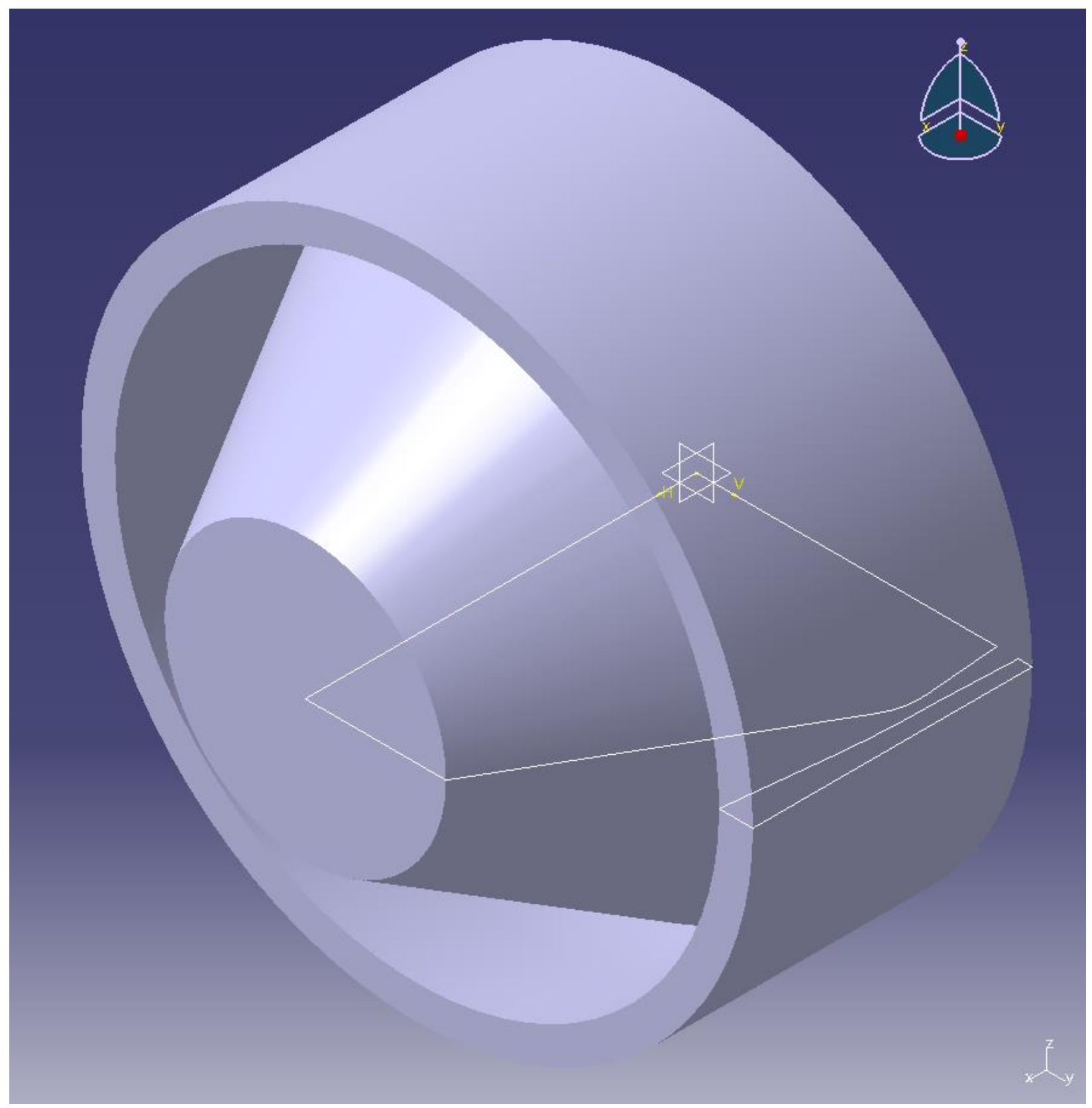

Figure 79: An isometric view of Aerospike 18 created in CATIA, by revolving the sketch from Figure 78 about its axis of symmetry. 


\section{CHAPTER 4}

Results for the CD Nozzle \& CB Models

Table 3: The original CD Nozzle and CD Nozzle \& CB models 1-8, with their corresponding predicted flow parameters and the results for the same parameters obtained using $C F D$.

\begin{tabular}{|l|l|l|l|l|}
\hline Case & Predicted $\boldsymbol{M}_{\boldsymbol{e}}$ & Predicted $\boldsymbol{P}_{\boldsymbol{e}}(\mathbf{P a})$ & $\begin{array}{l}\text { Averaged } \boldsymbol{M}_{\boldsymbol{e}} \\
\text { from CFD } \\
\text { Result }\end{array}$ & $\begin{array}{l}\text { Averaged } \boldsymbol{P}_{\boldsymbol{e}} \\
\text { (Pa) from CFD } \\
\text { Result }\end{array}$ \\
\hline CD Nozzle & 3.832 & 2847.5 & 3.547 & 3322.5 \\
\hline CD Nozzle \& CB 1 & 3.832 & 4342.7 & 3.601 & 5047.1 \\
\hline CD Nozzle \& CB 2 & 3.832 & 4342.7 & 3.556 & 5039.1 \\
\hline CD Nozzle \& CB 3 & 3.832 & 4342.7 & 3.546 & 5062.7 \\
\hline CD Nozzle \& CB 4 & 3.832 & 4342.7 & 3.545 & 5065.0 \\
\hline CD Nozzle \& CB 5 & 3.832 & 5713.5 & 3.468 & 6930.5 \\
\hline CD Nozzle \& CB 6 & 3.832 & 5713.5 & 3.474 & 6904.0 \\
\hline CD Nozzle \& CB 7 & 3.832 & 5713.5 & 3.460 & 6940.2 \\
\hline CD Nozzle \& CB 8 & 3.832 & 5713.5 & 3.457 & 6988.2 \\
\hline
\end{tabular}

Table 4: Summarized performance results for the original CD Nozzle and CD Nozzle \& CB models 1 - 8 at 20km standard atmosphere.

\begin{tabular}{|l|l|l|l|l|l|l|l|}
\hline Case & $\begin{array}{l}\text { Calculated } \\
\text { Mass Flow } \\
\text { Rate (kg/s) }\end{array}$ & $\begin{array}{l}\text { Thrust of CD } \\
\text { Section (N) }\end{array}$ & $\begin{array}{l}\text { Thrust of CB } \\
\text { Sloped } \\
\text { Section (N) }\end{array}$ & $\begin{array}{l}\text { Blunt End } \\
\text { Thrust (N) }\end{array}$ & $\begin{array}{l}\text { Total Thrust } \\
\text { of CB Section } \\
(\mathbf{N})\end{array}$ & $\begin{array}{l}\text { Total Thrust } \\
(\mathbf{N})\end{array}$ & $\boldsymbol{I}_{\boldsymbol{s} \boldsymbol{p}}(\mathbf{s})$ \\
\hline CD Nozzle & 9.659658701 & 10583.52356 & 0 & 0 & 0 & 10583.52356 & 111.6861941 \\
\hline $\begin{array}{l}\text { CD Nozzle } \\
\text { \& CB 1 }\end{array}$ & 9.651431671 & 10893.72208 & -298.8163534 & -58.80818079 & -357.6245342 & 10536.09755 & 111.2804915 \\
\hline $\begin{array}{l}\text { CD Nozzle } \\
\text { \& CB 2 }\end{array}$ & 9.663397476 & 10911.00548 & -300.2814802 & -59.21898063 & -359.5004608 & 10551.50501 & 111.3052268 \\
\hline $\begin{array}{l}\text { CD Nozzle } \\
\text { \& CB 3 }\end{array}$ & 9.660402259 & 10901.92148 & -292.7361748 & -58.32875524 & -351.06493 & 10550.85655 & 111.3328945 \\
\hline $\begin{array}{l}\text { CD Nozzle } \\
\text { \& CB 4 }\end{array}$ & 9.663476595 & 10893.95743 & 0 & -341.857944 & -341.857944 & 10552.09948 & 111.3105863 \\
\hline $\begin{array}{l}\text { CD Nozzle } \\
\text { \& CB 5 }\end{array}$ & 9.670337929 & 10968.74547 & -459.3712504 & -57.1078583 & -516.4791087 & 10452.26637 & 110.1792497 \\
\hline $\begin{array}{l}\text { CD Nozzle } \\
\text { \& CB 6 }\end{array}$ & 9.699331796 & 11007.75325 & -461.4776435 & -57.86702274 & -519.3446663 & 10488.40859 & 110.2297377 \\
\hline $\begin{array}{l}\text { CD Nozzle } \\
\text { \& CB 7 }\end{array}$ & 9.659290645 & 10942.34003 & -448.4383036 & -57.79833937 & -506.236643 & 10436.10339 & 110.1346894 \\
\hline $\begin{array}{l}\text { CD Nozzle } \\
\text { \& CB 8 }\end{array}$ & 9.683247971 & 10967.59877 & 0 & -474.6988801 & -474.6988801 & 10492.89989 & 110.4601092 \\
\hline
\end{tabular}

For all models of the CD Nozzle and CB, none out-performed the original CD Nozzle case in terms of $I_{s p}$, with every model producing a slightly lower $I_{s p}$ than the original CD Nozzle. All models operated under approximately the same mass flow rate, as listed in Table 4. The predicted mass flow rate, calculated based on the 1D isentropic flow equations is $9.69 \mathrm{~kg} / \mathrm{s}$, 
while calculated mass flow rates for each case, varied approximately between $9.65 \mathrm{~kg} / \mathrm{s}$ to 9.70 $\mathrm{kg} / \mathrm{s}$. Increasing the size of the Center Body radially for models 5 to 8 , resulted in a reduction of $I_{s p}$ by approximately $1.0 \mathrm{~s}$, in comparison to models 1 to 4 . In all cases of the CD Nozzle \& CB, the exterior section of the Center Body acts as a suction side to the flow and thus produces a negative thrust, since the exiting flow is directed away from the CB exposed surface area. This implies that the Center Body is acting to pull back on the rocket instead of pushing in the direction of thrust. In all design iterations of the $\mathrm{CD}$ Nozzle \& $\mathrm{CB}$, the exit static pressure is larger than that of the original CD Nozzle case, since all CD Nozzle \& CB models operate at higher inlet total pressures. A larger exit static pressure, reduces the possibility of nozzle flow separation, or if flow separation still occurs, the altitude range within the atmosphere in which flow separation occurs, is reduced. In real-life, a CD Nozzle with a CB imposed along its centerline, implies a heavier nozzle structural mass. The $\mathrm{CB}$ will require its own structural cooling and will add to the overall axial length of the nozzle. Based on the results presented in Table 4, it is more feasible to stick with the original CD Nozzle design rather than a CD Nozzle \& CB design.

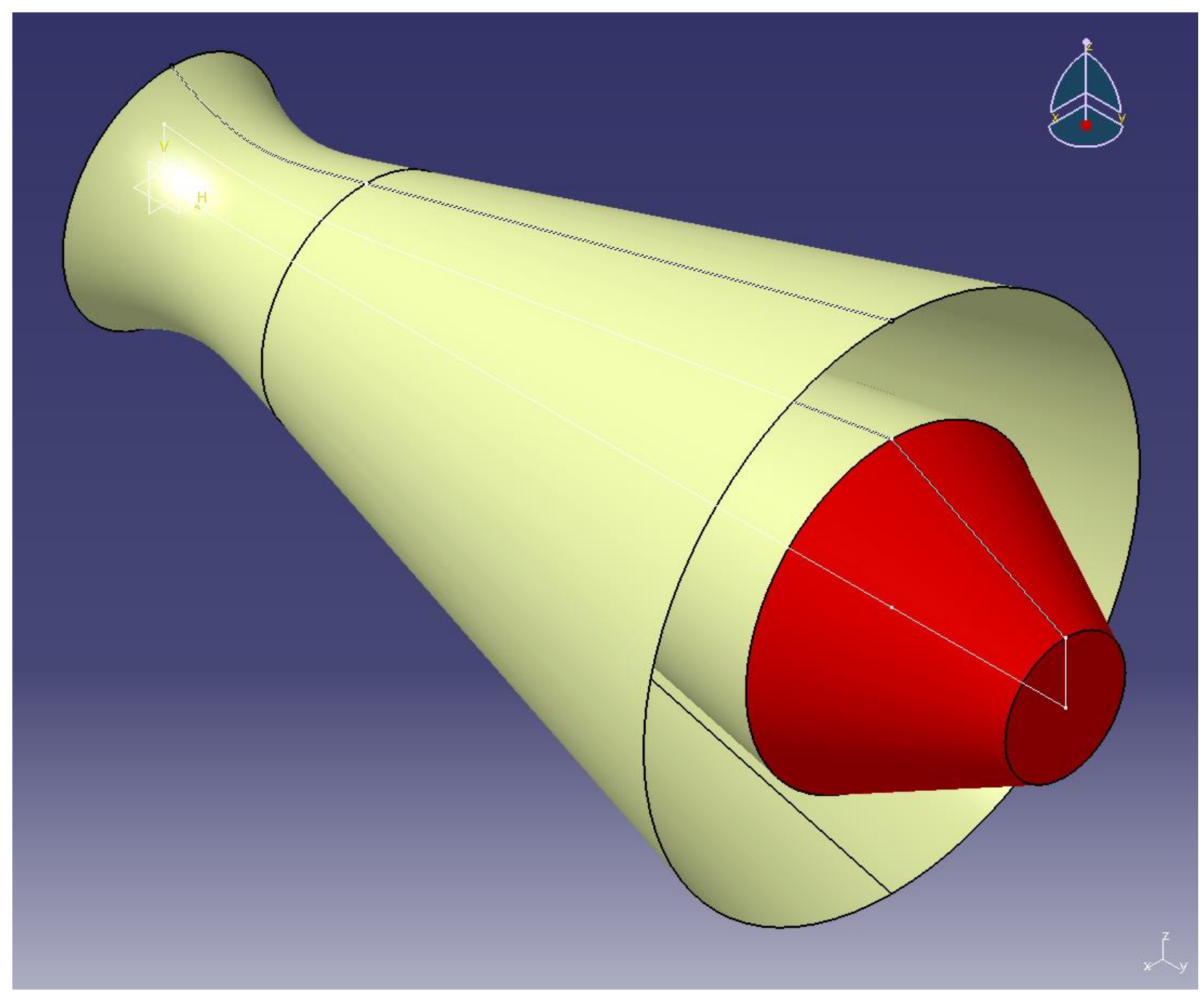

Figure 80: $C D$ Nozzle \& CB 1 with CB exposed surface area shown in red. 


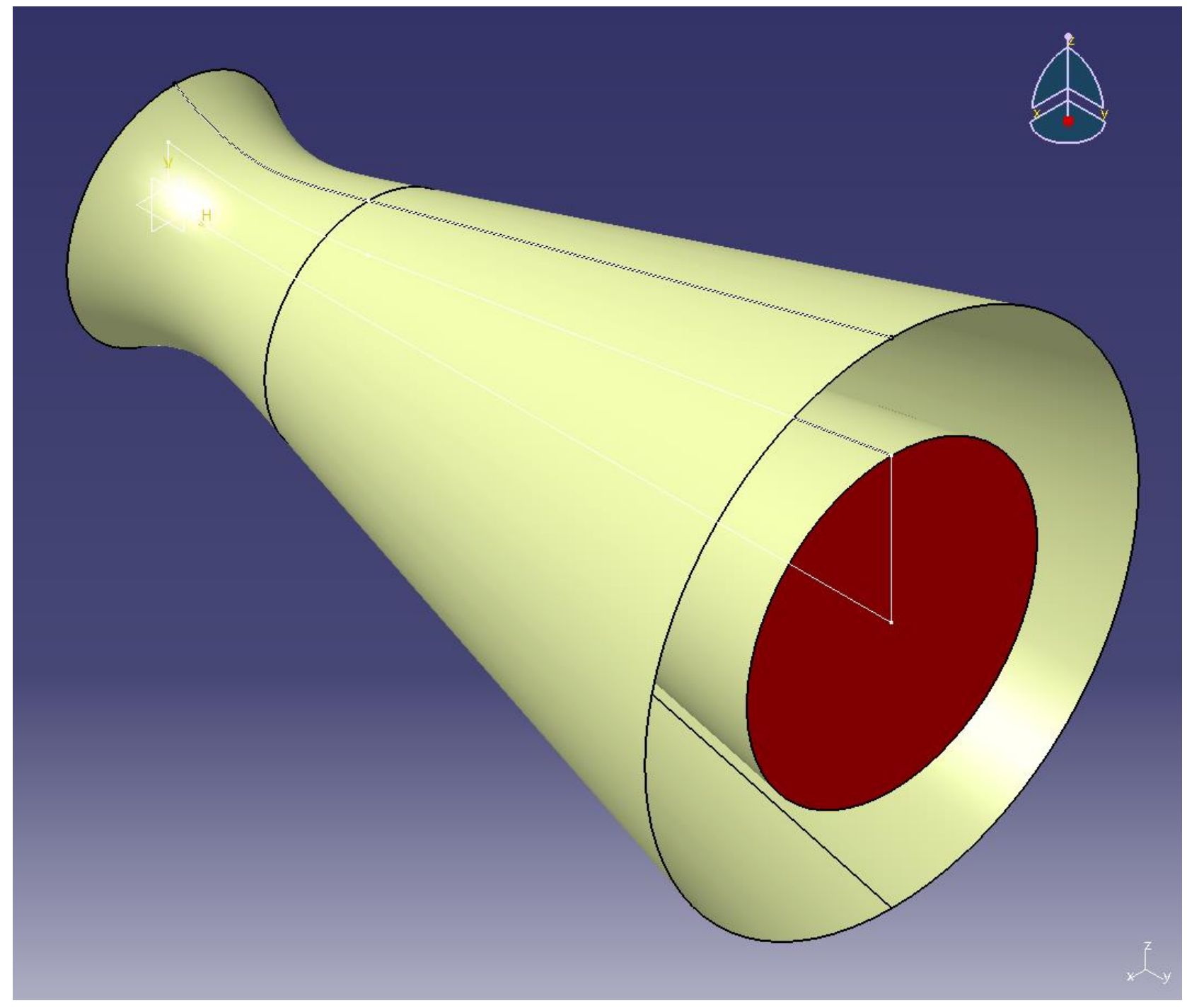

Figure 81: $C D$ Nozzle \& $C B 4$ with CB exposed surface area equal to base area, shown in red. 


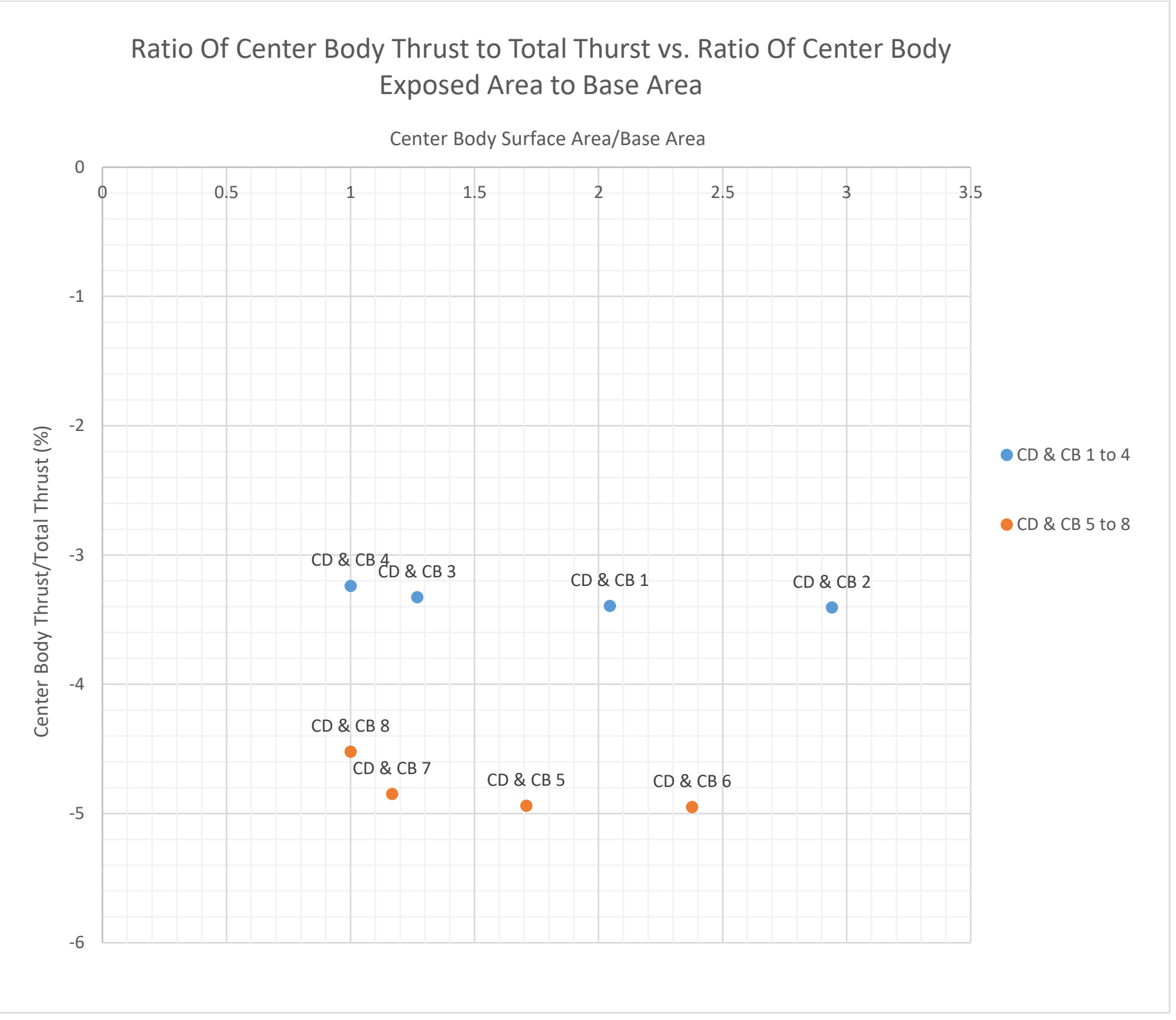

Figure 82: A plot of the ratio of center body thrust to total thrust versus the ratio of center body surface area to base area.

Center body exposed area and base area are highlighted in red in Figures 80 and 81. In Figure 82, the plot of the ratio of $\mathrm{CB}$ thrust to total thrust versus ratio of $\mathrm{CB}$ exposed surface area to base area, shows that the least detrimental thrust by the $\mathrm{CB}$ occurs when the ratio of exposed surface area to base area is one. The exposed surface area of the $\mathrm{CB}$ produces the least detrimental thrust, when the exposed surface area is just a blunt end. The trend is more clearly shown by CD Nozzle \& CB models 5 to 8 . A ratio of exposed surface area to base area equal to one, implies a lower nozzle length and reduced structural mass. 
CD Nozzle \& CB 1 Flow Contours

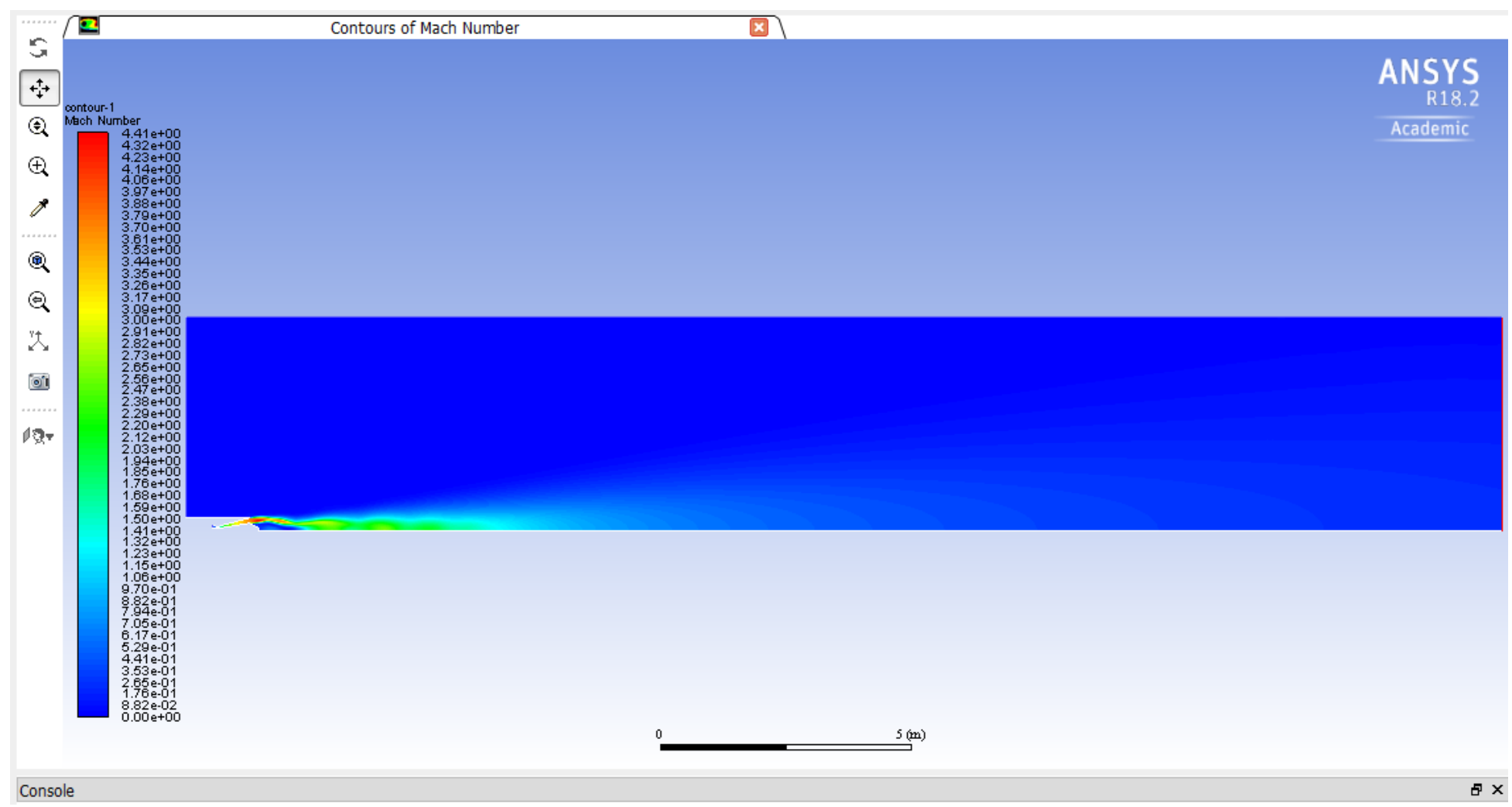

Figure 83: Contour of Mach number for CD Nozzle \& CB 1, with nozzle flow expansion into ambient air at 20km standard atmosphere. 


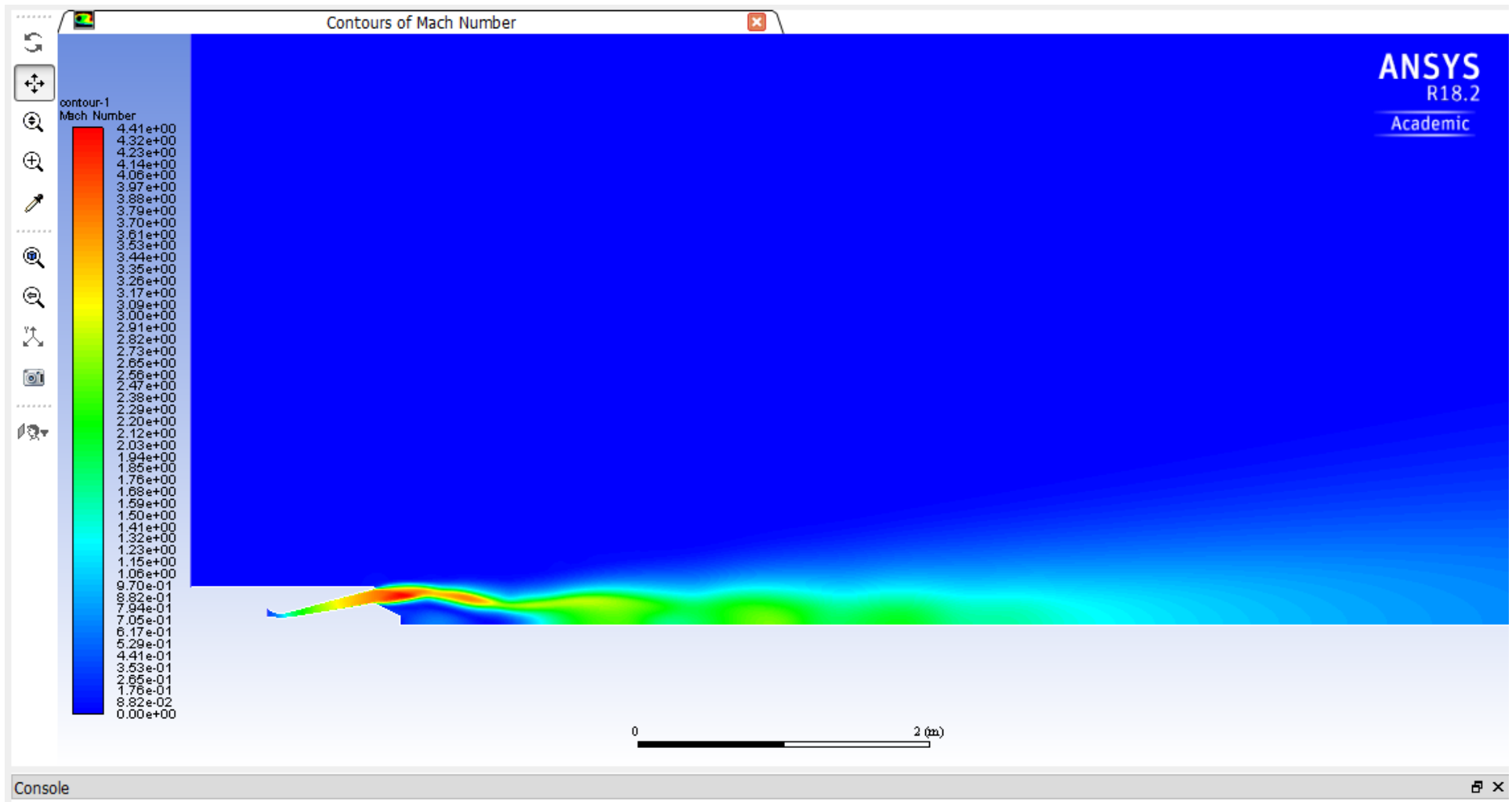

Figure 84: Contour of Mach number for CD Nozzle \& CB 1, with nozzle flow expansion into ambient air at $20 \mathrm{~km}$ standard atmosphere. 
CD Nozzle \& CB 2 Flow Contours

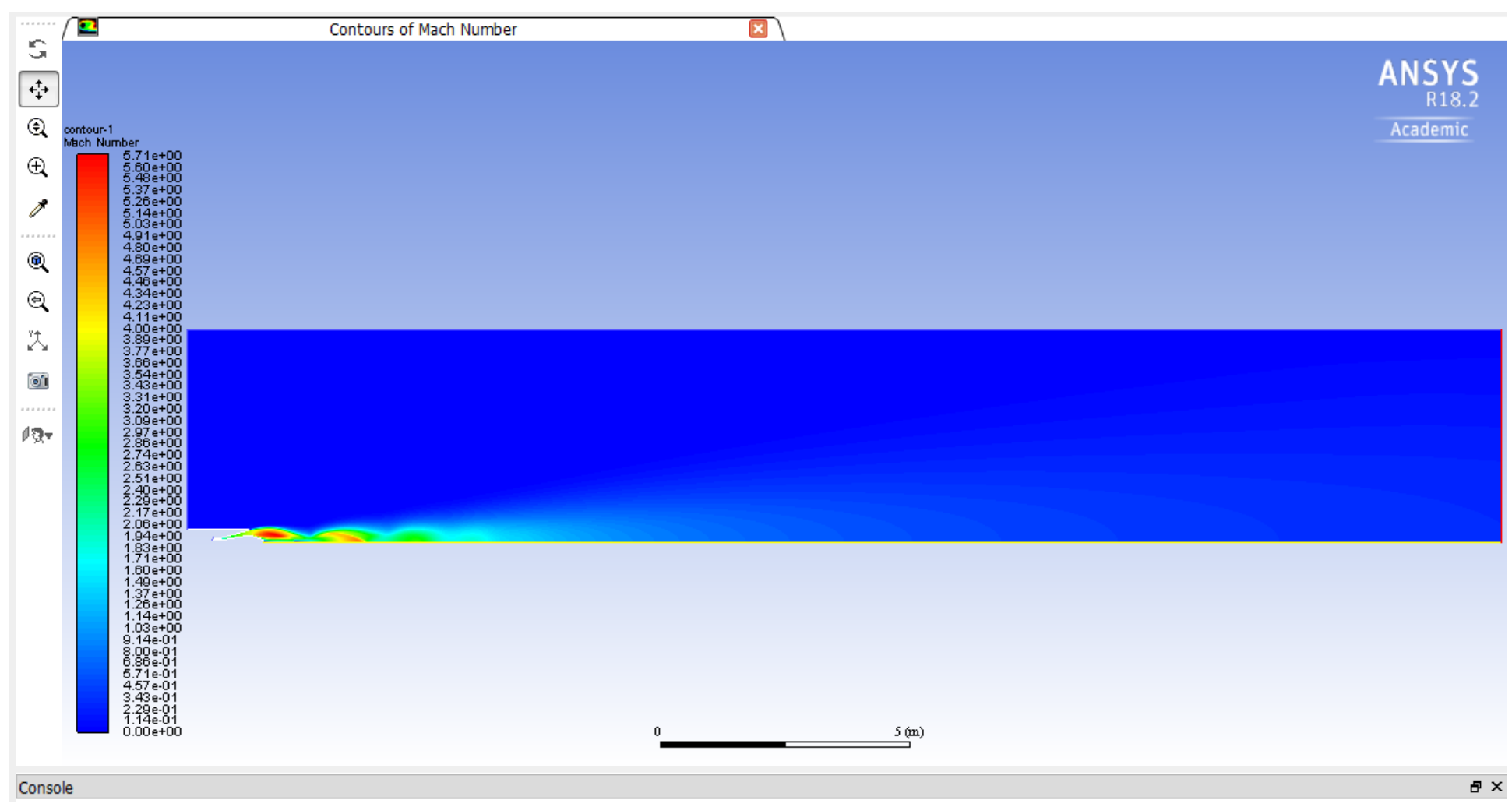

Figure 85: Contour of Mach number for CD Nozzle \& CB 2, with nozzle flow expansion into ambient air at 20km standard atmosphere. 


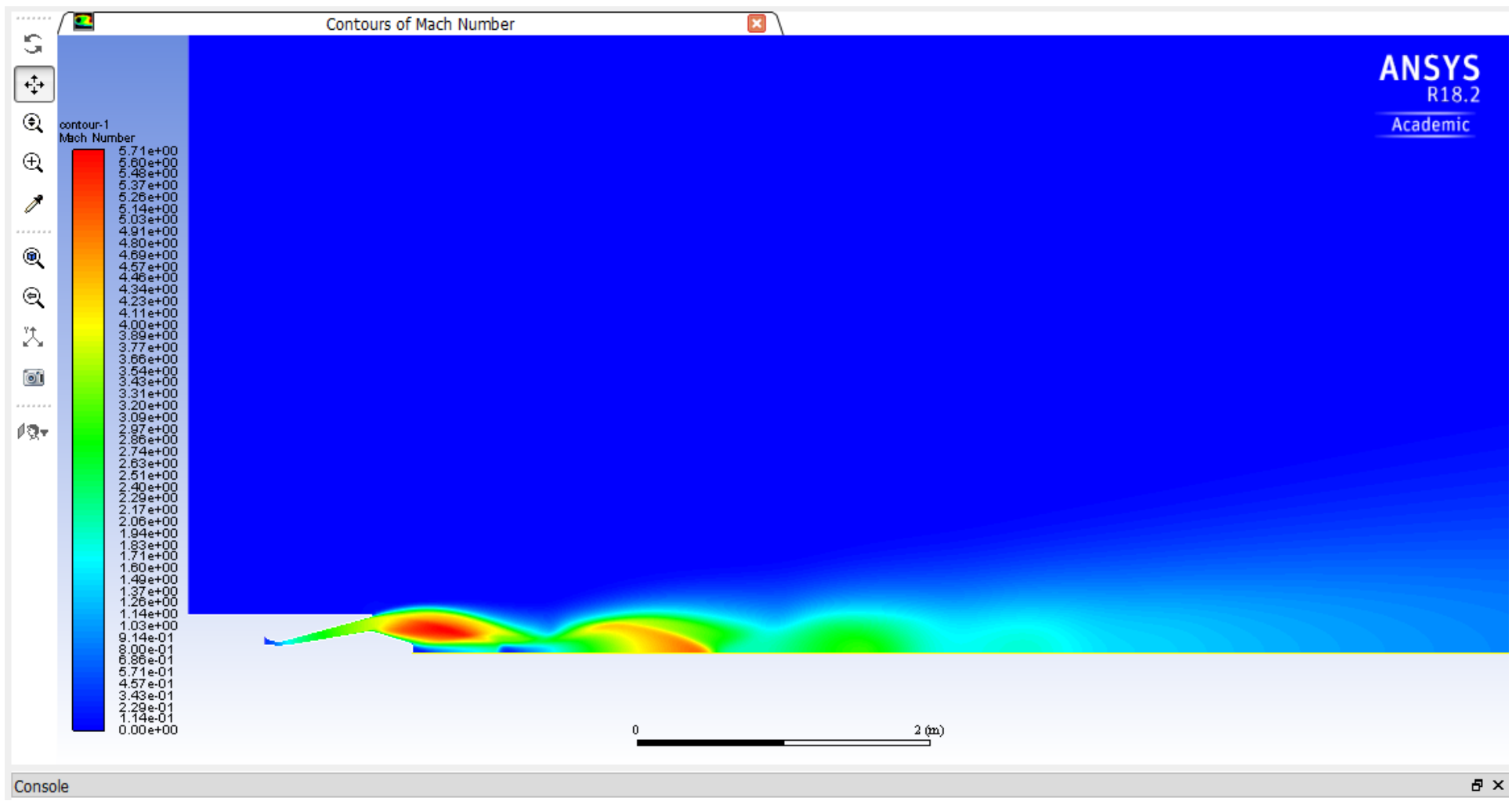

Figure 86: Contour of Mach number for CD Nozzle \& CB 2, with nozzle flow expansion into ambient air at 20km standard atmosphere. 
CD Nozzle \& CB 3 Flow Contours

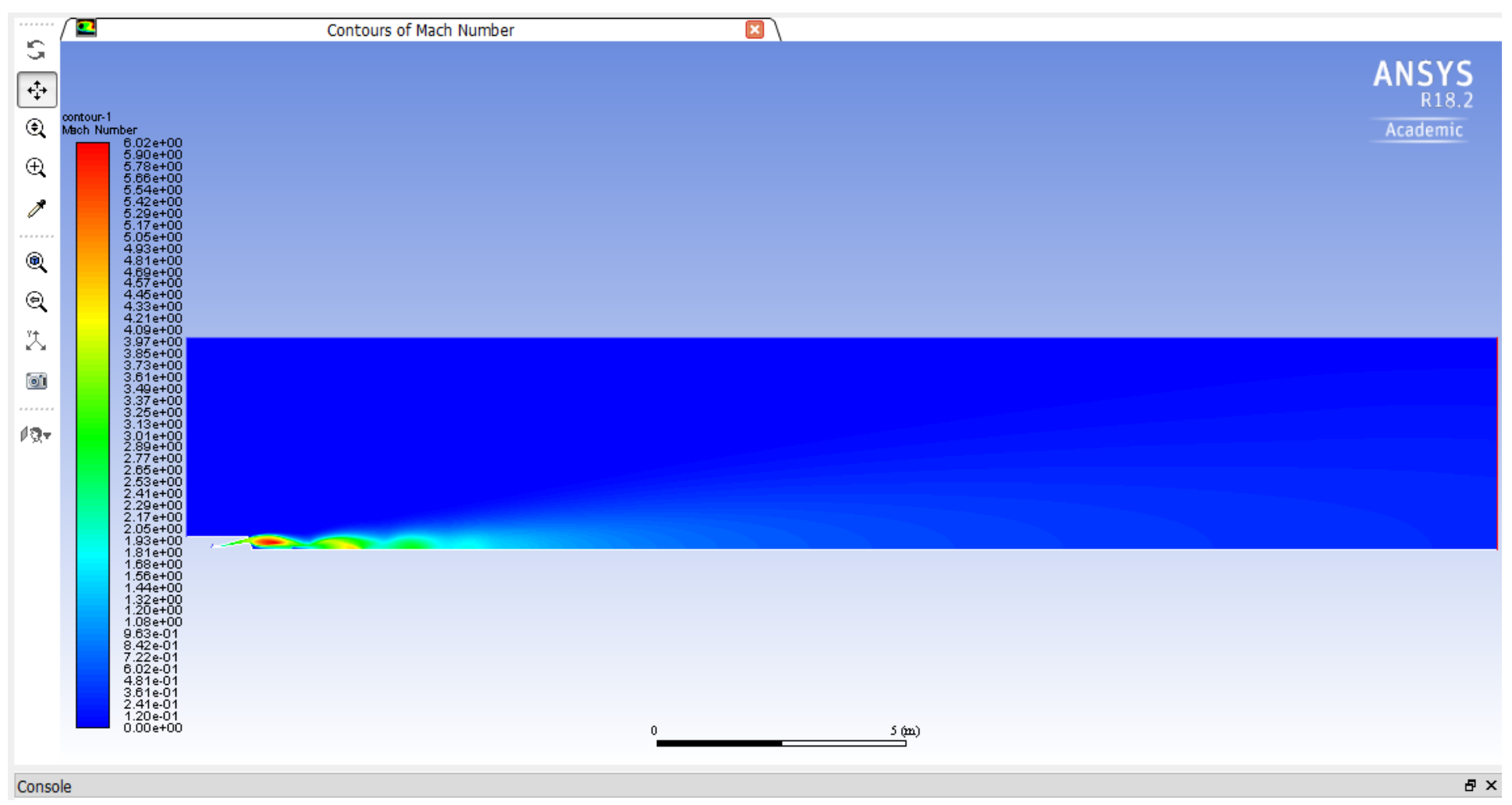

Figure 87: Contour of Mach number for CD Nozzle \& CB 3, with nozzle flow expansion into ambient air at 20km standard atmosphere. 


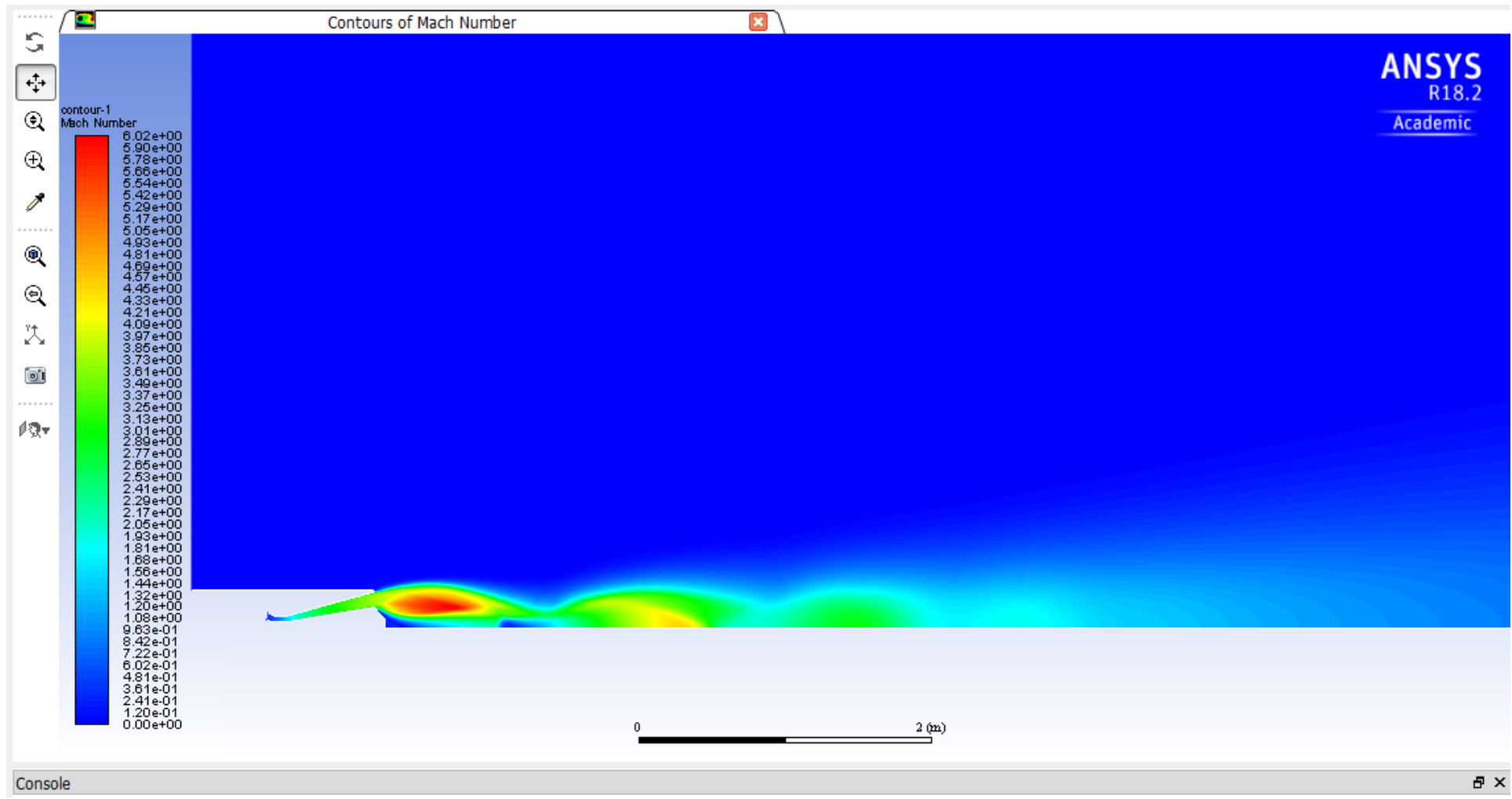

Figure 88: Contour of Mach number for CD Nozzle \& CB 3, with nozzle flow expansion into ambient air at 20km standard atmosphere. 
CD Nozzle \& CB 4 Flow Contours

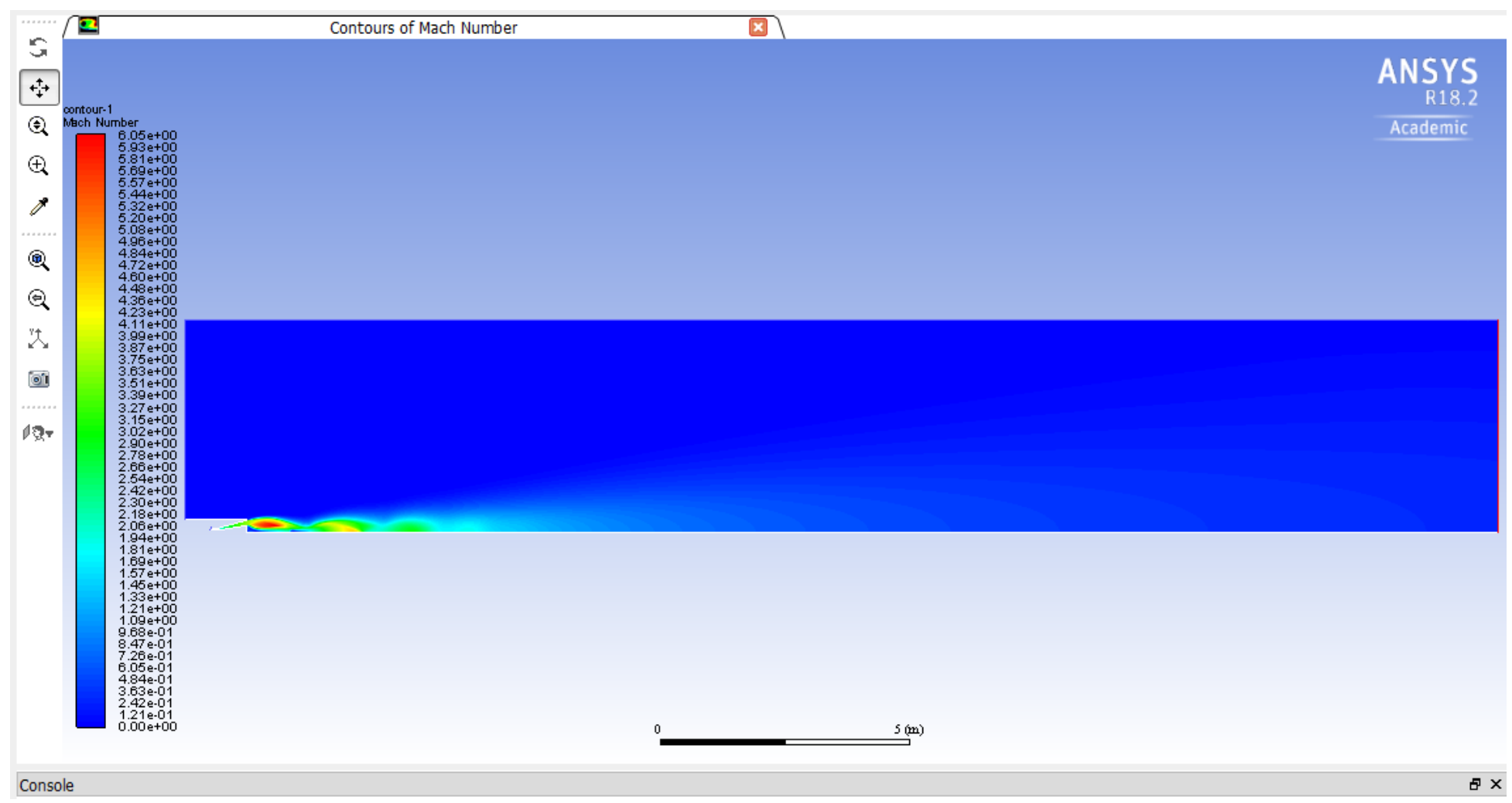

Figure 89: Contour of Mach number for CD Nozzle \& CB 4, with nozzle flow expansion into ambient air at $20 \mathrm{~km}$ standard atmosphere. 


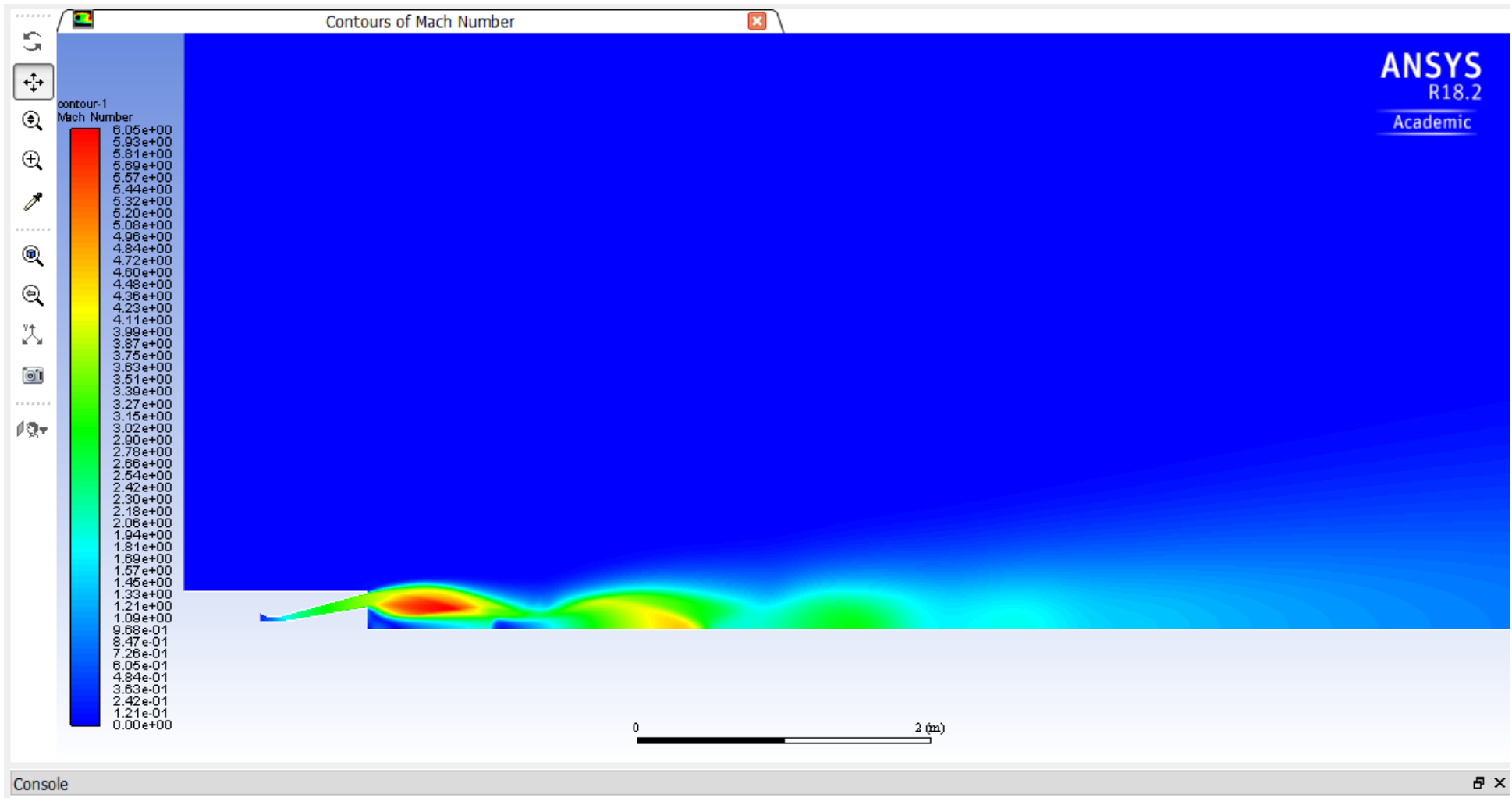

Figure 90: Contour of Mach number for CD Nozzle \& CB 4, with nozzle flow expansion into ambient air at $20 \mathrm{~km}$ standard atmosphere. 
CD Nozzle \& CB 5 Flow Contours

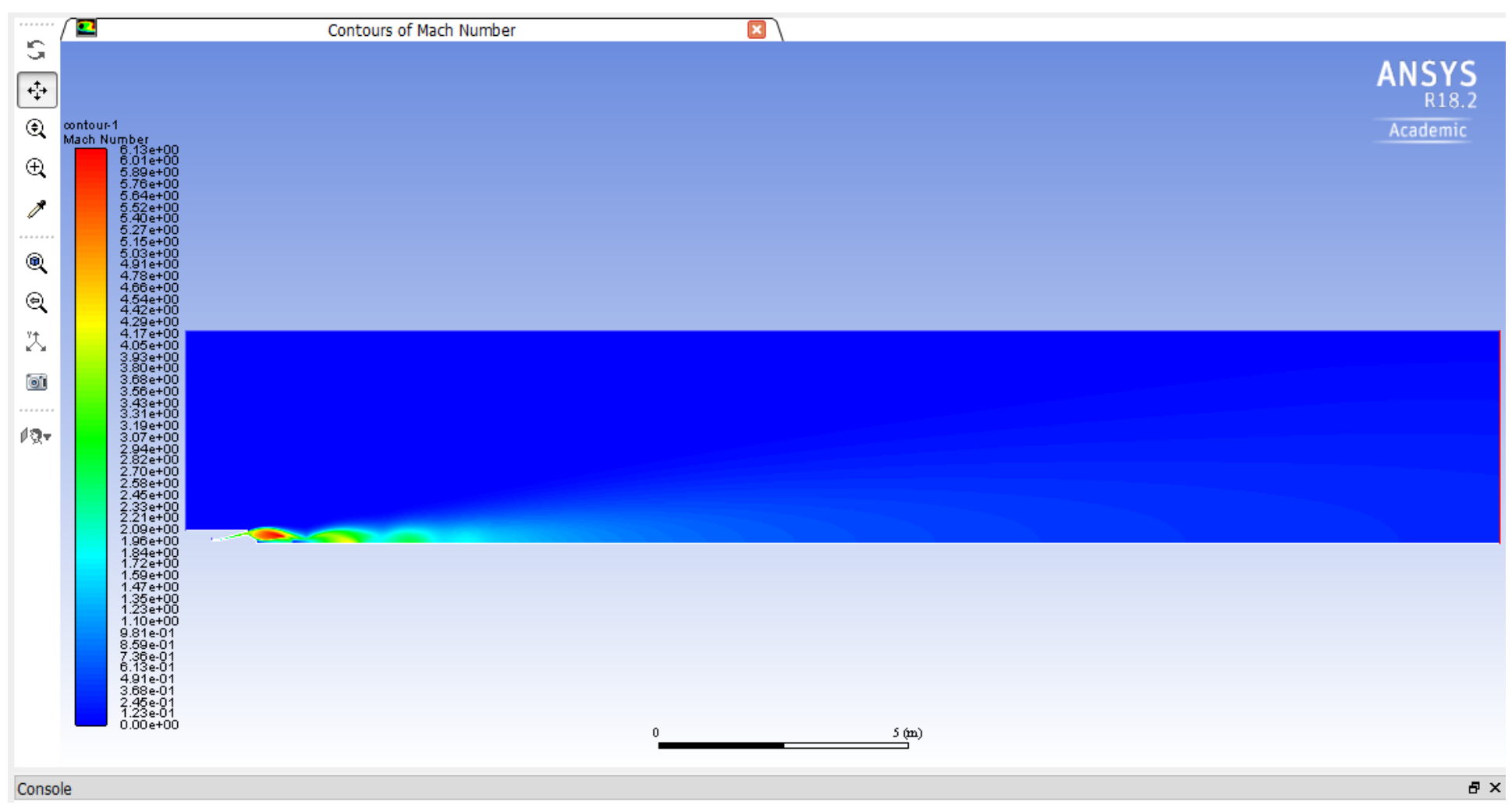

Figure 91: Contour of Mach number for CD Nozzle \& CB 5, with nozzle flow expansion into ambient air at 20km standard atmosphere. 


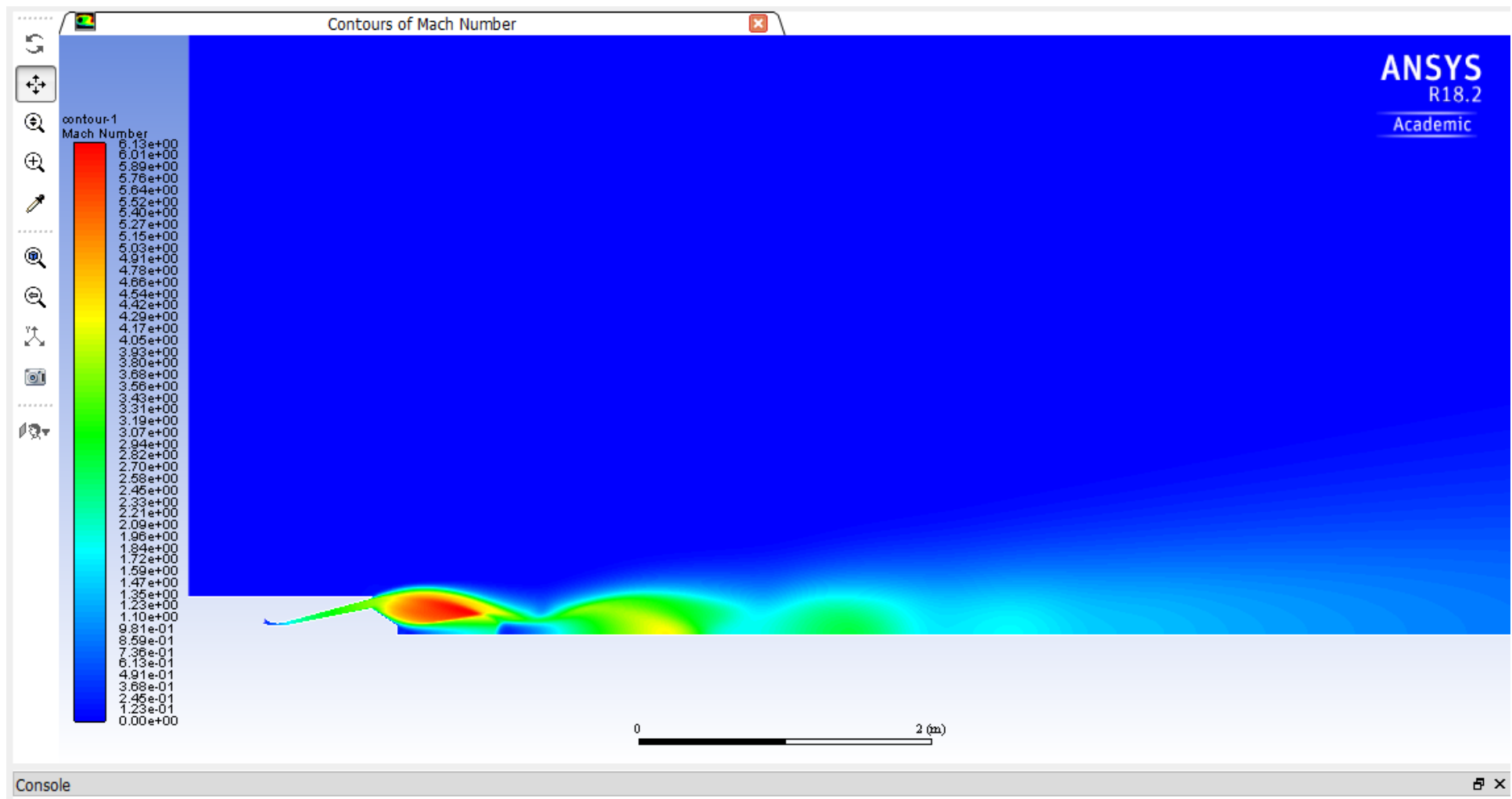

Figure 92: Contour of Mach number for CD Nozzle \& CB 5, with nozzle flow expansion into ambient air at 20km standard atmosphere. 
CD Nozzle \& CB 6 Flow Contours

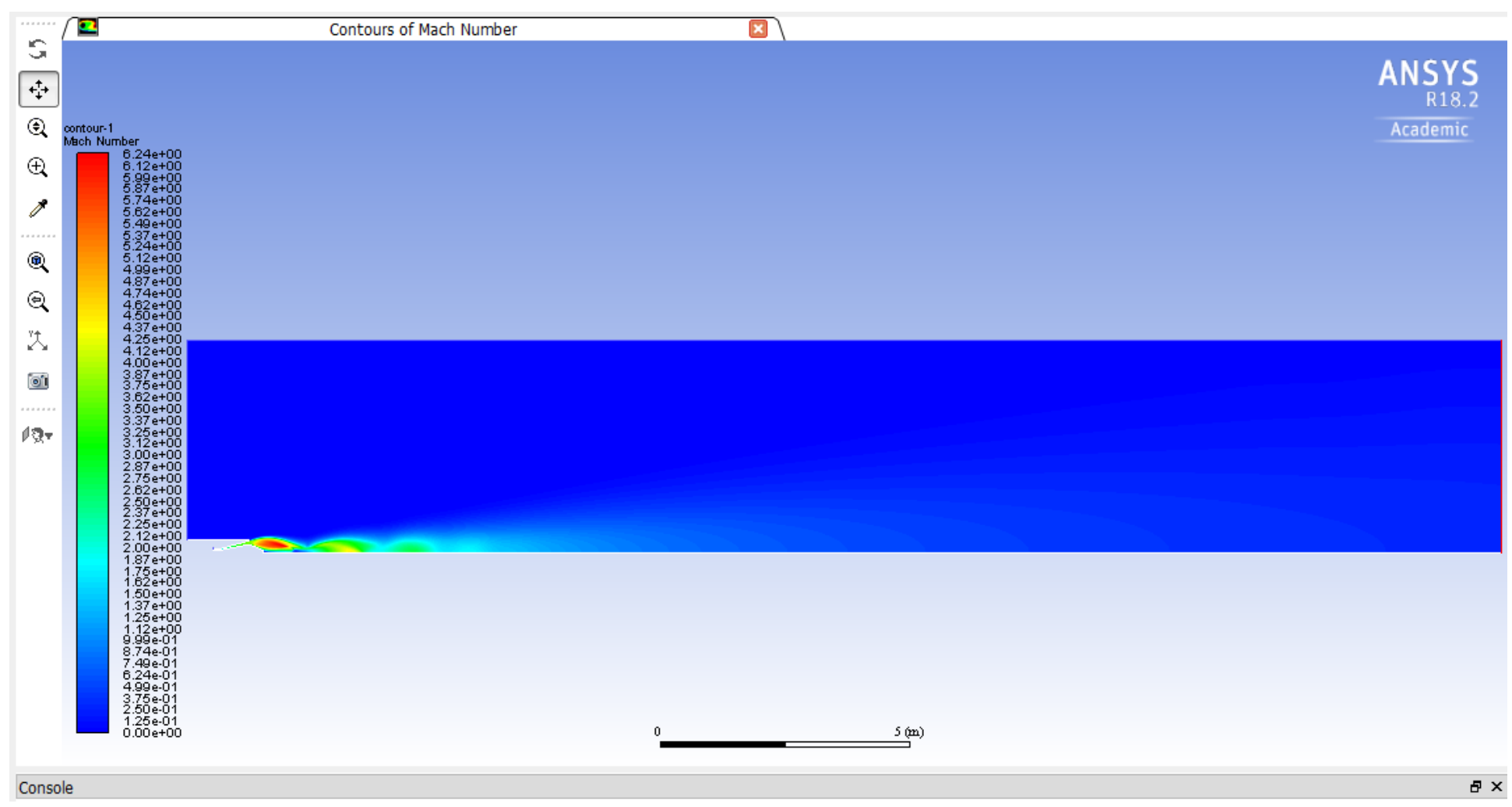

Figure 93: Contour of Mach number for CD Nozzle \& CB 6, with nozzle flow expansion into ambient air at 20km standard atmosphere. 


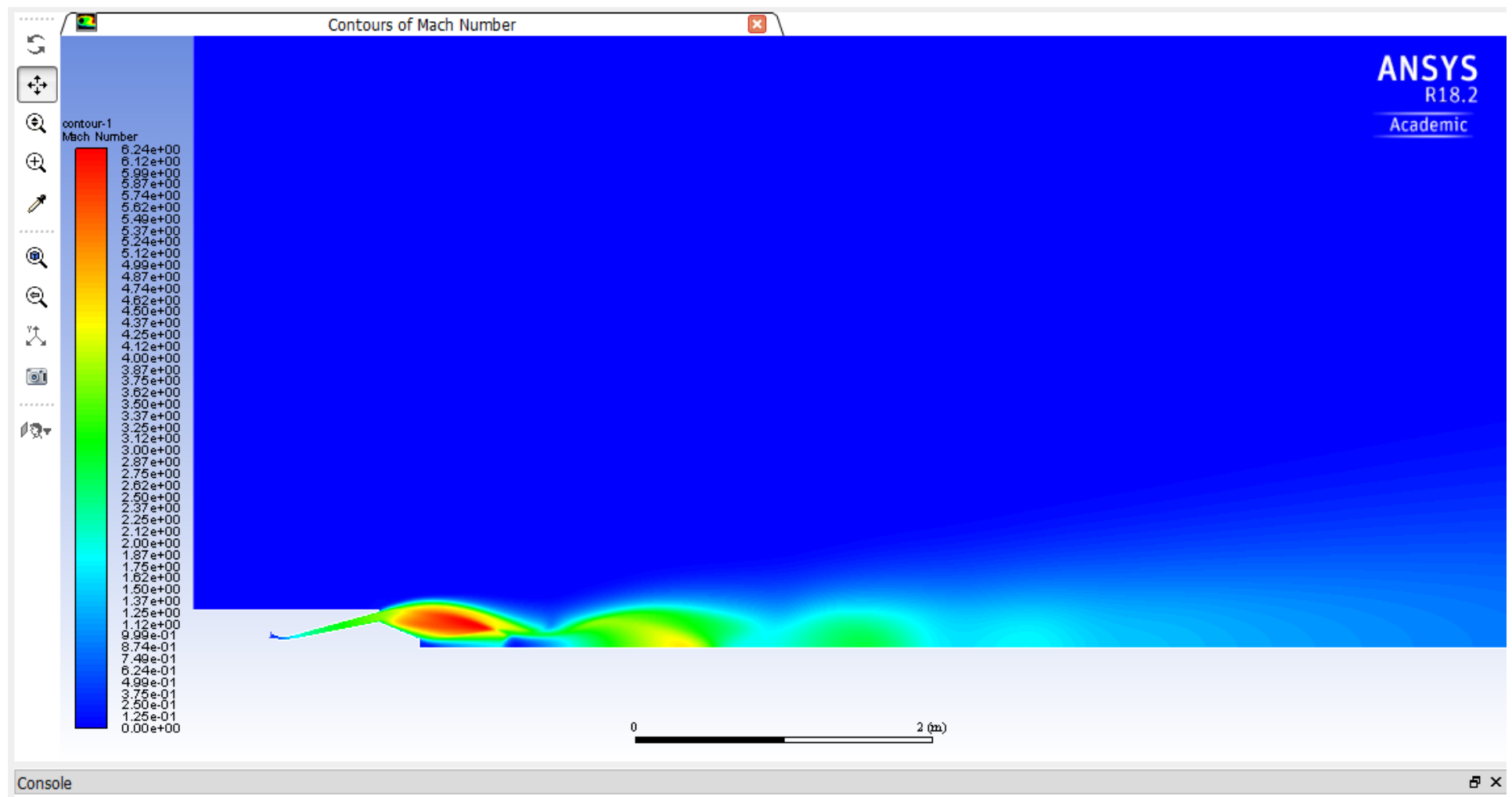

Figure 94: Contour of Mach number for CD Nozzle \& CB 6, with nozzle flow expansion into ambient air at 20km standard atmosphere. 
CD Nozzle \& CB 7 Flow Contours

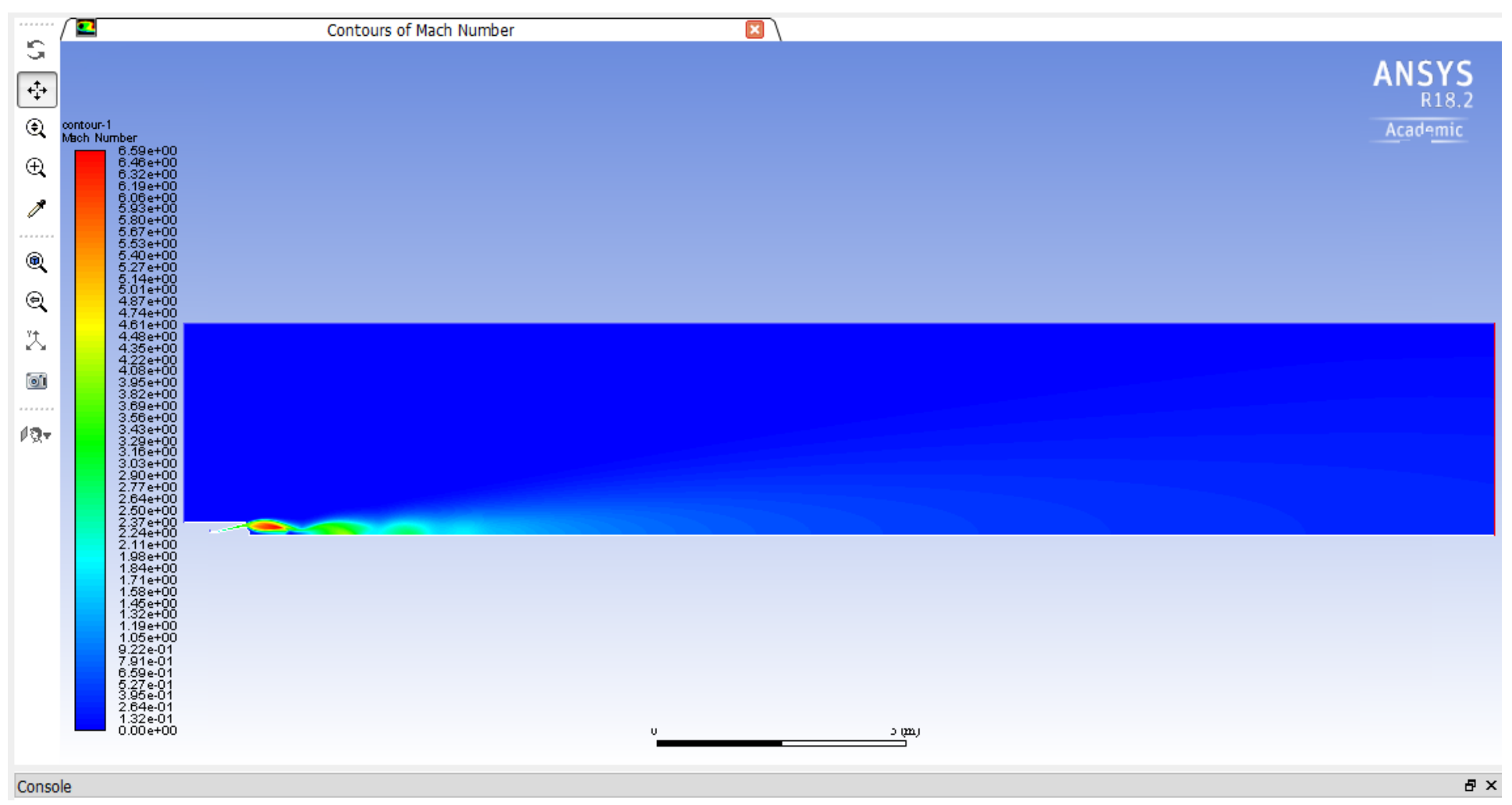

Figure 95: Contour of Mach number for CD Nozzle \& CB 7, with nozzle flow expansion into ambient air at 20km standard atmosphere. 


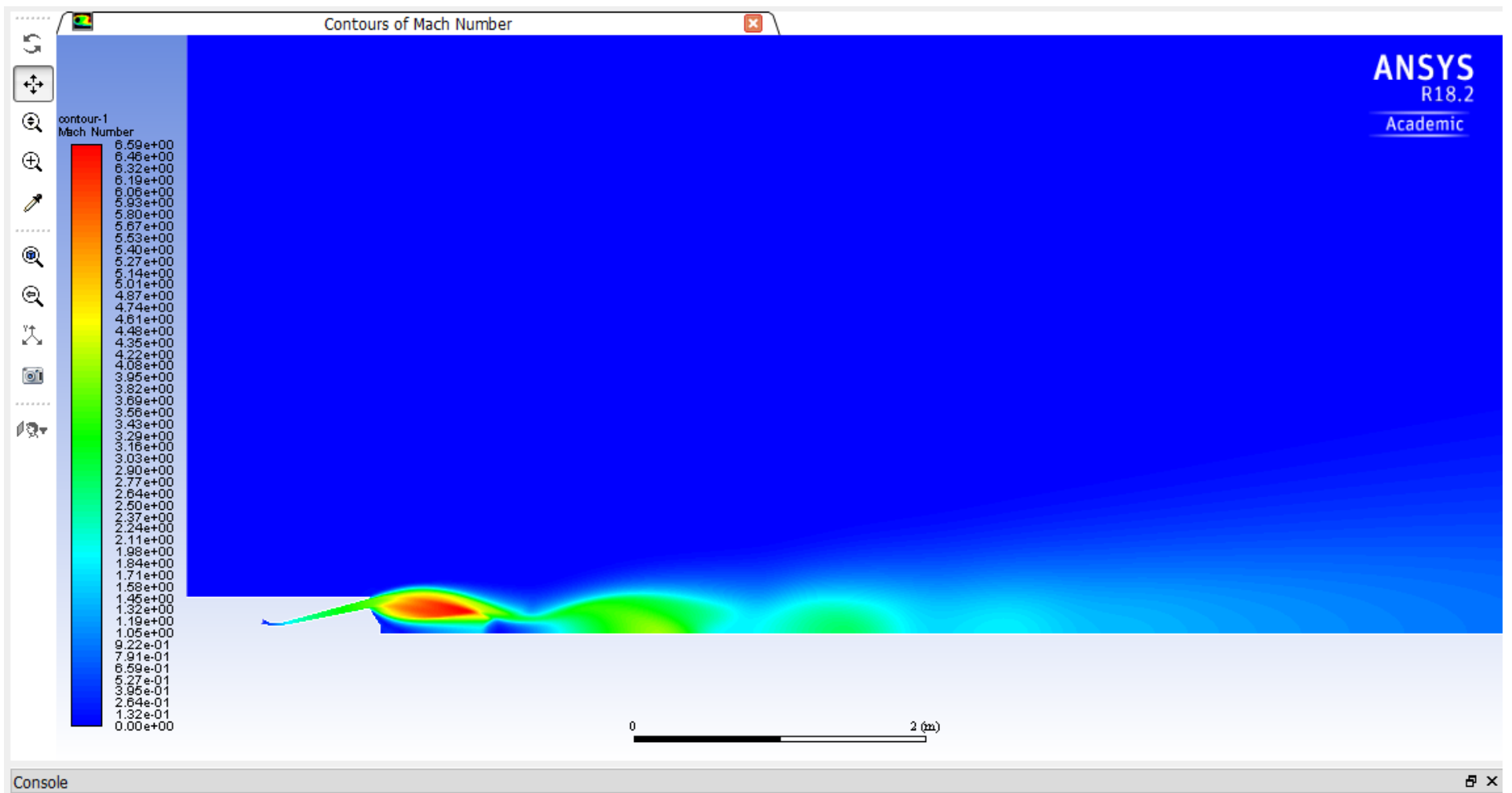

Figure 96: Contour of Mach number for CD Nozzle \& CB 7, with nozzle flow expansion into ambient air at 20km standard atmosphere. 
CD Nozzle \& CB 8 Flow Contours

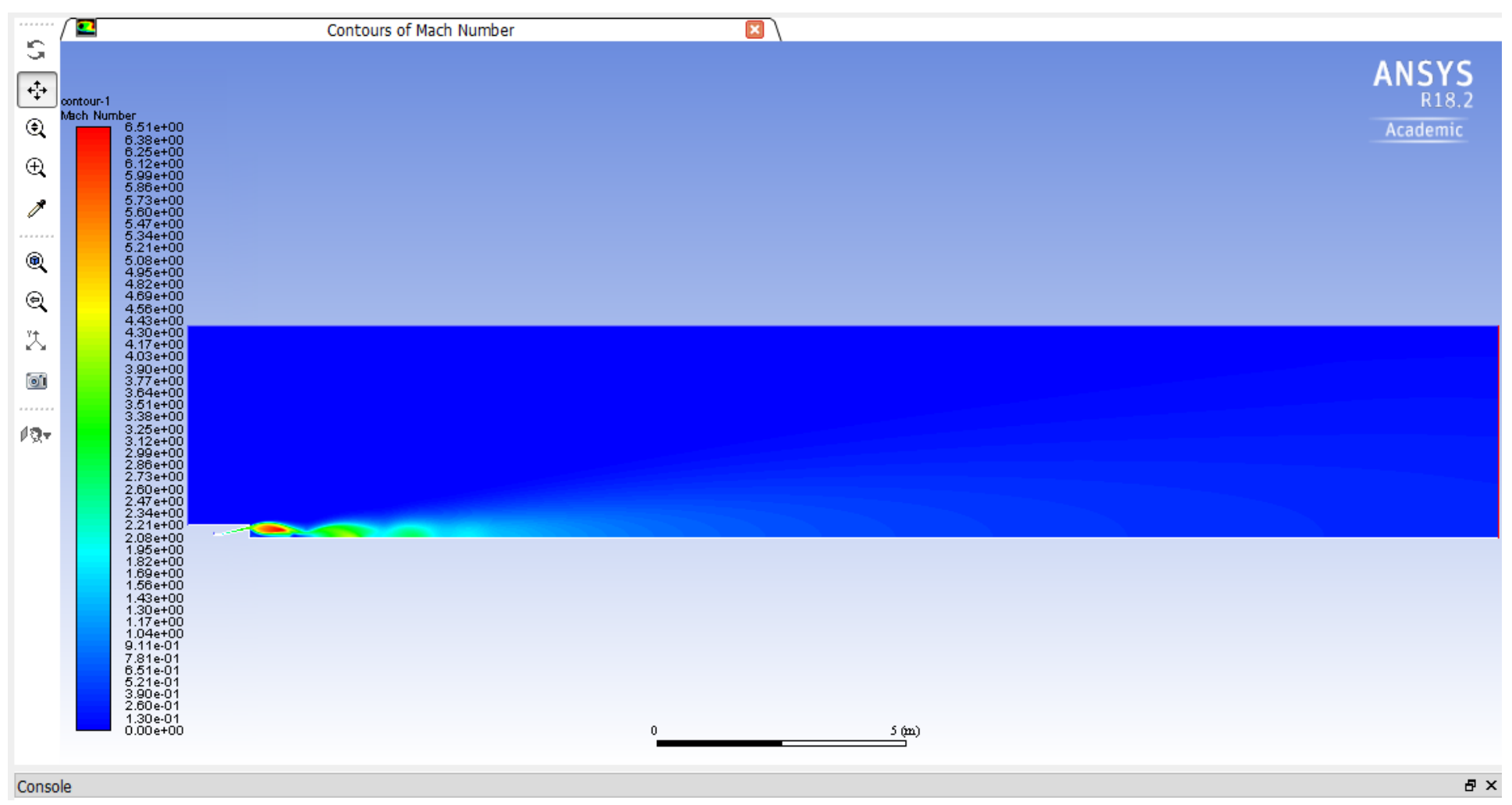

Figure 97: Contour of Mach number for CD Nozzle \& CB 8, with nozzle flow expansion into ambient air at 20km standard atmosphere. 


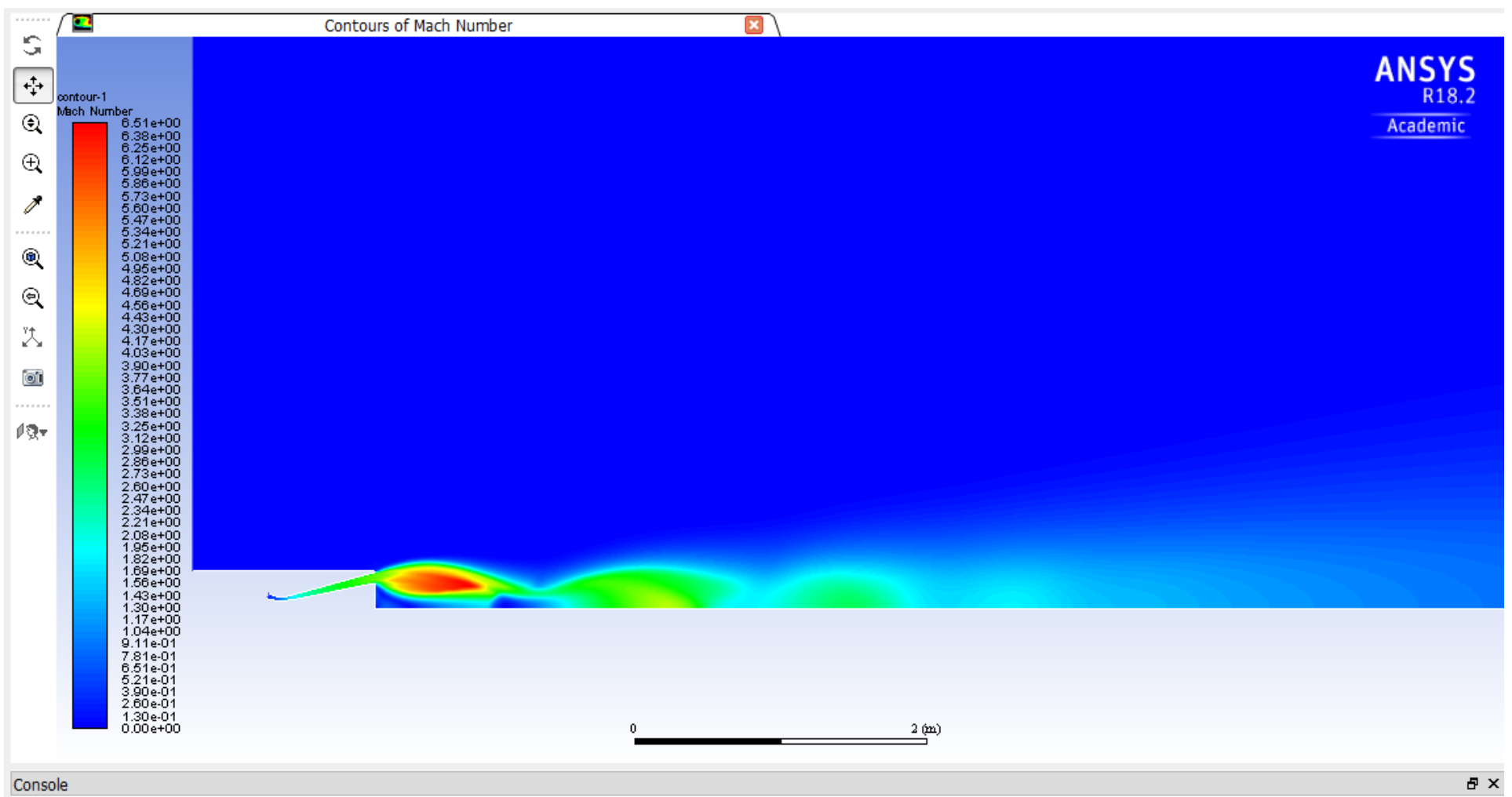

Figure 98: Contour of Mach number for CD Nozzle \& CB 8, with nozzle flow expansion into ambient air at 20km standard atmosphere. 
Results for the Aerospike Models

Table 5: Summarized performance results for the CD Nozzle case and Aerospikes 1 - 18 at 20km standard atmosphere.

\begin{tabular}{|c|c|c|c|c|c|c|c|}
\hline Case & $\begin{array}{l}\text { Calculated } \\
\text { Mass Flow } \\
\text { Rate (kg/s) }\end{array}$ & $\begin{array}{l}\text { Thrust of } \\
\text { CD Section } \\
(\mathrm{N})\end{array}$ & $\begin{array}{l}\text { Thrust of CB } \\
\text { Sloped Section } \\
\text { (N) }\end{array}$ & $\begin{array}{l}\text { Blunt End } \\
\text { Thrust (N) }\end{array}$ & $\begin{array}{l}\text { Total Thrust } \\
\text { of CB } \\
\text { Section (N) }\end{array}$ & $\begin{array}{l}\text { Total } \\
\text { Thrust (N) }\end{array}$ & $I_{s p}(\mathrm{~s})$ \\
\hline CD Nozzle & 9.659658701 & 10583.52356 & N/A & N/A & N/A & 10583.52356 & 111.6862 \\
\hline Aerospike 1 & 9.669471212 & 10089.50643 & 146.789795 & 171.3721562 & 318.1619511 & 10407.66838 & 109.7189679 \\
\hline Aerospike 2 & 9.669461583 & 9971.54707 & 224.5296596 & 104.7123142 & 329.2419738 & 10300.78904 & 108.5923405 \\
\hline Aerospike 3 & 9.66719447 & 9604.401617 & 337.251165 & 58.72843853 & 395.9796035 & 10000.38122 & 105.4501237 \\
\hline Aeros & 9.680822793 & 10095.64914 & 175.6929745 & 74.55115839 & 250.2441329 & 10345.89327 & 108.9398357 \\
\hline Aerosp & 9.674744503 & 9981.977514 & 201.626263 & 50.7015113 & 252.3277743 & 10234.30529 & 107.8325451 \\
\hline Aerospike 6 & 9.680822793 & 10083.45612 & 85.90354526 & 240.3085015 & 326.2120468 & 10409.66817 & 109.6113705 \\
\hline Aerospike 7 & 9.680822793 & 10074.15398 & 78.13116144 & 344.7689536 & 422.9001151 & 10497.0541 & 110.5315239 \\
\hline Aerospike 8 & 9.672983763 & 9495.434027 & 157.6359936 & 21.504 & 179.140529 & 9674.574556 & 101.9535634 \\
\hline Aerospike 9 & 9.667978793 & 10052.38518 & 0 & 761.8223653 & 761.8223653 & 10814.20755 & 114.0223543 \\
\hline Aerospike 10 & 9.674943522 & 10394.73894 & 1.756037615 & 154.4765583 & 156.2325959 & 10550.97154 & 111.1667747 \\
\hline Aerospike 11 & 9.676126181 & 10526.56913 & -47.74738227 & 42.73069538 & -5.016686887 & 10521.55244 & 110.8432608 \\
\hline Aerospike 12 & 9.68409867 & 10615.63772 & -63.2378119 & 71.99123636 & 8.753424455 & 10624.39114 & 111.8345097 \\
\hline Aerospike 13 & 9.67566055 & 10827.41068 & -70.77990905 & 125.1166184 & 54.33670935 & 10881.74739 & 114.6433871 \\
\hline Aerospike 14 & 9.676597713 & 10846.14133 & -73.67282299 & 19.29717639 & -54.3756466 & 10791.76568 & 113.6843841 \\
\hline Aerospike 15 & 9.676596897 & 10852.89207 & -46.57936378 & 10.21994086 & -36.35942292 & 10816.53264 & 113.9452979 \\
\hline Aerospike 16 & 9.673524651 & 10163.73688 & 60.65795641 & 373.1722259 & 433.8301823 & 10597.56706 & 111.6740903 \\
\hline Aerospike 17 & 9.671037013 & 10307.75484 & 40.23409984 & 377.6001162 & 417.834216 & 10725.58906 & 113.0522215 \\
\hline Aerospike 18 & 9.670638188 & 10842.77911 & -45.62105559 & 145.4689752 & 99.84791962 & 10942.62703 & 115.3446496 \\
\hline
\end{tabular}

As shown by the summarized results in Table 5, only Aerospikes 9, 13, 14, 15, 17, and 18 outperformed the original CD Nozzle case in terms of $I_{s p}$. Aerospike 12 has a slightly higher calculated $I_{s p}$ than the CD Nozzle, but the increase is not significant and could simply be due to a numerical error. Aerospike 16's calculated $I_{s p}$ is almost the same as that of the CD Nozzle. For Aerospikes 1 - 12, only Aerospike 9 significantly out - performed the original CD Nozzle case with $I_{s p}$. The problem with Aerospike 9 is that its design does not match what a typical Aerospike looks like. Aerospike 9 is simply a CD section, with flow expanding over a blunt end located at the exit of the CD section. The sketch for Aerospike 9 is shown in Figure 60. Aerospikes $1-12$ all operated under $P_{o}=344,738.0 P a, T_{i}=922.0389 \mathrm{~K}$, and predicted $\dot{m}=$ $9.689 \mathrm{~kg} / \mathrm{s}$. Aerospikes $2-12$ are design iterations from Aerospike 1 with varying exit areas, axial locations of exit areas, and center body geometries. Aerospikes $1-7$ all have considerably large CB thrust values, but relatively low CD thrust values, as listed in Table 5. The total thrust for each Aerospike $1-7$ is thus lower than the CD Nozzle case, and for relatively the same $\dot{m}$, each of these cases produces a lower $I_{s p}$ than the CD Nozzle. Aerospikes 1, 4, 6, 7, and 9 all have the same CD section geometry, but vary in terms CB geometry. Sketches for Aerospikes 1, 4, 6, 7, and 9 are shown in Figures 44, 50, 54, 56, and 60. Aerospike 4 was designed by simply 
extending the $\mathrm{CB}$ of Aerospike 1 axially by $40 \mathrm{~mm}$, such that the sloped section of the CB has a larger surface area and the blunt end has a lower surface area. Aerospike 6 is $40 \mathrm{~mm}$ shorter in axial length than Aerospike 1, such that the sloped section of the CB has a lower surface area and the blunt end has a larger surface area. The plot in Figure 101 shows that by increasing the blunt end area, while maintaining the same CB angle, the thrust contribution of the CB increases.

$$
\text { By maintaining } T_{i}=922.0389 \mathrm{~K}, \dot{m}=9.689 \mathrm{~kg} / \mathrm{s} \text {, and } \frac{A_{i}}{A^{*}}=1.924 \text { and reducing the }
$$
throat area from Aerospike 1, a new $P_{o}$ was calculated by rearranging Equation (13), to be used for Aerospike 13. Aerospikes $13-18$ all operated under $P_{o}=660,132.4 P a$. Aerospike 13 has a larger $I_{s p}$ than the original CD Nozzle case, by almost 3.0s. If the original CD Nozzle case were to operate under $P_{o}=660,132.4 P a$, this would result in $\dot{m}>9.689 \mathrm{~kg} / \mathrm{s}$ for the nozzle, making it difficult to compare with the Aerospike models. As listed in Table 5, all the cases that were tested have calculated mass flow rates that come close to the prediction for $\dot{m}$. For every case, $\dot{m}$ was calculated from the CFD results using averaged values of axial velocity and density, for known axial areas. One observed trend in performance is that, a significant increase in $I_{s p}$ can be achieved for an Aerospike, by having the Aerospike operate at an increased $P_{o}$, which also translates to an increased chamber pressure $\left(P_{c}\right)$, compared to a conventional nozzle, while maintaining $\dot{m}$ equal for both the Aerospike and conventional nozzle designs. Raising $P_{o}$ increases $P_{e}$, which increases the thrust contribution of the CD section, and since $P_{e}$ is larger, the $\mathrm{CB}$ of an Aerospike will experience larger static pressure values, increasing the $\mathrm{CB}$ thrust contribution.

For an Aerospike, it is desirable to optimize the thrust contribution of the CB. Aerospikes $1-8$ and Aerospikes $10-12$, all had a CB angled at $30^{\circ}$. Aerospike 11 was created by setting the $\mathrm{CB}$ angle for Aerospike 10 to $15^{\circ}$. Sketches for Aerospike's 10 and 11 are shown in Figures 62 and 64 respectively. By setting the $\mathrm{CB}$ at a shallower angle, while keeping the $\mathrm{CD}$ section at the same angle, an oblique shock wave is induced over the $\mathrm{CB}$, as the supersonic flow exits the $\mathrm{CD}$ section. The flow behind an oblique shockwave is higher in static pressure and lower in Mach number, than the flow ahead of the oblique shockwave [5]. By inducing an oblique shockwave over the $\mathrm{CB}$, larger static pressure values occur over the $\mathrm{CB}$. The purpose behind inducing larger static pressure values over the $\mathrm{CB}$, is to obtain a larger thrust contribution from the CB. However, as shown in Table 5, the opposite effect was achieved, by comparing the thrust components and total thrust of the CB for Aerospikes 10 and 11. The induced oblique shockwave for Aerospike 11 did produce the required increase in static pressure over the CB sloped section, as shown by comparing the plots in Figure 99. The loss in thrust in going from Aerospike 10 to 11 is mainly due to the $\mathrm{CB}$ being oriented at a much shallower angle for Aerospike 11. In order to determine the thrust of the $\mathrm{CB}$, the integral of static pressure over the $\mathrm{CB}$ with respect to axial area must be solved and the resultant value is multiplied by $\sin \theta$ to yield a force term in the axial direction. The shallower the slope, the closer the value of $\theta$ is to zero, the closer $\sin \theta$ is to zero. Using a steeper angle, closer to $90^{\circ}$, implies $\sin \theta$ is closer to 1 . The only advantage Aerospike 11 has over Aerospike 10, is that its CD thrust is significantly larger as listed in Table 5. This is due to part of the induced oblique shock being present in the exit axial area of Aerospike 11, which raises the average static pressure in the exit axial area. The idea for 
Aerospike 11 was also repeated of Aerospike 14 and the same effect was observed. Aerospike 14 is the modification of Aerospike 13, with the $\mathrm{CB}$ being angled at $20^{\circ}$, as shown by comparing Figures 68 and 70. A larger thrust from the CB was obtained from Aerospikes 16 and 17, as listed in Table 5, due to a CB angle of $40^{\circ}$ for these two cases compared to $30^{\circ}$ for previous cases. Aerospikes 16 and 17 failed to outperform Aerospike 13 with efficiency, since in both cases, the CD thrust is considerably lower than that of Aerospike 13, as listed in Table 5. By comparing the exit - to - throat area ratios for all the Aerospikes, listed in Tables 6 and 7, Aerospikes 16 and 17 rank relatively higher in terms of exit - to - throat area ratio, but lower in terms of CD thrust. Since the CB for Aerospikes 16 and 17 is placed at a steeper angle than that of Aerospike 13, the axial distance between the throat and exit areas is reduced. This will result in the flow undergoing more of a radial expansion and less of an axial expansion. It is more ideal to have a CD section contoured such that the flow will undergo more of an axial expansion rather than radial, in order to maximize the thrust produced. The axial distance between the throat and exit areas is $140 \mathrm{~mm}$ for Aerospike 13, based on Figure 68. The axial distance between the throat and exit is $90 \mathrm{~mm}$ for Aerospike 16 and $115 \mathrm{~mm}$ for Aerospike 17, based on Figures 74 and 76 respectively. Aerospike 17 has the largest exit - to - throat area ratio of all the Aerospikes and the highest exit area, listed in Table 7. However, as shown by the plots of exit area axial velocity versus radial distance, in Figure 104, Aerospike 17 is lower in terms of average exit axial velocity than Aerospike 13. As observed from Figure 105, Aerospikes 13 and 17 have relatively the same exit area average magnitude of velocity. This implies that the supersonic flow of Aerospike 17 undergoes a larger radial expansion in the CD section than that for Aerospike 13. Based on a comparison of the predicted Mach numbers listed in Table 7, Aerospike 17 is expected to produce the largest exit area magnitude of velocity and exit area axial velocity. However, that is not the case, since the flow in the CD section of Aerospike 17 undergoes a much more significant radial expansion, due to a more compressed contour of the CD section, resulting in an averaged exit Mach number that deviates further from the predicted Mach number. This is shown by comparing predicted Mach number with averaged Mach number in Table 7, for Aerospikes 13 and 17. The same effect is also observed for Aerospikes 14 and 16, by comparison of the plots in Figures 106 and 107.

Based on the summarized results in Table 5, for a given mass flow rate of propellant, in order to achieve a larger $I_{s p}$ from an Aerospike design, it is preferable to have the design operate under a larger $P_{o}$ or $P_{c}$ than a conventional CD nozzle design. A larger $P_{o}$ will allow the CD section of an Aerospike to achieve a larger thrust and will result in larger static pressure values over the $\mathrm{CB}$, increasing the $\mathrm{CB}$ thrust contribution. For significant improvements in $I_{s p}$ from Aerospike 13, $P_{o}$ must be further increased. An increased $T_{i}$ is also preferable, in order to the prevent the gas behavior from possibly deviating significantly from the ideal gas law. Increasing $T_{i}$ also allows for a larger thrust from the CD section of an Aerospike. For all cases tested in this report, $T_{i}=922.0 \mathrm{~K}$. Possible $T_{i}$ values for the next Aerospike design, can be 1,200K or $1,500 K$. 


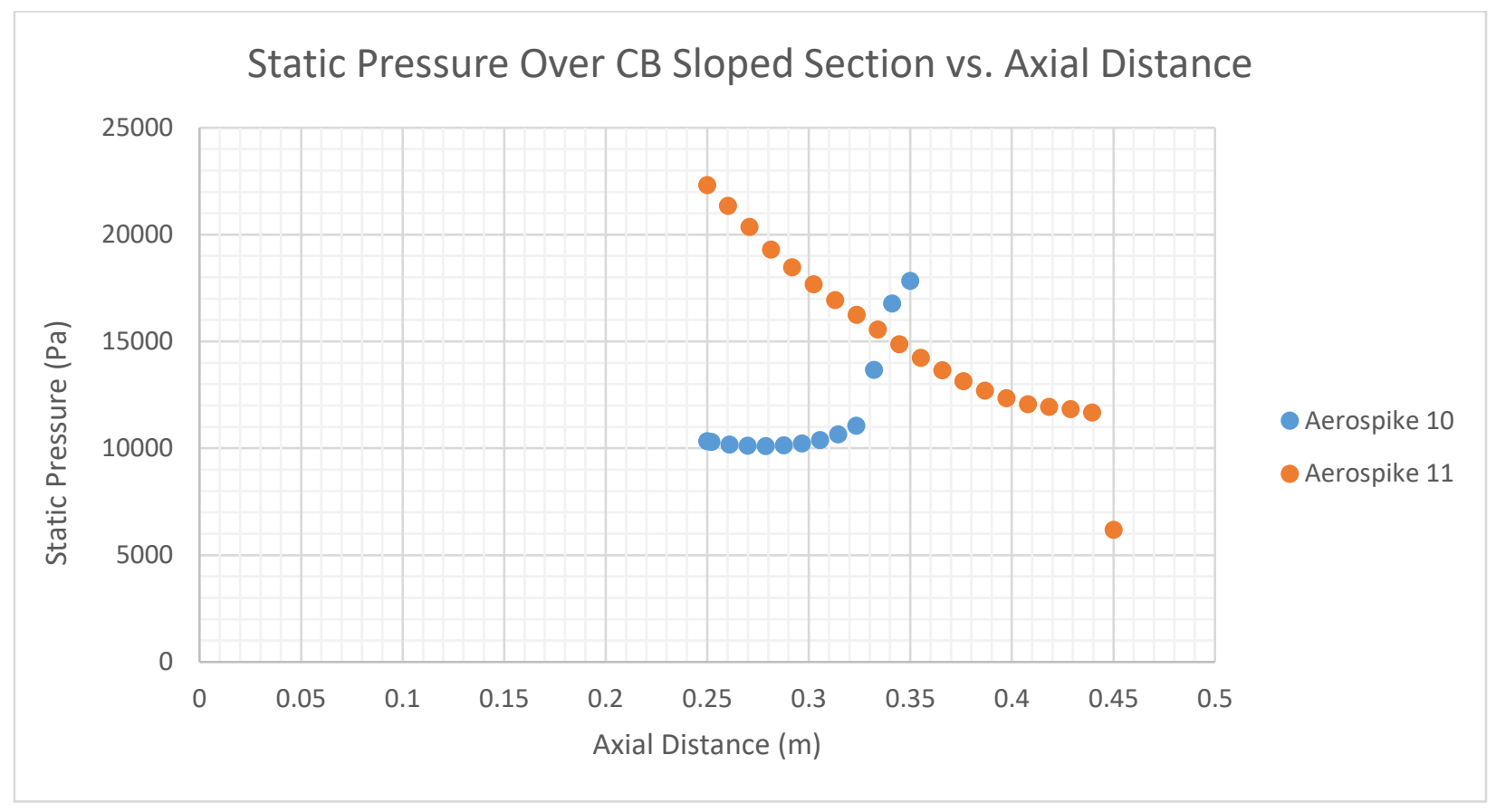

Figure 99: Plots of static pressure distribution over the center - body sloped section versus axial distance, for Aerospikes 10 and 11. 


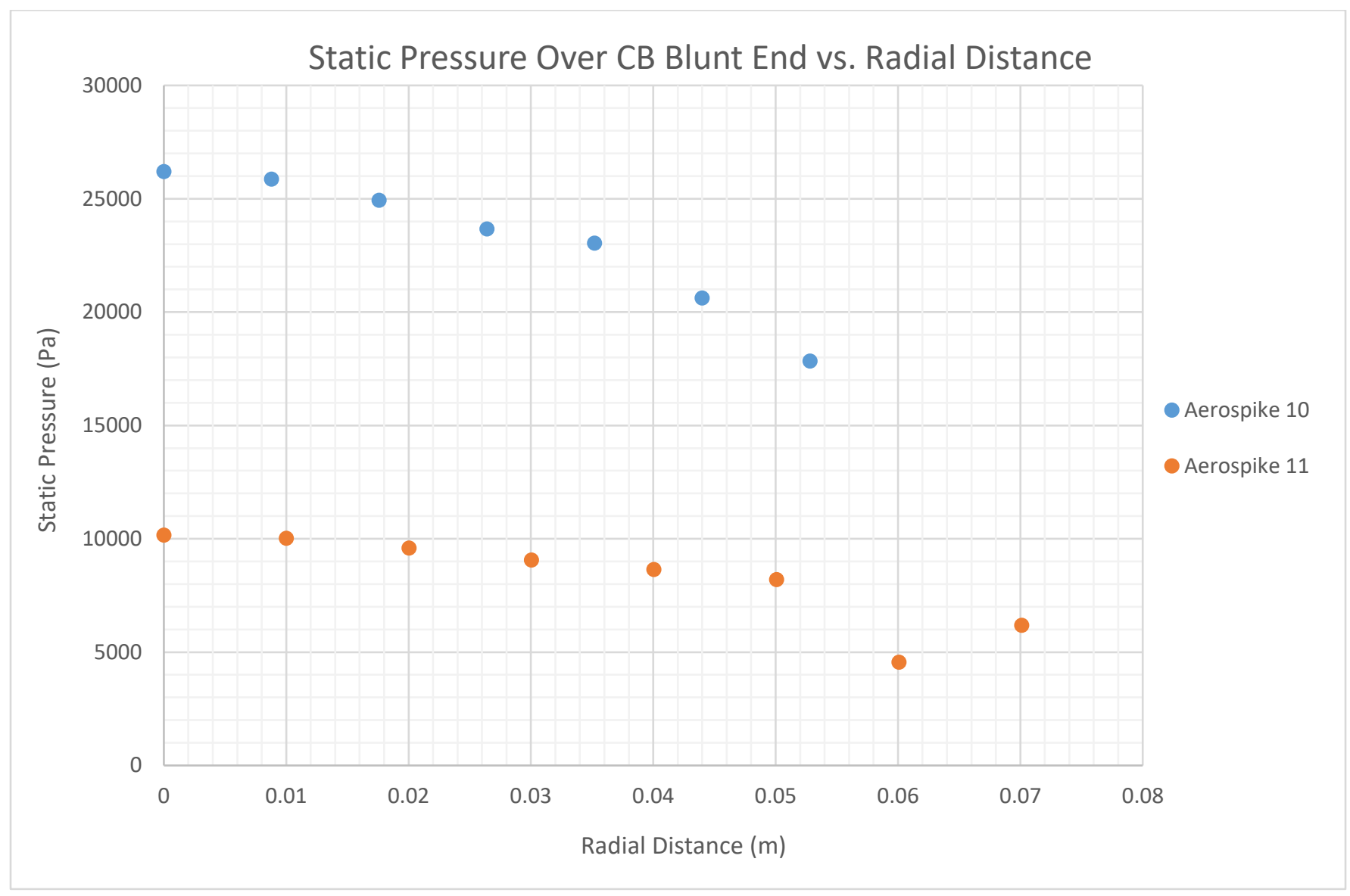

Figure 100: Plots of static pressure distribution over the center - body blunt end versus radial distance, for Aerospikes 10 and 11. 
Table 6: Aerospikes 1 - 12 with their corresponding predicted flow parameters and the results for the same parameters obtained using CFD. For each case, $P_{o}=344,738.0 P a$.

\begin{tabular}{|l|l|l|l|l|}
\hline Case & Predicted $\boldsymbol{M}_{\boldsymbol{e}}$ & Predicted $\boldsymbol{P}_{\boldsymbol{e}}(\mathbf{P a})$ & $\begin{array}{l}\text { Averaged } \boldsymbol{M}_{\boldsymbol{e}} \\
\text { from CFD } \\
\text { Result }\end{array}$ & $\begin{array}{l}\text { Averaged } \boldsymbol{P}_{\boldsymbol{e}} \\
\text { (Pa) from CFD } \\
\text { Result }\end{array}$ \\
\hline CD Nozzle & 3.833 & $2,845.2$ & 3.547 & $3,322.5$ \\
\hline Aerospike 1 & 2.587 & $17,616.9$ & 2.415 & $20,959.1$ \\
\hline Aerospike 2 & 2.435 & $22,309.1$ & 2.298 & $26,253.7$ \\
\hline Aerospike 3 & 2.187 & $32,903.1$ & 2.017 & $40,748.6$ \\
\hline Aerospike 4 & 2.587 & $17,616.9$ & 2.428 & $20,828.6$ \\
\hline Aerospike 5 & 2.435 & $22,309.1$ & 2.304 & $26,280.4$ \\
\hline Aerospike 6 & 2.587 & $17,616.7$ & 2.422 & $20,818.0$ \\
\hline Aerospike 7 & 2.587 & $17,616.9$ & 2.420 & $20,820.4$ \\
\hline Aerospike 8 & 1.797 & $60,311.0$ & 1.675 & $70,358.5$ \\
\hline Aerospike 9 & 2.587 & $17,616.9$ & 2.424 & $20,986.8$ \\
\hline Aerospike 10 & 3.090 & $8,201.0$ & 2.905 & $9,528.4$ \\
\hline Aerospike 12 & 3.521 & $4,389.7$ & 3.334 & $4,998.9$ \\
\hline
\end{tabular}

Table 7: Aerospikes 13, 16, 17, and 18 with their corresponding predicted flow parameters and the results for the same parameters obtained using CFD. For the CD Nozzle base case, $P_{o}=344,738.0 P a$. For Aerospikes 13, 16, 17, and 18, $P_{o}=$ $660,132.4 P a$.

\begin{tabular}{|l|l|l|l|l|}
\hline Case & Predicted $\boldsymbol{M}_{\boldsymbol{e}}$ & $\begin{array}{l}\text { Predicted } \boldsymbol{P}_{\boldsymbol{e}} \\
(\mathbf{P a})\end{array}$ & $\begin{array}{l}\text { Averaged } \boldsymbol{M}_{\boldsymbol{e}} \\
\text { from CFD } \\
\text { Result }\end{array}$ & $\begin{array}{l}\text { Averaged } \boldsymbol{P}_{\boldsymbol{e}} \\
\text { (Pa) from CFD } \\
\text { Result }\end{array}$ \\
\hline CD Nozzle & 3.833 & $2,845.2$ & 3.547 & $3,322.5$ \\
\hline Aerospike 13 & 3.547 & $8,094.1$ & 3.335 & $9,392.4$ \\
\hline Aerospike 16 & 3.414 & $9,782.7$ & 3.131 & $12,687.4$ \\
\hline Aerospike 17 & 3.620 & $7,310.8$ & 3.343 & $9,212.1$ \\
\hline Aerospike 18 & 3.547 & $8,094.1$ & 3.338 & $9,336.9$ \\
\hline
\end{tabular}


Table 8: CD Nozzle base case and Aerospikes 1-12 with their corresponding calculated mass flow rates and CD Thrust (at $20 \mathrm{~km}$ standard atmosphere) using CFD results. For each case, $P_{o}=344,738.0 P a$.

\begin{tabular}{|l|l|l|l|l|}
\hline Case & $\begin{array}{l}\text { Calculated Mass } \\
\text { Flow Rate (kg/s) }\end{array}$ & Thrust of CD Section $(\mathbf{N})$ & Exit Axial Area/Throat Area & Exit Axial Area (m^2) \\
\hline CD Nozzle & 9.659658701 & 10583.52356 & 9.220 & 0.1966 \\
\hline Aerospike 1 & 9.669471212 & 10089.50643 & 2.862 & 0.06104 \\
\hline Aerospike 2 & 9.669461583 & 9971.54707 & 2.483 & 0.05296 \\
\hline Aerospike 3 & 9.66719447 & 9604.401617 & 1.982 & 0.04228 \\
\hline Aerospike 4 & 9.680822793 & 10095.64914 & 2.862 & 0.06104 \\
\hline Aerospike 5 & 9.674744503 & 9981.977514 & 2.483 & 0.05296 \\
\hline Aerospike 6 & 9.680822793 & 10071.99266 & 1.982 & 0.04228 \\
\hline Aerospike 7 & 9.680822793 & 10074.15398 & 2.862 & 0.06104 \\
\hline Aerospike 8 & 9.672983763 & 9495.434027 & 1.435 & 0.03061 \\
\hline Aerospike 9 & 9.667978793 & 10052.38518 & 2.862 & 0.06104 \\
\hline Aerospike 10 & 9.674943522 & 10394.73894 & 4.615 & 0.09843 \\
\hline Aerospike 11 & 9.676126181 & 10526.56913 & 4.161 & 0.08876 \\
\hline Aerospike 12 & 9.68409867 & 10615.63772 & 6.921 & 0.1476 \\
\hline
\end{tabular}

Table 9: Aerospikes 13 - 18 with their corresponding calculated mass flow rates and CD Thrust (at 20km standard atmosphere) using CFD results. For the CD Nozzle base case, $P_{o}=344,738.0 P a$. For each case in Aerospikes 13 - 18, $P_{O}=660,132.4 P a$.

\begin{tabular}{|l|l|l|l|l|}
\hline Case & $\begin{array}{l}\text { Calculated Mass } \\
\text { Flow Rate (kg/s) }\end{array}$ & Thrust of CD Section (N) & Exit Axial Area/Throat Area & Exit Axial Area (m^2) \\
\hline CD Nozzle & 9.659658701 & 10583.52356 & 9.220 & 0.1966 \\
\hline Aerospike 13 & 9.67566055 & 10827.41068 & 7.095 & 0.07903 \\
\hline Aerospike 14 & 9.676597713 & 10846.14133 & 6.553 & 0.07299 \\
\hline Aerospike 15 & 9.676596897 & 10852.89207 & 6.553 & 0.07299 \\
\hline Aerospike 16 & 9.673524651 & 10163.73688 & 6.267 & 0.06981 \\
\hline Aerospike 17 & 9.671037013 & 10307.75484 & 7.587 & 0.08452 \\
\hline Aerospike 18 & 9.670638188 & 10842.77911 & 7.095 & 0.07903 \\
\hline
\end{tabular}




\section{Ratio Of Center Body Thrust to Total Thrust vs. Ratio Of Center Body Exposed Area to Base Area}

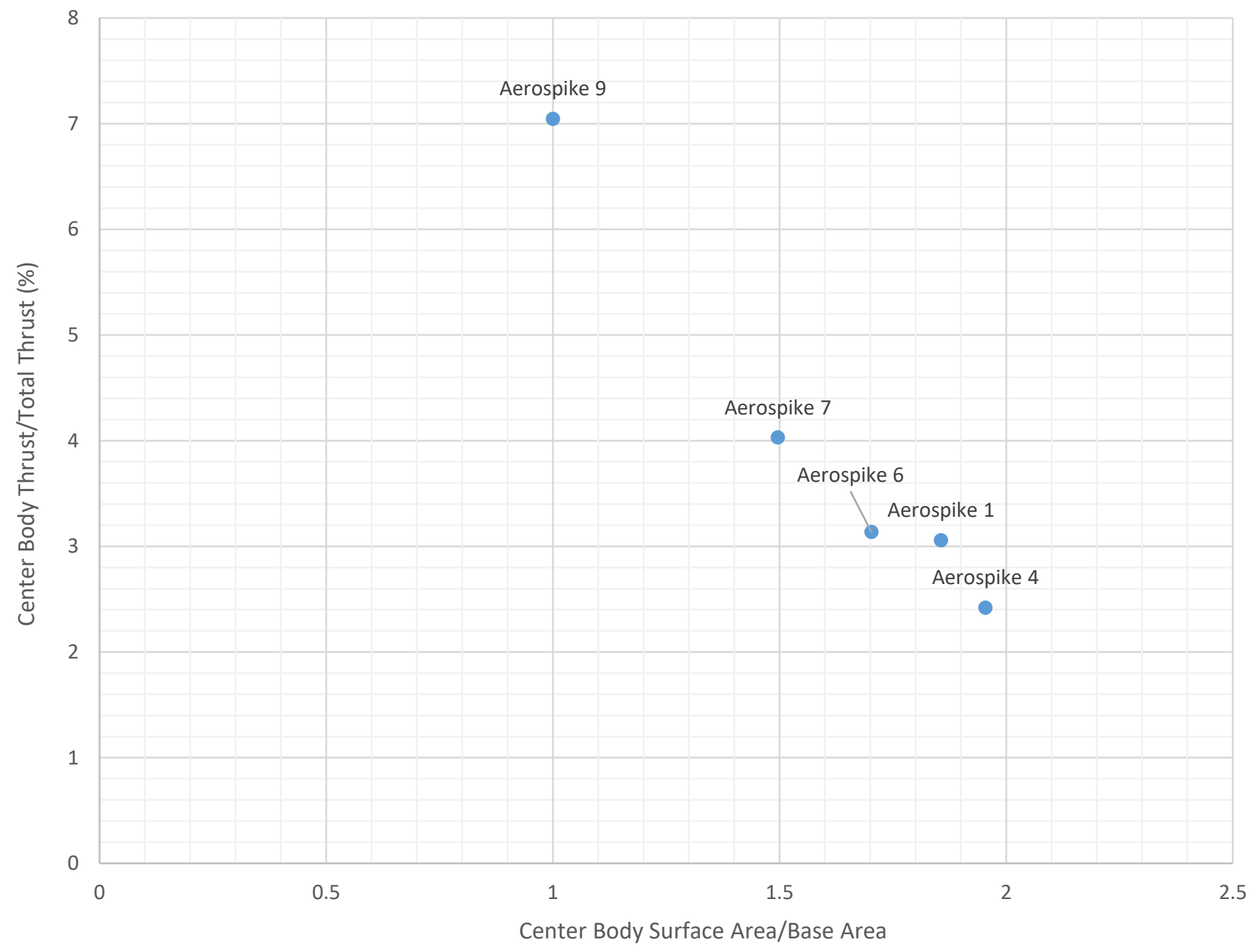

Figure 101: A plot of the ratio of center body thrust to total thrust versus the ratio of center body surface area to base area. 


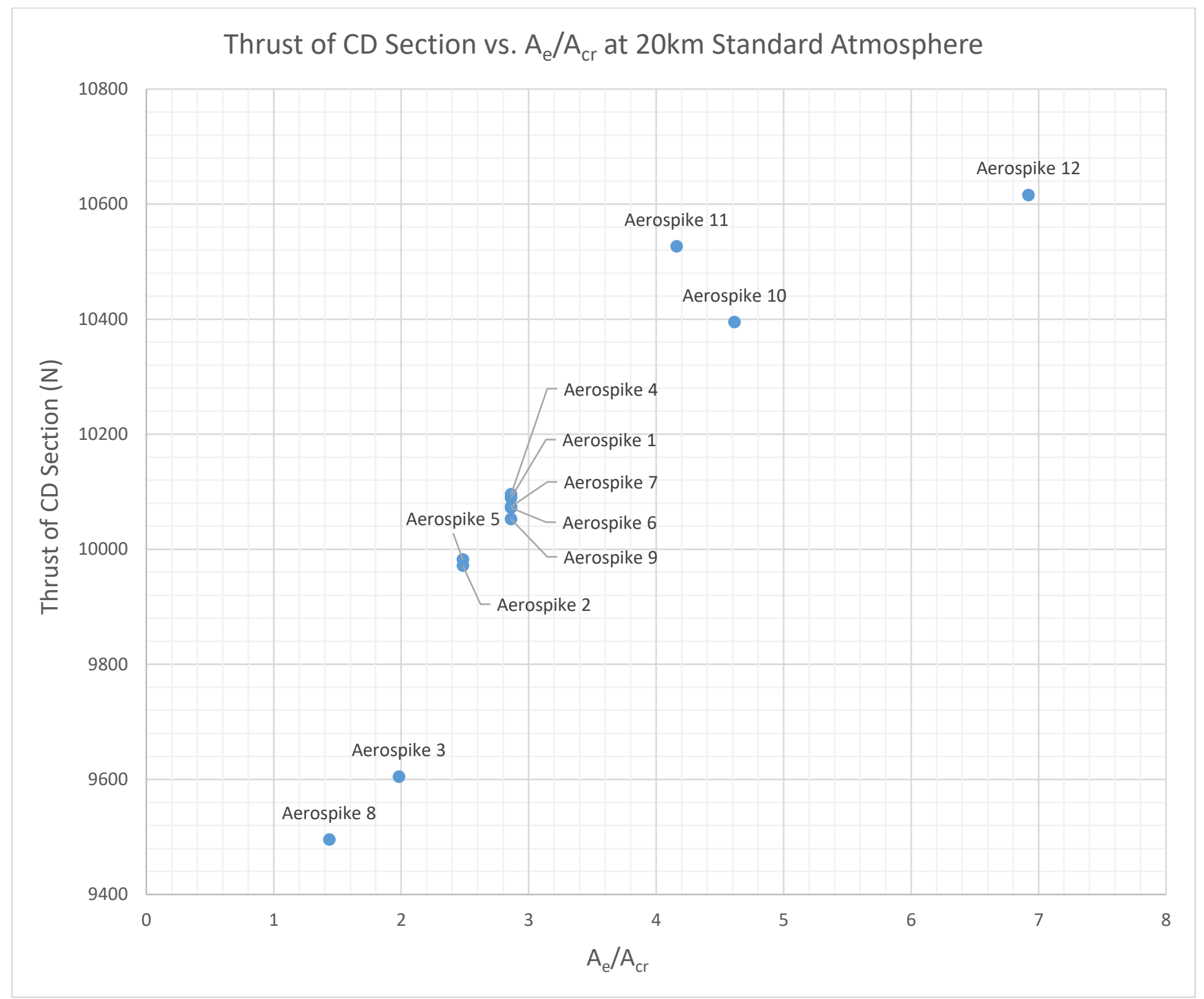

Figure 102: Thrust of CD section versus exit - to - throat area ratio at $20 \mathrm{~km}$ standard atmosphere. For each case $P_{o}=$ 344,738.0Pa. 


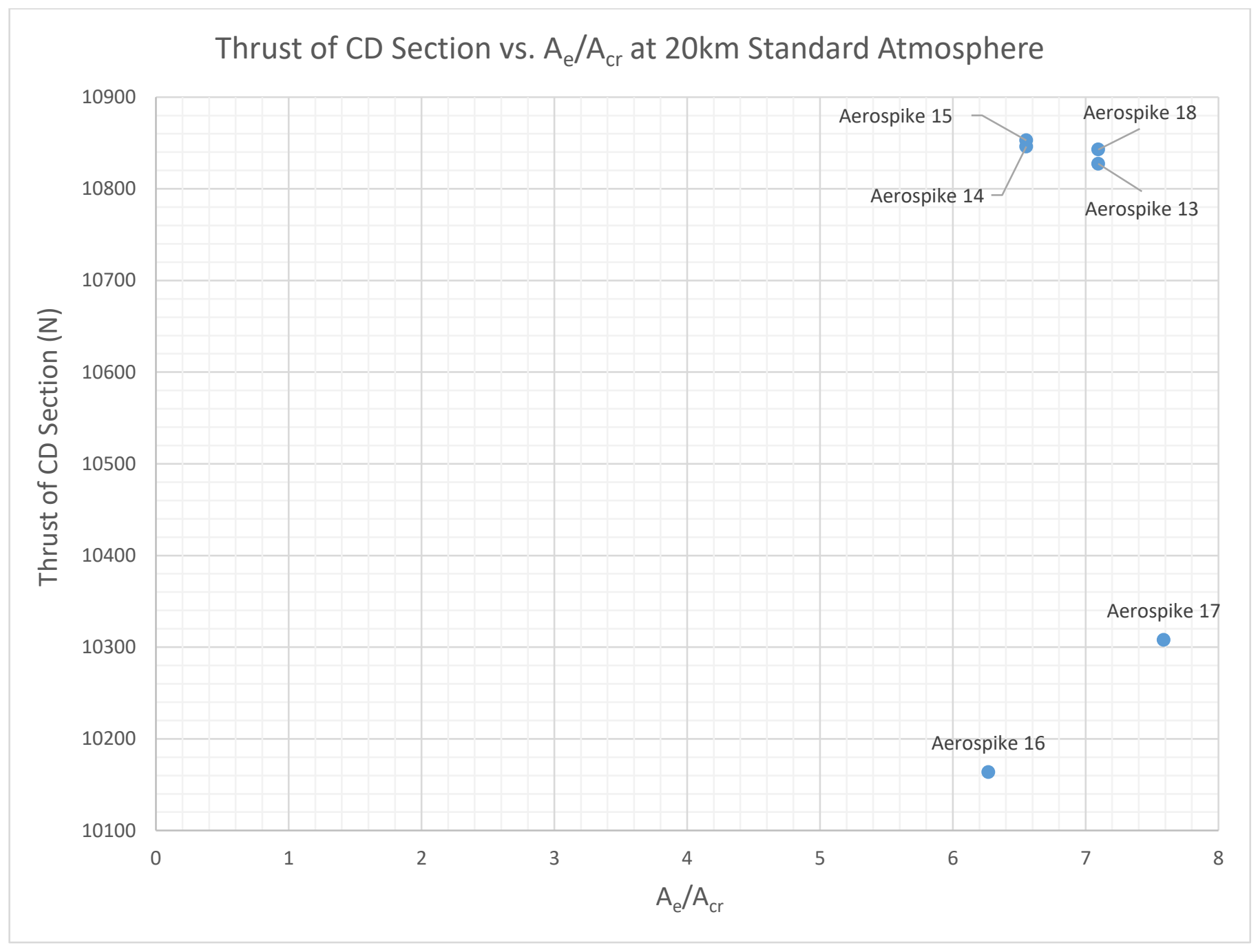

Figure 103: Thrust of CD section versus exit - to - throat area ratio at $20 \mathrm{~km}$ standard atmosphere. For each case $P_{o}=$ 660,132.4Pa. 


\section{Exit Axial Velocity vs. Radial Position}

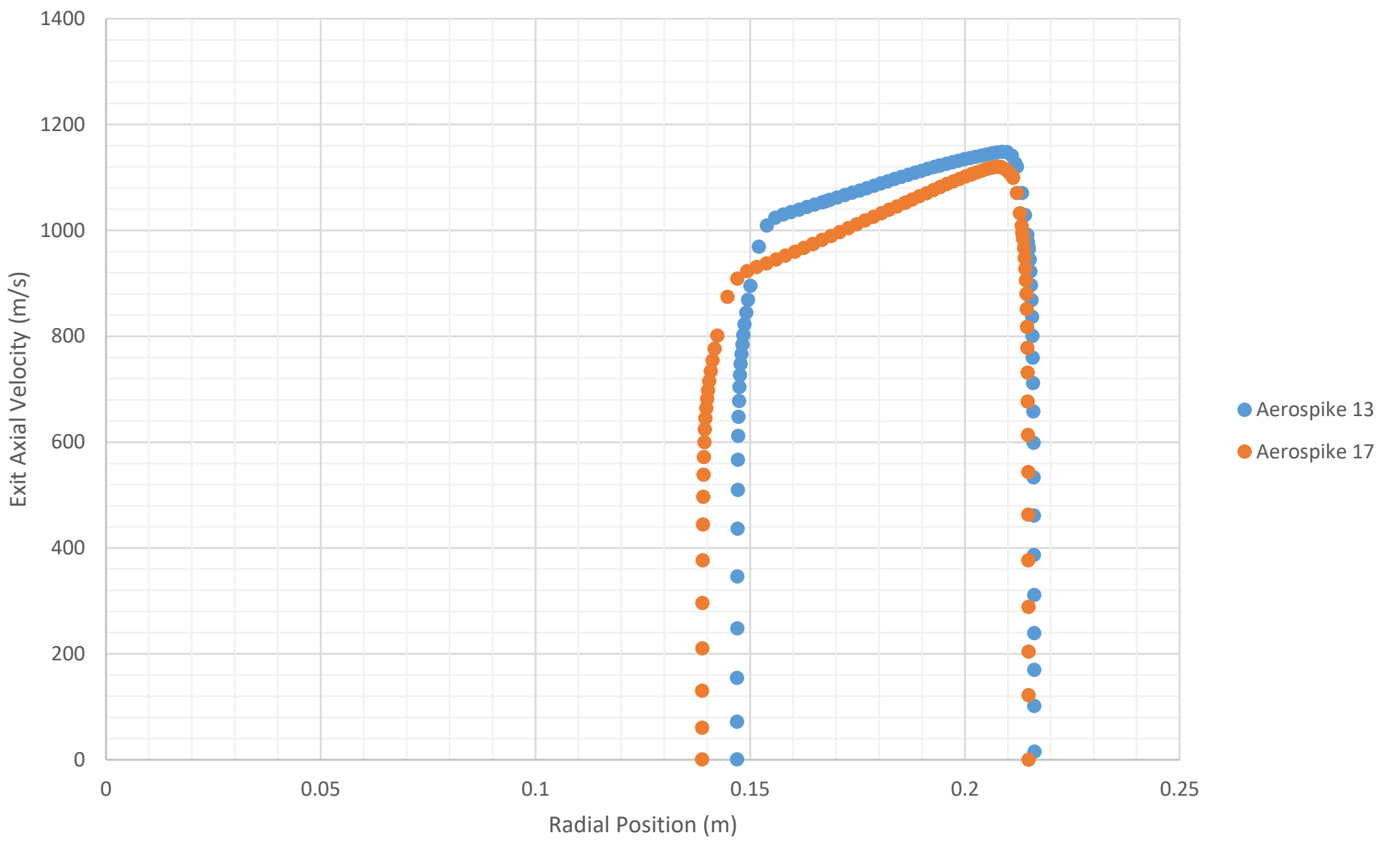

Figure 104: Exit axial velocity versus radial position for Aerospikes 13 and 17. 


\section{Exit Magnitude of Velocity vs. Radial Position}

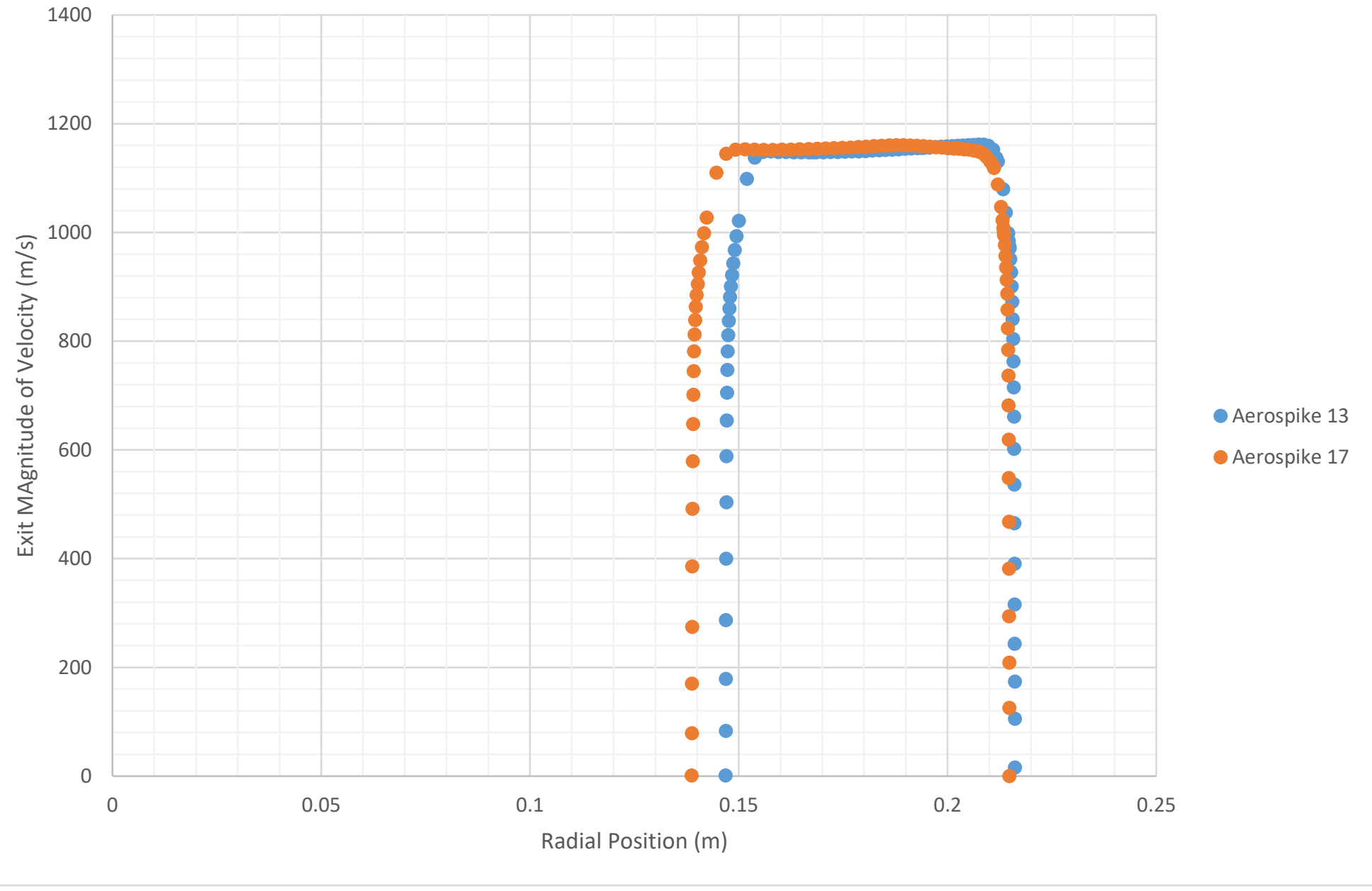

Figure 105: Exit magnitude of velocity versus radial position for Aerospikes 13 and 17. 


\section{Exit Axial Velocity vs. Radial Position}

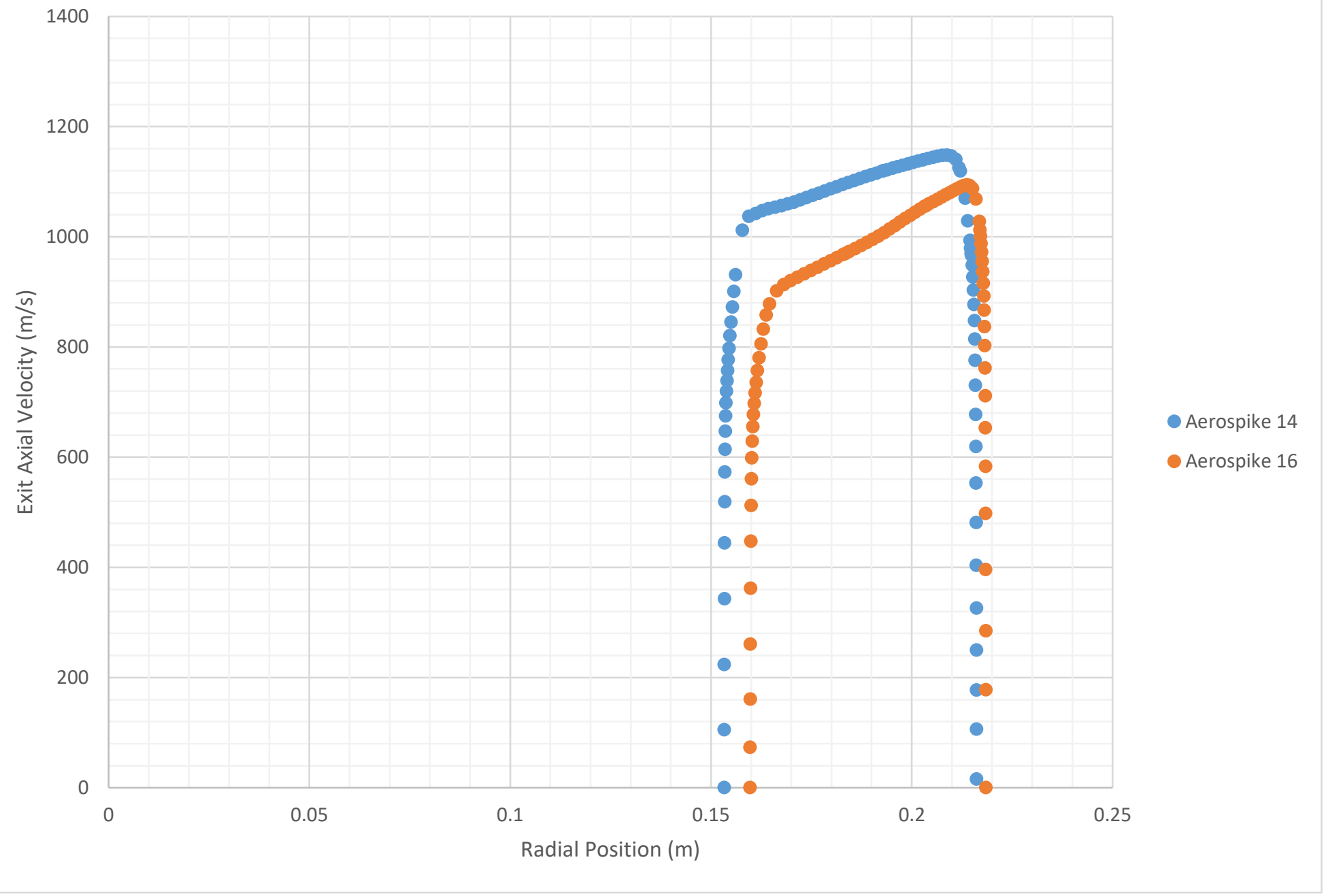

Figure 106: Exit axial velocity versus radial position for Aerospikes 14 and 16. 


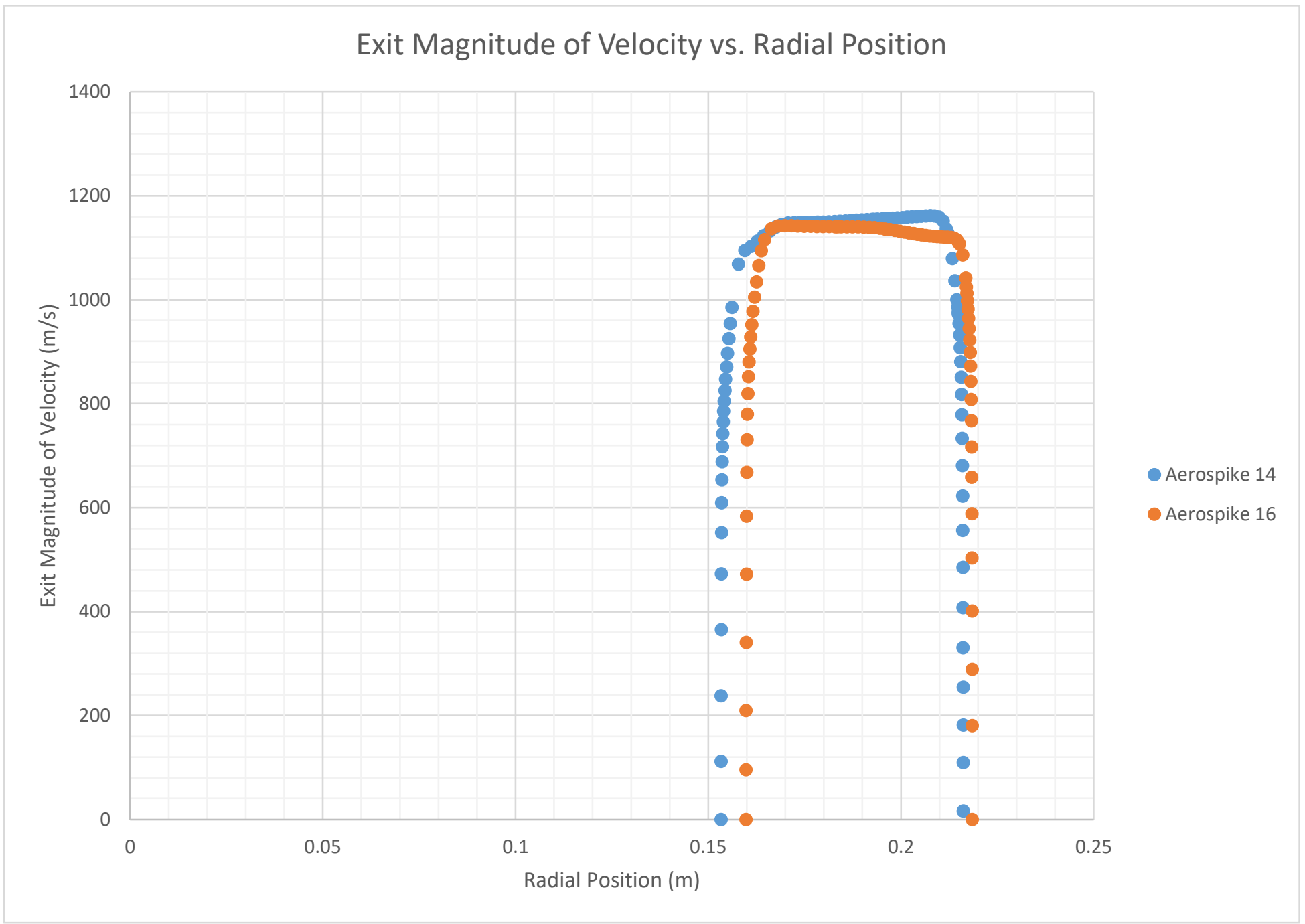

Figure 107: Exit magnitude of velocity versus radial position for Aerospikes 14 and 16. 


\section{Aerospike 1 Flow Contours}

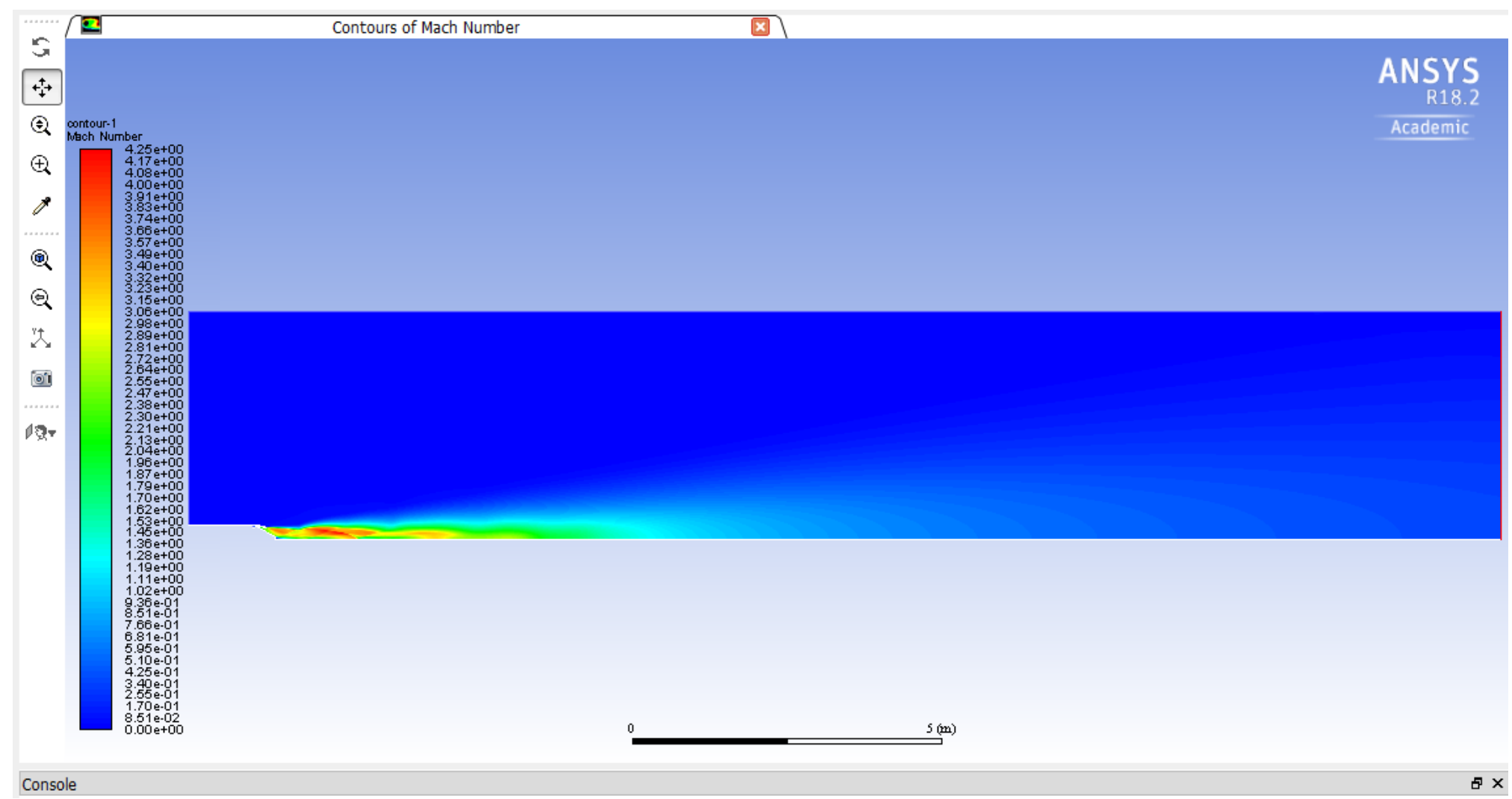

Figure 108: Contour of Mach number for Aerospike 1, with nozzle flow expansion into ambient air at $20 \mathrm{~km}$ standard atmosphere. 


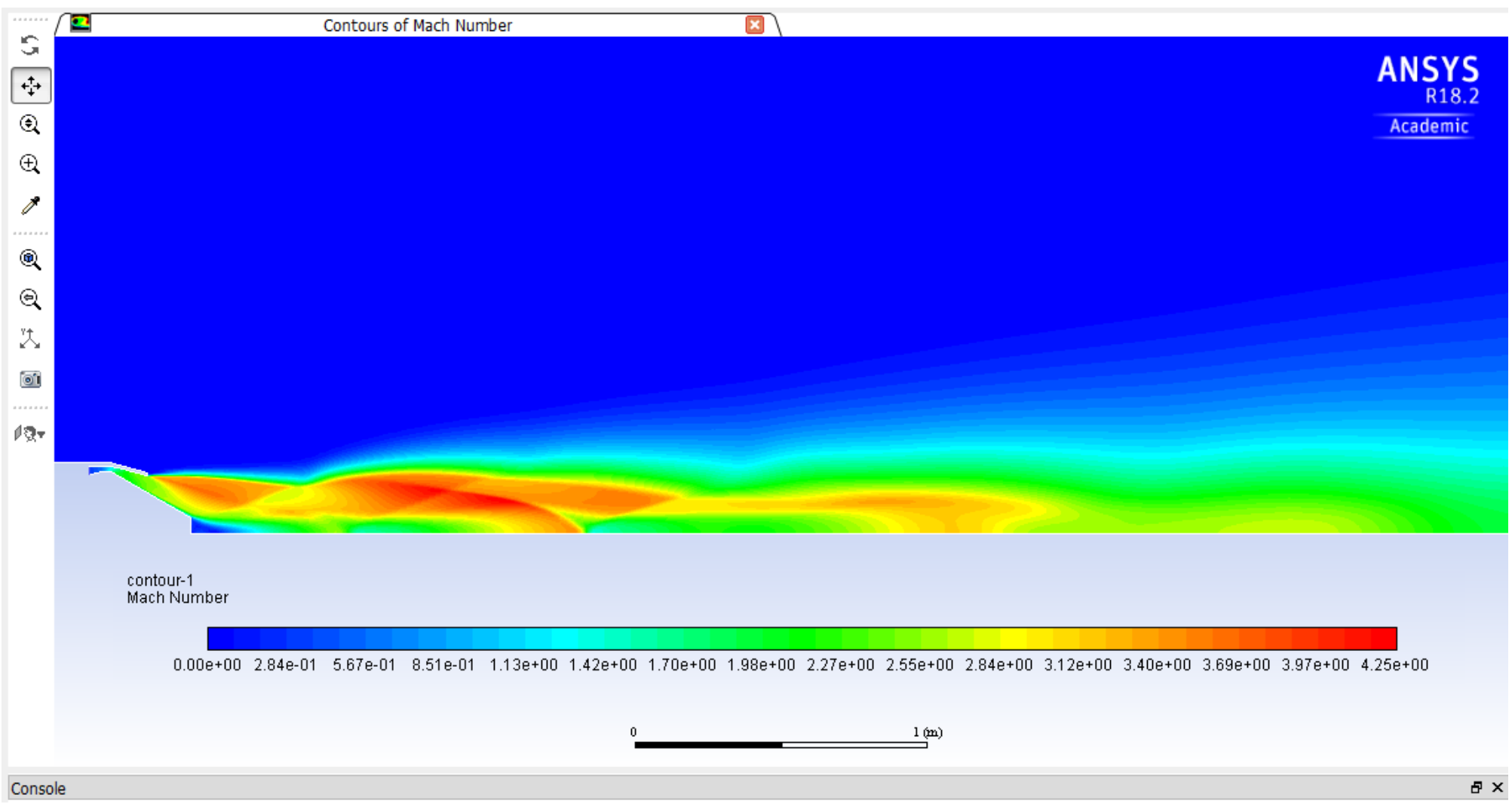

Figure 109: Contour of Mach number for Aerospike 1, with nozzle flow expansion into ambient air at $20 \mathrm{~km}$ standard atmosphere. 


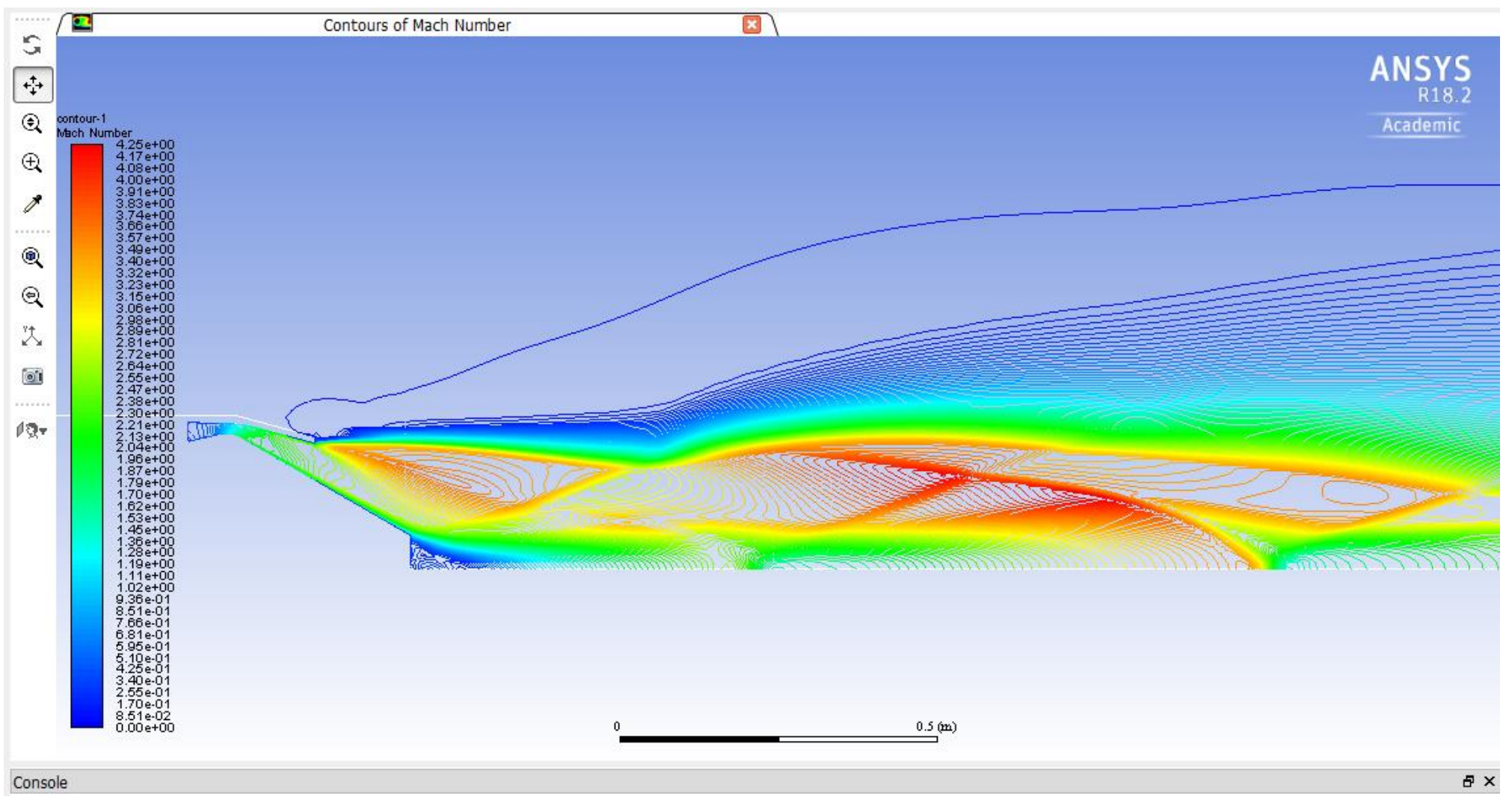

Figure 110: Line contours of Mach number for Aerospike 1, with nozzle flow expansion into ambient air at 20km standard atmosphere. 


\section{Aerospike 9 Flow Contours}

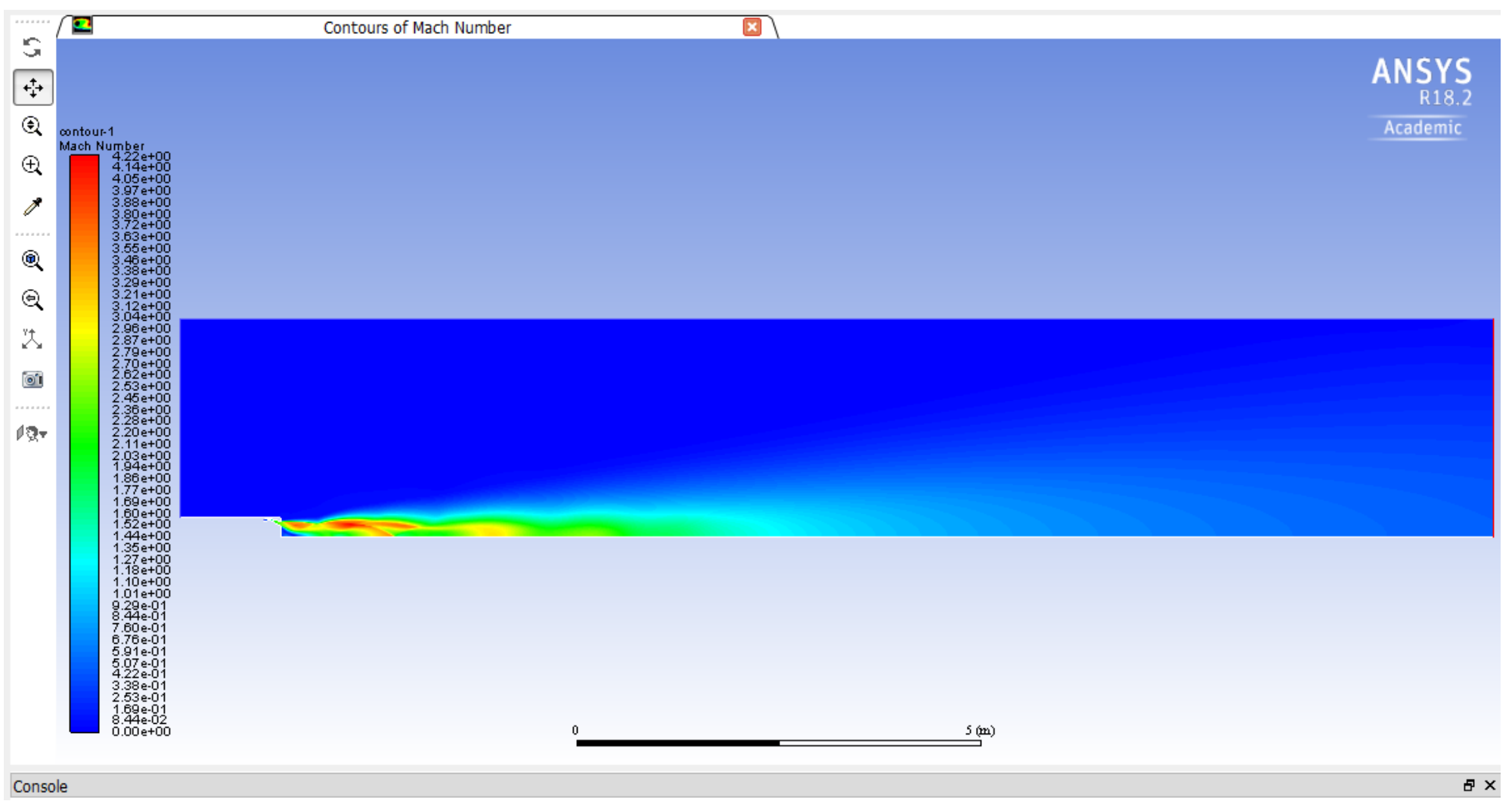

Figure 111: Contour of Mach number for Aerospike 9, with nozzle flow expansion into ambient air at 20km standard atmosphere. 


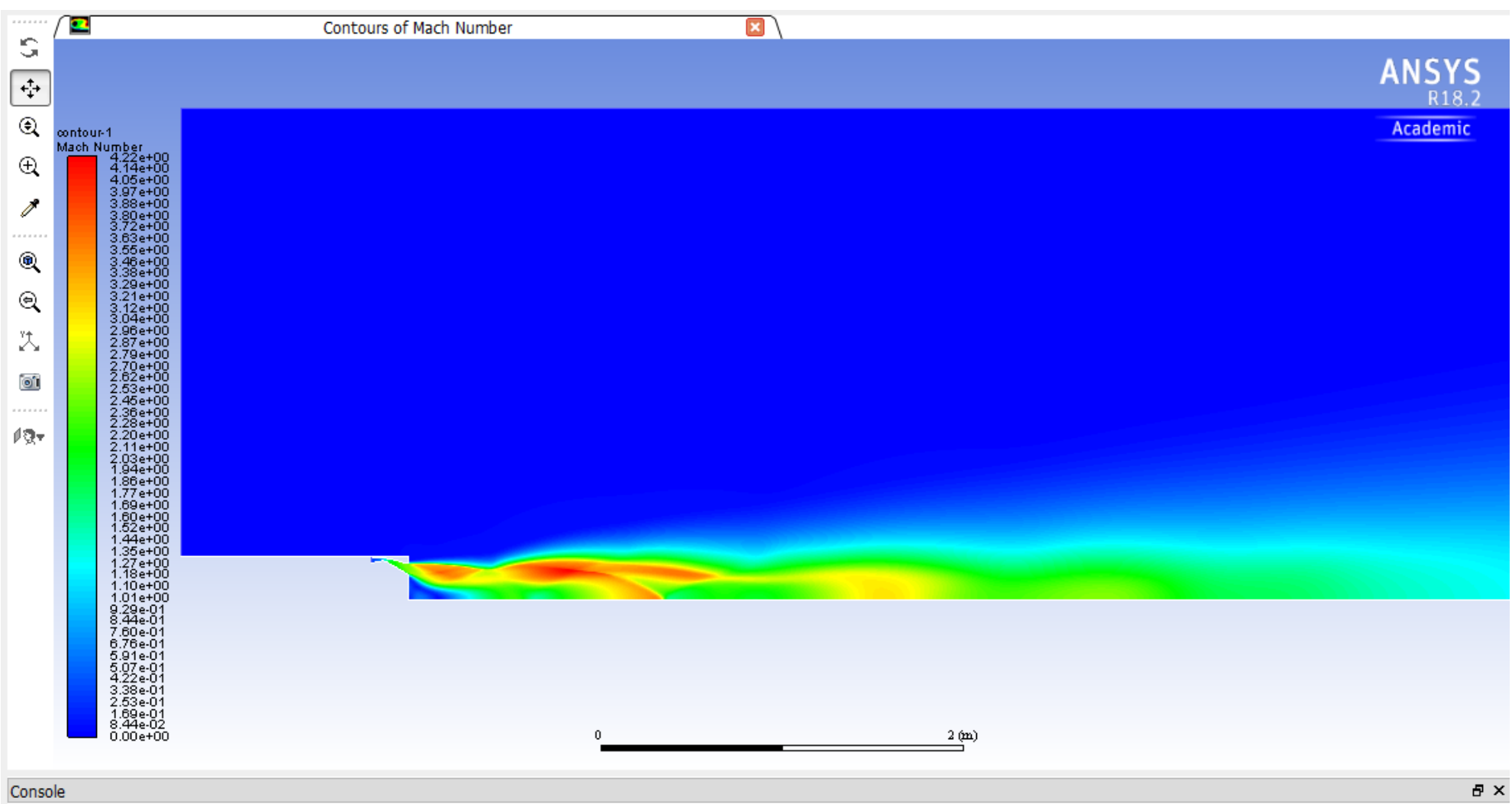

Figure 112: Contour of Mach number for Aerospike 9, with nozzle flow expansion into ambient air at 20km standard atmosphere. 


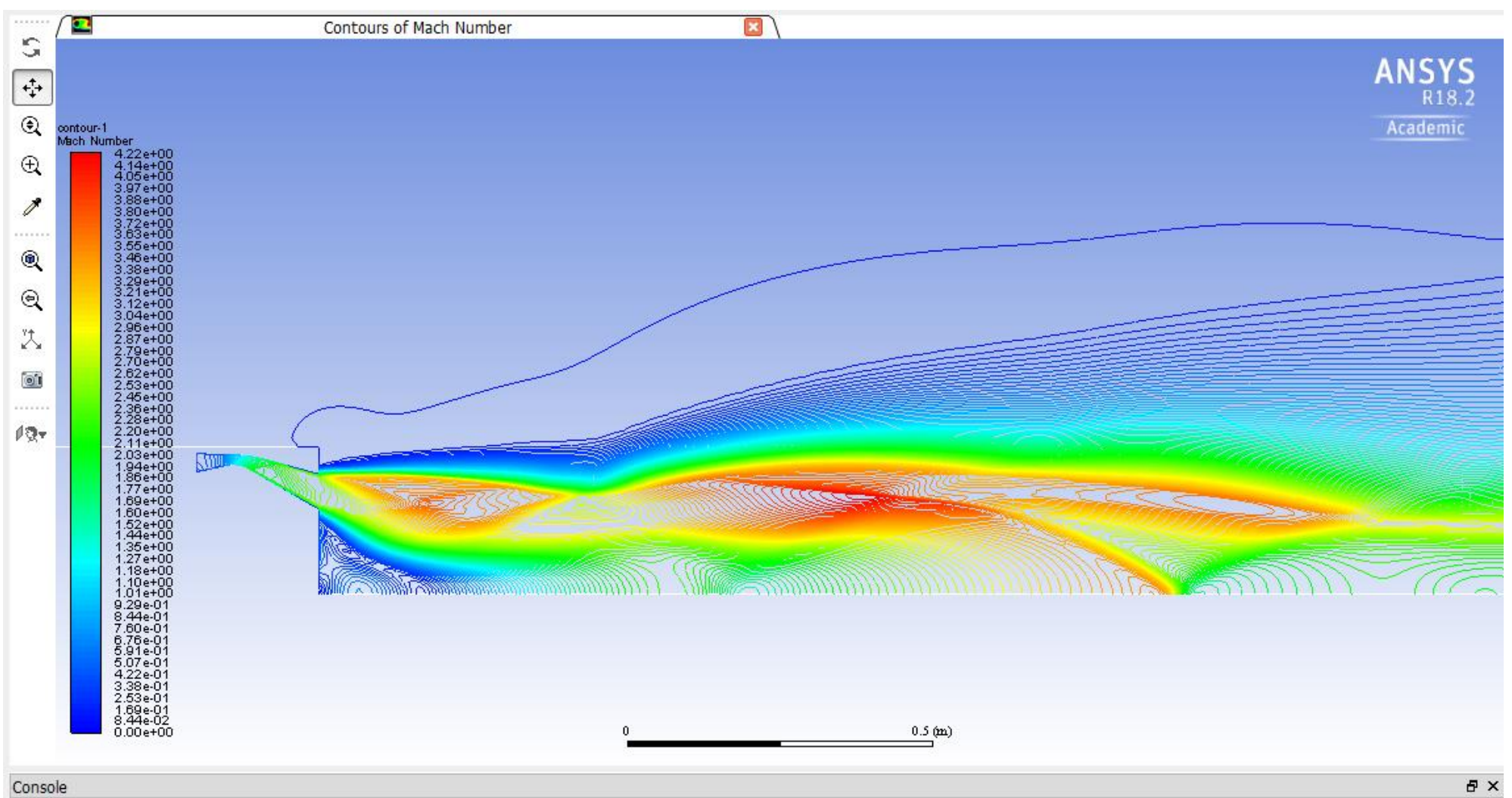

Figure 113: Line contours of Mach number for Aerospike 9, with nozzle flow expansion into ambient air at 20km standard atmosphere. 


\section{Aerospike 13 Flow Contours}

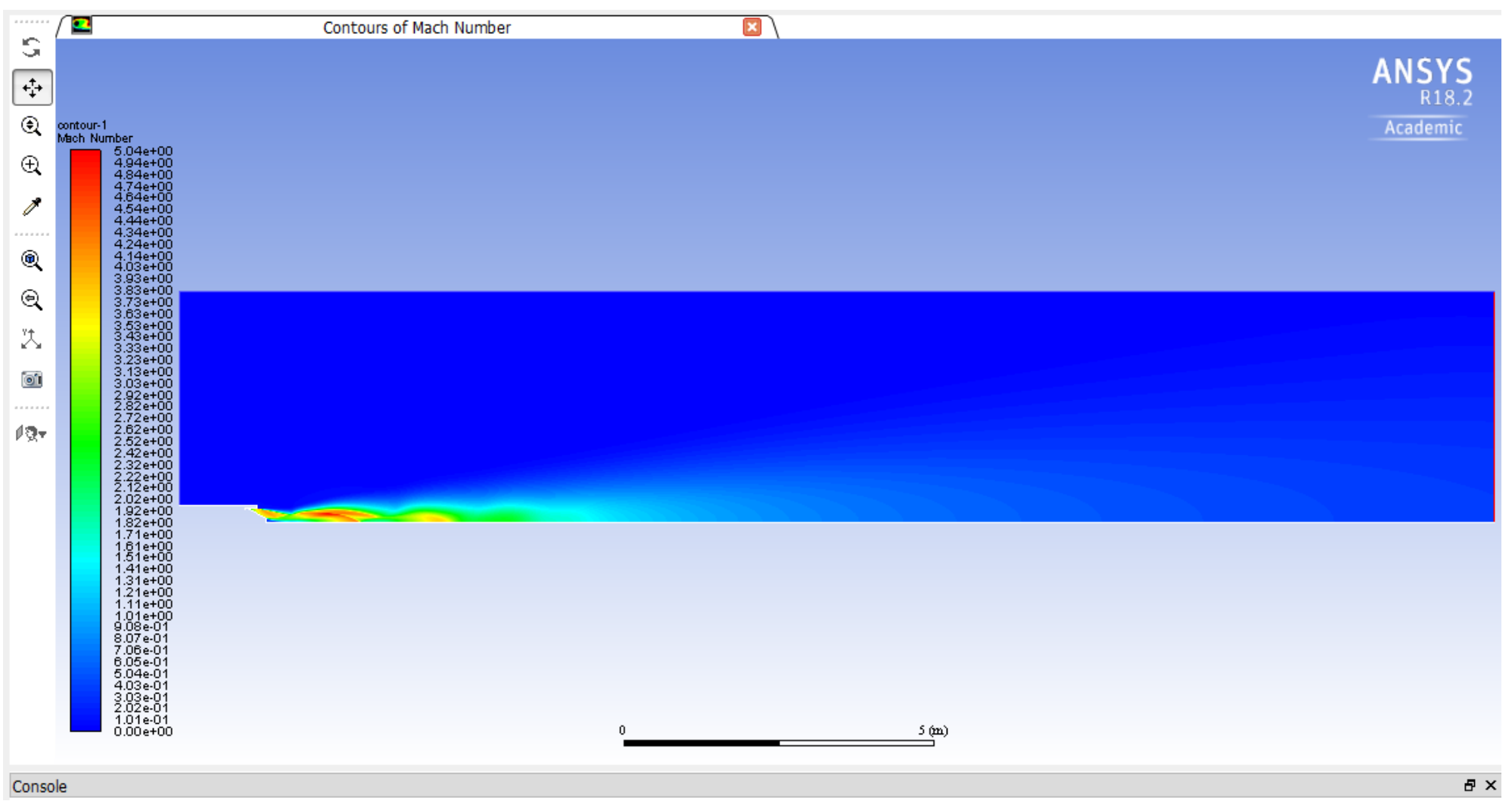

Figure 114: Contour of Mach number for Aerospike 13, with nozzle flow expansion into ambient air at 20km standard atmosphere. 


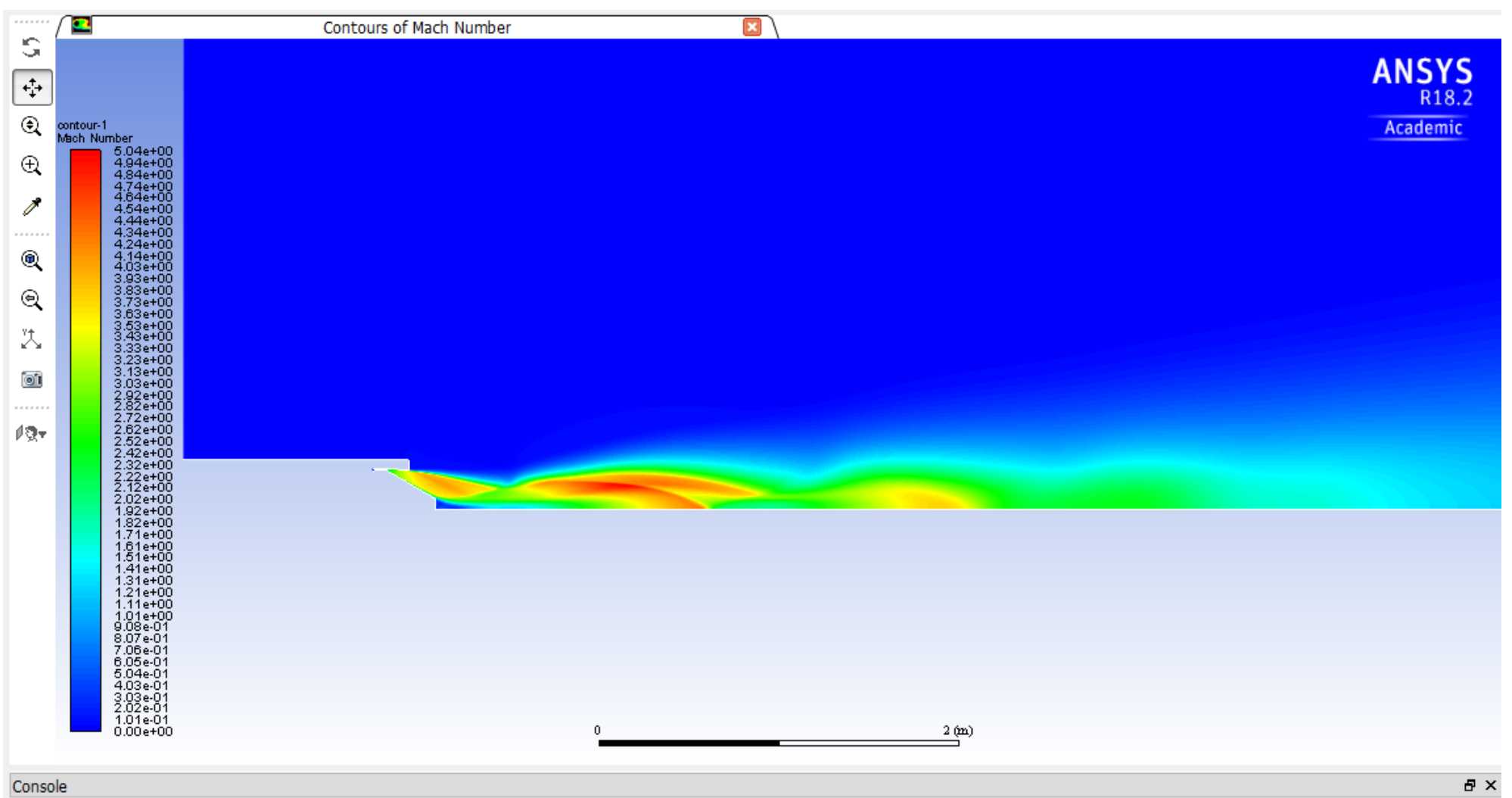

Figure 115: Contour of Mach number for Aerospike 13, with nozzle flow expansion into ambient air at $20 \mathrm{~km}$ standard atmosphere. 


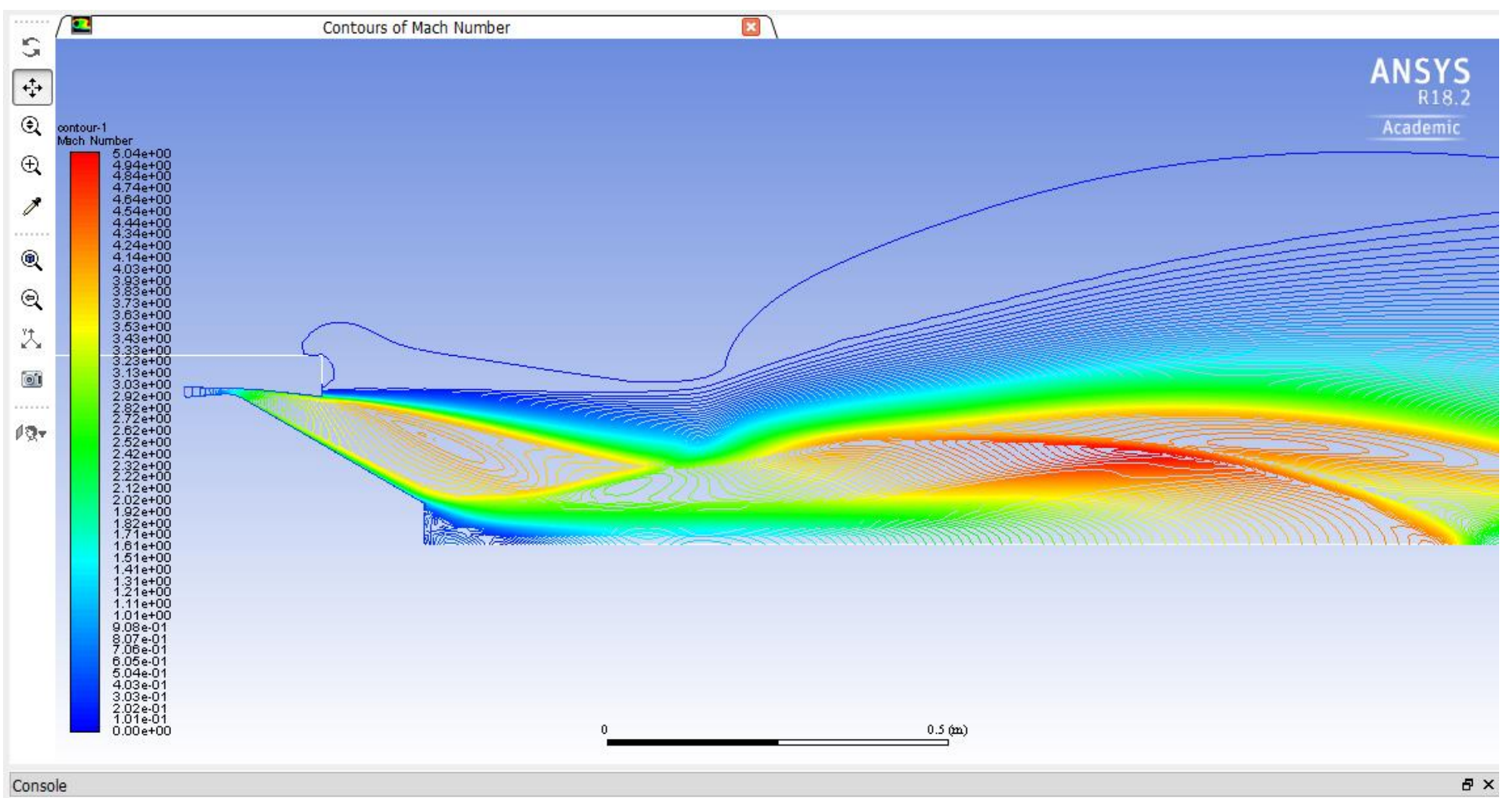

Figure 116: Line contours of Mach number for Aerospike 13, with nozzle flow expansion into ambient air at 20km standard atmosphere. 


\section{Aerospike 18 Flow Contours}

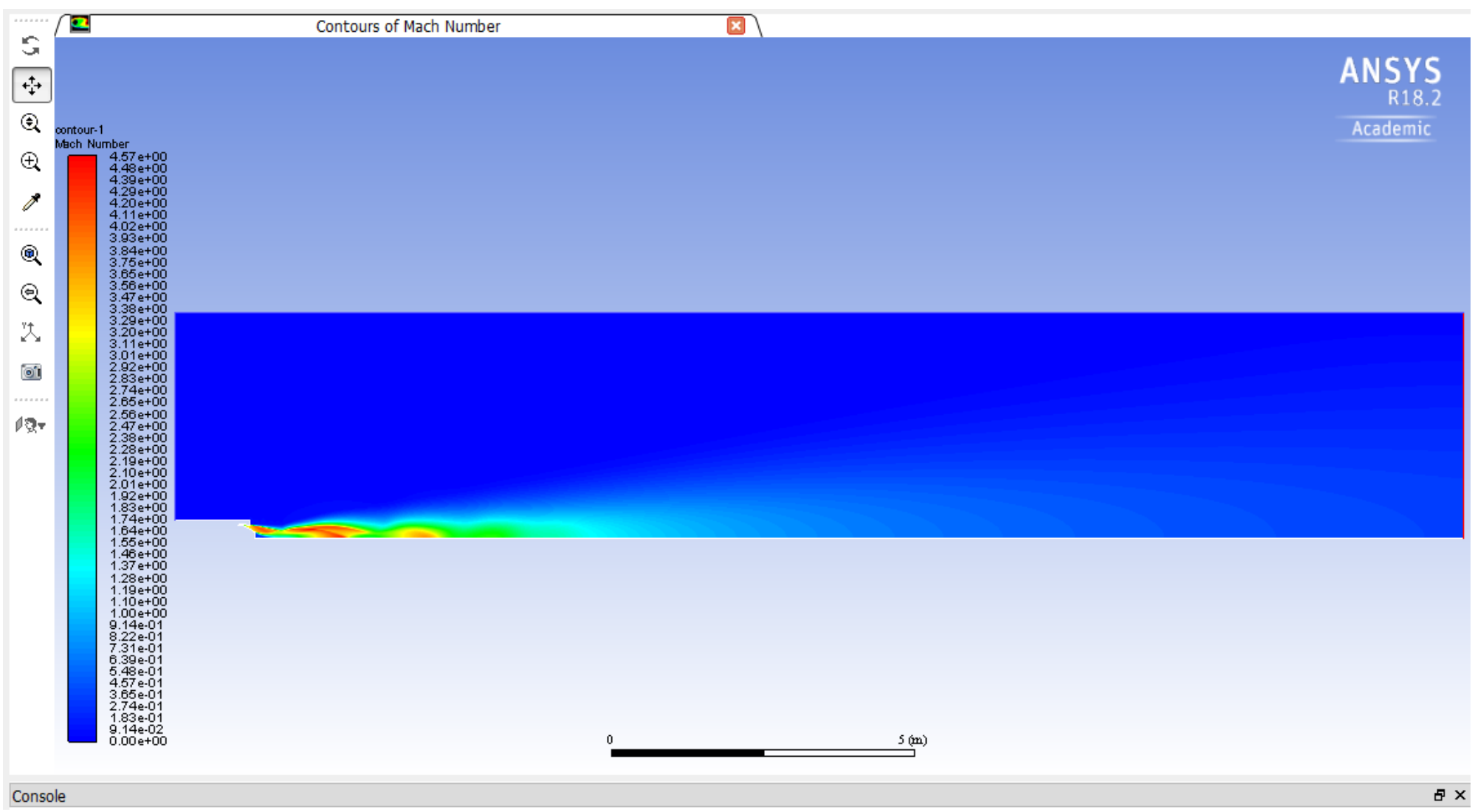

Figure 117: Contour of Mach number for Aerospike 18, with nozzle flow expansion into ambient air at 20km standard atmosphere. 


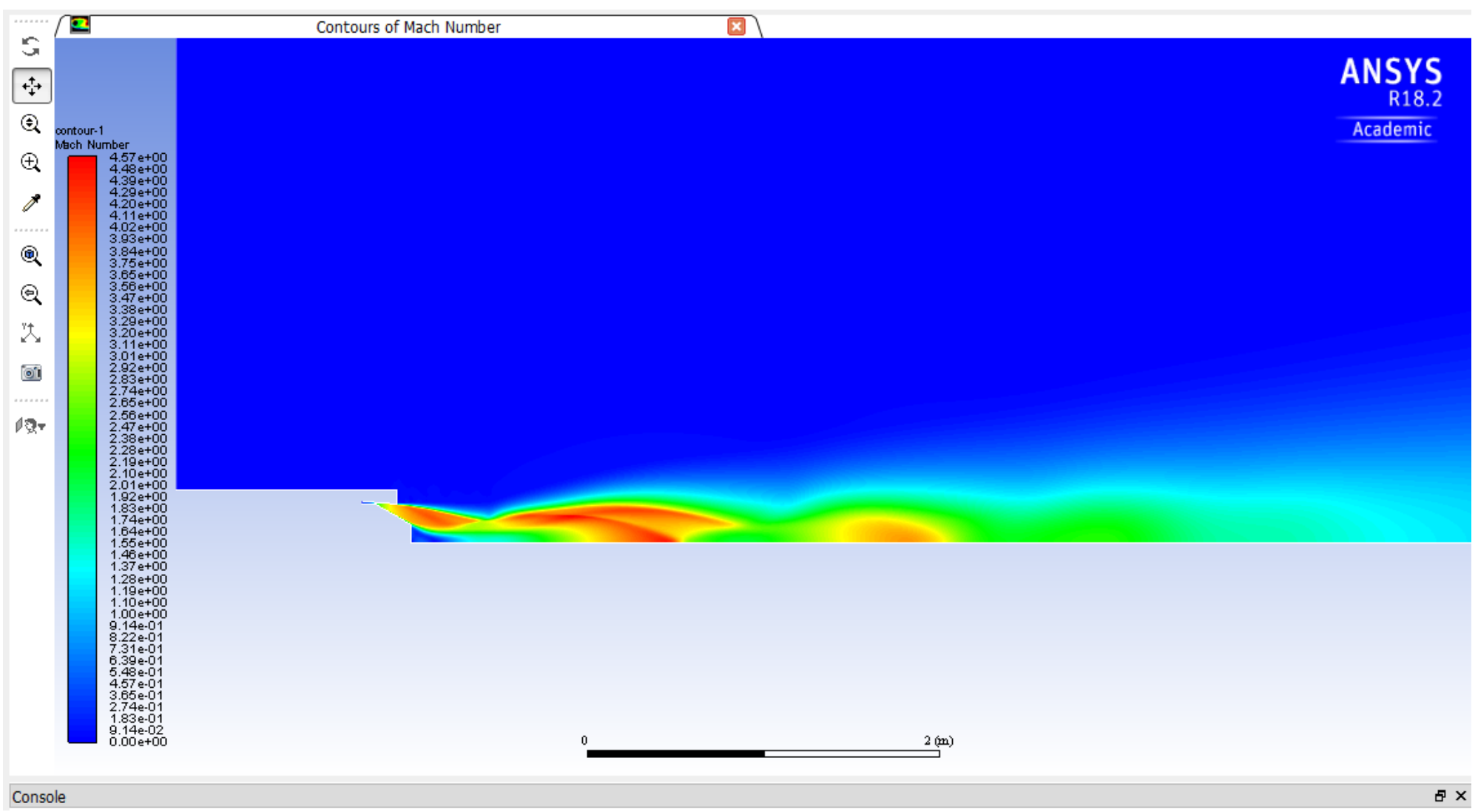

Figure 118: Contour of Mach number for Aerospike 18, with nozzle flow expansion into ambient air at 20km standard atmosphere. 


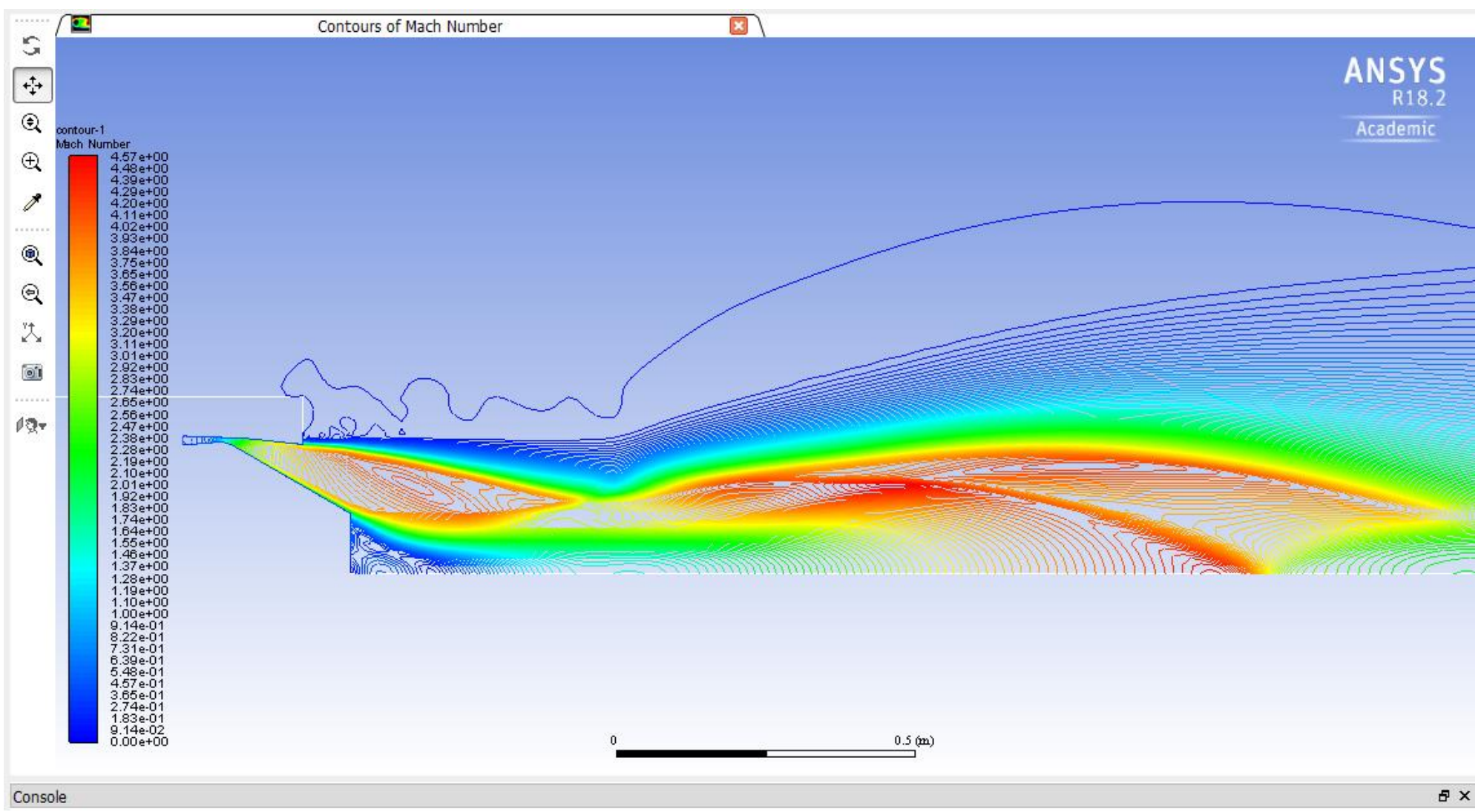

Figure 119: Line contours of Mach number for Aerospike 18, with nozzle flow expansion into ambient air at 20km standard atmosphere. 


\section{CONCLUSION}

The aim behind the use of Aerospikes is to achieve higher specific impulse values than with conventional supersonic bell nozzles. However, not every Aerospike will achieve a larger specific impulse than a conventional nozzle, as shown by the results of the cases tested for this report. Most of the Aerospike designs did not achieve larger specific impulses than the base case, due to the convergent - divergent section of an Aerospike design being significantly lower in thrust than for the base case, and with the center - body of an Aerospike design not being able to over-compensate for the loss of thrust from the convergent - divergent section. In order to compare nozzles, it is desirable to have nozzle designs that utilize the same mass flow rate. In this way, for an aerospike design to be higher in specific impulse and a better contender as a replacement for a conventional nozzle, the aerospike will have to produce a larger thrust for the same mass flow rate. Aerospikes tend to be significantly shorter in axial length than conventional nozzles, and all the Aerospike designs tested for this report are axially and radially shorter than the base case. A shorter nozzle design tends to have a reduced structural mass. Based on the results of this report, in order to achieve higher specific impulse values from Aerospike designs, the chamber or total pressure for an Aerospike must be larger than that for a conventional nozzle, given that both the Aerospike and conventional nozzle operate under the mass flow rate. 


\section{APPENDIX}

\section{Ideal \& Real Gas Calculations}

Increasing the total pressure $\left(P_{o}\right)$ of the inlet gas increases in its static pressure $\left(P_{i}\right)$. However, if the static inlet temperature $\left(T_{i}\right)$ is kept constant, there is a chance the gas behaviour will deviate from the ideal gas law, since its static pressure is being increased while its static temperature is kept constant [9]. This for the case were $P_{o}=691,706.7447 \mathrm{~Pa}$ and $T_{i}=$ $922.0389 \mathrm{~K}$. In order to prove that the gas properties can still be predicted using the ideal gas law, a value for molar volume $\left(V_{m}\right)$ was calculated using the ideal gas law, and compared with results from the Van der Waals and Redlich - Kwong models:

$$
\begin{gathered}
P_{i}=\frac{P_{o}}{\left(1+\frac{\gamma-1}{2} M_{i}^{2}\right)^{\gamma /(\gamma-1)}} \\
=\frac{691,706.7447 P a}{\left[1+\frac{1.4-1}{2}(0.2968)^{2}\right]^{1.4 /(1.4-1)}} \\
=650,691.6109 P a \\
T_{i}=922.0389 \mathrm{~K}
\end{gathered}
$$

Gas density and molar volume for air as an ideal gas:

$$
\begin{gathered}
\rho_{i}=\frac{P_{i}}{R T_{i}} \\
=2.45892 \mathrm{~kg} / \mathrm{m}^{3} \\
V_{m}=\frac{M}{P_{i}} \\
=\frac{0.02897 \mathrm{~kg} / \mathrm{mol}^{3}}{2.45892 \mathrm{~kg} / \mathrm{m}^{3}}
\end{gathered}
$$

Van der Waals model [9]:

$$
R T_{i}=\left(P_{i}+\frac{a}{V_{m}^{2}}\right)\left(V_{m}-b\right)
$$




$$
\begin{gathered}
a=\frac{27 R^{2} T_{c}^{2}}{64 P_{c}} \\
b=\frac{R T_{c}}{8 P_{c}} \\
V_{m}=\frac{M}{P_{i}} \\
R T_{i}=P_{i} V_{m}-P_{i} b+\frac{a}{V_{m}}-\frac{a b}{V_{m}^{2}} \\
P_{i} V_{m}+\frac{a}{V_{m}}-\frac{a b}{V_{m}^{2}}=R T_{i}+P_{i} b
\end{gathered}
$$

Right - hand side (RHS):

$$
\begin{gathered}
R T_{i}+P_{i} b=R T_{i}+P_{i}\left(\frac{R T_{c}}{8 P_{c}}\right) \\
=(8.31446 \mathrm{~J} / \mathrm{K} \cdot \mathrm{mol})(922.0389 \mathrm{~K})+(650,691.6109 \mathrm{~Pa})\left[\frac{(8.31446 \mathrm{~J} / \mathrm{K} \cdot \mathrm{mol})(132.63 \mathrm{~K})}{8(3785502 \mathrm{~Pa})}\right] \\
=7,689.95 \mathrm{~J} / \mathrm{mol}
\end{gathered}
$$

Left - hand side (LHS):

$$
\begin{gathered}
P_{i} V_{m}+\frac{a}{V_{m}}-\frac{a b}{V_{m}^{2}}=P_{i} V_{m}+\frac{\frac{27 R^{2} T_{c}^{2}}{64 P_{c}}}{V_{m}}-\frac{\left(\frac{27 R^{2} T_{c}^{2}}{64 P_{c}}\right)\left(\frac{R T_{c}}{8 P_{c}}\right)}{V_{m}^{2}} \\
=(650,691.6109 \mathrm{~Pa}) V_{m}+\frac{\frac{27(8.31446 \mathrm{~J} / \mathrm{K} \cdot \mathrm{mol})^{2}(132.63 \mathrm{~K})^{2}}{64(3,785,502 \mathrm{~Pa})}}{V_{m}} \\
\left.-\frac{\left[\frac{27(8.31446 \mathrm{~J} / \mathrm{K} \cdot \mathrm{mol})^{2}(132.63 \mathrm{~K})^{2}}{64(3,785,502 \mathrm{~Pa})}\right]\left[\frac{(8.31446 \mathrm{~J} / \mathrm{K} \cdot \mathrm{mol})(132.63 \mathrm{~K})}{8(3,785,502 \mathrm{~Pa})}\right]}{V_{m}^{2}}\right] \\
=(650,691.6109 \mathrm{~Pa}) V_{m}+\frac{0.135523 \mathrm{~J}^{2} / \mathrm{Pa} \cdot \mathrm{mol}^{2}}{V_{m}}-\frac{0.00000493485 \mathrm{~J}^{3} / \mathrm{Pa}^{2} \cdot \mathrm{mol}^{3}}{V_{m}^{2}}
\end{gathered}
$$

For $V_{m}=0.01178 \mathrm{~m}^{3} / \mathrm{mol}$ from ideal gas law $\rightarrow L H S=7676.62 \mathrm{~J} / \mathrm{mol}$ 


$$
\begin{gathered}
\% \text { error }=\left|\frac{7,689.95 \mathrm{~J} / \mathrm{mol}-7,676.62 \mathrm{~J} / \mathrm{mol}}{7,689.95 \mathrm{~J} / \mathrm{mol}}\right| \times 100 \\
=0.173
\end{gathered}
$$

Redlich - Kwong model [10]:

$$
\begin{gathered}
R T_{i}=\left[P_{i}+\frac{a}{\sqrt{T_{i}} V_{m}\left(V_{m}+b\right)}\right]\left(V_{m}-b\right) \\
a=0.42748 \frac{R^{2} T_{c}^{5 / 2}}{P_{c}} \\
b=0.08664 \frac{R T_{c}}{P_{c}} \\
R T_{i}=P_{i}\left(V_{m}-b\right)+\frac{a\left(V_{m}-b\right)}{\sqrt{T_{i}} V_{m}\left(V_{m}+b\right)} \\
=P_{i} V_{m}-P_{i} b+\frac{a}{\sqrt{T_{i}}\left(V_{m}+b\right)}-\frac{a b}{\sqrt{T_{i}} V_{m}\left(V_{m}+b\right)} \\
R T_{i}+P_{i} b=P_{i} V_{m}+\frac{a}{\sqrt{T_{i}}\left(V_{m}+b\right)}-\frac{a b}{\sqrt{T_{i}} V_{m}\left(V_{m}+b\right)}
\end{gathered}
$$

RHS:

$$
\begin{gathered}
R T_{i}+P_{i} b=R T_{i}+P_{i}\left(0.08664 \frac{R T_{c}}{P_{c}}\right) \\
=(8.31446 \mathrm{~J} / \mathrm{K} \cdot \mathrm{mol})(922.0389 \mathrm{~K}) \\
+(650,691.6109 \mathrm{~Pa})\left[(0.08664) \frac{(8.31446 \mathrm{~J} / \mathrm{K} \cdot \mathrm{mol})(132.36 \mathrm{~K})}{3,785,502 \mathrm{~Pa}}\right] \\
=7,682.68 \mathrm{~J} / \mathrm{mol}
\end{gathered}
$$


LHS:

$$
\begin{array}{r}
P_{i} V_{m}+\frac{a}{\sqrt{T_{i}}\left(V_{m}+b\right)}-\frac{a b}{\sqrt{T_{i}} V_{m}\left(V_{m}+b\right)} \\
=P_{i} V_{m}+\frac{0.42748 \frac{R^{2} T_{c}^{\frac{5}{2}}}{P_{c}}}{\sqrt{T_{i}}\left(V_{m}+b\right)}-\frac{\left(0.42748 \frac{R^{2} T_{c}^{\frac{5}{2}}}{P_{c}}\right)\left(0.08664 \frac{R T_{c}}{P_{c}}\right)}{\sqrt{T_{i}} V_{m}\left(V_{m}+b\right)} \\
=(650,691.6109 P a) V_{m}+\frac{1.581484142 J^{2} \cdot K^{\frac{3}{2}} /\left(P a \cdot m o l^{2}\right)}{\sqrt{T_{i}}\left(V_{m}+b\right)} \\
-\frac{0.00003991495307 J^{3} \cdot K^{\frac{5}{2}} /\left(P a^{2} \cdot m o l^{3}\right)}{\sqrt{T_{i}} V_{m}\left(V_{m}+b\right)}
\end{array}
$$

For $V_{m}=0.01178 \mathrm{~m}^{3} / \mathrm{mol}$ from ideal gas law $\rightarrow$ LHS $=7,669.57 \mathrm{~J} / \mathrm{mol}$

$$
\begin{gathered}
\% \text { error }=\left|\frac{7,682.68 \mathrm{~J} / \mathrm{mol}-7,669.57 \mathrm{~J} / \mathrm{mol}}{7,682.68 \mathrm{~J} / \mathrm{mol}}\right| \times 100 \\
=0.171
\end{gathered}
$$

$\Rightarrow L H S \approx R H S$ in both Van der Waals and Redlich

- Kwong models, using the value of $V_{m}$ obtained from the ideal gas law 
Aerospike 2 Flow Contours

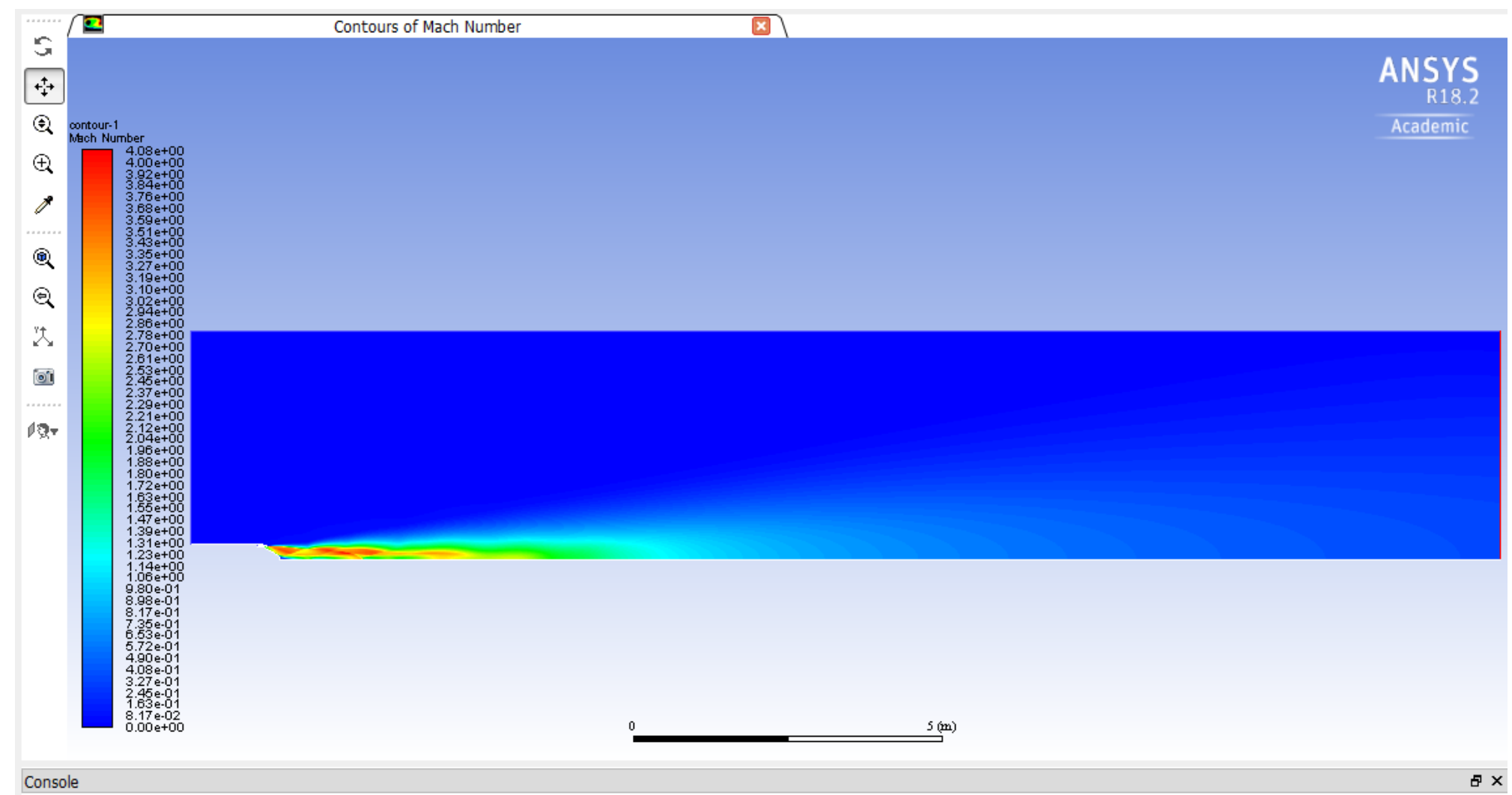

Figure 120: Contour of Mach number for Aerospike 2, with nozzle flow expansion into ambient air at 20km standard atmosphere. 


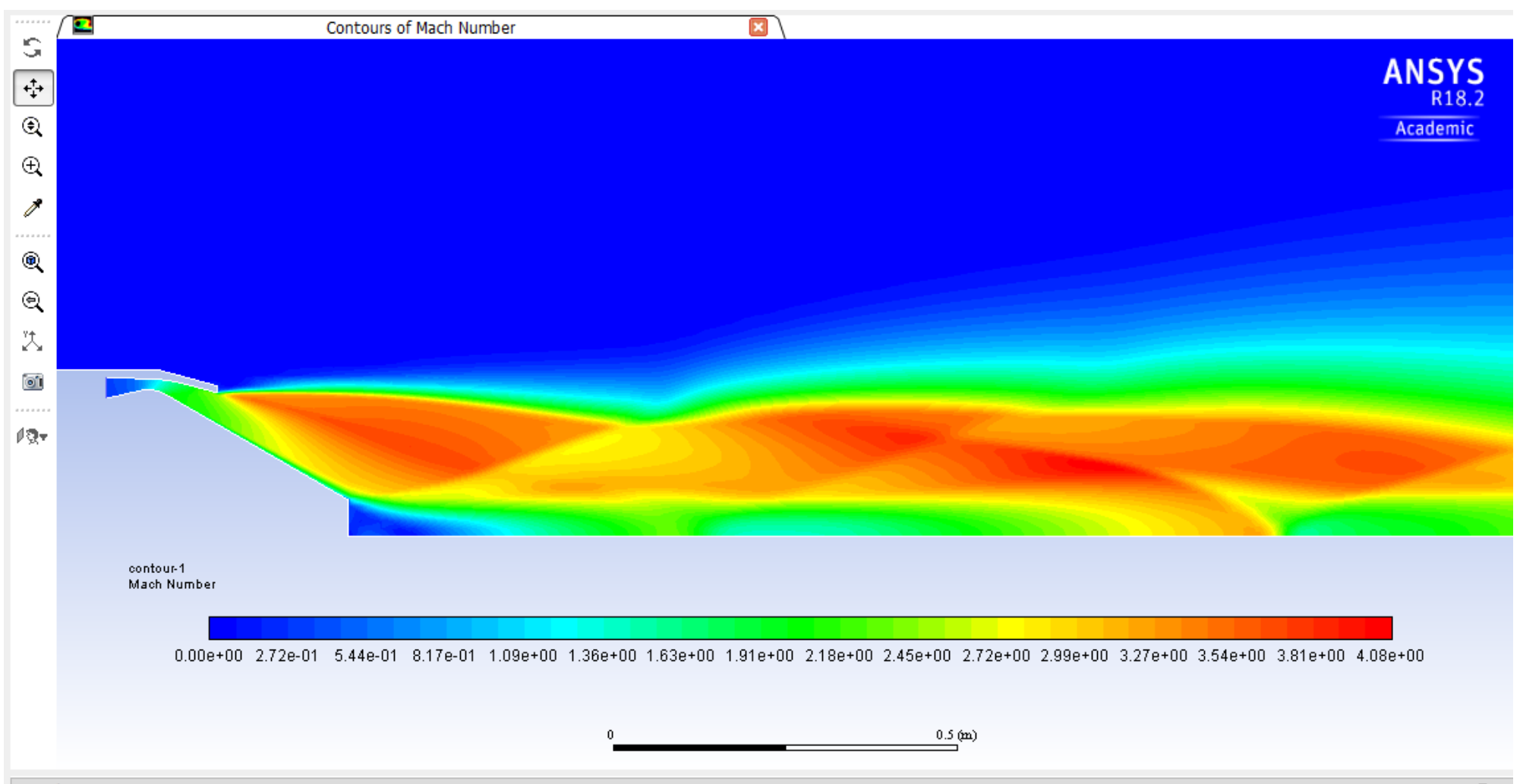

Figure 121: Contour of Mach number for Aerospike 2, with nozzle flow expansion into ambient air at 20km standard atmosphere. 


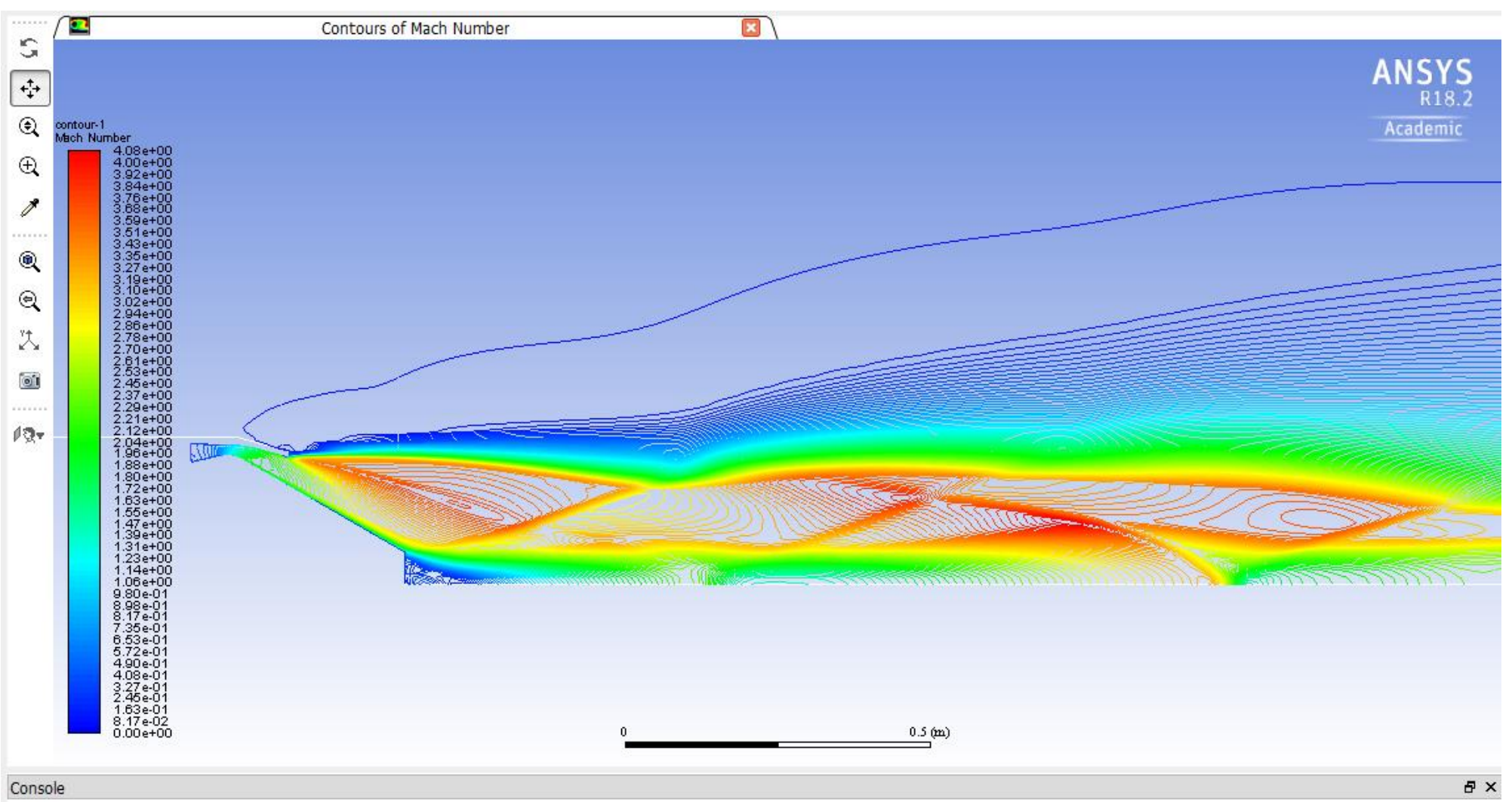

Figure 122: Line contours of Mach number for Aerospike 2, with nozzle flow expansion into ambient air at $20 \mathrm{~km}$ standard atmosphere. 
Aerospike 3 Flow Contours

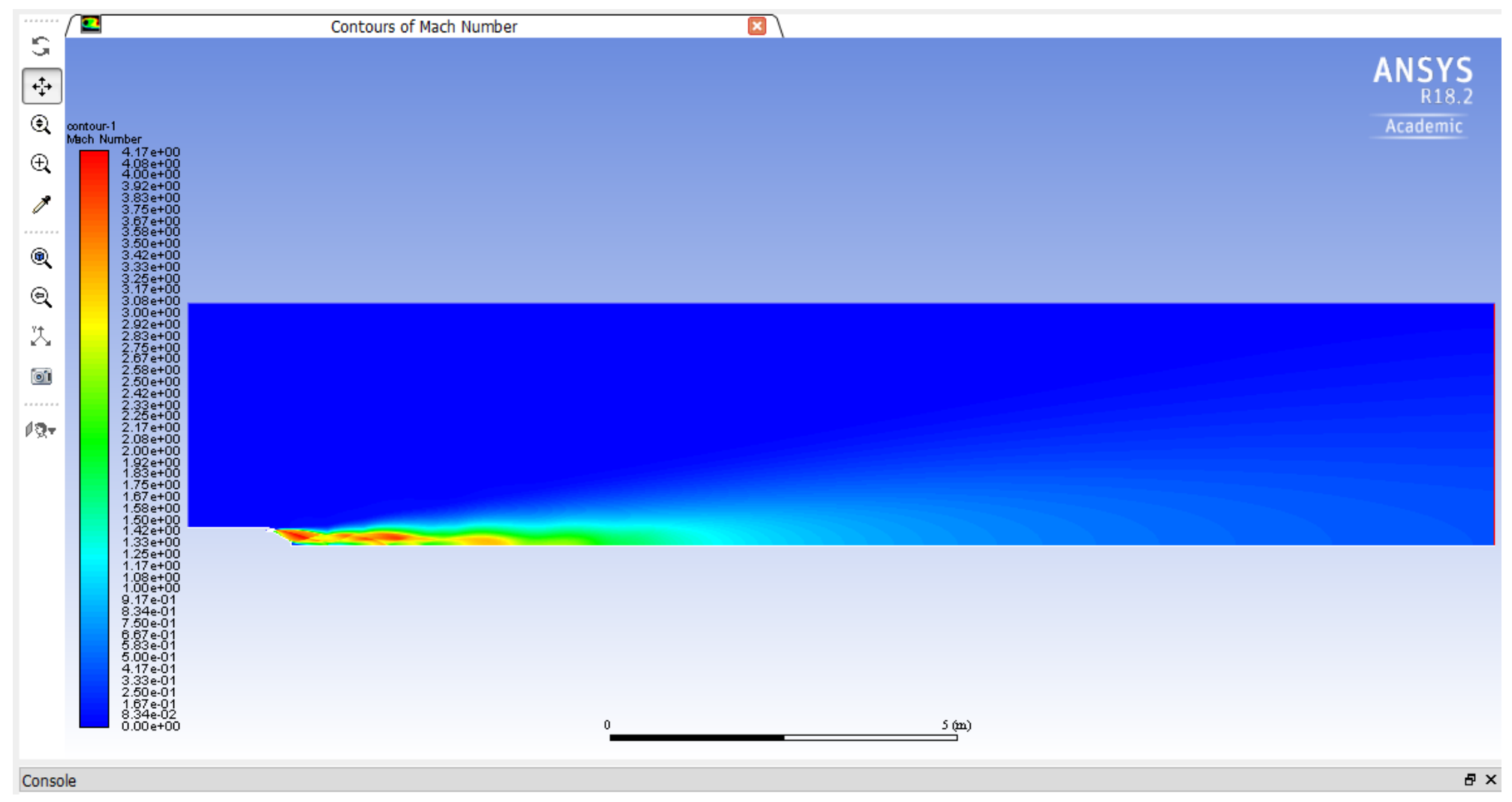

Figure 123: Contour of Mach number for Aerospike 3, with nozzle flow expansion into ambient air at 20km standard atmosphere. 


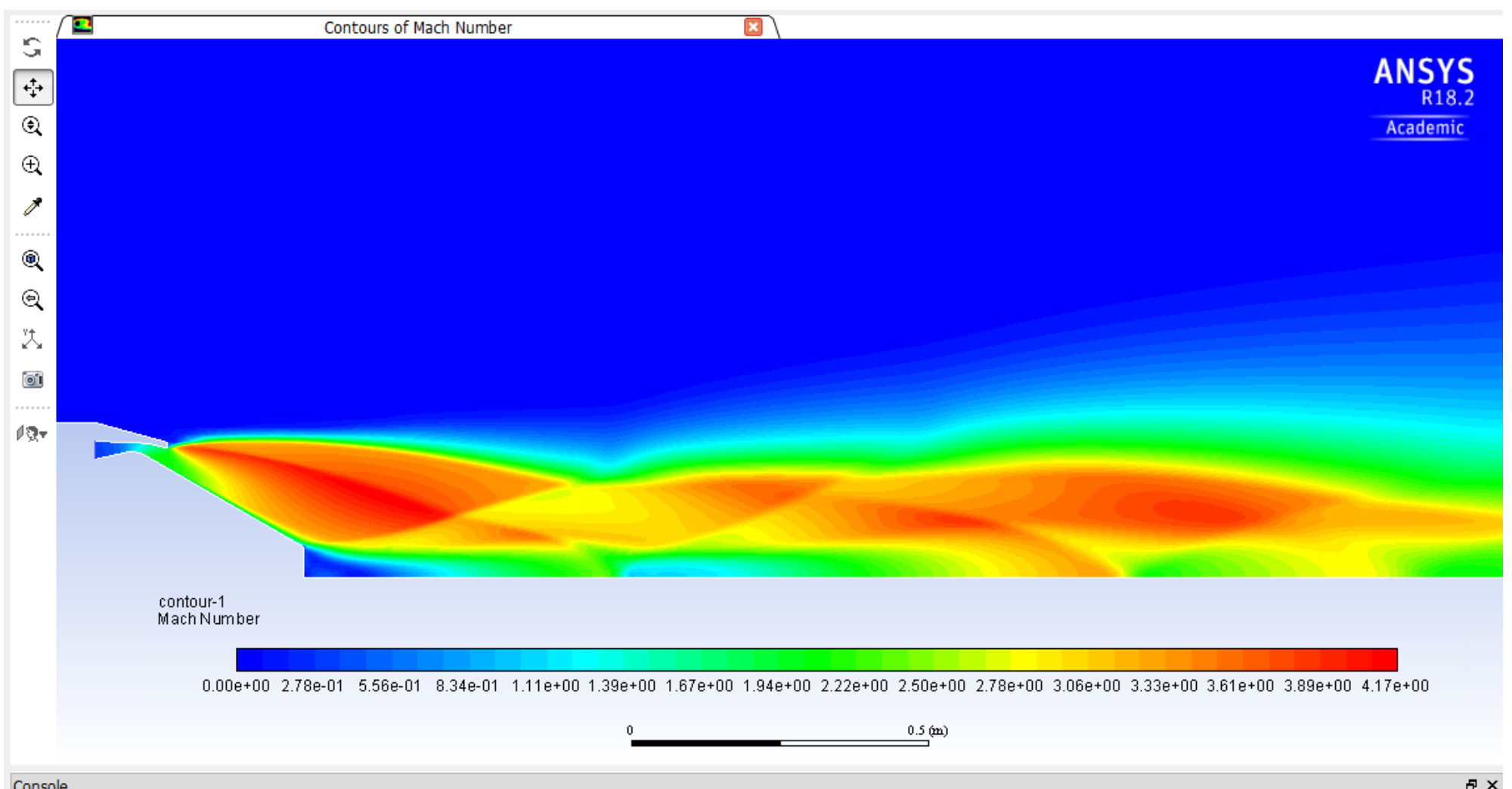

Figure 124: Contour of Mach number for Aerospike 3, with nozzle flow expansion into ambient air at $20 \mathrm{~km}$ standard atmosphere. 


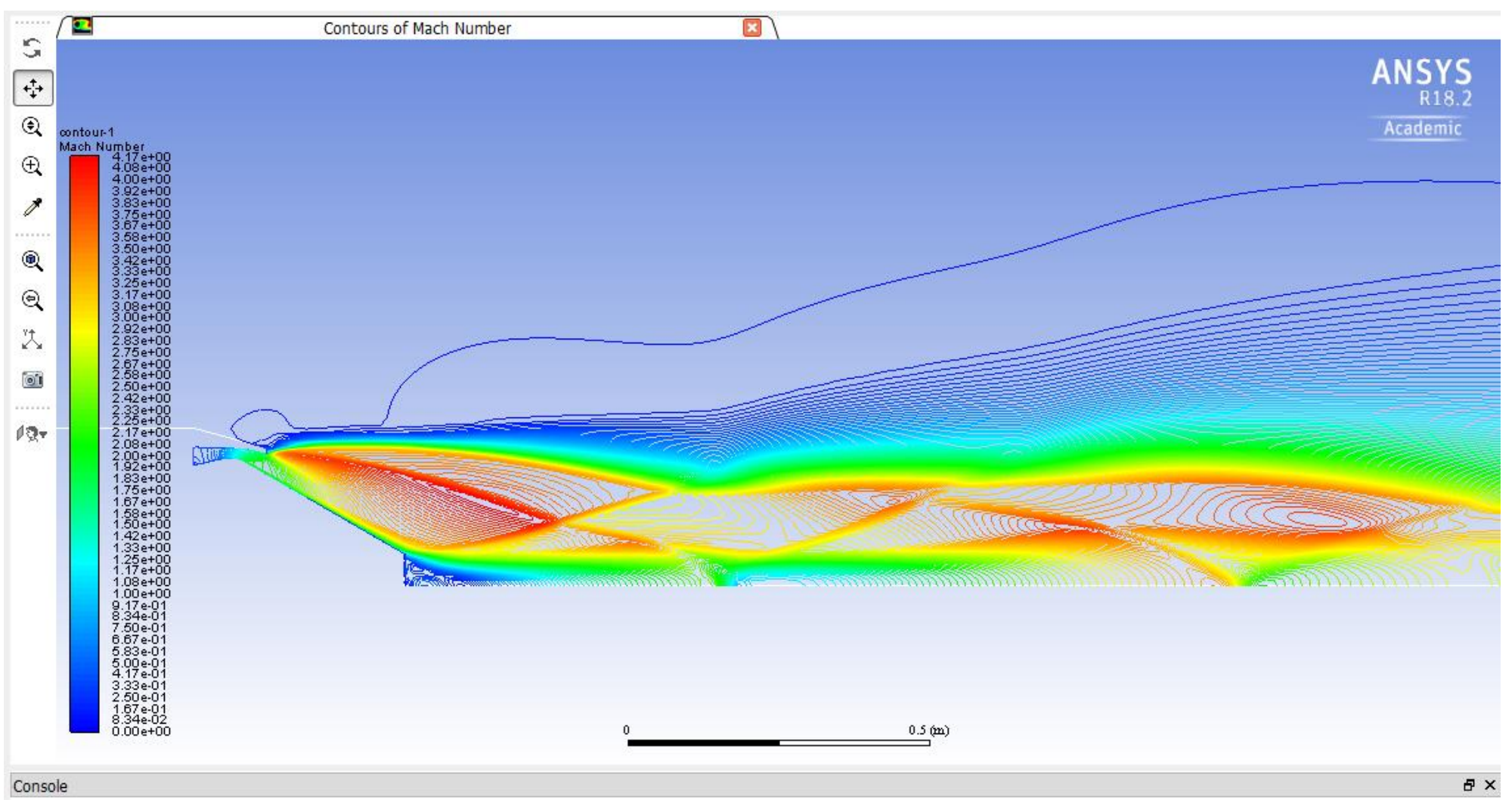

Figure 125: Line contours of Mach number for Aerospike 3, with nozzle flow expansion into ambient air at 20km standard atmosphere. 
Aerospike 4 Flow Contours

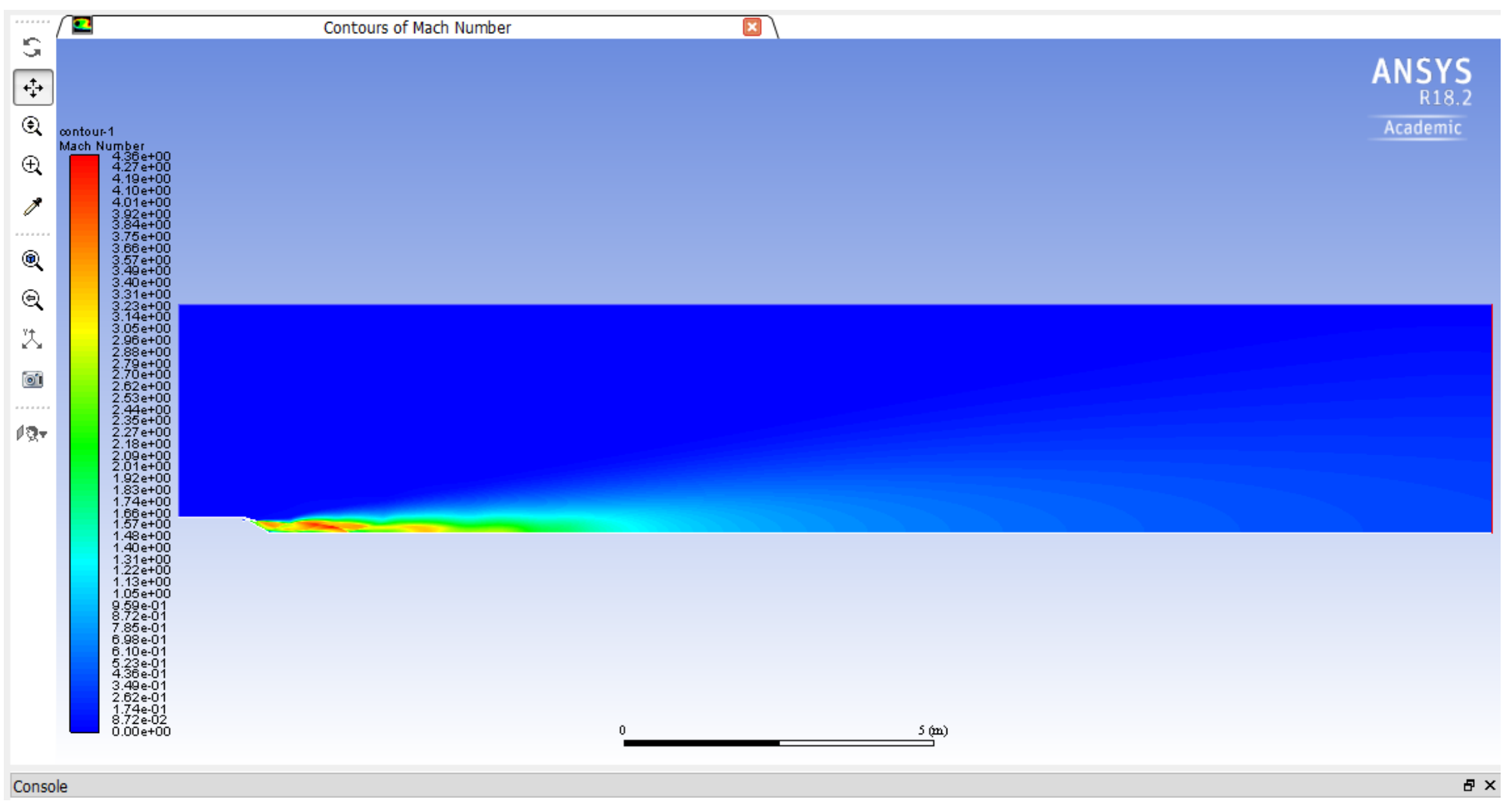

Figure 126: Contour of Mach number for Aerospike 4, with nozzle flow expansion into ambient air at 20km standard atmosphere. 


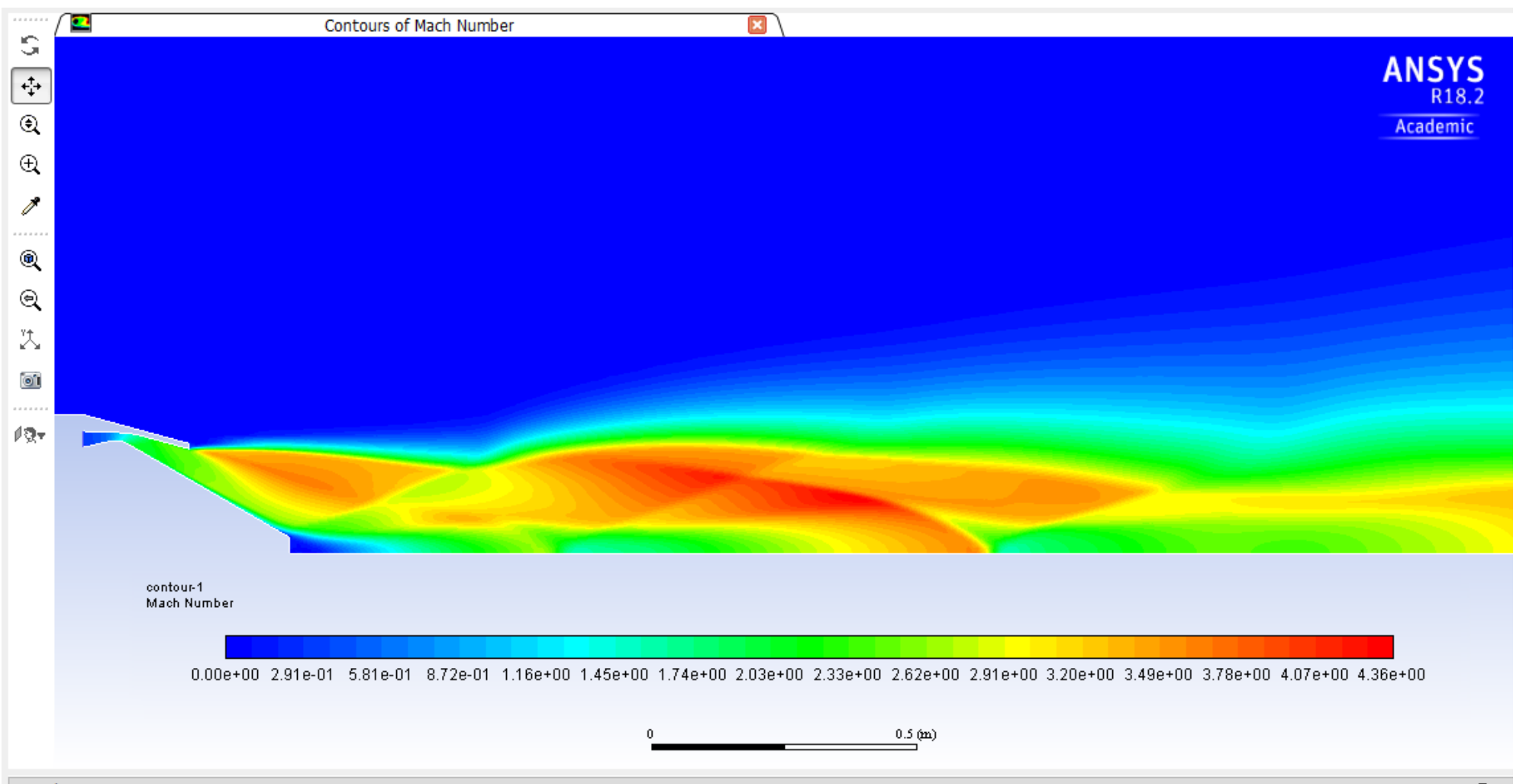

Console

Figure 127: Contour of Mach number for Aerospike 4, with nozzle flow expansion into ambient air at 20km standard atmosphere. 


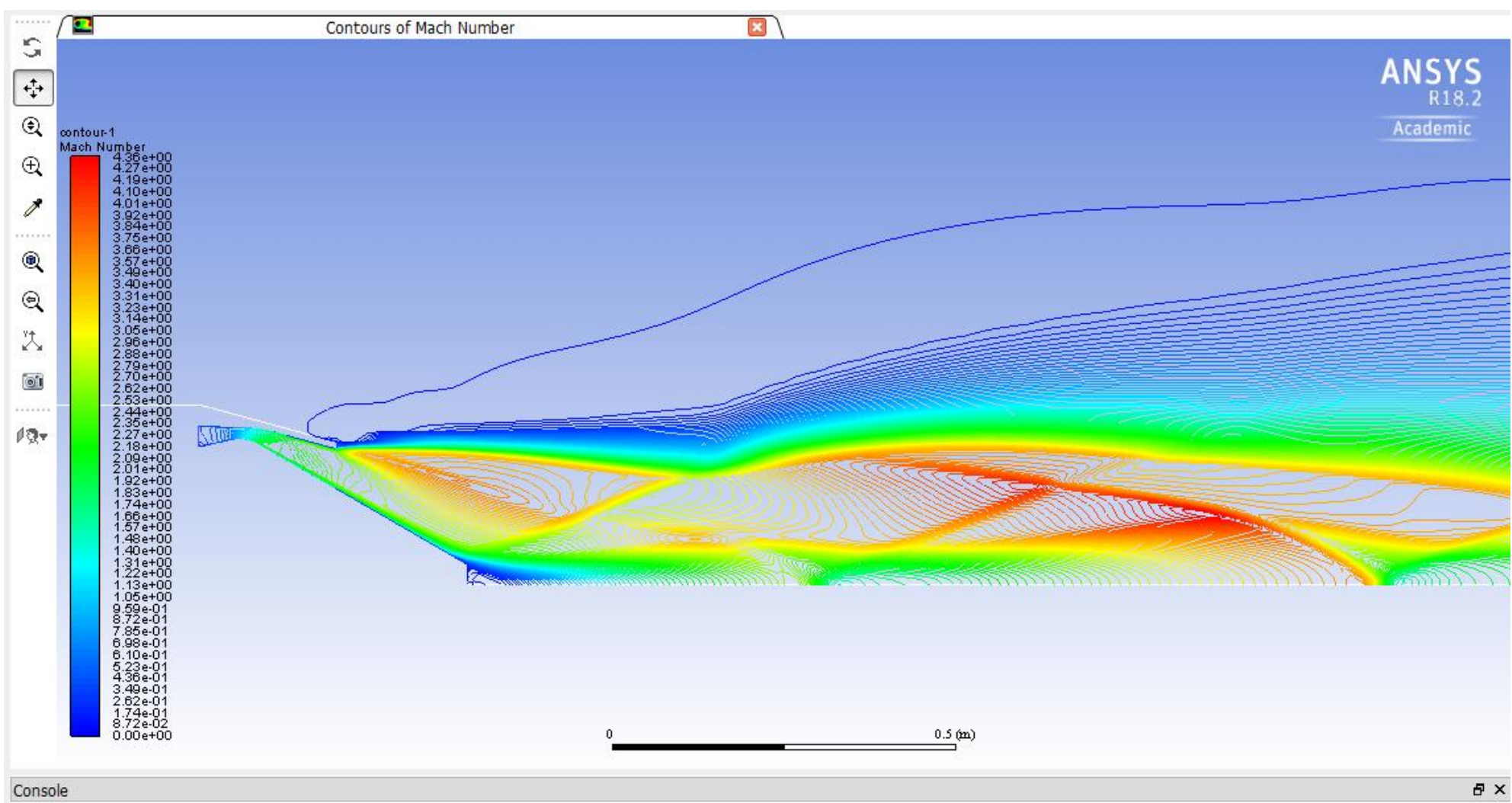

Figure 128: Line contours of Mach number for Aerospike 4, with nozzle flow expansion into ambient air at 20km standard atmosphere. 
Aerospike 5 Flow Contours

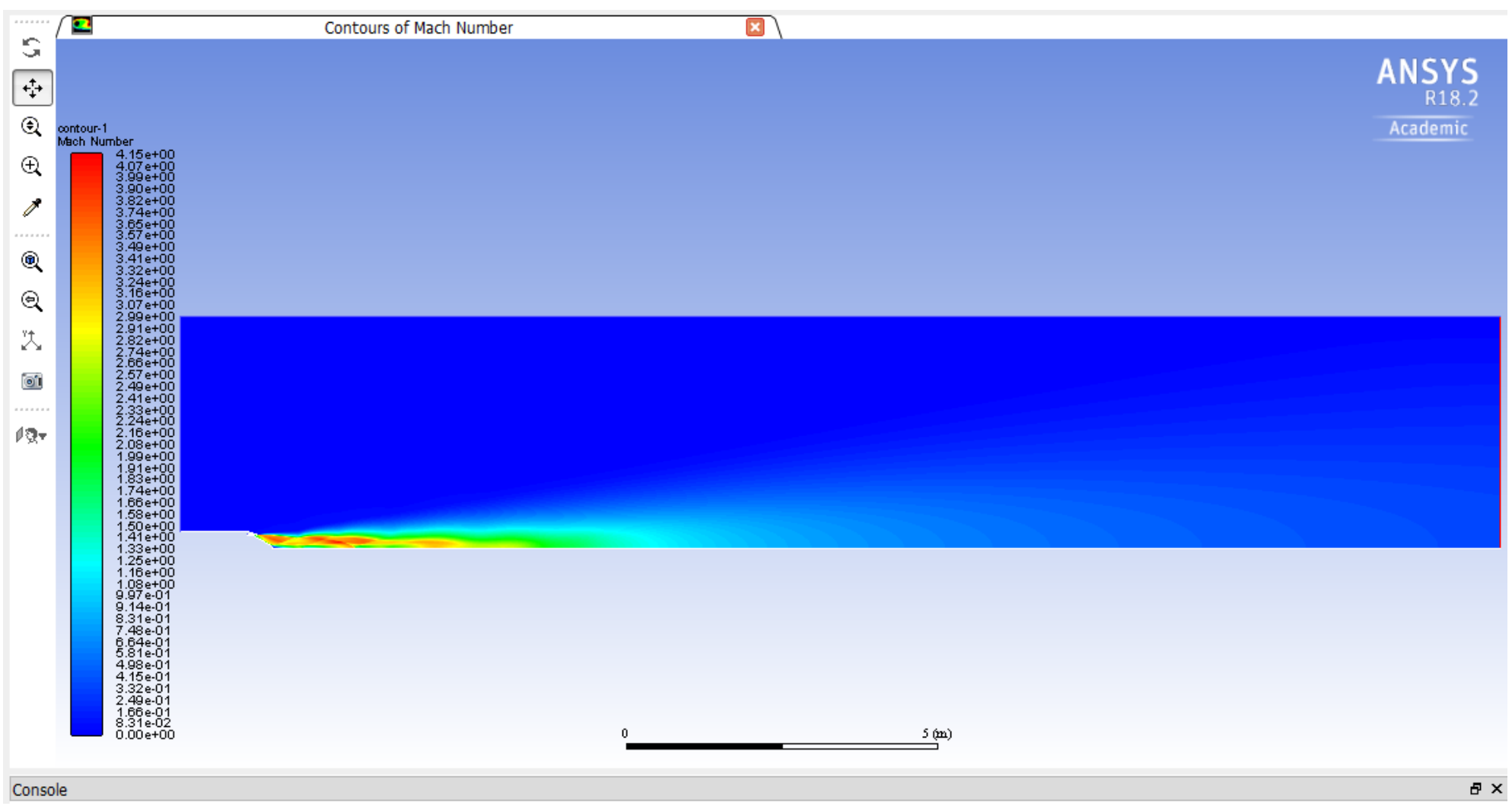

Figure 129: Contour of Mach number for Aerospike 5, with nozzle flow expansion into ambient air at 20km standard atmosphere. 


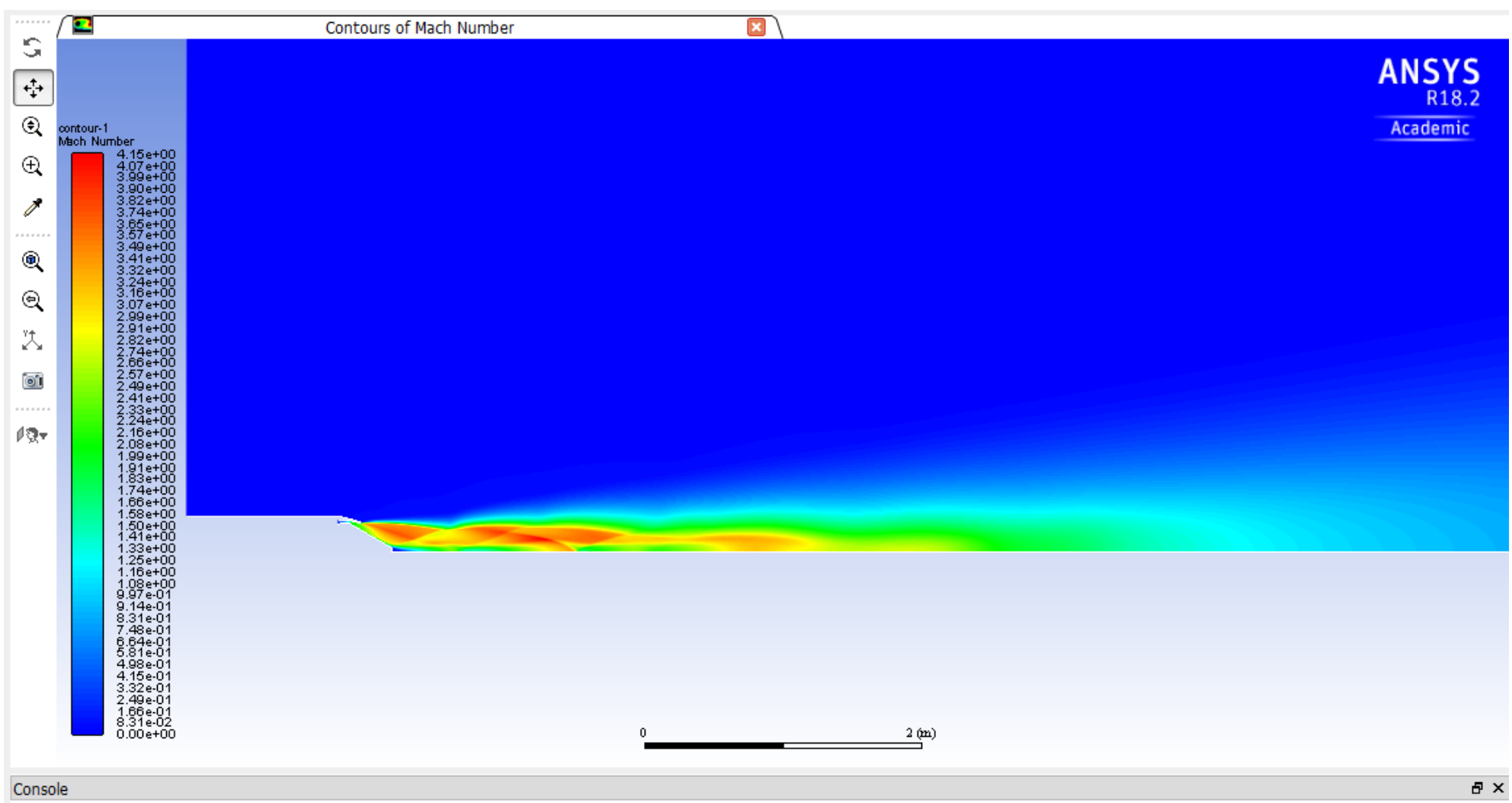

Figure 130: Contour of Mach number for Aerospike 5, with nozzle flow expansion into ambient air at 20km standard atmosphere. 


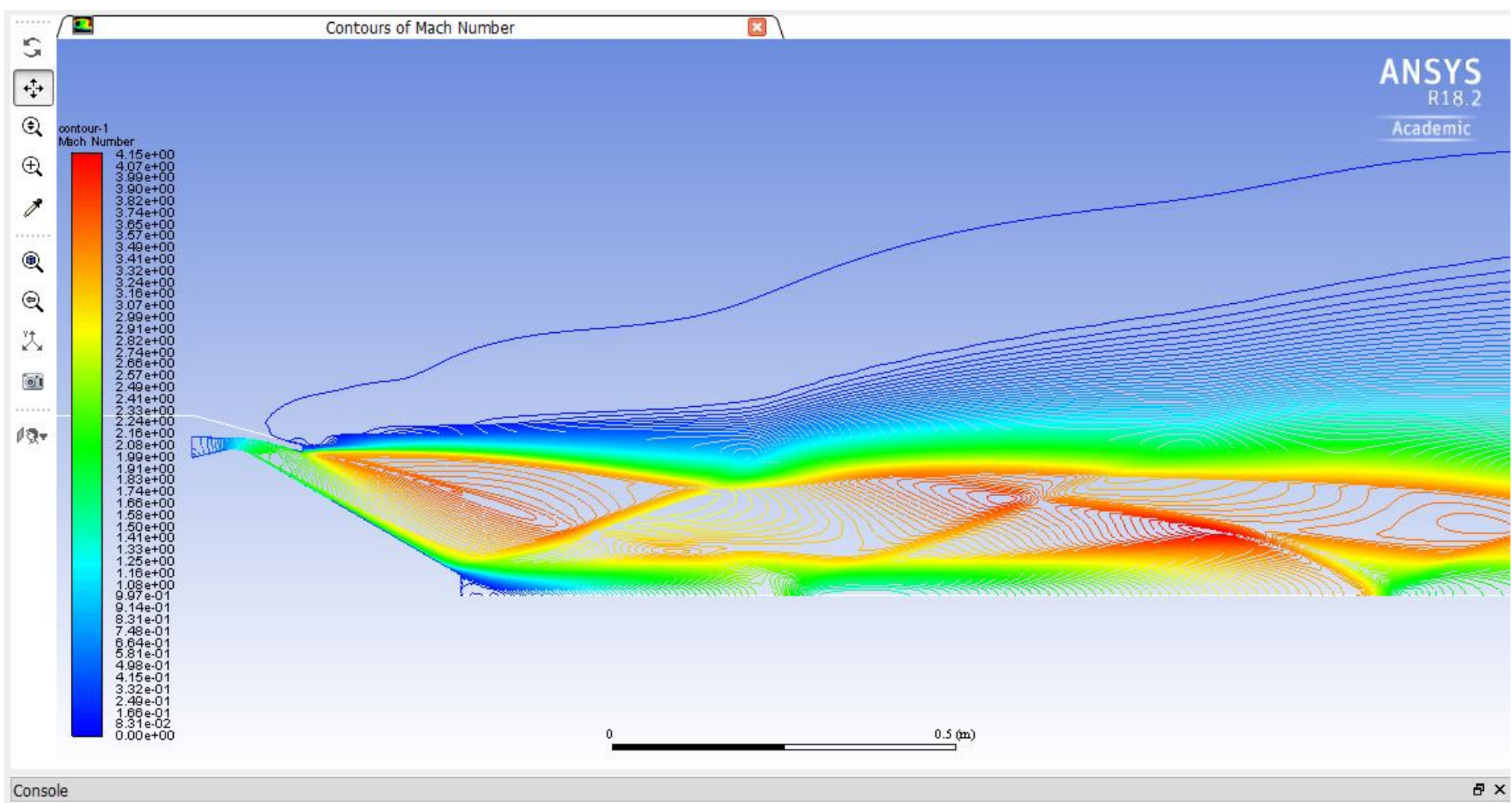

Figure 131: Line contours of Mach number for Aerospike 5, with nozzle flow expansion into ambient air at 20km standard atmosphere. 
Aerospike 6 Flow Contours

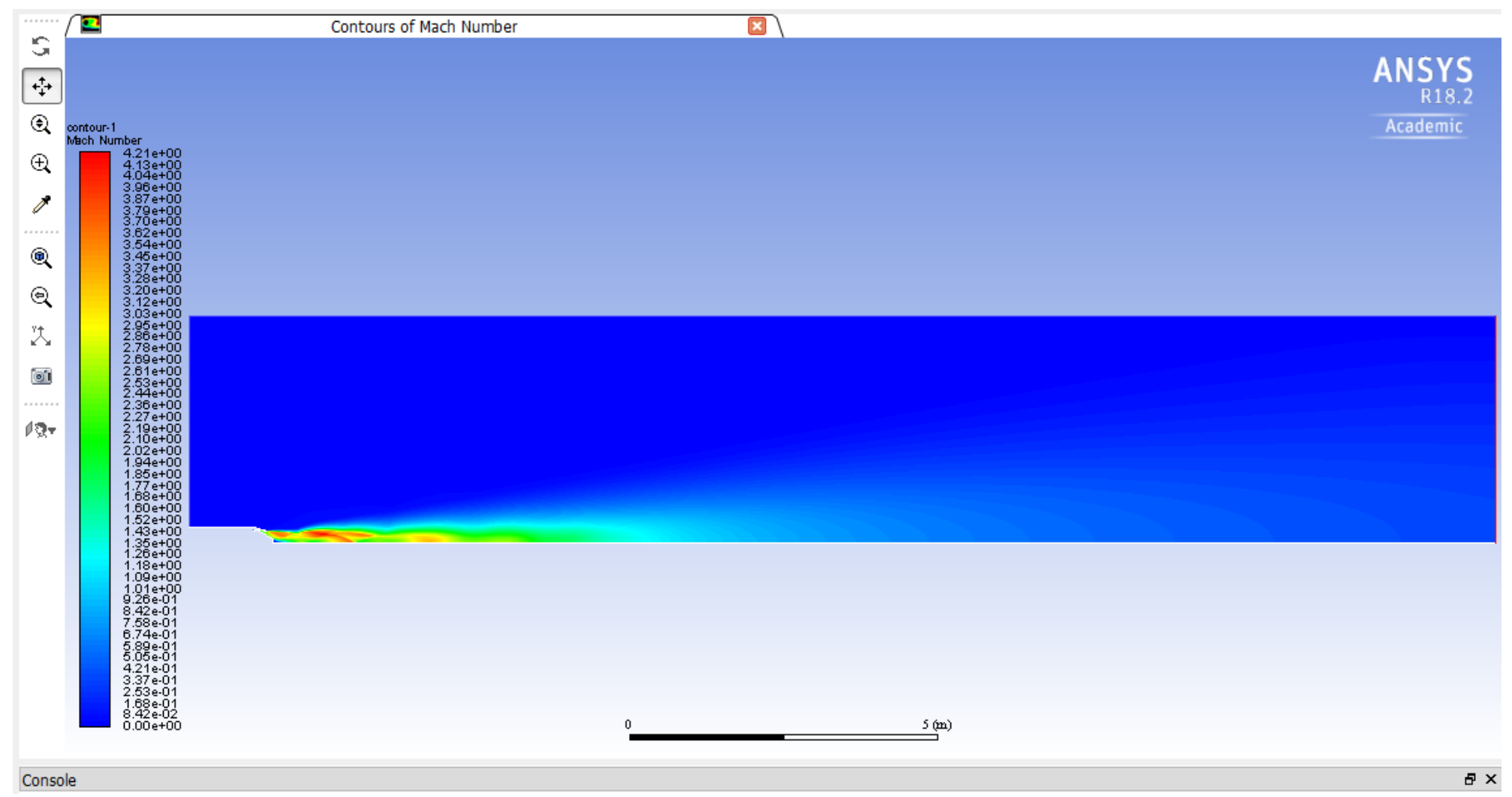

Figure 132: Contour of Mach number for Aerospike 6, with nozzle flow expansion into ambient air at 20km standard atmosphere. 


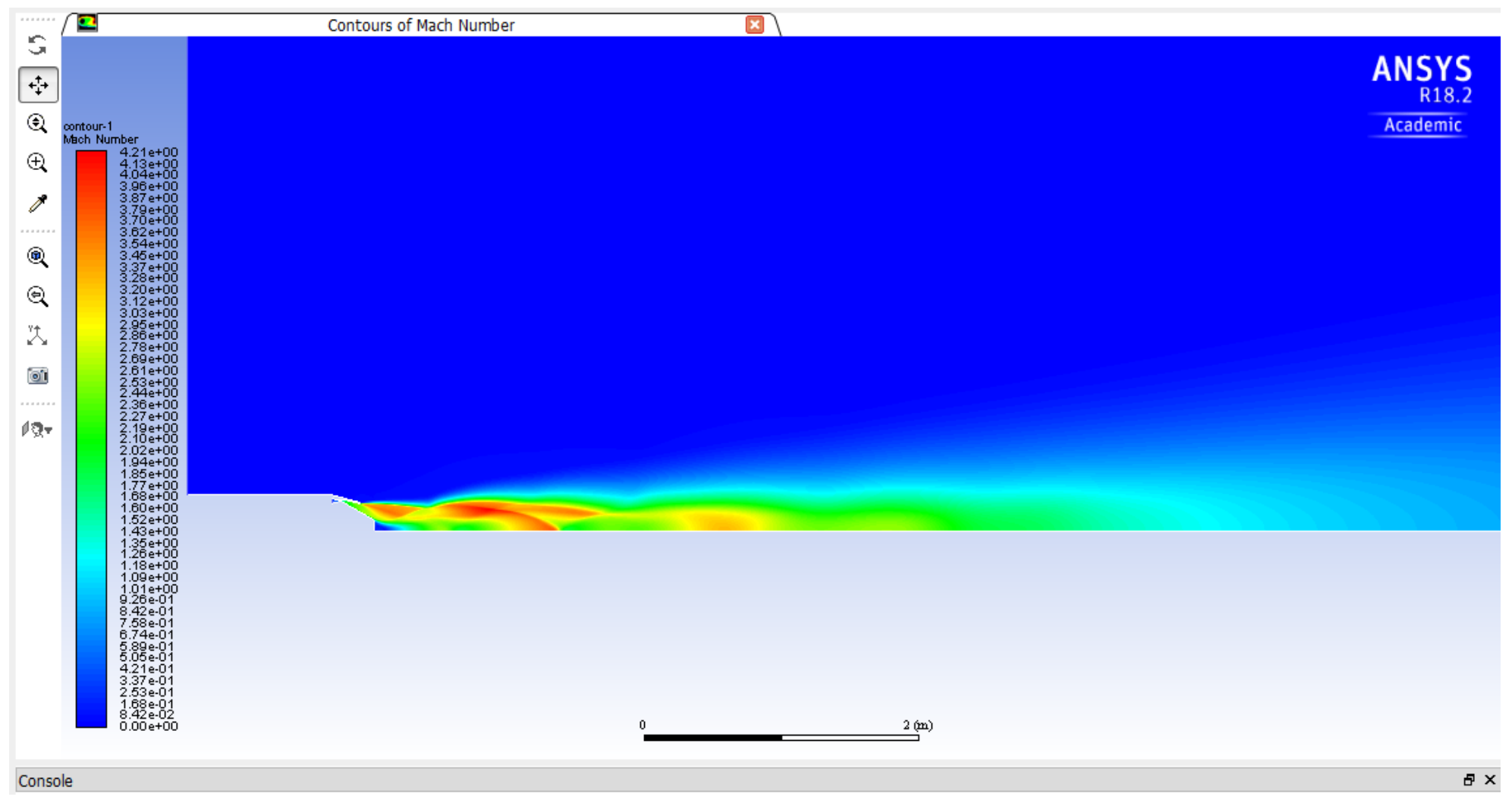

Figure 133: Contour of Mach number for Aerospike 6, with nozzle flow expansion into ambient air at 20km standard atmosphere. 


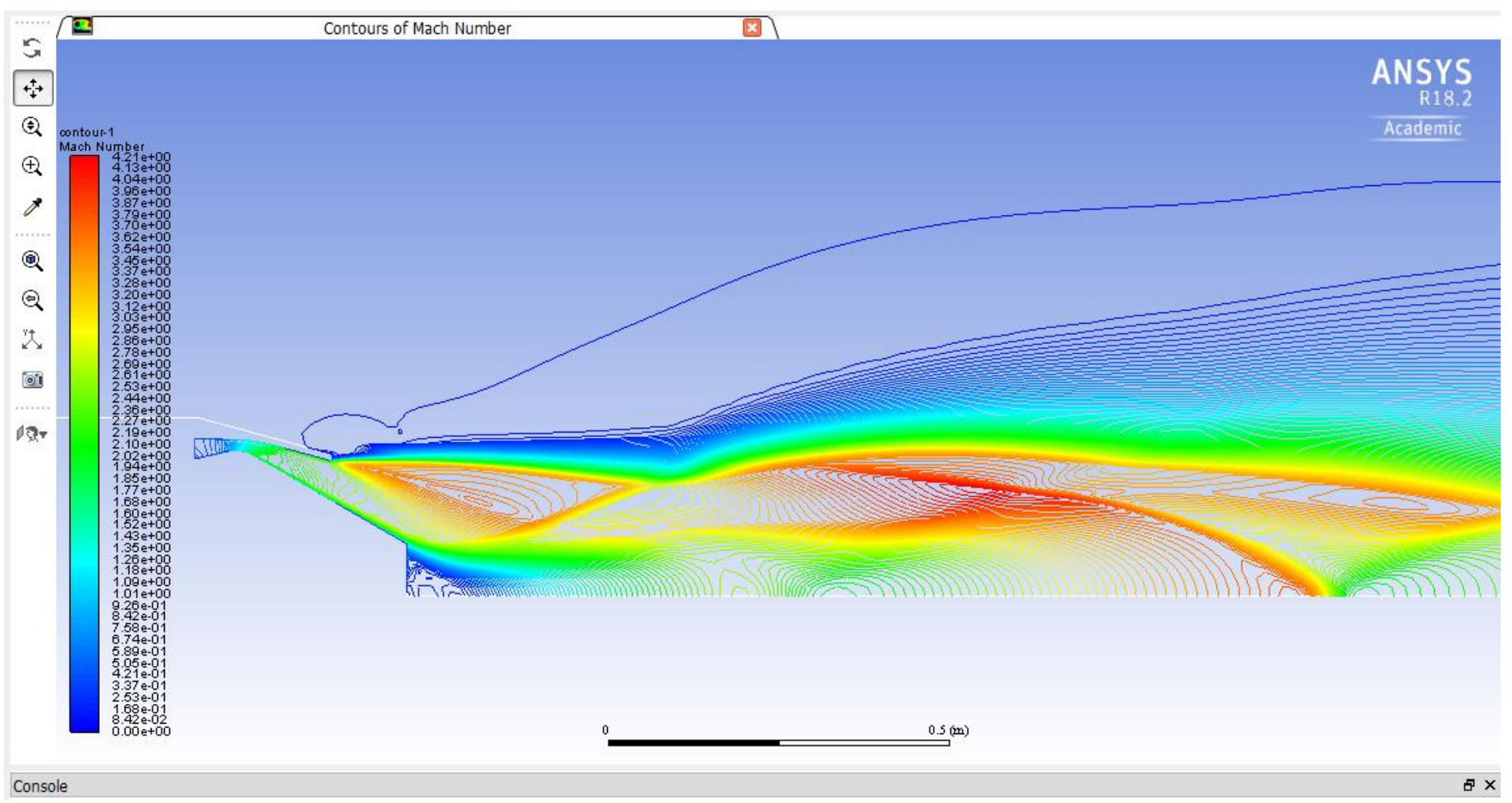

Figure 134: Line contours of Mach number for Aerospike 6, with nozzle flow expansion into ambient air at 20km standard atmosphere. 


\section{Aerospike 7 Flow Contours}

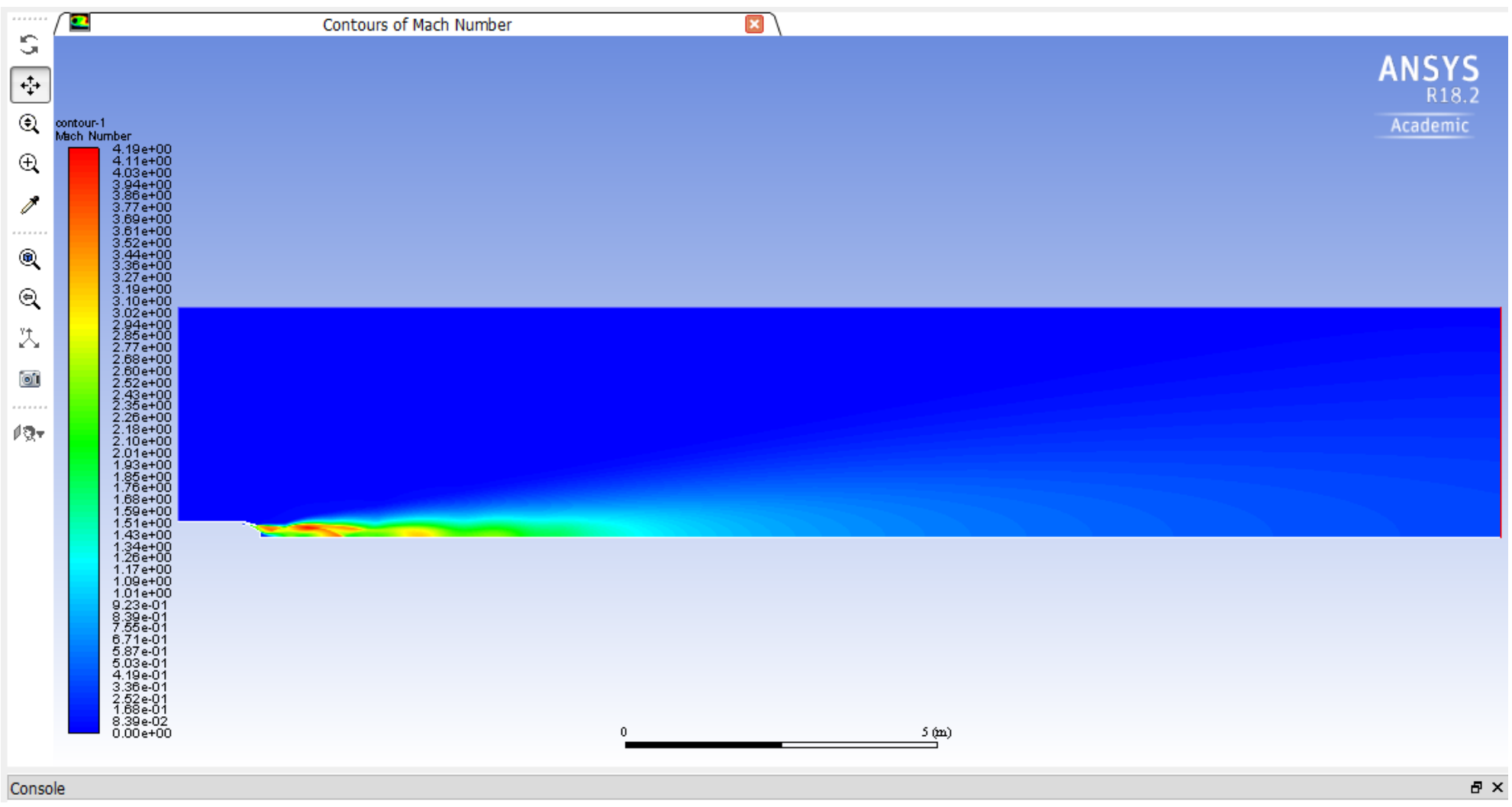

Figure 135: Contour of Mach number for Aerospike 7, with nozzle flow expansion into ambient air at 20km standard atmosphere. 


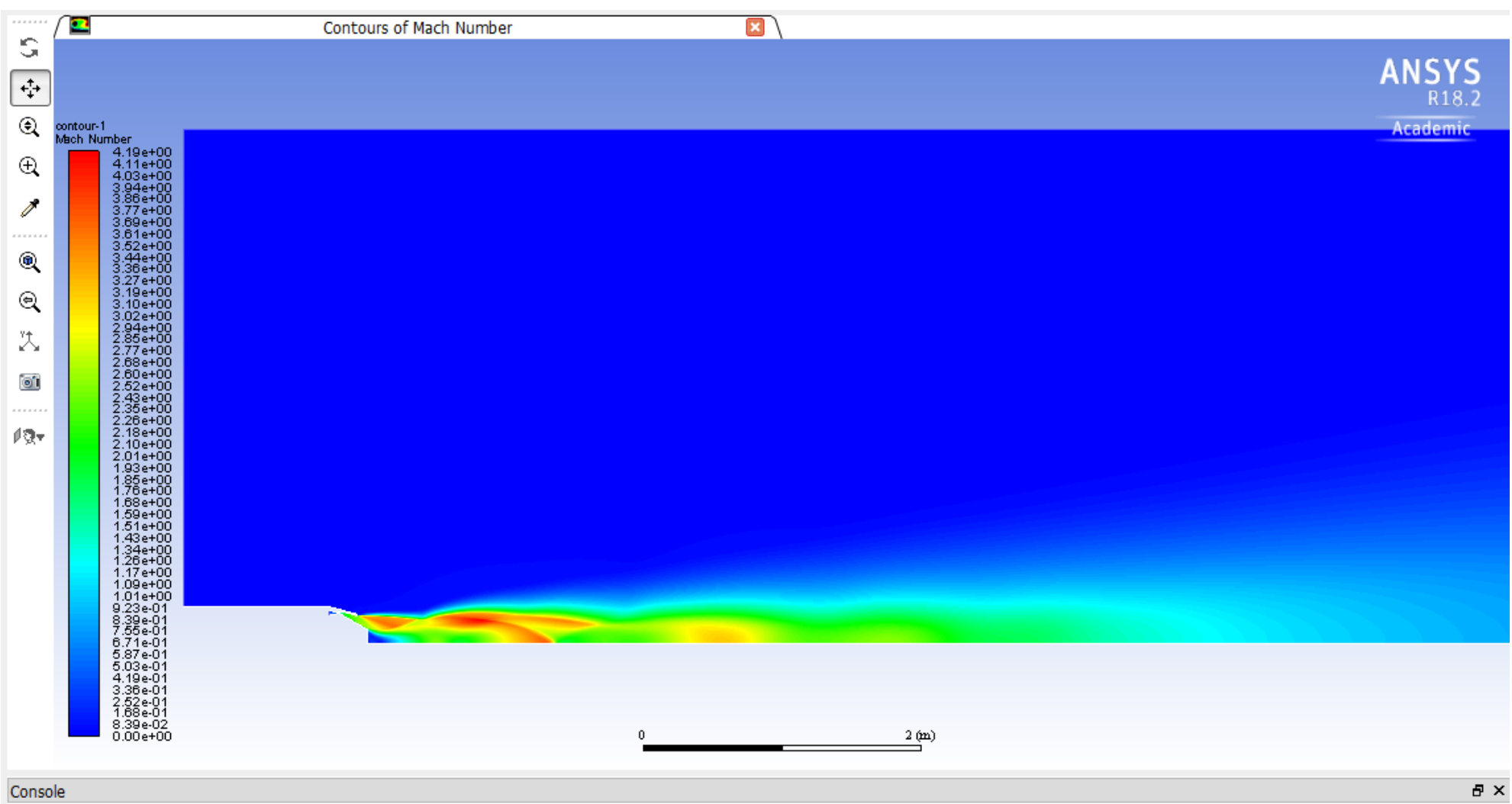

Figure 136: Contour of Mach number for Aerospike 7, with nozzle flow expansion into ambient air at 20km standard atmosphere. 


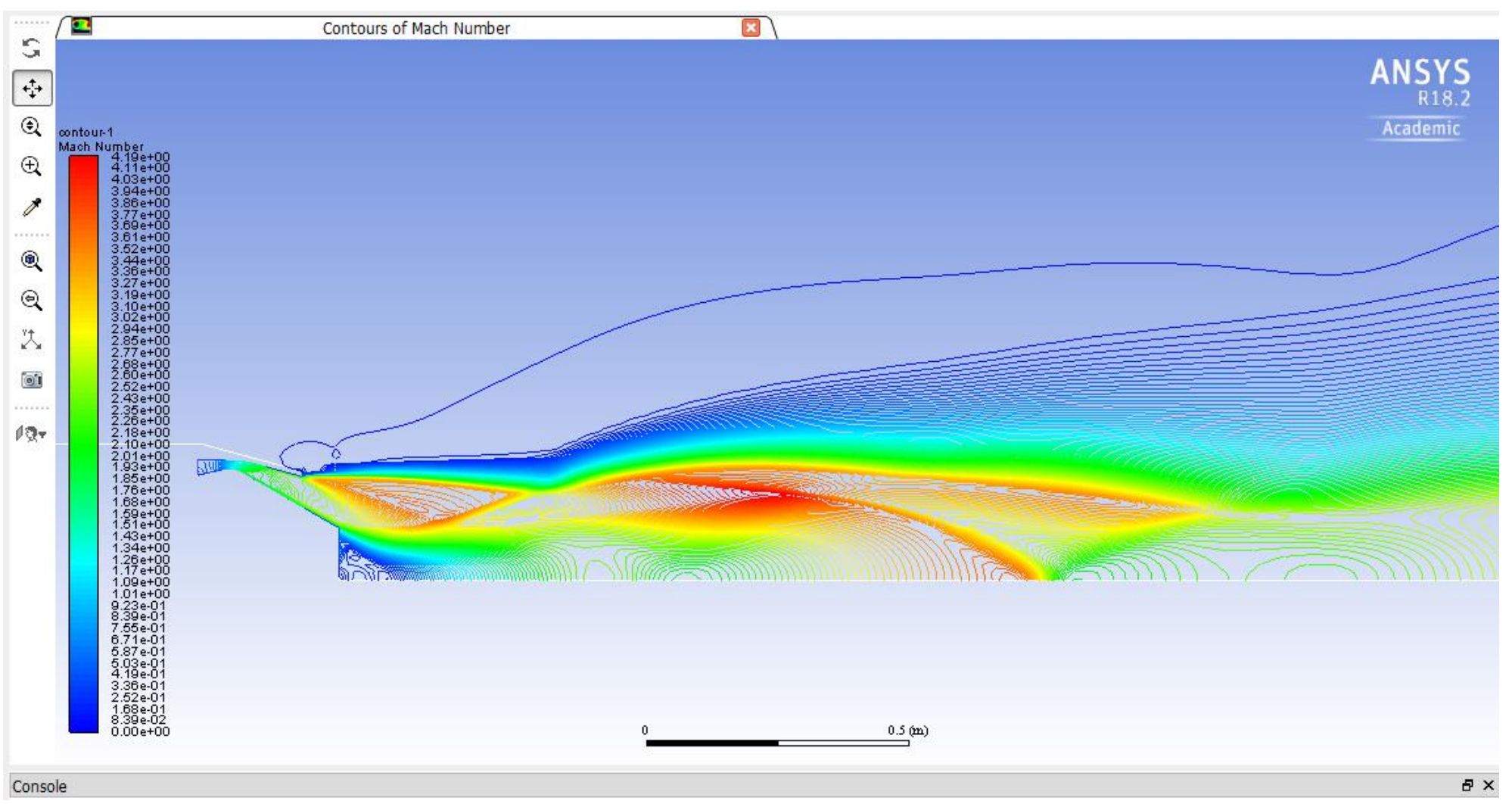

Figure 137: Line contours of Mach number for Aerospike 7, with nozzle flow expansion into ambient air at 20km standard atmosphere. 


\section{Aerospike 8 Flow Contours}

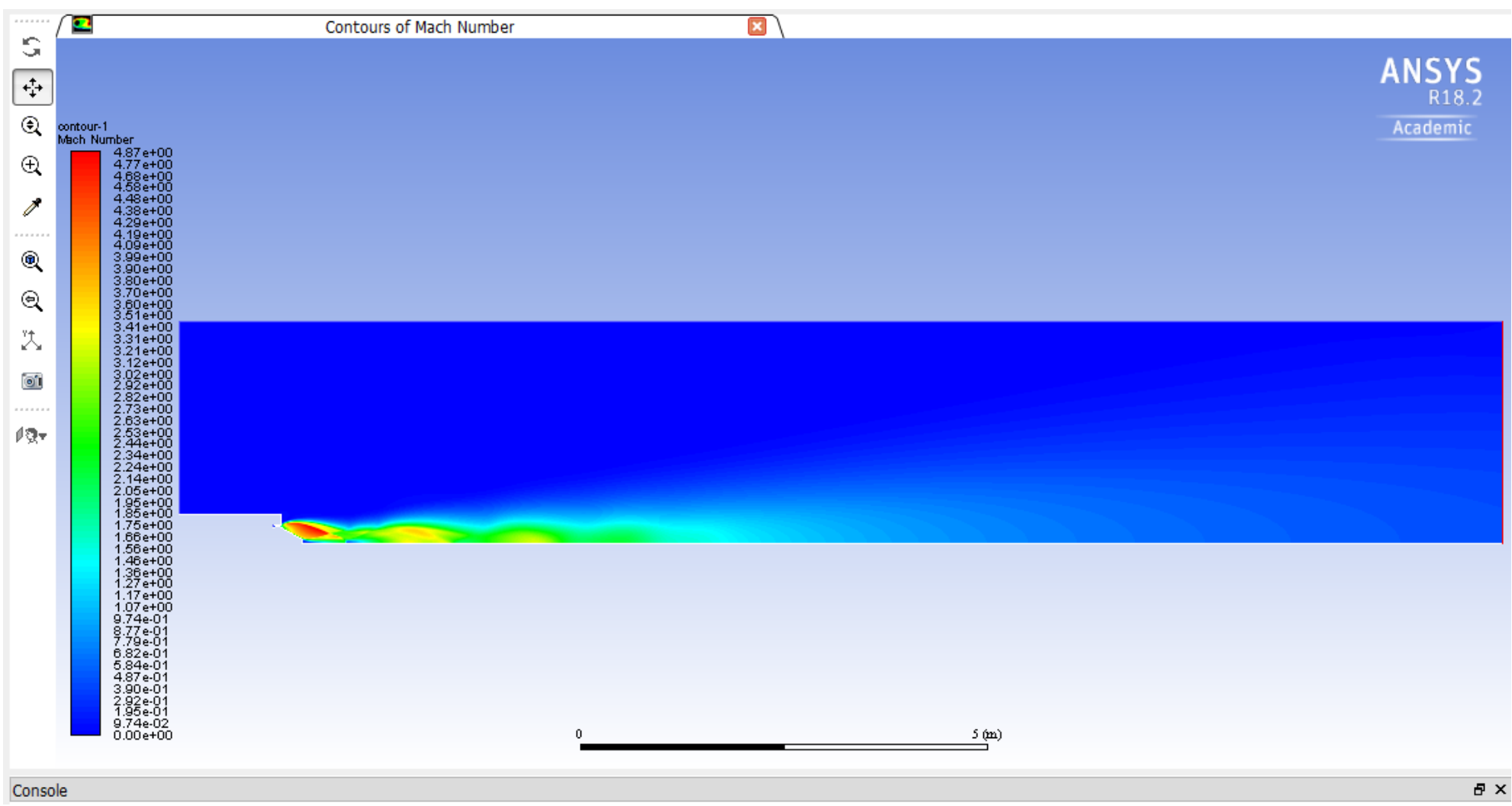

Figure 138: Contour of Mach number for Aerospike 8, with nozzle flow expansion into ambient air at $20 \mathrm{~km}$ standard atmosphere. 


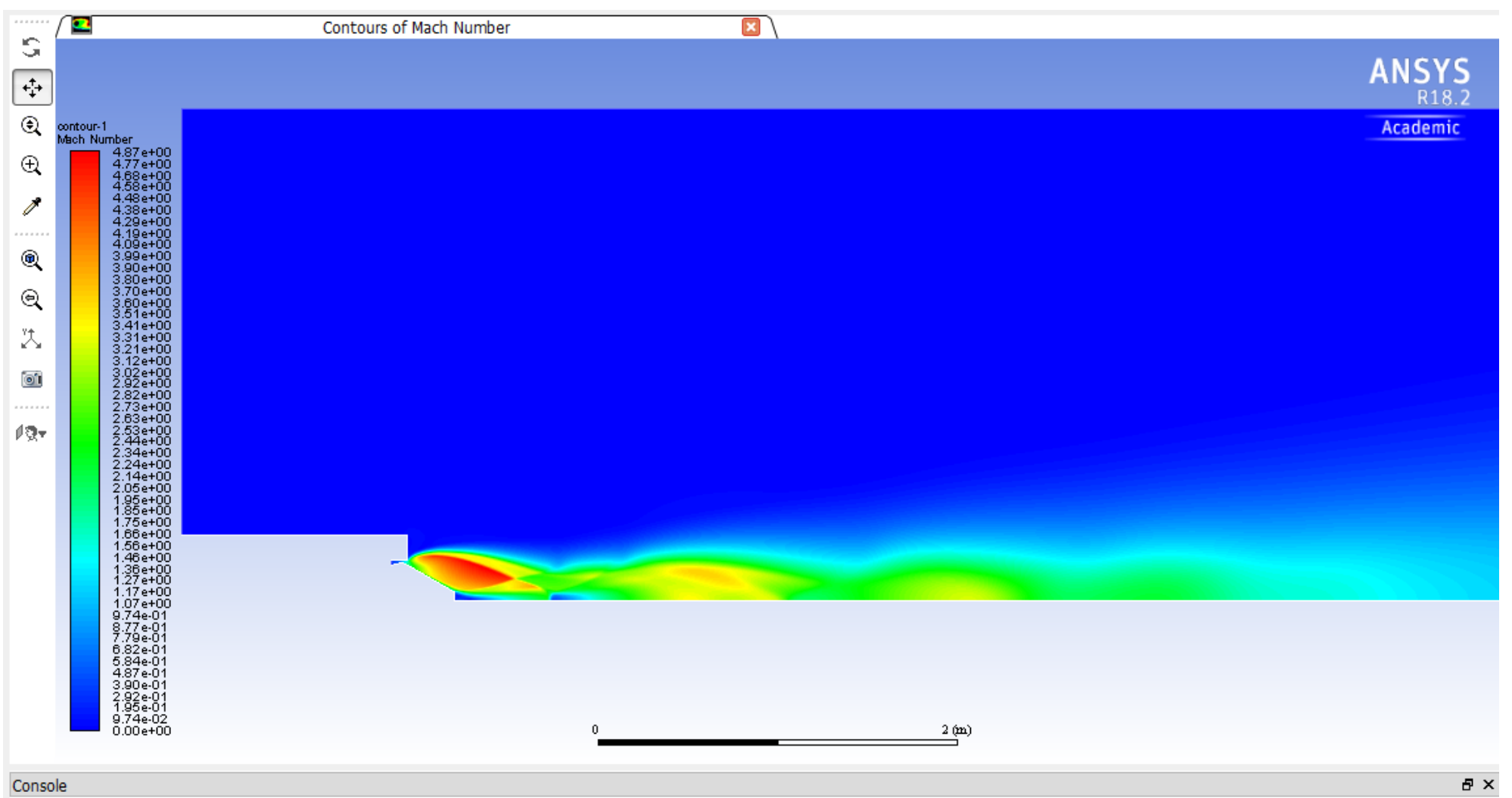

Figure 139: Contour of Mach number for Aerospike 8, with nozzle flow expansion into ambient air at 20km standard atmosphere. 


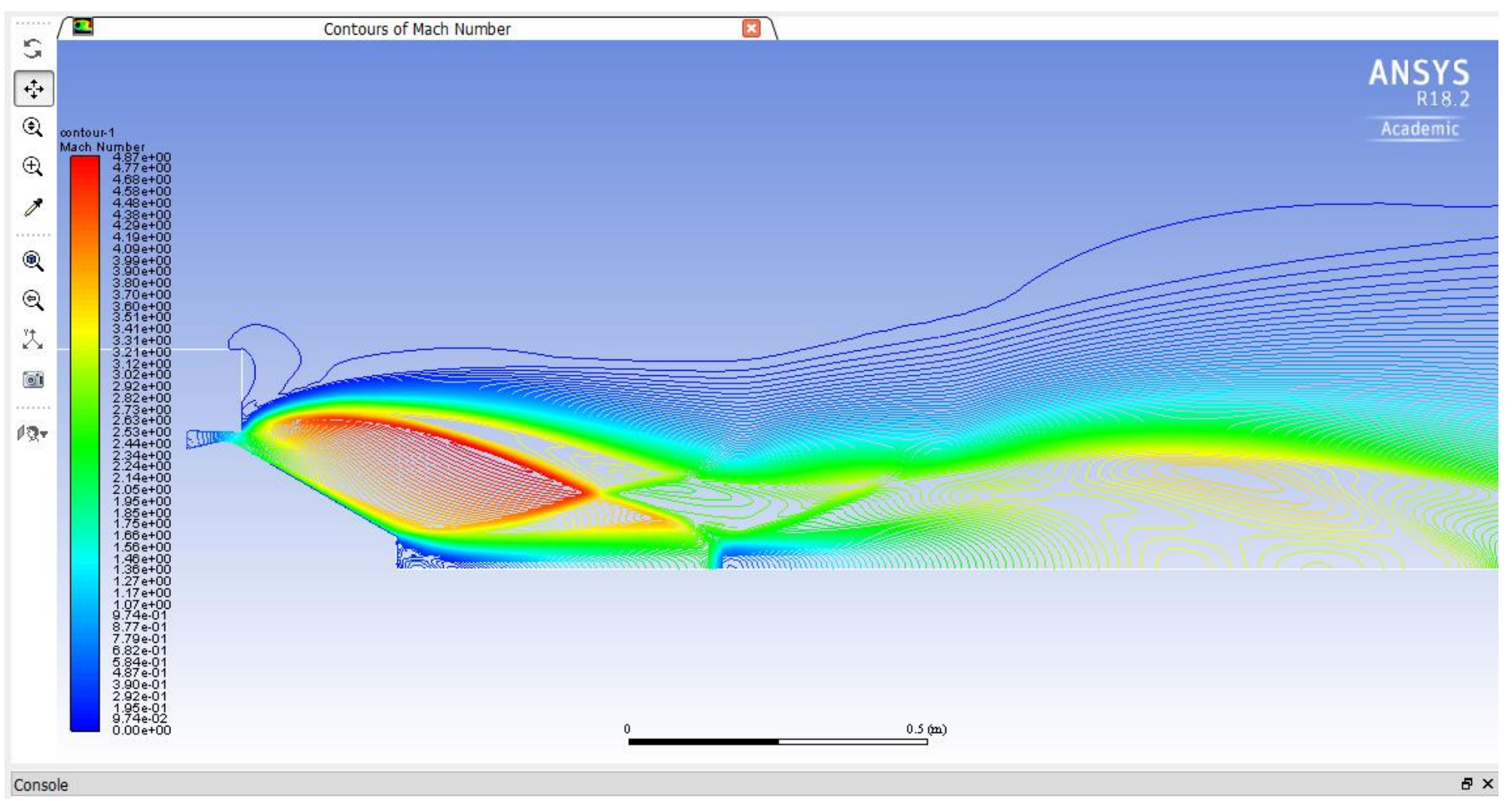

Figure 140: Line contours of Mach number for Aerospike 8, with nozzle flow expansion into ambient air at 20km standard atmosphere. 
Aerospike 10 Flow Contours

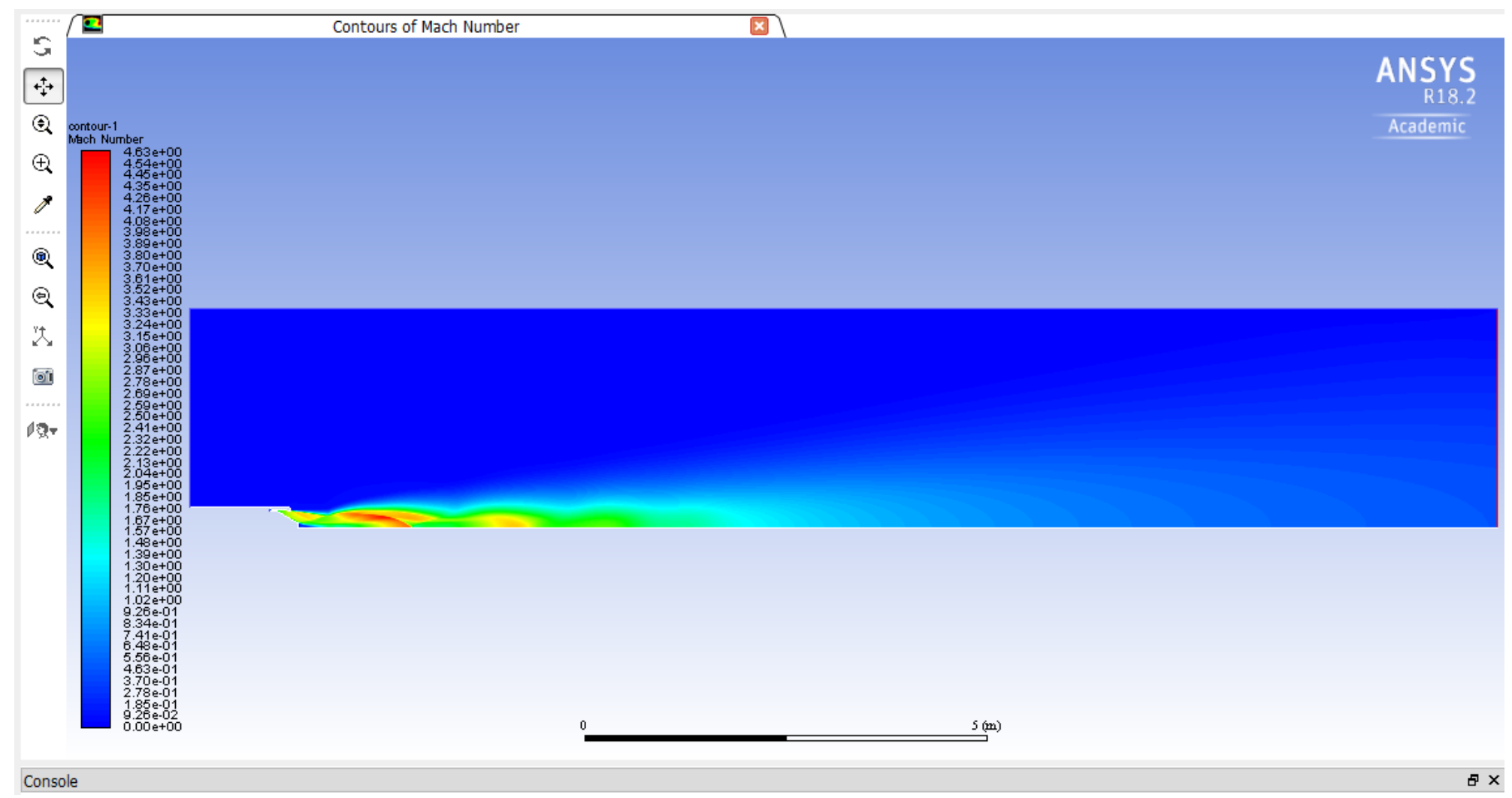

Figure 141: Contour of Mach number for Aerospike 10, with nozzle flow expansion into ambient air at $20 \mathrm{~km}$ standard atmosphere. 


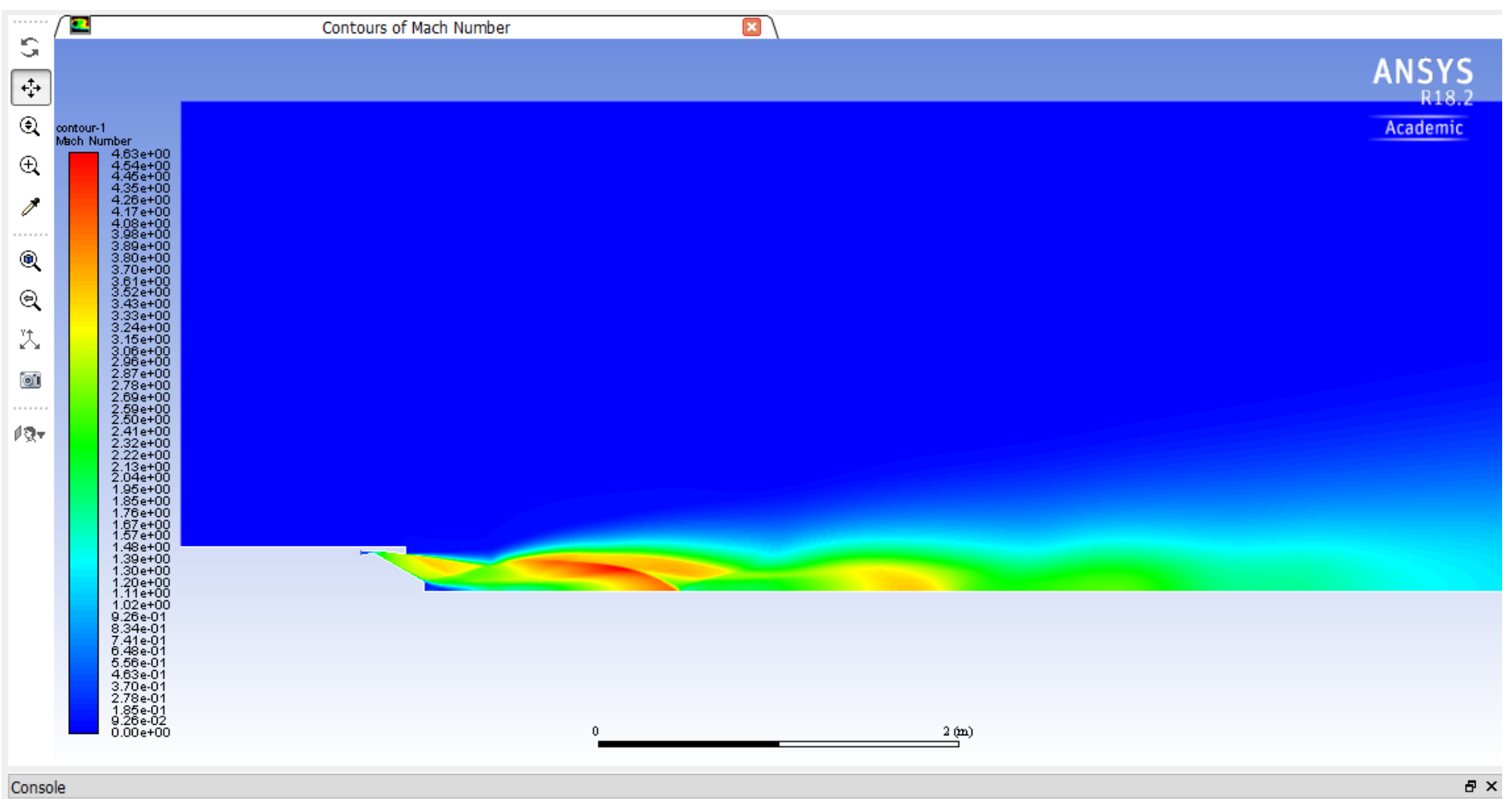

Figure 142: Contour of Mach number for Aerospike 10, with nozzle flow expansion into ambient air at 20km standard atmosphere. 


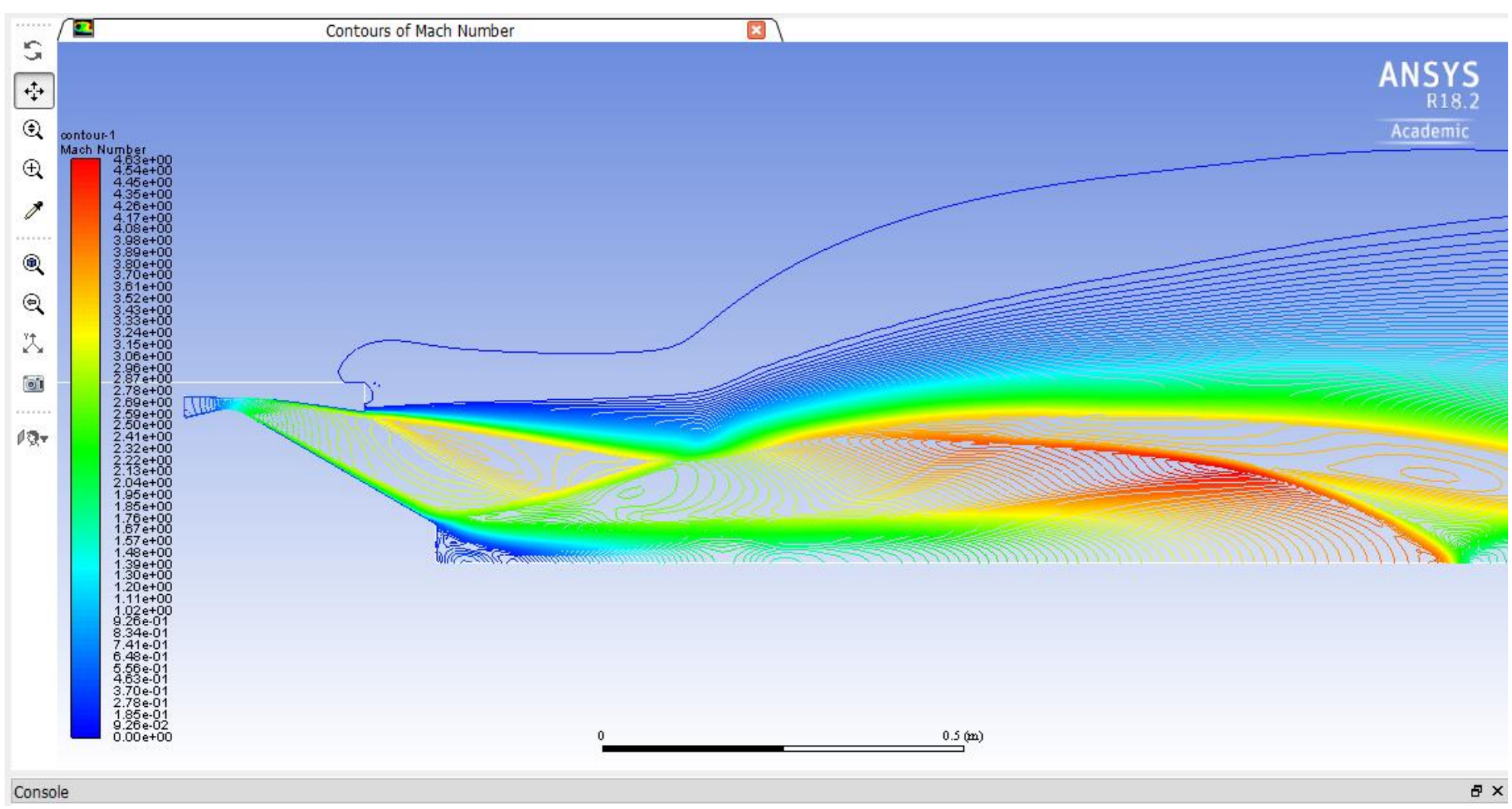

Figure 143: Line contours of Mach number for Aerospike 10, with nozzle flow expansion into ambient air at 20km standard atmosphere. 


\section{Aerospike 11 Flow Contours}

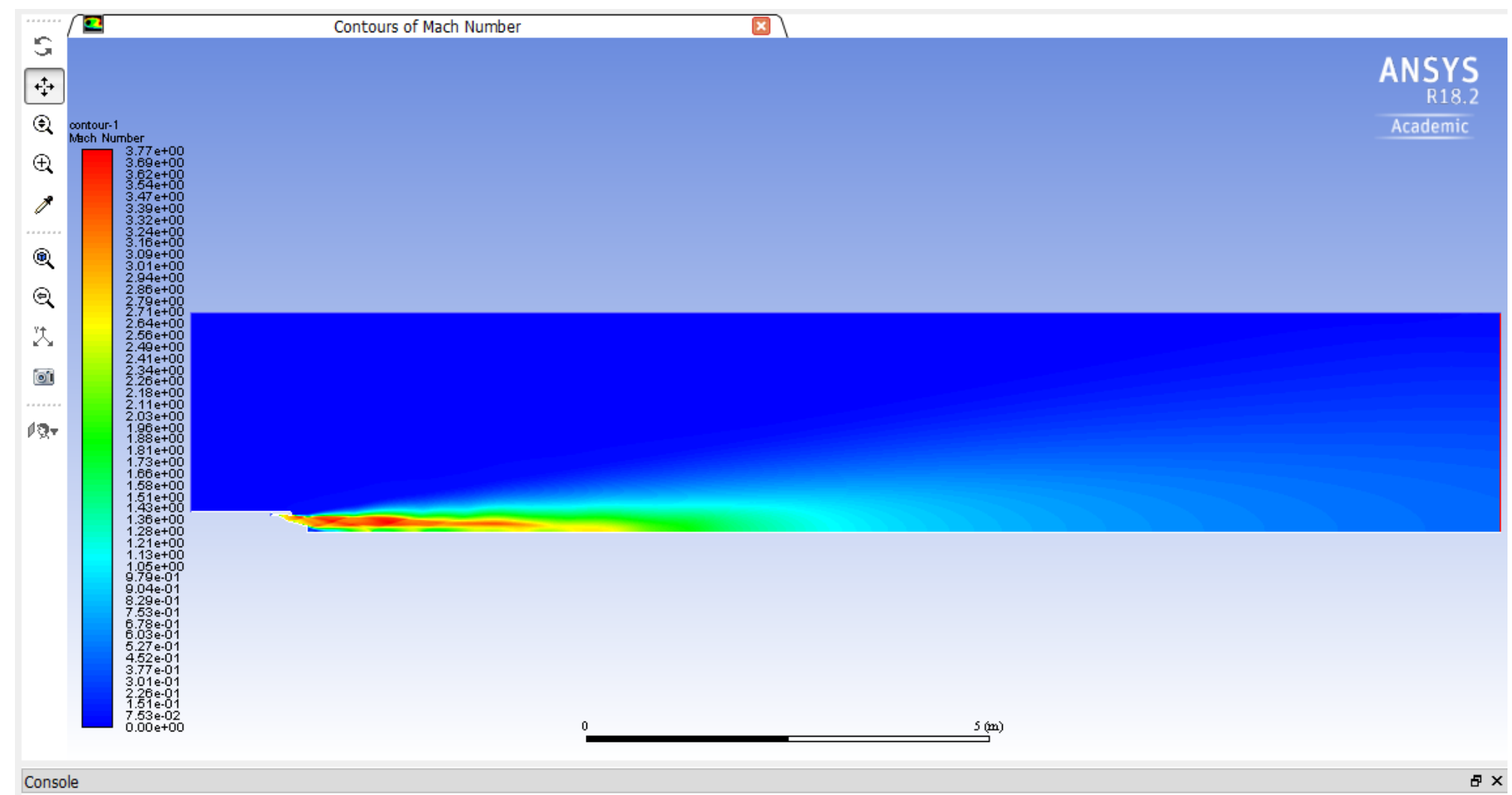

Figure 144: Contour of Mach number for Aerospike 11, with nozzle flow expansion into ambient air at $20 \mathrm{~km}$ standard atmosphere. 


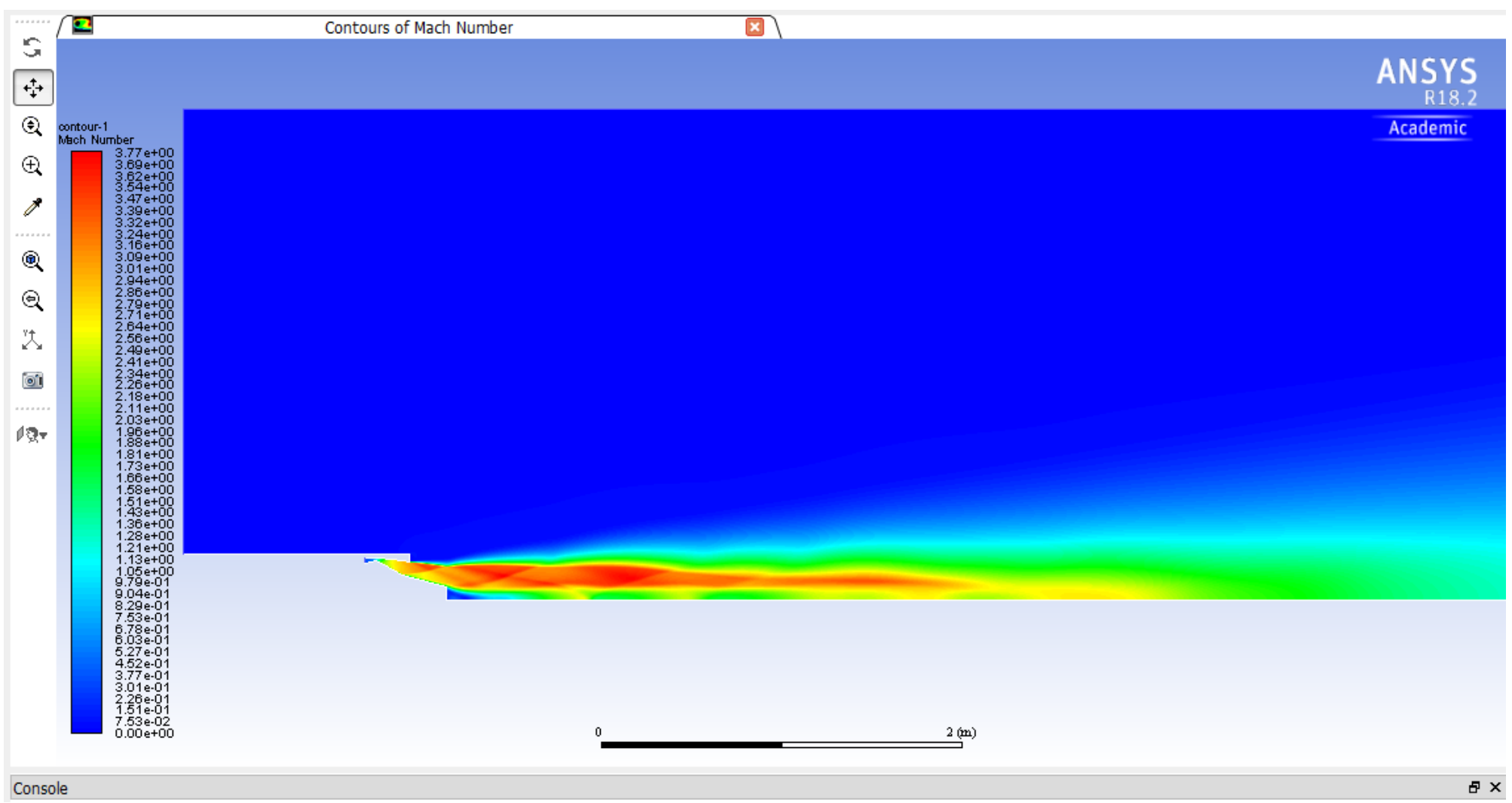

Figure 145: Contour of Mach number for Aerospike 11, with nozzle flow expansion into ambient air at 20km standard atmosphere. 


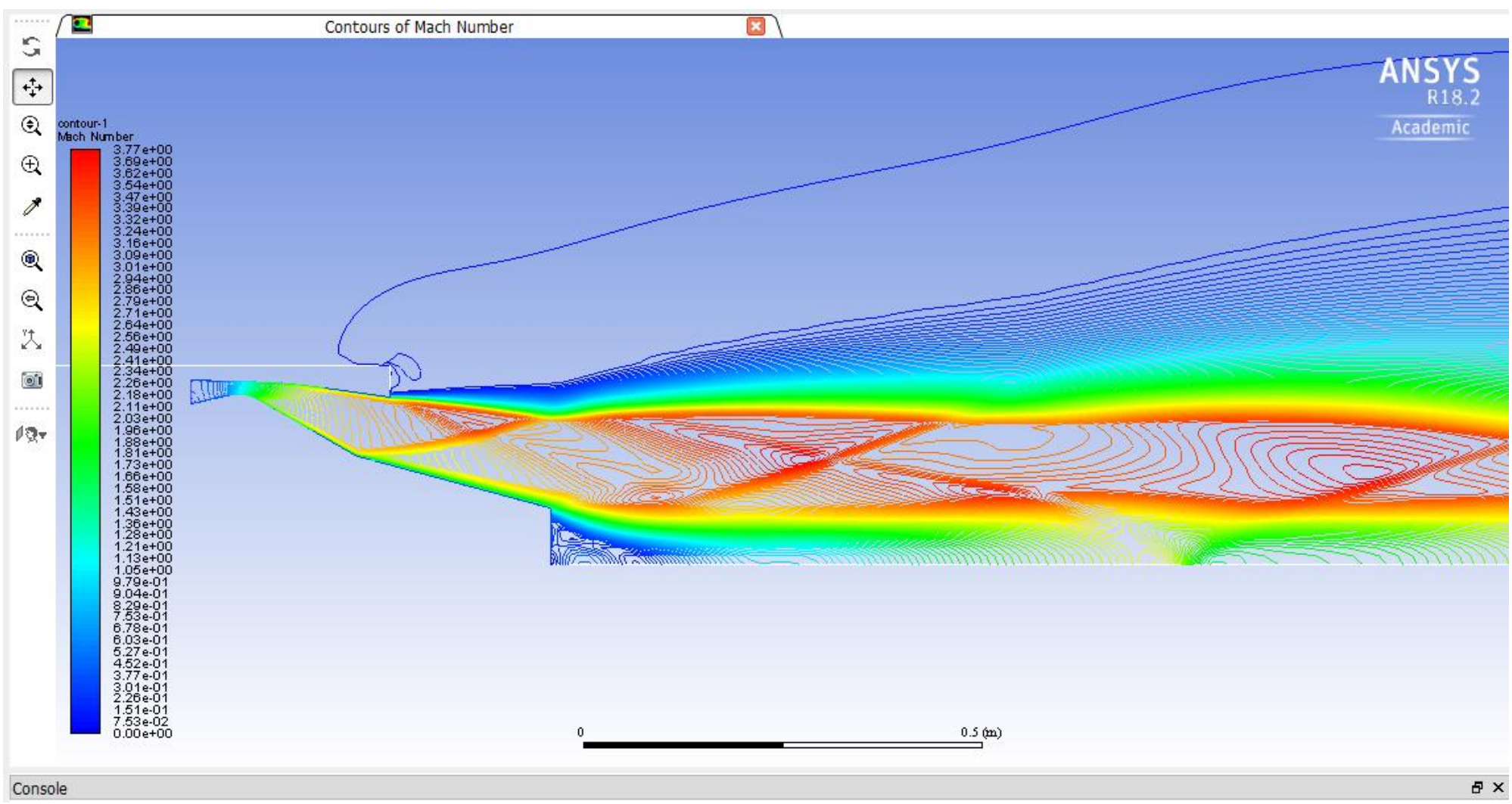

Figure 146: Line contours of Mach number for Aerospike 11, with nozzle flow expansion into ambient air at 20km standard atmosphere. 


\section{Aerospike 12 Flow Contours}

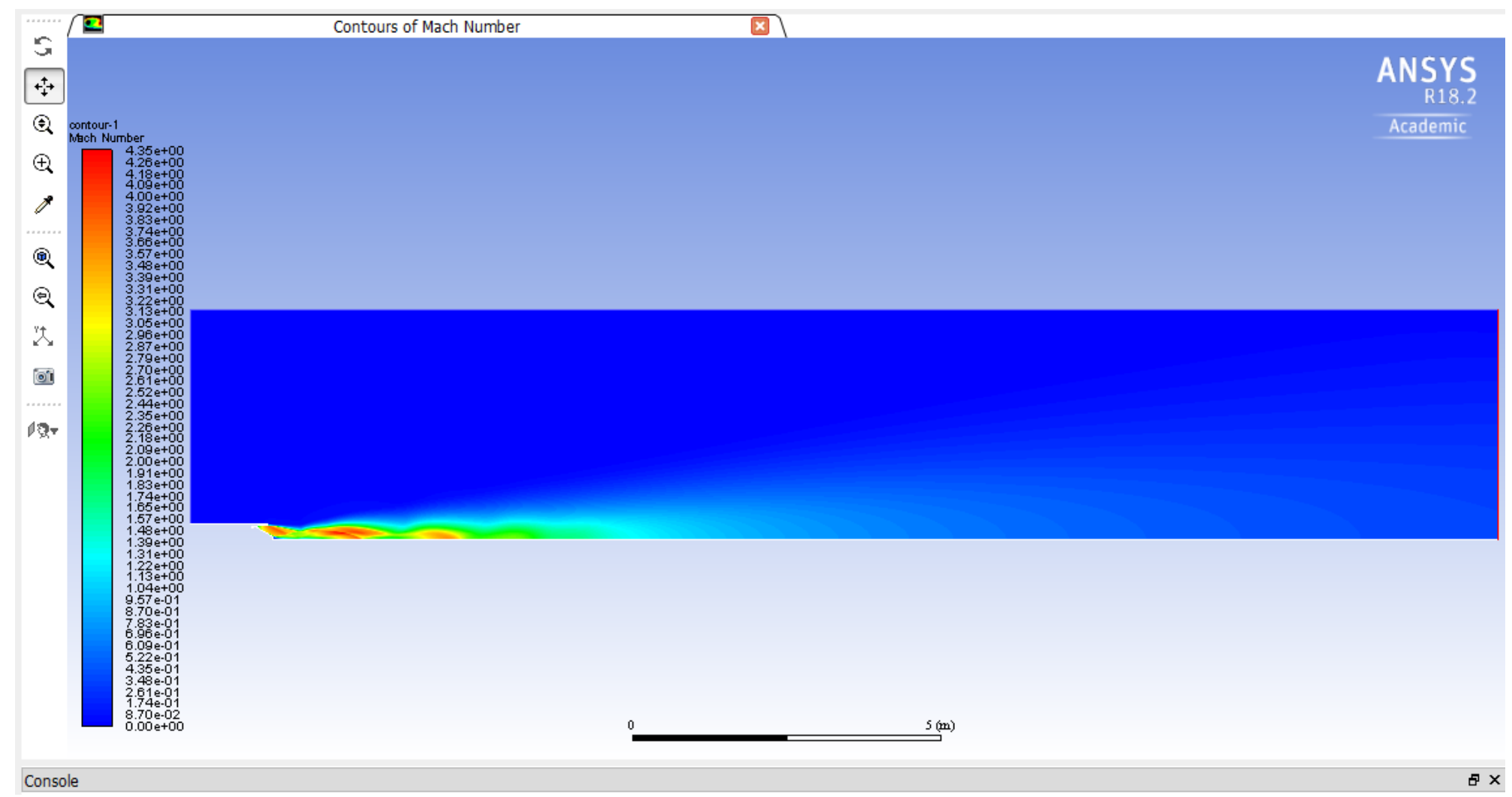

Figure 147: Contour of Mach number for Aerospike 12, with nozzle flow expansion into ambient air at 20km standard atmosphere. 


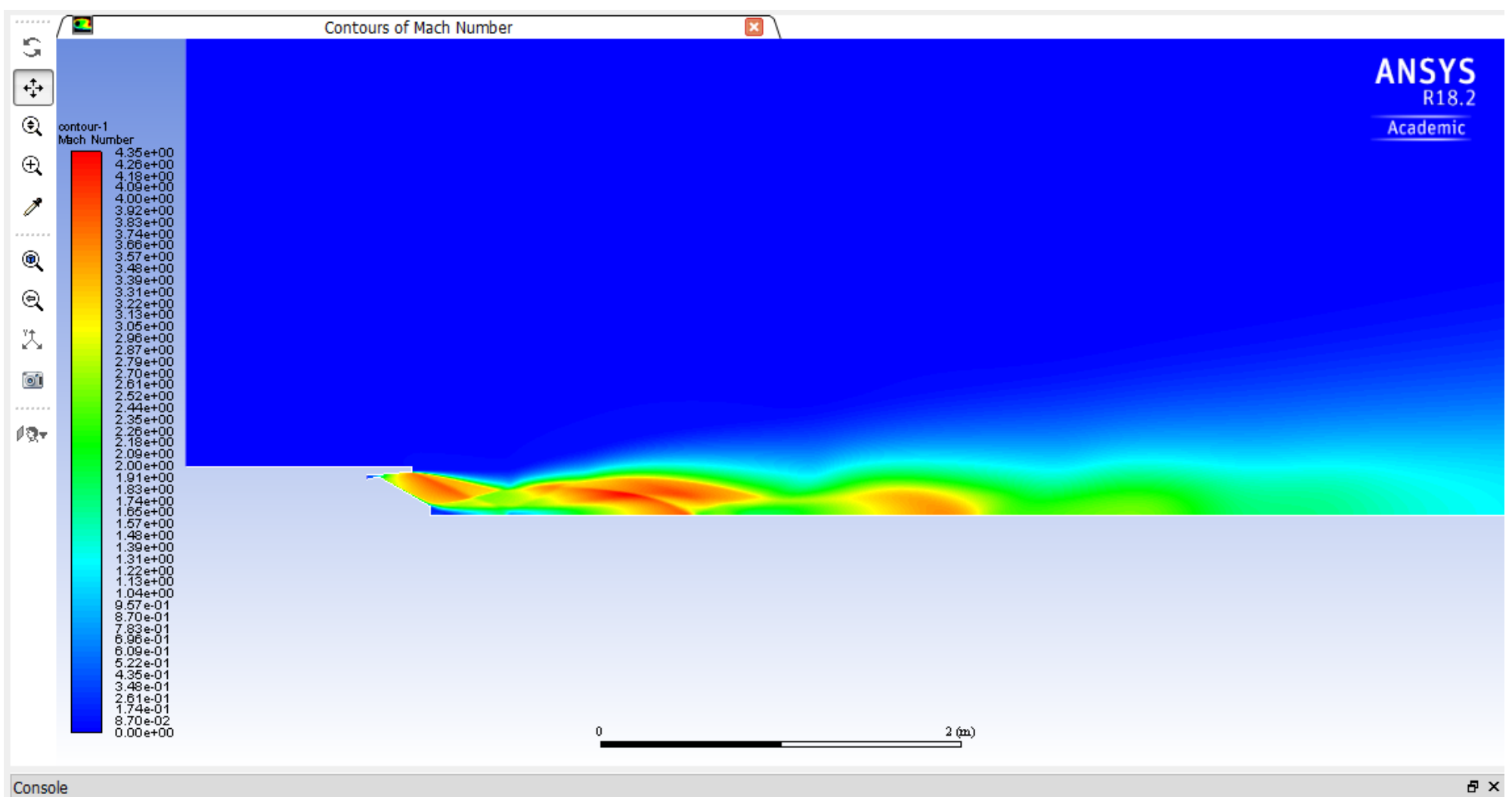

Figure 148: Contour of Mach number for Aerospike 12, with nozzle flow expansion into ambient air at 20km standard atmosphere. 


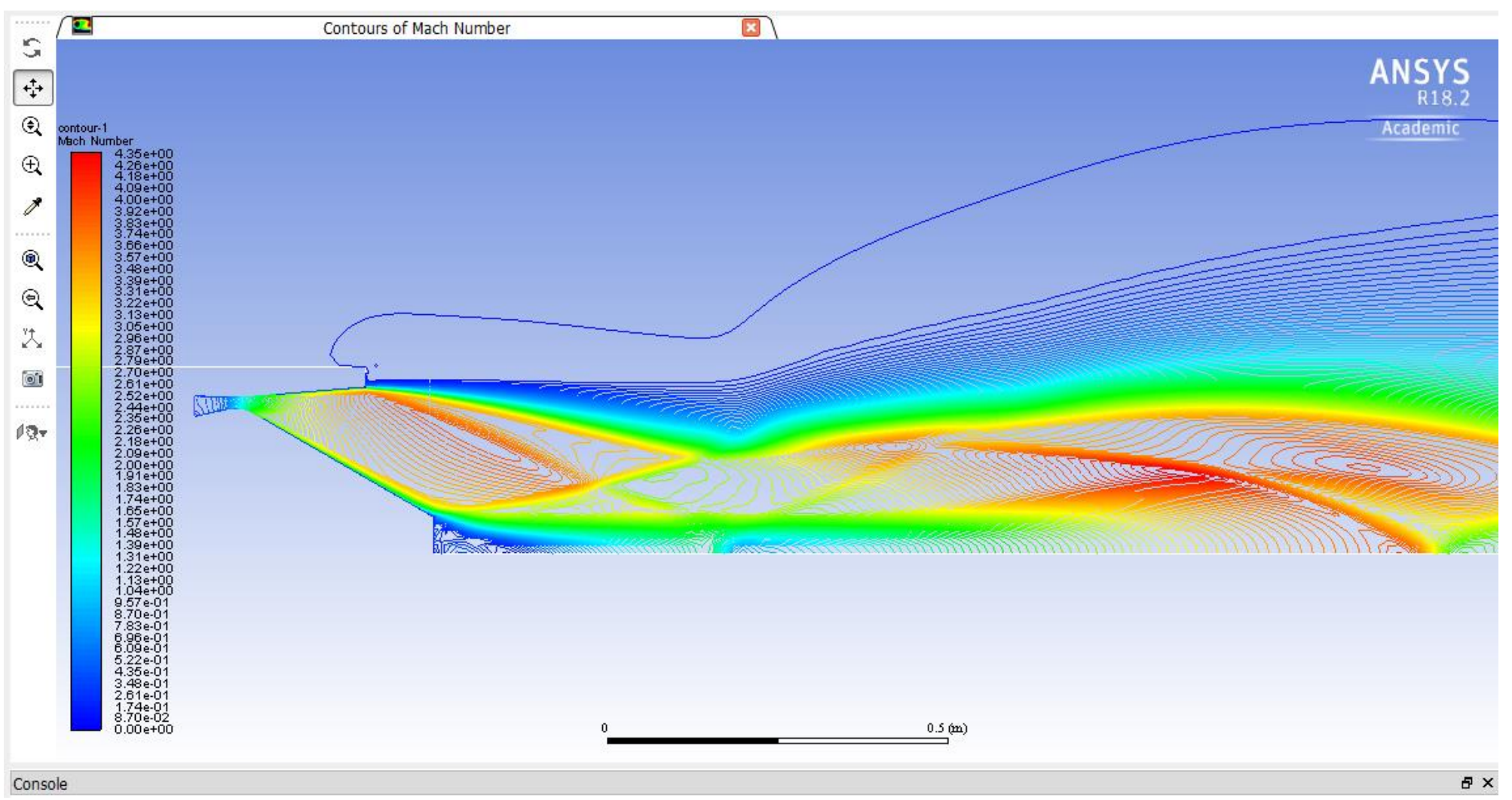

Figure 149: Line contours of Mach number for Aerospike 12, with nozzle flow expansion into ambient air at $20 \mathrm{~km}$ standard atmosphere. 


\section{Aerospike 14 Flow Contours}

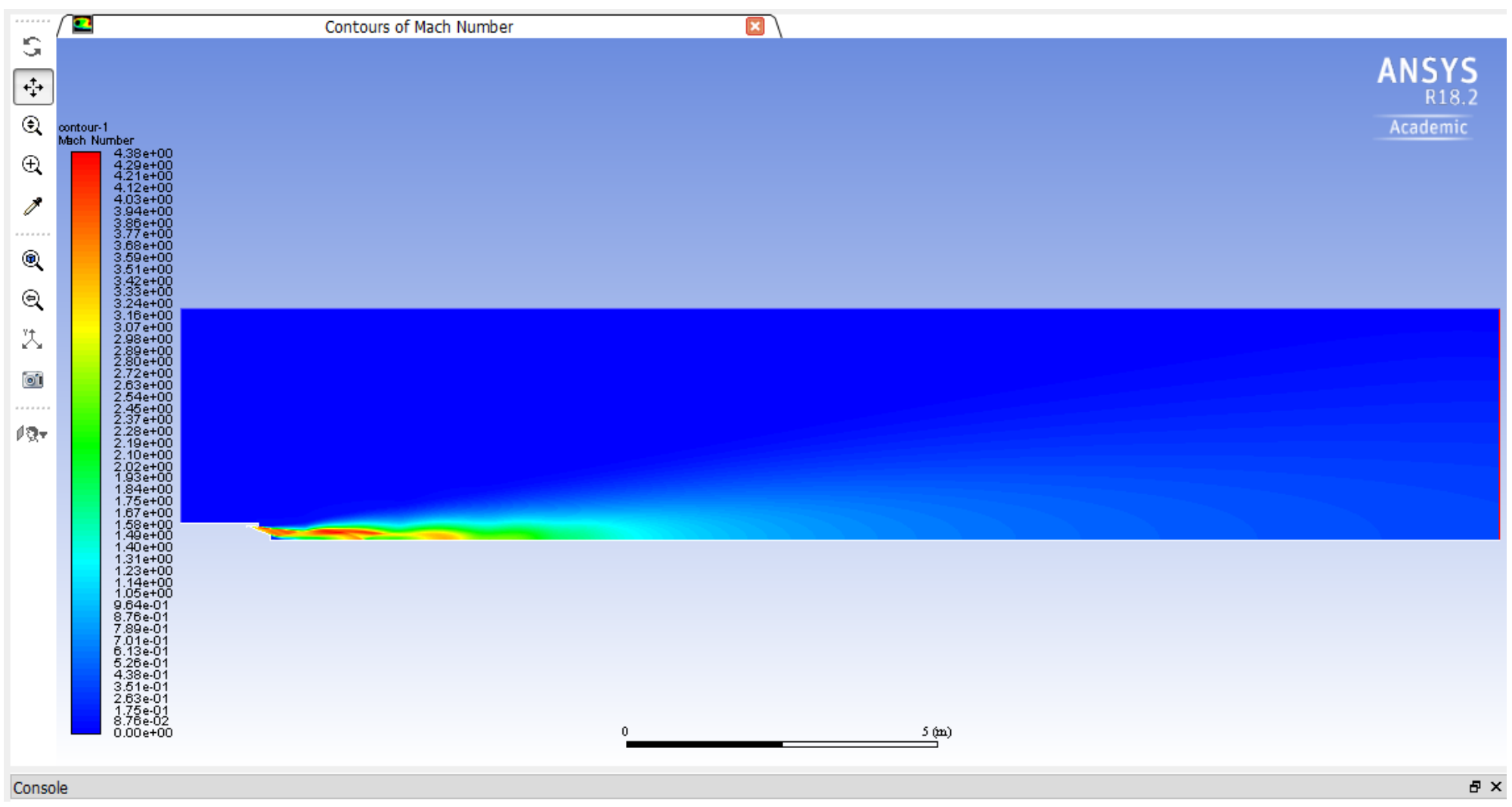

Figure 150: Contour of Mach number for Aerospike 14, with nozzle flow expansion into ambient air at $20 \mathrm{~km}$ standard atmosphere. 


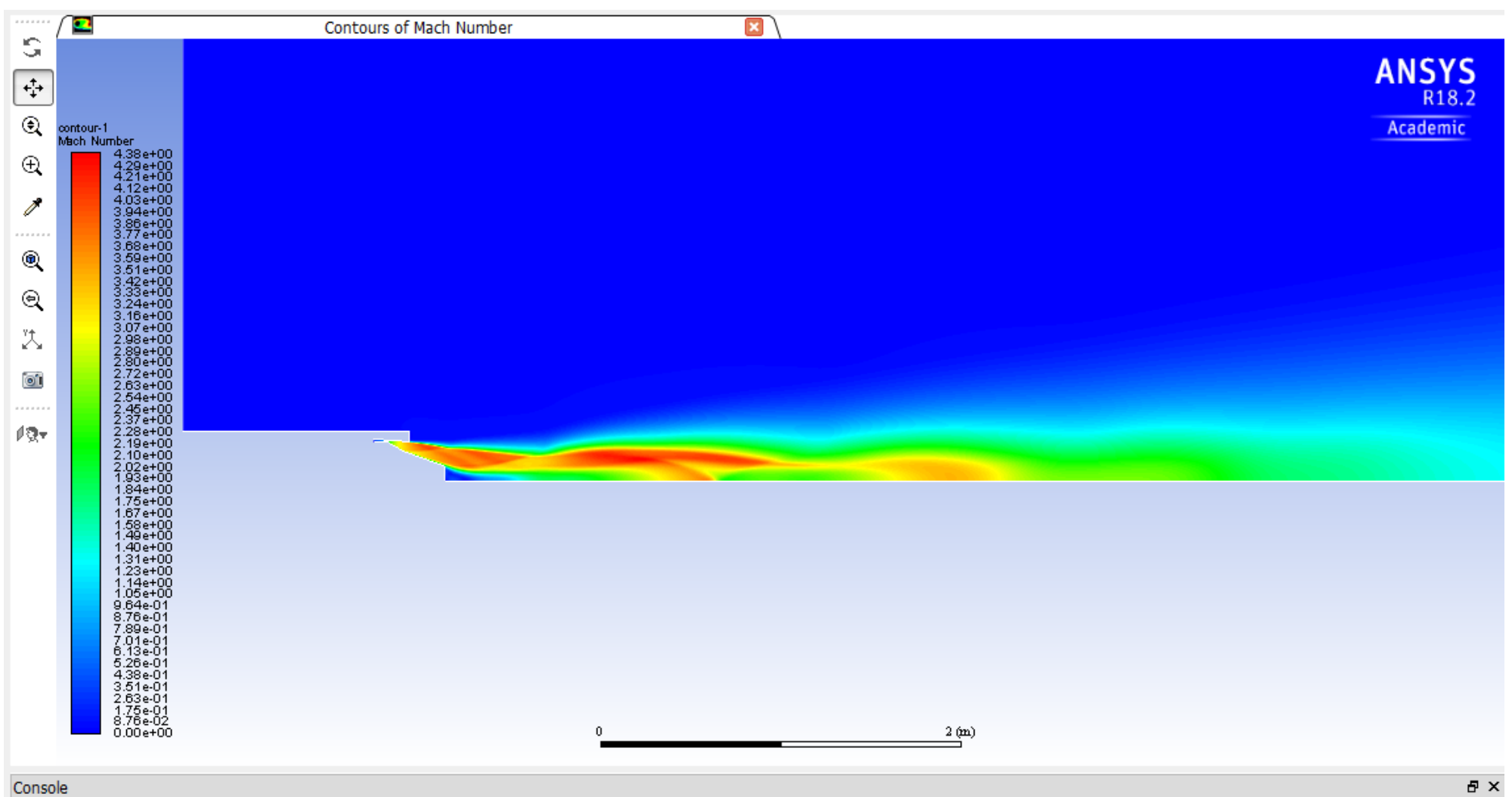

Figure 151: Contour of Mach number for Aerospike 14, with nozzle flow expansion into ambient air at $20 \mathrm{~km}$ standard atmosphere. 


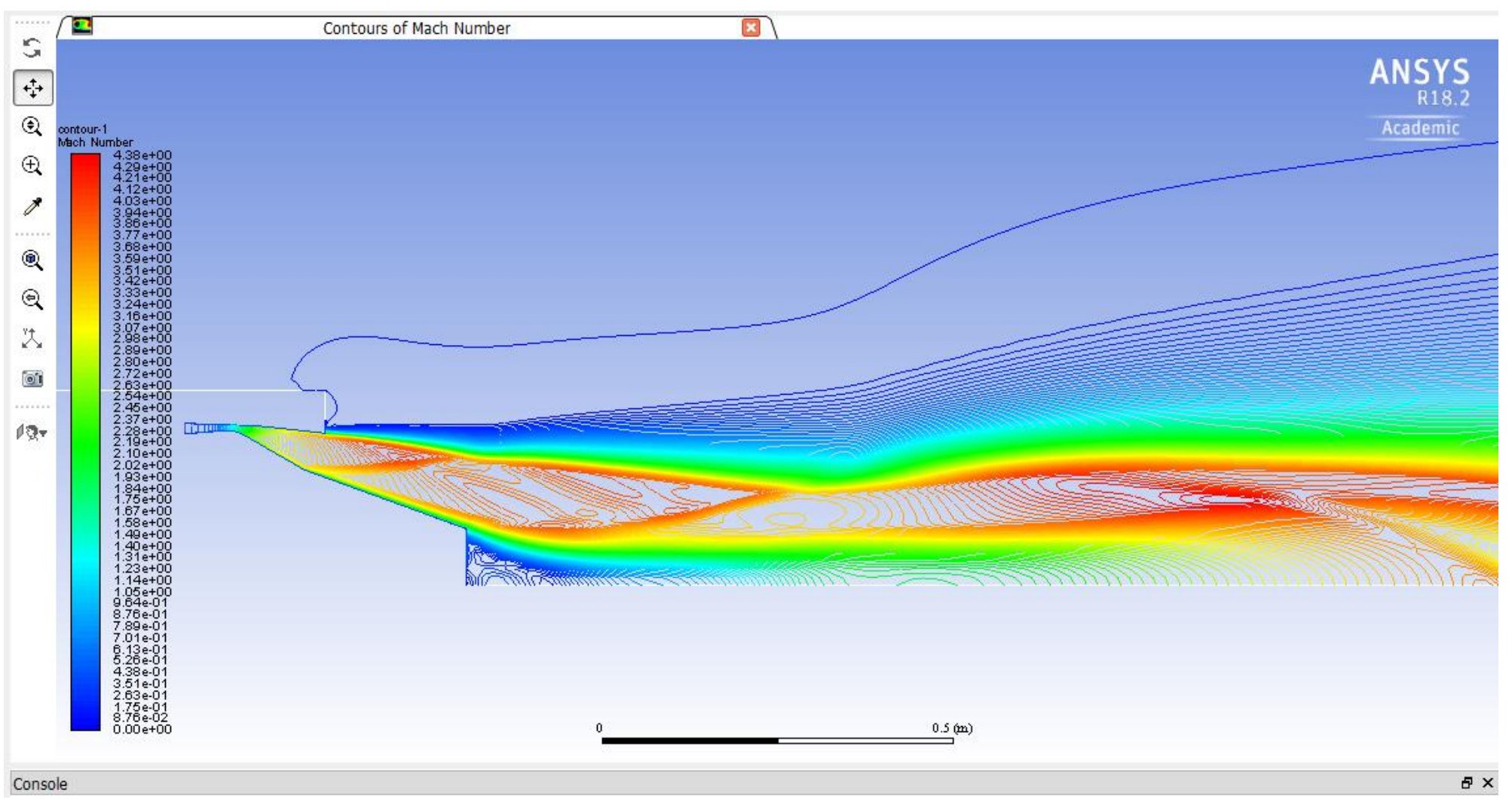

Figure 152: Line contours of Mach number for Aerospike 14, with nozzle flow expansion into ambient air at $20 \mathrm{~km}$ standard atmosphere. 


\section{Aerospike 15 Flow Contours}

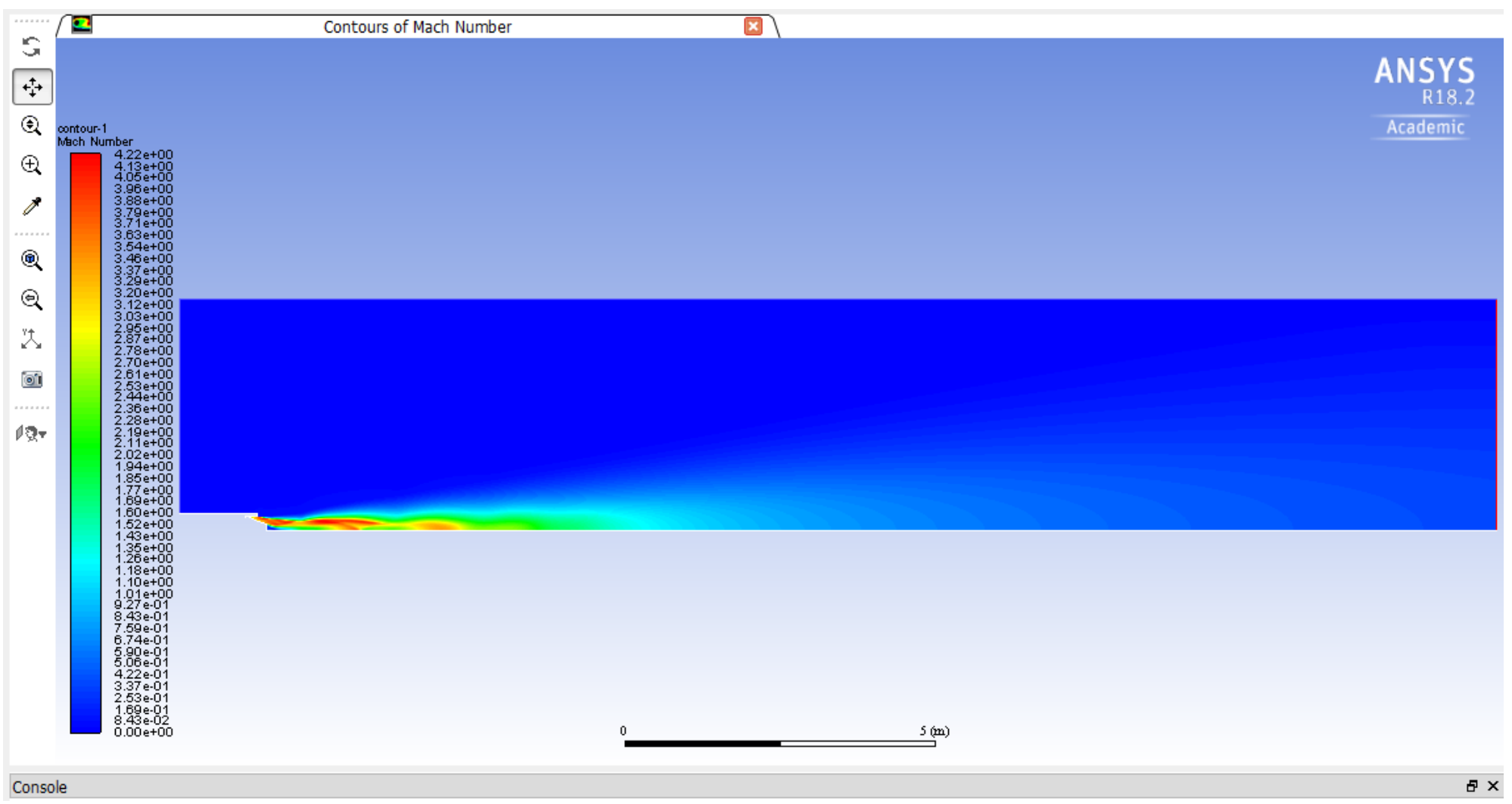

Figure 153: Contour of Mach number for Aerospike 15, with nozzle flow expansion into ambient air at 20km standard atmosphere. 


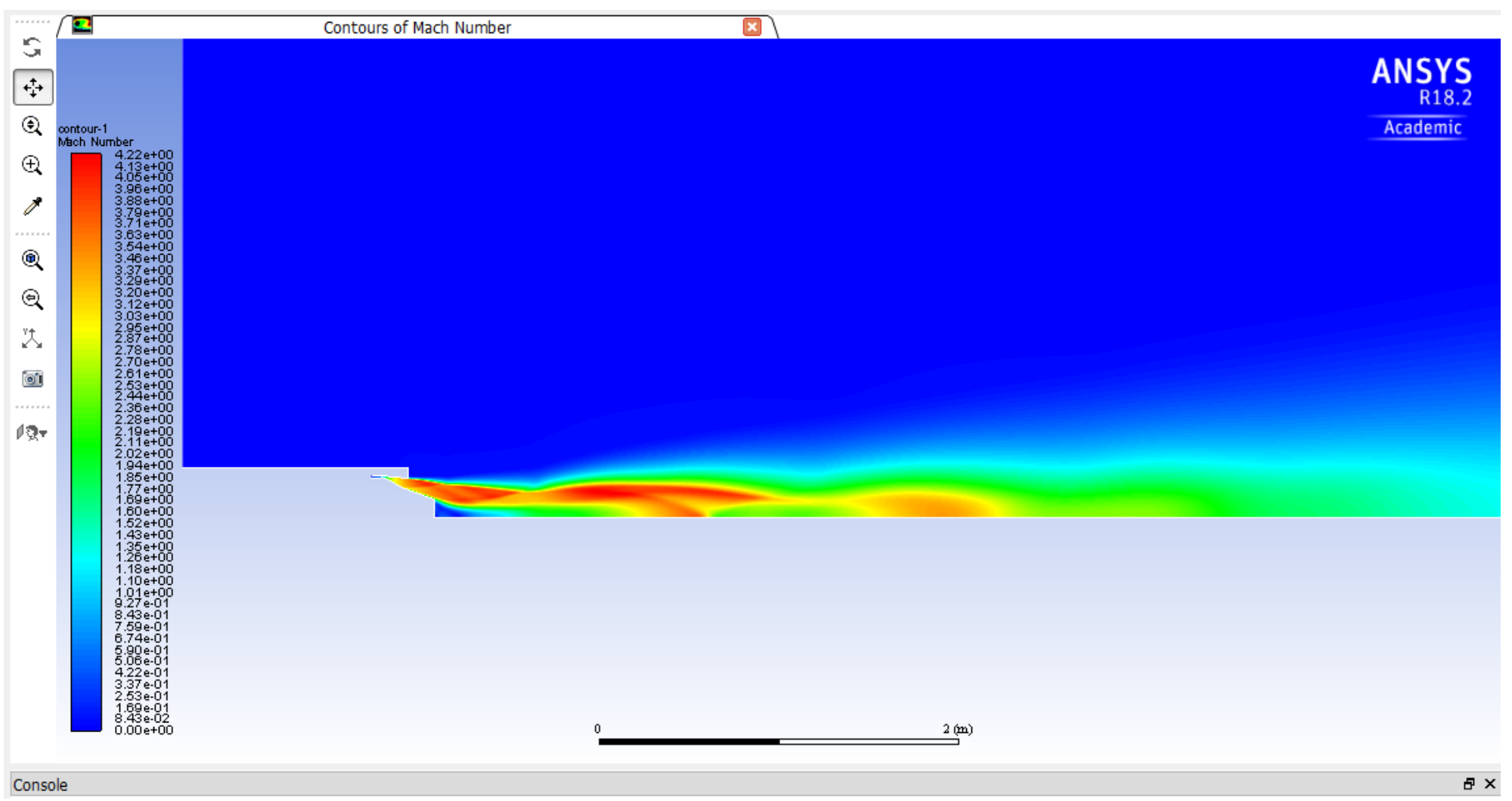

Figure 154: Contour of Mach number for Aerospike 15, with nozzle flow expansion into ambient air at $20 \mathrm{~km}$ standard atmosphere. 


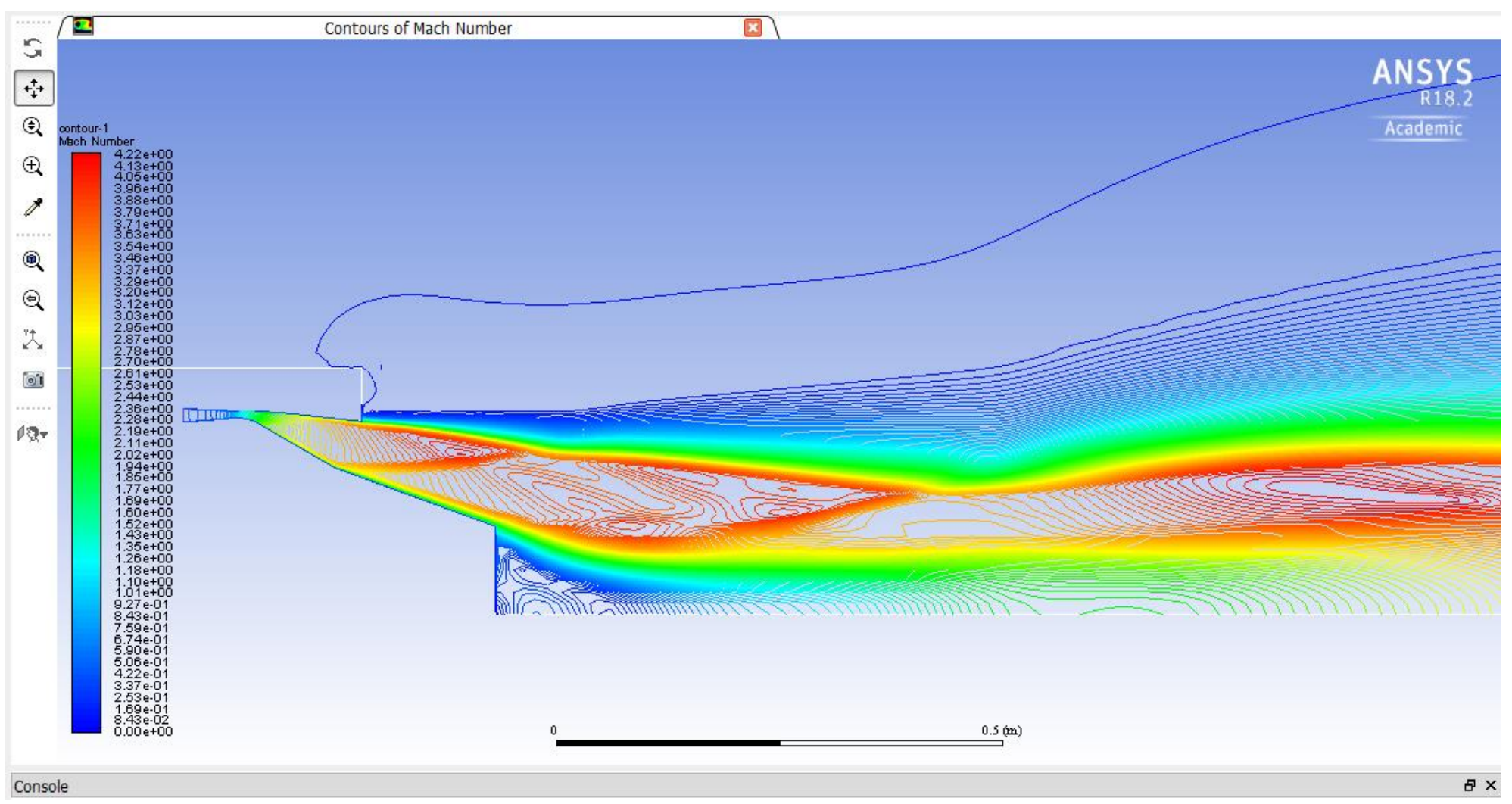

Figure 155: Line contours of Mach number for Aerospike 15, with nozzle flow expansion into ambient air at 20km standard atmosphere. 
Aerospike 16 Flow Contours

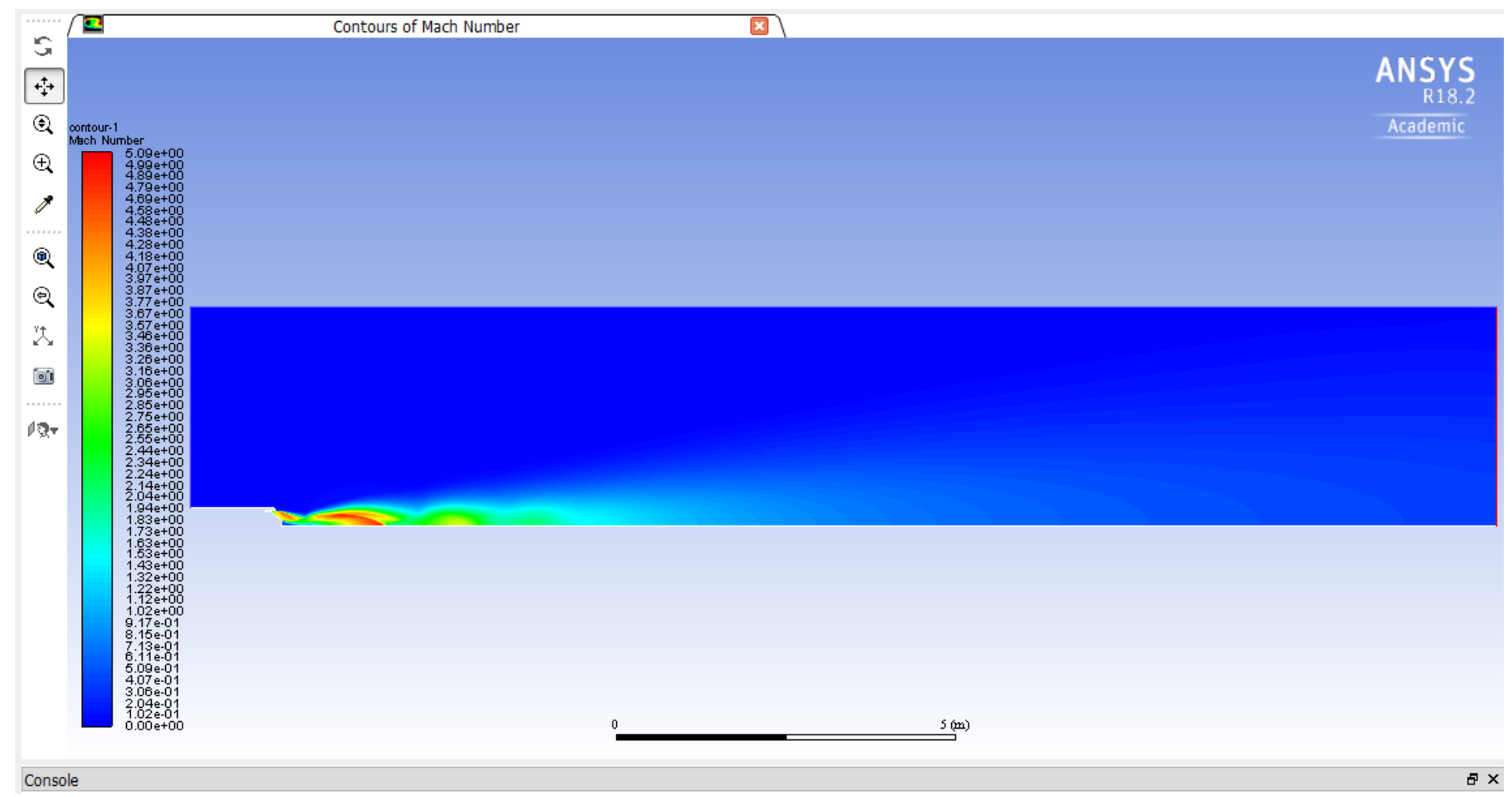

Figure 156: Contour of Mach number for Aerospike 16, with nozzle flow expansion into ambient air at $20 \mathrm{~km}$ standard atmosphere. 


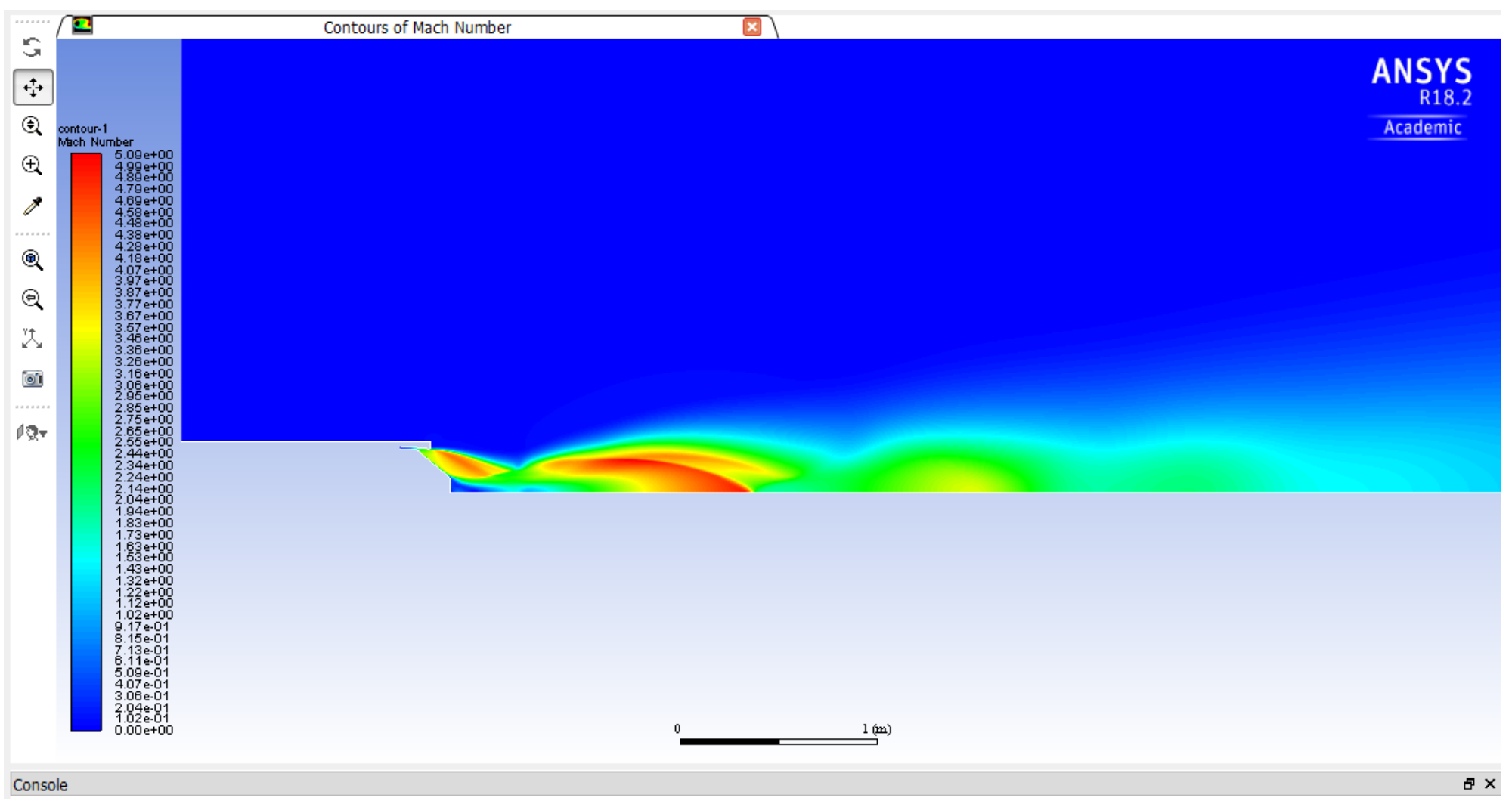

Figure 157: Contour of Mach number for Aerospike 16, with nozzle flow expansion into ambient air at $20 \mathrm{~km}$ standard atmosphere. 


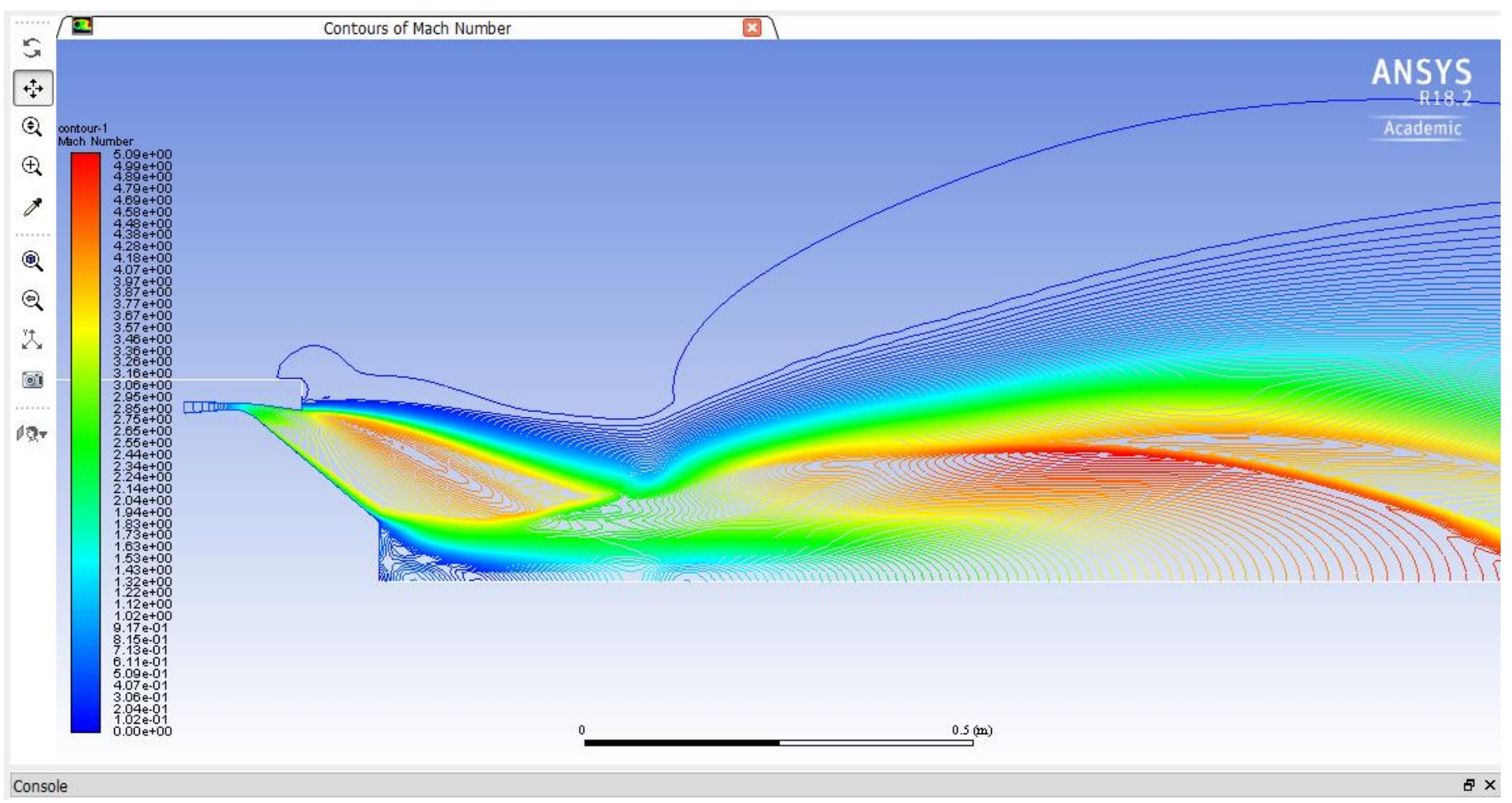

Figure 158: Line contours of Mach number for Aerospike 16, with nozzle flow expansion into ambient air at 20km standard atmosphere. 


\section{Aerospike 17 Flow Contours}

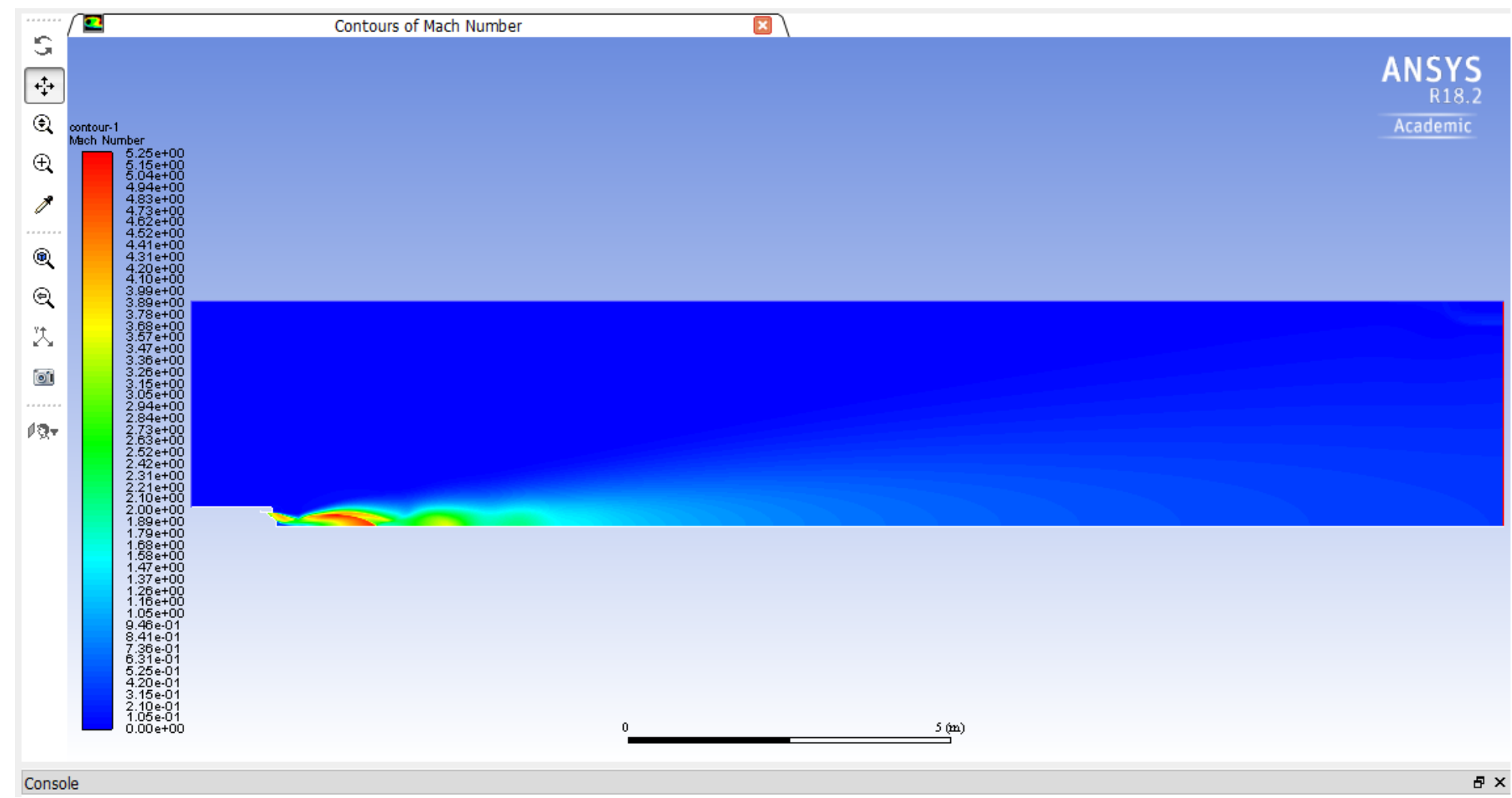

Figure 159: Contour of Mach number for Aerospike 17, with nozzle flow expansion into ambient air at $20 \mathrm{~km}$ standard atmosphere. 


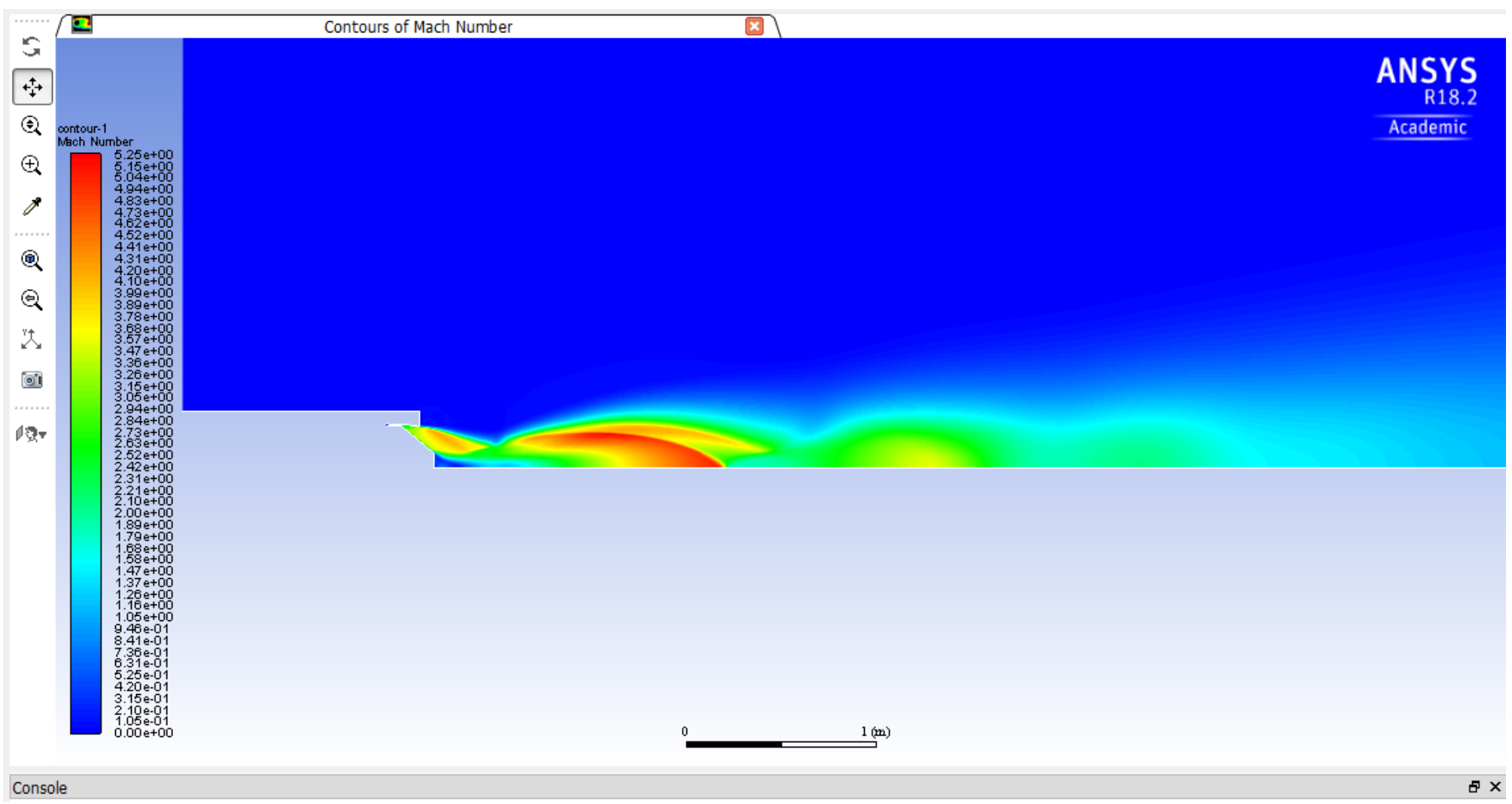

Figure 160: Contour of Mach number for Aerospike 17, with nozzle flow expansion into ambient air at 20km standard atmosphere. 


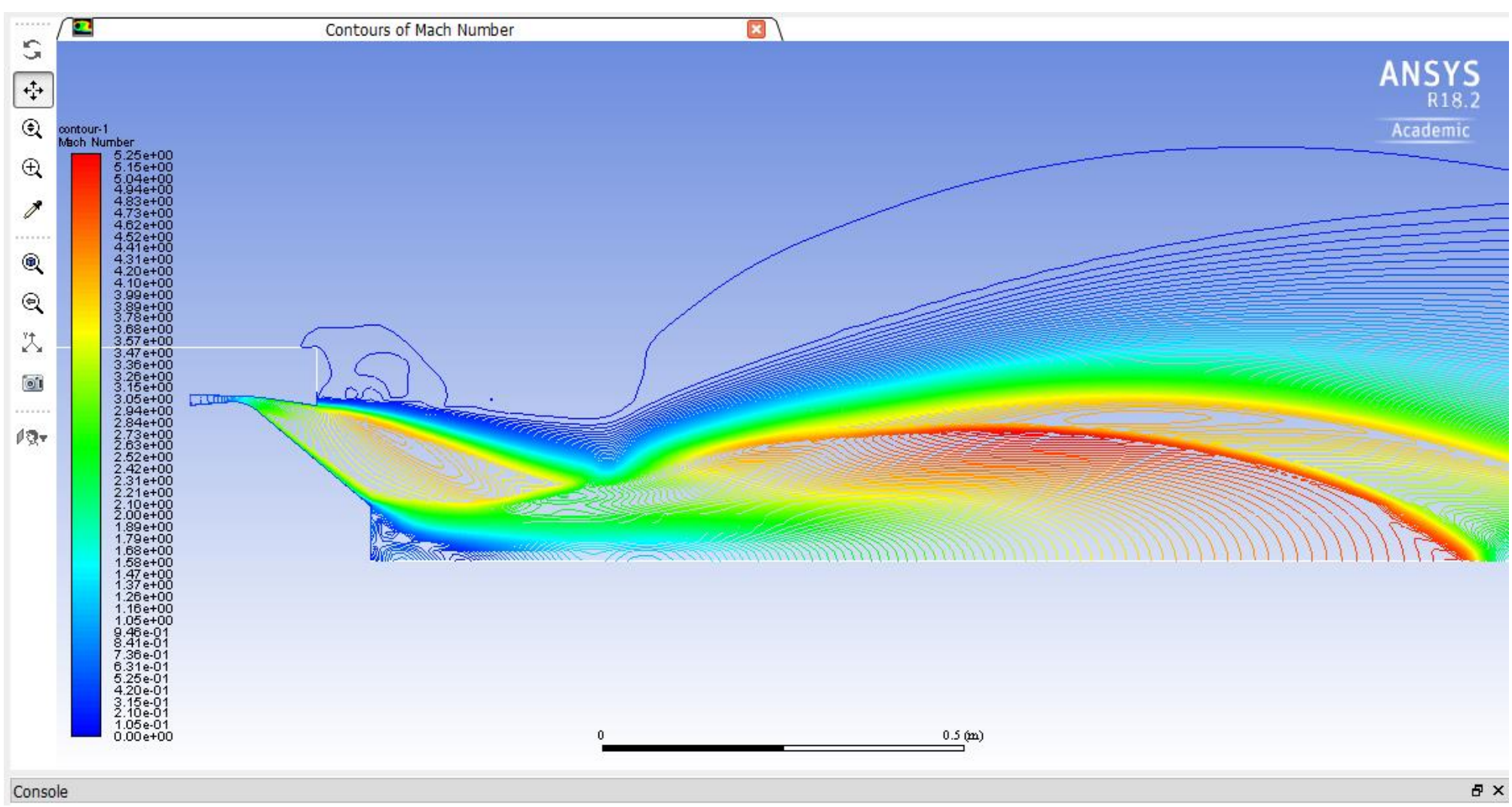

Figure 161: Line contours of Mach number for Aerospike 17, with nozzle flow expansion into ambient air at 20km standard atmosphere. 


\section{REFERENCES}

[1] B. Dunbar, "Linear Aerospike Engine fact sheet (08/00)," NASA, 12-Apr-2008. [Online].

Available: https://www.nasa.gov/centers/marshall/news/background/facts/aerospike.html.

[Accessed: 15-Apr-2019].

[2] “X-33 Engine Comparison Line Art.” NASA Dryden Flight Research Center, 02-May-2002.

[3] "X-33 by Lockheed Martin above Earth - Computer Graphic.” NASA Dryden Flight

Research Center, 21-Dec-2004.

[4] J. D. Anderson, Fundamentals of aerodynamics, 5th ed. New Delhi: McGraw Hill Education, 2010 .

[5] D. Jones, T. Bui, and J. Ruf, "Proposed Flight Research of a Dual-Bell Rocket Nozzle Using the NASA F-15 Airplane,” NASA, rep., 2013.

[6] D. R. Greatrix, Powered flight: the Engineering of Aerospace Propulsion. London: Springer, 2012.

[7] Korte, "Parametric Model of an Aerospike Rocket Engine," NASA Langley Research Center, Hampton, Virginia, tech., 2000.

[8] Campbell and Farley, "Performance of Several Conical Convergent-Divergent Rocket-Type Exhaust Nozzles," Cleveland, Ohio, tech., 1960.

[9] R. A. Alberty and R. J. Silbey, Physical chemistry. New York: Wiley, 2005.

[10] J. W. Murdock, Fundamental fluid mechanics for the practicing engineer. New York: M. Dekker, 1993. 